\title{
UEBER DIE
}

\section{EIERSTÖCKE DER SÄUGETHIERE}

\author{
IND
}

\section{DES MENSCHEN}

\author{
VON
}

\section{$\mathrm{D}^{\mathrm{R} .}$ E. F. W. PFLÜGER,}

O. Ö. PROHESAOR DEL PIYSIOLOGIE AN DER UXIYERSITÄT BONX.

AUSGEGEBEN DEN 2S. MÄRZ 1563.

MIT FÜNF KUPFERTAFELN.

LEIPZIG,

VERLAG VON WILHELM ENGELMANN.

1863. 
Das Recht der Uebersetzung in die enghische und französische Sprache hat sich der Verfasser und der Verleger rorbehalten. 


\section{SEINEM LIEBEN FREUNDE}

\section{HERRN N. PRINGSHEIM \\ IN BERLIN}

IN GRÖSSTER HOCHACH'TUNG UND TEREHRUNG

DER VERFASSER. 
Digitized by the Internet Archive in 2015 


\section{OR W ORT.}

Die mitgetheilten Untersuchungen sind das Ergebniss cincr zweijïhrigen Arbeit, auf welche ich fast alle meine freie \%eit verwandt habe.

Am gründlichsten ist die Entstehung und Bildung des Süngethiereies verfolgt worden, welche bis heute Niemand ror mir geschen hat. Hiermit ist die Entwicklung des Graaf'schen Follikels schr eng verknüpft, sodass ein rollgüil. tiger Beweis für deren Modus nur nach ciner klaren Einsicht in die (iesetze der Oogenese aufgestellt werden kann.

Andere 'Theile meiner Untersuchungen, besonders' dicjenigen, welche sich auf die periodischen Veränderungen der Ovarien erwachsener 'Thiere und des Menschen bezichen, hätte ich gründlicher und ausführlicher gewünscht. Da ich hicrbei aber sehr von dem mir kärglichst zufliessenden Materiale abhängig bin, sodass ich noch längere unbestimmte Zeit mit der Publication hätte warten müssen, schien es mir angemessener, die Begründung meiner bereits vorläufig gemeldeten Resultate nicht lïnger dem wissenschaftlichen Verkehr vorzuenthalten. Indem ich demgemäss rorliegende Abhandlung als einen ersten Abschnitt ansehe, behalte ich mir ror, in eincm zweiten die besonders auf das erwachsene menschliche Weib bezüglichen periodischen Verïnderungen der keimbereitenden Sexualorgane zu erforschen.

Bonn, den 1. Mär\% 1863.

Der Verfasser. 



\section{N II A L 'T'.}

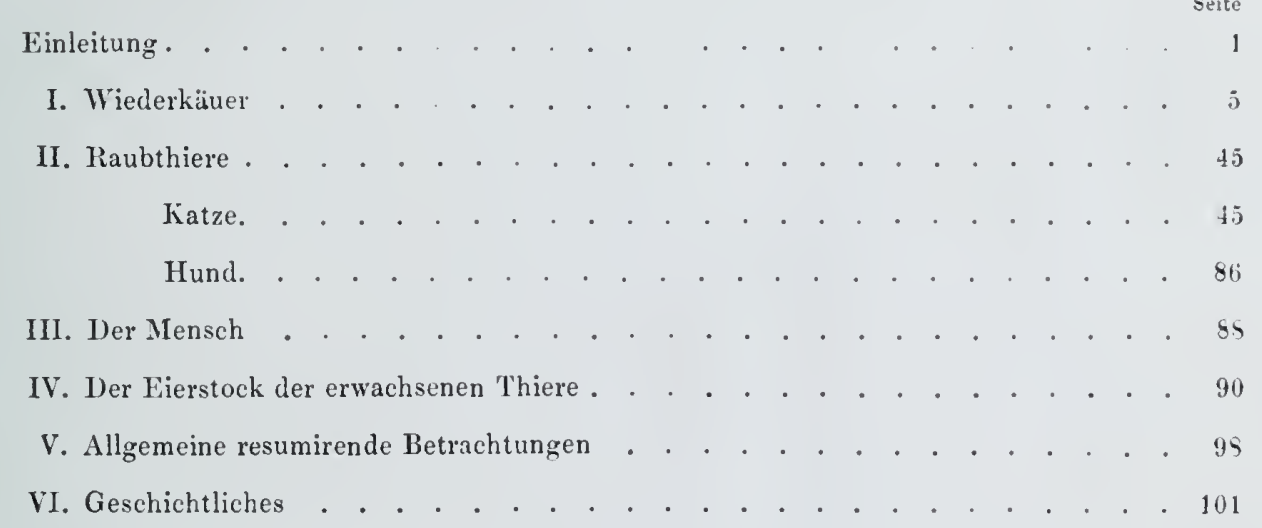





\section{EINLEITUNG.}

Dass die Entstehungsgesetze der Eier der Säugethiere bis dahin vollkommen unhehannt waren, und der Charakter der Eierstocksdrüse bisher durchaus verkannt worden ist, findet seinen Grund in den sehr grossen Schwierigkeiten, welche sich der mikroskopischen Untersuchung dieses Organes entgegenstellen. Das wird bereits dadurch bewiesen, dass diese Organe von vielen der ausgezeichnetsten Forscher sorgfaltigst untersucht worden sind. Das Gesagte gilt für die Eibildung unbedingt. Was den Charakter der Driise aber betrifft, so ist dieser von Valextix und Billnoti bereits richtig als der einer tubulösen erkannt worden.

VAlextix's Angaben wurden von allen Autoren in Zweifel gezogen oder geradezu negirt, so dlass neuerdings kein Handbuch der Histiologie es mehr der Muihe werth gefunden hat, auch nur die vor fast 30 Jahren publicirte Ansicht Valextrx's zu erwăhnen.

Ebenso ist es einer allerdings sehr aphoristischen Bemerkung Buцıоти's ergangen, die von Niemand weiter berücksichtigt worden ist, vermuthlich weil alle nähern Angaben fehlton.

So bin denn auch ich gefasst auf grosses Misstrauen, mit dem man diese Untersuchungen entgegennehmen wird, da ihre Resultate durchaus andere als die der meisten bisherigen Forscher sind, deren Beobachtungstalent und Geschicklichkeit, üler allen Zweifel erhaben ist. Um dieses Misstrauen einigermassen zu beseitigen, erinnere ich zunäclist daran, dlass in der mikroskopischen Forschung, wie mir einmal Joluxxes Mǘlen im Gespräich sagte uncl alle Histiologen zugeben werden, oft die wichtigsten Funde durch Zufall oder gliuckliche Fügung gemacht werden, indem einem Forscher gerade diejenigen Verhältnisse sich darbieten, unter welchen ein bestimmtes Phänomen allein oder doch am leichtesten wahrgenommen werden kann. Solclıe Verhältnisse sind nun hier entschieden vorhanden. Ich will davon cinige erwähnen, um es hegreiflich zu machen, wie ein mit der vollendetsten Beobachtungsgabe und der grössten Geschicklichkeit und Erfahrung ausgeristeter Forscher an die Untersuchung des Eierstocks der Säugethiere gehen kann, olne dass er im Stande ist, die Gesetze der Eibildung zu erkennen oder den Charakter der Drüse festzustellen. Zu dem Ende muss man nämlich wissen, dass wenigstens bei gewissen Thieren, z. B. der Katze, die Ei- und Schlauchbildung nur in ganz bestimmPflüger, Eierstöche. 
ten Lebensperioden zu constatiren ist, so dass einfach zu gewissen Zeiten absolut keine primoldialen Eier und keine Schliuche zu finden sind. Jene Periode ist aber von selır kurzer Dauer und an ihrem Ende weist nur das haufenweise Zusanmenliegon junger Gustr scher Follikel noch auf einen gremeinsamen Ursprung derselben aus einem Drüsenschlauche hin. Wendet man sich aher bei der Untersuchung an ein grösseres erwachsenes Thier, dessen Eierstöche leicht zu haben sind und darum wohl auch viel benutzt wurden, so hat man zu bedenken, dass, je grösser ein Thier ist, un so geringer seine Fruchtbarkeit sich erweist. Gleichwohl besitzen die grossen Thiere auch grosse, d. h. voluminöse Eierstöcke; letztere sind bei den Săugethieren in Allgencinen der Grösse der Thiere proportional. Demgremäss entwickelt der winzige Eierstock einer Katze von der Grösse einer kleinen Bohne eine alısolut grössere Zeugungsthäitigheit als der fast faustgrosse emer Stute, inden er jährlich melır Eier ausstösst. Hieraus folgt schon, dass das ächte Drüsengewebe bei dem grossen Thiere seiner Menge nach gegen das Zwischengeweloe des Stroma's ganz zurucktritt, während es bei dem kieinen Thier, z. B. der Katze, umgekehrt ist. So hann man deshalb bei der Kuh gar manchen Schnitt machen, ehe man so gliucklich ist, nicht blos einen Drüsenschlauch zu treffen, sondern ihn auch longitudinal in dem Segmente verlaufen zu sehen. Denn schneidet man ihn quer durch und es liegt ein Ei in dem Lumen, so wird man nicht zu dem Schlusse berechtigt sein, dass es sich um einen Follikel nicht handele.

Hierzu kommt dann, dass gewöhnlich die Drüsenschlauche nicht so wie bei vielen andern Drỉsen, durch die eigenthümliche Beschaffenheit ilırer Zellen sich stark vor dem Stroma auszeichnen und darum dem Auge des Beobachters sich aufdringen. Es gibt hiervon allerdings Aasnahmen bei seltner untersuchten Thieren, wie z. B. dem frischen Eierstock des Hundes, wo die Schläuche wegen des sehr starken Glanzes ihrer Zellen sogar sehr leicht zu sehen sind, wenn der Eierstock sich gerarle in der richtigen Periode befindet. Doch bezieht sich das auf den noch warmen eben aus den erwachsenen'Thier genommenen Eierstock, der mit humor aqueus odler der Flüssigkieit eines Grasf'schen Follikels oder mit Blutserum untersucht wird bei Vermeidung jerlweden Druckes durch das Deckglas, welches einige Wachströpfchen tragen. Zu alledem kommt nun, dass eines der vorziiglichsten Mittel zur Untersuchung der thierischen Gewebe, nämlich die Isolation bei gewissen älteren Thieren, z. B. der Kuh odler dem Hunde so gut wie unnöglich gemacht ist entweder durch häufige Anastomosen der Schläuche oder — und das ist die Hauptsache - durch das stare derbe Gewebe, in welches die Drüsensubstanz gleichsam eingekittet ist. Will man isoliren, so muss man sich deshalb an junge Thiere wenden, bei denen jene lederartige Derbheit der Stroma's noch nicht vorhanden ist oder durch Reagentien olıne Zerstörung der ächten Drüsensubstanz heseitigt werden kann.

Unter Umständen ferner truibt sich das Gewehe des Eierstocks in gewissen Thätigkeitsperioden durch zahllose äusserst kleine Fettkügelchen, welche in das Protoplasma der Zellen 
dieses Organes abgelagert werden und deshalb demsellen ein gelbes Ansehen geben, das zuweilen dem der corpora lutea nahehommt. Dieser Vorgang, von dem ich glaube, dass or einen Riickbildungsprocess der Gewebe des Eierstocks bezeiclnet, wie wir spaiter genatuer selıen wollen, zeigt sich zuweilen auch besonders nach schlechter Ernährung der Thiere zur Zeit der Bildung der primordialen Eier, welche selbst von solcher Eunulsion erfüllt sind. Die dichte Trübung des Gewebes verhindert nun begreiflicher Weise die Walınehmung so zarter Contouren, wie diejenigen sind, un welche es sich handelt. Das junge Druisengewebe krafitiger gesunder Thiere ist aber blass und durchsichtig und die Zellen laben sanfte, sehr zarte Contouren.

Wenn man demgenıäss von den richtigen Objecte einen Schnitt der frischen Drüsensubstanz anfertigt und ihn in humor aquens untersucht, so wird man oft nicht befriedigt sein. woil das Bild zu wenig bestimmten Anlıalt bietel. Hier ist alterdings eine Ausnalıme zı erwailııen, auf welche der Zufall den Untersuchenden nicht immer sogleich fülırt. Dengenłass muissen in Allgemeinen Reagentien herangezogen werden. Wenn man nun die Variationen bedenkt, die durch ihre Zahl, durch die Dauer ihrer Einwirkung, durch ihre verschiedene Concentration. durch Mischung verschiedener möglich sind, so liegt es auf der Hand, dass hier der Methode im Allgemeinen keine grosse Macht zur Seite steht und nur die Auslauer im Experiment schliesslich zum Ziele führen kann.

Hat man aber auch die günstigen Methoden kennen gelernt, d h. solche. welche die Zellen des Organes mit ihren wesentlichen Bestandtheilen vollkommen erhalten und sie dem Auge stark bemerkbar machen, so treten besonders bei gewissen Thieren noch eine Reihe von Complicationen auf, welche die Untersuchung selır erschweren, wie wir dies im Laufe dieser Abhandlung genugsam erfahren werden.

Aus allen diesen Gründen nun ergibt sich, dass wir zur Feststellung der hier vorliegenden Thatsachen Nichts unversucht lassen dürfen, was neue Aufklärungen zu bieten geeignet ist. Wir werden uns demgemäss nicht auf die Untersuchung einer Thierart besclıränken, weil hier die vergleichende Analyse den ausgezeichnetsten Aufschluss in schwierigen Fragen zu geben rermag. Gerade bei dem Eierstock gilt dieser Satz ganz besonders, indem die Verschiedenlieiten desselben bei verschiedenen Säugethierspecies sehr bedeutend sind, wenn es sich auch schliesslich nur um eine Modification eines allgemeinen Schema's handelt. Auf der einen Seite ergibt sich hieraus freilich eine neue Schwierigkeit, indem nan bei dem Uebergange von einer Thierspecies zu einer andern sich aufs Neue orientiren und gleichzeitig die unlichsame Erfahrung machen muss, dass Reagentien, die sich bei der einen Species rortrefllich bewahren, bei ler andern zwar nicht gerade unbrauchbar, aber doch viel weniger günstig sint. Es ist alser dennoch dieser an sich den Forscher wieder hemmende Umstand ein sehr grosser Vortlueil, insofern man bei dem Eierstock einer Species gewisse Verhältnisse auf clas Unzweifellaftste und leicht constatiren kann, was bei der anderen vielleicht erst nach Ueberwindung der grössten 
Schwierigkeiten festzustellen ist. Letzteres ist immer ein relativer Mangel der Untersuchung, indem man Gefahır läuft, leicht die Bestätigung der Thatsachen durch andere Forscher ausbleiben zu sehen, weil sie nicht immer die Zeit haben können, gleiche Anstrengungen zu machen, um festzustellen, was, wenn es richtig ist, doch schliesslich von den Zeitgenossen als bereits festgestellt angenommen wird. In dem Folgenden werde ich demnach die Eierstöcke verschiedener Species nach einander in der Ordnung vornehmen, wie es am geeignetsten sein wird, um vor den Augen des Lesers allıählich das Gesammtbild in stetiger logischer Folge sich aufbauen zu sehen.

Bei der Untersuchung des Eierstocks, deren Methode ich später speciell darlegen will, Lat man aus den angeführten Gründen einen möglichst einfachen Weg zu gehen. Demgemäss beginne $m$ an die Untersuchung nicht mit den Eierstöcken alter, sondern junger Thiere. Dic Tortheile, die uns hierdurch erwachsen, sind sehr bedleutend. Tor Allem weiss man wegen des Alters der Thiere, ob man die richtige Zeit zur Untersuchung des Organes ror sich hat, indem man bald die Epochen nach oder vor der Geburt ermittelt, wo die Verhältnisse am günstigsten sind. Das Alter junger Thiere lässt sich aber stets leicht annähernd mit für unsere Zwecke hinreichender Genauigkeit bestimmen. Indem man dann mit der Zunahme des Alters des Thieres die Veränderungen erforscht, welche die Gewebe des Eierstockes durchmachen, ist es sicher, was man als die früheren, was als die späteren Zustände der Druisengeloilde auffassen muss. Dies ist ein unschätzbarer Umstand, der nicht hoch genug anzuschlagen ist, wo es sich um die Beurtheilung von Bewegungserscheinungen handelt, die aus absolut ruhenden Gegenständen gefolgert werden. Bei den erwachsenen Thieren wird der Beginn orler die Phase dêr Eizeugungsperiode nicht mit Genauigkeit ohne Weiteres festgestellt werden können. - Ferner aber sind in dem Eierstocke des erwachsenen Thieres Bildungen, welche bei den jungen Thieren nicht vorhanden sind; ich meine die grrösseren Follikel und die gelben Körper, deren Rudimente lange im Eierstock verharren, vielfache durchaus nicht hinlänglich gekannte Metamorphosen durchmachen und immerhin zu Tæauschungen Veranlassung geben könnten.

Ferner aber sind bei den jungen Thieren die ächten Drüsenmassen der Eierstöcke zahlreicher vorhanden und folglich bietet sich in einem Schnitt ein günstiges und beweisendes Object leichter dar. Von dem ausserordentlichen Vortheil, den die Eierstöcke junger Thiere dadurch gewähren, dass die Drüsenelemente, $\mathrm{d} . \mathrm{h}$. die Schläuche sich leichter isoliren lassen, habe ich bereits gesprochen.

Alles das zeigt, dass naturgemäss unsere Untersuchung den einfachsten und besten Wegg geht, wenn wir mit jungen Thieren beginnen. Ist einmal der Bildungsmorlus lier festgestellt, dann fallen die Schwierigkeiten bei Erwachsenen olıne Weiteres viel kleiner aus.

Beginnen wir demgemảss mit der Untersuchung selbst. 


\section{Wiederkäuer.}

Indem ich mir vorsetze, die Resultate meiner Untersuchungen darzulegen, werde ich nicht, wie sonst wohl zwecknassig geschieht, den Weg chronologischer Succession befolgen, sondern ungekehrt von den bereits bekannten in der Wissenschaft festgestellten Bildungen ausgehend rückwărts zu den unbekannten Gebieten vorschreiten. Diese Art der Darstellung grestattet es, die Verhältnisse in ungleich überzeugenderer Weise dem Leser vorzuführen, was hei ausführlichen wissenschaftlichen Darstellungen wohl unzweifelhaft der wesentlichste und oberste Gesichtspunkt bleiben muss.

Ich heginne mit der Betrachtung des GraAf'schen Follihels des Kalbes in denjenigen Stadium seiner Entwicklung, in welchem über seine Deutung ein Zweifel unmöglich ist. GraAr'sche Follikel heissen bekanntlich die in den Eierstöcken der Säugethiere vorkommenden meist rundlichen Zellenhäufchen, welche ein Ei umschliessen. Bedenkt man nun, dass der Eierstock ein Organ ist, in welchem wenigstens zu gewissen Zeiten die üppigsten Zellenvegetationen stattfinden, erwägt man, dass jede grössere Mutterzelle, die auf irgendwelche Weise in sich eine Schaar Tochterzellen erzeugt hat, ein rundliches Zellenhäufchen darstellt, so liegt es olıne Weiteres auf der Hand, dass es durchaus verwerflich ist, jedes im Eierstock aufzufindende rundliche Zellenhåufchen mit mehr oder weniger scharfer Umgrenzung ohne Weiteres als jungen Grasf'schen Follikel anzusprechen. Damit man hierzu berechtigt sei, müssen bessere Gründe beigebracht werden. Ich nenne demgemäss ein rundliches Zellenhảufchen nur dlann einen GraAf'schen Follikel und bin sicher hierin keinem Widerspruch zu begegnen, wenn ein init allen wesentlichen auf ihre relativen Grössenverhältnisse untersuchten Theilen versehenes Ei von Zellen, welche bestimmt zu definirende Charaktere tragen, unschlossen wird.

Die wesentlichen Theile des Eies sind aber ein feinkörniger rundlicher meist scharfbegrenzter Dotter, der ein wasserklares rundes scharfbegrenztes Blaschen, das Keimbläschen, beherbergt, welches wieder einen stärker lichtbrechenden soliden Körper, den 
Keimflech enthält. Ol) das Ei eine Membran bereits in den jüngsten Follikeln besitze, ist so nicht zu entscheiden. Ich werde auf diese Frage später eingchen. In den jungen Follikeln des Kalbes, deren Natur nicht streitig sein kann, stellt das Ei stets die gröosste Zelle dlar und zeigt, wemn es scllsst die Grösse von $0,0300 \mathrm{Mm}$. besitzt, folgende Grössenverhältnisse. Das hierzu gehörigge Keimbläschen misst: 0,0123 Mn., der Keimfleck 0,0037 Mm. - Die Flüssigykeit, in welcher der Follikel untersuclıt wurde. war eine $0,3 \%$ Lösung von doppeltchronısaurenı Káli. Man stellt sich diese einfach so her, dass man hei mittlerer Trmperatur (15" C.) ron chemisch-reinem hrystallisirtem saurem clıromsaurem Kali eine concentrirte Lösung bereitet, wobei man zu beachten hat, dass die Lösung sehr langsam vor sich gelıt. Die concentrirte Lösung enthält 10\% saures chromsaures Kali. (S. Handwörterluch der Chemie Bd. II. p. 1238).

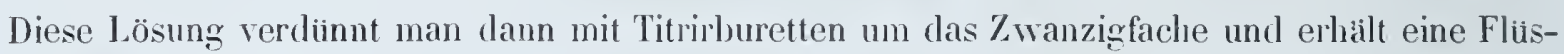
sigkeit, welche ganz ausgezeichnet ist fur selbst so sehr zarte Verhältnisse, wie sie im Eierstocke zu demoustriren sind.

Was bei dieser Untersuchungsmethode, welche bei frischen Präparaten sehr klare Bilder grilst, nun ferner iilser die Charaktere der kleinen Zellen zu sagen ist, welche das Ei umhüllen, so ist dies Folgendes. Wie aus ihrer kugrgen in testillirtem Wasser orler in ciner $0,1 \%$ Lösung von saurem chromsaurem Kali erfolgenden prallen. Aufblälung zu schliessen wohl gestattel sein diurfte, besitzen dieselben eine sehr zarte Membran, ein Protoplasma ron sehr geringer Granulation, so dass die wässrige klare durchsichtige Beschaffenheit derselben auffallend von dem getrübten Dotter der Eizelle absticht. In allen etwas grösseren dieser Zellen, welche die zellige Eilizille, membrana granulosa seu cellulosa des Eies darstellen, sieht man leicht einen runden oder etwas ovalen scharfhegrenzten Kern. Ob diese Verschiedenheit nur in der Lagrerung des Kernes gegen den Beobachter, dem er bald seine schmale. bald seine breite Fläche zukehrt, Grund hat oder in einem vielleicht auf Kerntheilung hinzielenden wirklichen Uebergang runder in elliptische Kerne, muss ich unentschieden lassen. Meist trat mir in der genannten Untersuchungsflissigkeit die mehr rundliche Form entgegen. Die Grösse des Kernes übertrifft gewöhnlich etwas den dritten Theil des Durchmessers der Zelle. In ausgesprochener Weise ist es so bei Zellen von 0,0126 Mm. Das Ansehen des Kernes ist bei der erwähnten Untersuchungsmethode nicht wasserhell wie das des Keimblaschens, sondern ron etwas schwach glianzender aber sonst gleichmåssiger, das heisst granulationsloser Beschaffenheit. Der Contour des Kernblaschens ist sehr zart wie das ganze Gebilde, aber darum doch vollkommen deutlich. Ich habe mich nun unter günstigen Verhältnissen mit IIiulfe derselben Methorle auf das Unzweifellafteste ïberzeugt, dass das Kernbläschen noch ein Kernhörperchen entlält. Dieses ist wiederum scharf begrenzt, rund, stärker lichthrechend als der Kern, gleichmisssiğ glänzend und ibertrifft wiederum den dritten Theil des Durchnessers des Kernblaschens. Was num die Totalgestalt unserer Zellen betriflt, so wechselt diese nicht unbetrichtlich, obwohl man es im Allge- 
meinen mit rundlichen, durch seitliche Compression wohl auch polygonal gewordenen Zellen zu thun hat. Wenn ich den frischen Kalbseierstock in Alliohol von :00 Vol. "\% 12 stunden hairtete und dann Schnitte machte. so zeigten die Zellen der membrana gramulosa eine melı cylindrische Forn, welche durch eine Verlangerung derselben in radiarer Richtung bedingt war. I)ureds diese Verläneerung hatten sich die inneren Enden der Zellen in das Protoplasmal des Dotters eingesenkt, der nun stralıligg oder sternförmig aussah, weil er die dreieckigen Raume zwischen zwei der gestreckten Zellen der membrana cellulosa ausfiillte. Diese Veränderung der Zellen lag wohl daran, dass das Ei mit zarterer Begrenzung und Protoplasma durch den Alkohol stirker schrumpfte als die anderen consistenteren Bildungen, so dass diese dann bei der allgemeinen Contraction des Organes des Eierstocks in die leerwerdende Höhle, die das Ei beherbergrte, hineingedrängt wurden, wobei sie sich von den Seiten sellsst drüchten, also an Querdurchmesser abnahmen. So mag aus der rundlichen Zolle dann die fast eylindrische entstehen. Achnliches lıabe ich zuweilen indessen auch hesonders bei ganz jungen Follikeln geselen, wenn ich (lestillirtes Wasser zur Untersuchung anwandte, was den Eierstock nicht tribt und darum für manche Verhältnisse recht brauchbar ist. Rasch schwellen die Zellen der membrana cellulosa mächtigr auf und stemmen sich streckend, wie radiäre Strebepfeiler gegen das Ei, welches unter dem Druck schnell zu einem körnigen Klümpchen sich zusammenzieht. Dieses Zusammensinken des jungen Eies in dem Follikel bei Zusatz von destillirtem Wasser ist eine schr sonderbare Erscheinung; denn das Ei enthält eine incompressible Flüssigkeit. Wie kommt es, dass so sclınell und leicht - der Versuch gelingt fast immer - die Zellen der membrana gramulosa aufschwellend, das Ei zu einem kleinen Klïmpchen Körnchen comprimiren? Wir werden später darauf Antwort geben, was wir ohne mehr als möglich vorzugreifen, jetzt nicht kïnnen. Es hat dies eine sehr tiefe Bedeutung. - Bei diesen Gestaltveränderungen blieben die Zellen stets der Peripherie des Follikels anhaften und entfernten sich von ihr niemals, woraus ich indessen nichts weiter schliessen will als dass sie derselben, welche man für den optischen Ausdruck einer IIaut (membrana propria) des Graaf'schen Follikels liält, frisch sehr innig anlıften.

Nachdem ich die Gestaltreränderungen der Zellen der membrana cellulosa erörtert, wende ich mich zu einer noch bedeutungsvolleren Frage, der nach der Grösse derselben. An jungen Follikeln sieht man nämlich ganz gewöhnlich eine sehr grosse Verschiedenheit (Tâf. I. Fig. 1). Dies kann so sein, dass zwischen zwei grossen Zellen eine kleine steckt (Taf. I. Fig. 1. a.), die (ler Peripherie des Follikels aufsitzt, also nach innen nicht so weit gegen das Ei vorragt als die nebenliegenden Zellen und dureh einen stark lichtbrechenden verhajtnissmässig grossen Kern sich auszeichnet. Bei genauerem Studium bemerkt man aber an sehr vielen Follikeln leicht - und es ist dies wohl bei allen der Fall - dass ein gewisses Gesetz an der Follikelperipherie grosse und kleine Zellen von sehr verschiedenem Ausmaasse wechseln lässt. An einer, zuweilen an zwei sich gegenüberliegenden Stellen des Follikels sielıt man 
(Taf. I. Fig. 1. b.) schöne grosse Epithelialzellen, welche in ausgezeichneter Weise die olsen beschriehenen Charaktere besitzen. Von dieser einen Stelle oder von diesen beiden Stellen nehmen dann die Zellen stetig nach einer anderen oder zwei Stellen, die ich die Pole des Follikels nennen werde, stetig stark an Grösse ab (Taf. I. Fig. I. c. c.). Wenn an einem Follikel zwei Pole nachweisbar sind, liegen sich diese stets gegenüber oder befinden sich nahezu auf demselben Kugeldurchmesser. In keinem Falle ist dieses Verhältniss ausgezeichneter als wenn an dem Pole in kleiner oder grösserer Ausdehnung, die ich beim Kalbe $1 / 5$ der Eiperipherie habe einnehmen sehen, noch absolut gar keine Zellen sind (Taf. I. Fig. I. c. c.). An diesem Pole geht der derbe Follikelcontour zellenlos über das Ei fort. Der Einwand, dass es sich hier un ein Artefact handle, ist leicht zu widerlegen. Denn wie sollte es kommen, dass, wenn zwei Pole vorhanden, diese diametral gegenuber liegen? Sodann aber - und das ist durchschlagend - zeigt es sich, wenn man von dem zellenlosen Follikelpol langsam an der Follikelperipherie weiter geht, dass zuerst ganz winzige an der Grenze mikroskopischer Sichtbarkeit stehende Zellchen erscheinen, wie dies naturgetreu in der Zeichnung (Taf. I. Fig. 1. c. c.) dargestellt ist. Ziemlich rasch und stetig mit allen Uebergảngen kommen dann in derselben Folge weiter immer grössere Zellen, bis man zu den bedeutendsten vorgeschritten ist. Jeder erkennt nun sofort, dass es sich hier un eigenthiumliche Verhältnisse handelt. Wenn man nämlich von dem dicken Theil der membrana gramulosa nach dem zellenlosen Pole vorschreitet, so sieht man stetig und regelmässig dieselbe abnehmen bis die letzten Zellchen so klein geworden sind als der Contour, welcher am Pole das Ei überzieht, dick ist. Diese winzigen Bildungen liegen aber nicht auf dem Contour, sondern in ihm. Oder offenbar besteht er mindestens zum Theil aus Zellchen von verschwindender Kleinheit, sicher an denjenigen Stellen, die in der Nähe des Anfanges der mem. brana gramulosa liegen. Der Contour am Pole besteht demgemäss entweder aus winzigen Zellen, die nicht mehr mit unsern optischen Hülfsmitteln mit Sicherheit zu ermitteln sind, oder es hat sich das Protoplasma der Zellen der membrana gramulosa gleichsam sarcodeähnlich über das Ei ergossen. Sehr eigenthümlich ist auch die Lage der un den Follikelpol liegenden kleinen Zellchen der membrana gramilosa. Denn je näher sie demselben gelegen sind, desto mehr nehmen sie in jüngsten Zustande eine dachziegelförmige Gruppirung an und zwar so, dass die dem Pol nähere kleinere Zelle sich zwischen die entferntere und die Peripherie des Follikels einschiebt, wobei die Zellchen länglich geworden ihre Längsachse immer mehr parallel legen der Tangente an die Follikelkugel. Von einer Theilung oder Sprossung in jüngeren Follikeln babe ich bei grösseren Zellen der membrana cellulosa niemals etwas gesehen, so dass es also die kleinsten sein müssen, von denen die Vermehrung ausgeht. An rorgeschritteneren Follikeln (Taf. I. Fig. 2.p.) weist die Kleinheit der Zellen an der einen, die bedeutende Grösse derselben an der entgegengesetzten Seite und die stetigen Uebergänge zwischen beiden noch sehr bestimmt auf die Follikelpole hin. Aber auch nachdem die sämmtlichen kleinen Zellen der memlrana gramulosa 
zu grossen lierangewachsen sind und den anderen gleichkommen, in wolchem Falle num ein von gleichförmigen Zellen gebildeter Zellenmantel das Ei umgilut, zeichnet sich noch lange der Follikelpol aus. Vielleicht thut er rlas immer. An einer ganz kleinen Stolle, im Centrum der früheren Polarzone des Follikels, also an Ende der Follikelachse libldet siclı keine Epithelialzclle. oder es finden sich an zwei diametral gegenüber liegenden Enden nackte Stellen in Innerı des Follikels, welche sich auszeichnen durch eine glänzende orler körnige Ausfüllungsmasse, die auf der Peripherie des Follikels aufsitzt und nach dem Centrun zu an das Ei stősst oder in dasselbe übergeht. Zunächst sieht es so aus (s. die Figur 3. $p$ p. Taf. I.), als ob das Ei durch zwei diametral entgegengesetzte Zipfel an die sogenannte membrana propria angeleftet ware, etwa wie der grelbe Hühnerdotter durch die chalazae an die innere Schalenhaut des Eies. Auf alle diese leicht zu constatirenden Thatsachen weiss die gegenwärtige Lelıre ïber die Entstehung der Eier und Guas'schen Follikel keine Antwort zu geben. Um zu einer Lösunğ dieser lraggen zu gaelangen, müssen wir in unserem Studium der Gruar'schen Follikel weiter schreiten, indem wir nach Anfertigıng feiner Schnilte frischer Eierstöcke oder an Zerzupfungspräparaten untersuchen. Es ist nicht schwer und bietet sich häufig dar, dass man nicht einzelne isolirte Folliliel finded, sondern solche, die scheinbar aneinander hängen (wie in Taf. I. Fig. 4.), als ol) sie mit der membrana propria aneinander klebten. Das gezeichnete Präparat war $g$ anz isolirt. Erregt man Strömungen in der Flïssigkeit, in welcher diese Follikelketten suspendirt sind, so schwimmen sie, immer in derselben Weise zusammenhaftend, herum, selbst wenn sie auf die mannichfachste Weise um irgend welche Achse rollen. Uebt man durch das Deckglas einen Druck aus, so bemerkt man trotz der ihnen ertheilten und sie vielleicht auseinander ziehenden Bewegung, dass sie nachher wieder in die alte Lage zurückschnellen, mit einem Worte sehr innig an den Berührungspunkten zusammenhalten. Höchst selten liegen drei, fast niemals vier frei schwebend in einer Ebene, sondern fast stets befinden sich die Mittelpunkte der Follikelkugeln auf einer doppelt gehrimmten Curve. Es ist nicht nothwendig, dass ein Follikel nur mit einem orler zweien, was allerdings gewöhnlich der Fall ist, auf nahezı gegeniiberliegenden Punkien der Kugel zusammenhảngt, sondern es können einen Follikel drei und vielleicht mehr andere aufsitzend berühren. Als wichtig hebe ich hervor, dass solche "Ke 1 en " zwar nicht alssolut dieselbe Grösse aller Follikel zeigen, gleichwohl aber selten sehr in ihrer Entwicklunğ auseinander liegen, wie das dlie vorliegende Figur, sowie diejenige, welche ich sptiter noch ron der Katze beibringen werde, darthun soll. Welche Bewandniss hat es nun mit diesem Zusammenhaften der Follikel in einem Punlite? Berühren sie sich, weil sie nach Verdrängung des zwischen ihnen früher gelegenen Bindlegewebes grösser geworlen sind, oder weist der Zusammenhang, der allerdings nur noch punktförmig ist, auf einen Ursprung aus gemeinsamer Anlage hin? Derlkt man daran, dass im Laufe der Entwicklung die Follikel eine immer dickere Umhïllungsschicht einer faserigen Masse (sogenannten Bindlegewebes) bemerken lassen, so wird jene Anschauungr 
der zufalligen Beriulurung gar wenig wahrscheinlich. Einen weiteren sicheren Aufschluss über das Zusammenhaften gilut uns aber ein frisches Pràparat, welches wie das in Taf. I. Fig. 气 abgebildete beschaffen ist. Die Untersuchungsflissigkeit war eine Lösung von saureu chrounsaurenı Kali von $0,1 \%$. Hier hängen zwei Follikel nicht blos durch einfache innige Berüll'ung zusammen, sondern zeigen uns noch einen Uebergang der membrana graulosa des ainen Follikels in den anderen und eine Communication beider Follikelhöhlen mit einander durch ein noch offenes Loch (Taf. I. Fig ̈̈. a.). Auf das Unzweifelhafteste sind beide Follikel durch keinen ausselen Contour von einander gesondert, obschon dieser sonst rorhanden ist und beide Follikelanlagen naclı aussen abgrenzt. Es ist aber nicht schwer, Zustände zu finden, wo der Zusammenhang zweier Follikel ein noch innigerer ist, so dass sie eine schuhsohlenfö̀nige odel' liscuitförmige Gestalt darbieten, bei der eine leichte Einbiegung das Streben beginnender Sonderung zuerst andentet (Taf. I. Fig. 6.). Die Untersuchungsfluissigkeit für das abermals frische Práparat war dieselbe wie vorher. Wenn ich mich nicht täusclie, liegen in diesem Schlauche mehr als zwei junge Eier neben einander. Zwischen den beiden Eiern sieht man, wie von dem Epitlel her sich ein Hiigel erhelst (Taf. I. Fig. (. a.), indem an einer Stelle die Zellen stärker wuchernd sich zwichen beile Eier einschieben. Nichts gibt uns aber überzeugendere und instructivere Ansichten als solche Präparate, bei denen ein Haufen von Follikeln noch unzweifelhaft in genannter Weise zusammenhängt, während die Sonderung der Follikel alle Stufen darbietet (Taf. I. Fig. 7.). Hiel sieht man (a. und b.) zwei aller(lings rerschieden grosse Follikel, von denen der eine grössere $(a$. g gleichsam an einem langen zelligen Stiele $(c$.) hängt, wăhrend der andere kleinere b.) mit kurzen Halse (d.) einem Zellenstrange aufsitzt, der sich nach del einen Seite in jenen Stiel fortsetzt, nach der anderen Seite sich sehr bestimmt in einen Schlauch (e.) verfolgen lảsst, der durch seitliche Einkerbungen und wie aus der Zahl der in demselben bemerkbaren Eier (f.) geschlossen werden darf, sich in wenigstens 3 Follikel zu sondern anfägt.

A us alledem darf man demgemäss folgern, dass diespater einzeln im Eierstock zerstreut liegenden Follikel ursprüglich aus zus ammenhängenlen scharf algegrenzten Zellenmassen durch eine Art Abschnürung, wie wir vor der IIand sagen wollen, hervorgegangen sind.

Dieser bereits ron BuLnotu für den menschlichen Eierstock aufgefundene und ron mir l,estatigte neue Satz soll nun strenger festgestellt werden, indem wir erstens zeigen, dass die "primordial en Follikelan laggen “ wirklich zusammenlaăgende, zusammengehörige Massen bilden und sodaun den Modus des vorläufig Alsschniirung genannten Processes genauer studiren wollen.

Jedler einigermassen erfahrene Mikroskopiker weiss, wieviel bei der grösseren oder geringeren Klarheit des Präparates auf die absolute Wahrheitsliebe des Forschers gegen sich und andere ankomnt. Hier nun könnte Mancher versucht sein zu glauben, dass wir vielleicht nur 
zusanmengedrückte, aneinandergedrängte Follikel vor uns geliabt liătten, bei denen also eine Zusammengehörigkeit nur scheinbar gewesen wäre. Diesen Einwand kann ich auf das Entschiedenste, auf das Unbedingteste willerlegen. Es gelingt zwar nicht leicht, dennoch aber bei einiger Ausdauer öfter bein Kalhe noch zusammenträngende mehr oder weniger in der Abschnürung begriffene primordiale Follikelanlagen zll isoliren. Solche umgilit ein scliarfer Contour, wie er bestimmter nicht gewiinscht werden kann. An der Eimbiegrmgsstelle beginnender Sonderung geht er ununterbrochen mit gleicher Schärfe weg, ohne dass hier noch eine Spur bereits beginnender Spaltung sich zwischen die Epithelialgebilde der Anlage fortzusetzen braucht, ohne dass auch nur ein Fäserchen sich zwischen die Zellen einschöbe. Betrachtet man die sich durch gegenseitigen Druck oft polygonal abplattenden Epithelien, so kann man sie stetig und olıne dass sich etwas zwischen sie schiebt uber die beginnende Einschniurung verfolgen. Was num aber in dieser Beziehung ganz unzweifelhaft beweisend erscheint, ist, dass ich zwar nicht beim Kalbe, aber bei alten und jungen Katzen eine membrama propria nachweisen konnte, welche nach aussen als feinste Haut die primordialen Follikelanlagen abgrenzte. Hier ging von dem einen primordialen Follikel die durchsichtige Haut auf den andern Follikel iiber, der noch in derselben lag, aber sich von den vorhergehenden bereits gesondert hatte.

Aber auch beim Kalbe kann man sich besonders an Schnitten von der Zusammengehörigkeit der primordialen Follikelanlagen leicht noch folgendermassen weiter überzeugen. Die frischen ganz unveränderten Follikelanlagen haben ein silberweisses etwas glänzendes zart getrübtes Ansehen ohne jede Spur von Streifung irgend einer Art und zeigen ein zartes aber sicher zu sehendes Epithel. Man bereitet sich von dem ganz frischen Eierstocke des Kalbes mit recht scharfem Rasirmesser einen Schnitt, der senkrecht auf die Oberfläche fallt. Die Eierstöcke, die noch so weit in der Entwickelung zuriick sind, dass man von aussen noch keine Grasf'schen Bläschen mit unbewaffneten Auge am Eierstocke sehen kann, sind die günstigsten für die Untersuchung. Nach Anbringung dreier ganz niedriger Wachströptehen legt maul das Deckglảschen auf, so dass es die Oberfläche des Schnittes berührt. Ist der Eierstock so durchtränkt gewesen, dass eine capillare Flüssigkeitsschicht sich zwischen das Deckgläschen angesogen hat, so beginnt man die Untersuchung. Ist dies nicht, so kann man olne Bedenken von der Seite ein Tröpfchen einer 1\% Lösung von doppelt chromsaurem Kali hinzufliessen lassen, welches, wenn es chemisch rein ist. wovon man sich zu iberzeugen hat, da die iur Handel vorkommenden Krystalle oft Beimengungen anderer Substanzen. besonders $\mathrm{SO}_{3} \mathrm{KO}$ enthalten, das Gewebe klar lässt und vor Allem die Follikelanlagen einige Zeit sehr gut erhält. Ich bin in der Concentration bis zu $0,1 \%$ herabgegangen, wobei natülich sich durch Wasserimbibition die Follikelanlagen stark ansaugen und prall angeschwollen noch schärfere Begrenzıngen ihrer Randcontouren darbieten. Sogar lestillirtes Wasser leistet kurze Zeit einige Dienste, olıwolıl es natürlich bald die Zellen unmässig durch Diffusion aufschwellt. - Ein anderes gutes Mittel, 
un die scharfe Abgrenzung der Follikelanlagen und den Zusammenhang der cinzelnen sich abschniirenden Follikel miteinander deutlich zu sehen, ist eine verdiunnte Lösung von carminsaurem Ammoniak in destillirtem Wasser, welches eine Spur freien Ammoniumoxydes enthălt. Zwei Tropfen einer concentrirten Lösung carminsauren Ammoniaks auf eine Unze destillirten Wassers thun gute Dienste.

Wer auf diesc Weise auch nur einmal die Follikelanlagen wie prall geschwollene, mit prallen Ausbuchtungen versehene Würste glänzend weiss mit schärfsten Contouren, sich von der schwarzgestrichelten Stromasubstanz des Eierstocks abheben sieht, und mit ihnen im Zusammenhang gleichausschende sich abschnürende Follikel und ebenso ausselıende bereits abgeschnürte, dom kann kein Zweifel bleiben, dass die Grasf'schen Follikel aus ursprünglich zusammenhångenden zelligen scharf umgrenzten Anlagen hervorgehen. Ich betrachte diesen Satz, den ich bei anderen Thieren abermals beweisen werde, als abgemacht. Er ist leicht mit meinen Methoden zu constatiren und kein Mikroskopiker kann, wenn er sich ein paar Stunden damit bei passend guten äusseren Mitteh beschäftigt, im Zweifel bleiben. Oft genügt der erste Schnitt, um viele beweisende Präparate zu erhalten; zuweilen muss man mehrere machen. Ich brauche naturlich haum zu bemerken, dass je feiner der Schnitt, um so besser, je stärker die Vergrösserung um so überzeugrender das Präparat. 'Ich untersuchte gewöhnlich mit einer' 350 maligen Vergrösserung eines vortrefllichen Ziss'schen Mikroskopes und benutzte nur zuweilen mein ausgezeichnetes System $F$. Wenn der Eierstock ganz frisch und gesund ist, so lässt er sich gut, ja sogar sehr got in "ausserst feine Lamellen zerleggen, wenn nur das Messer scharf ist. Bei kalter Witterung bleibt er bis 3 Tage brauchbar; doch wird er schon nach 24 Stunden weich und breïg, lässt sich schlechter in dünne Lamellen spalten und gilst weniger gute Bilder. Hichei bemerke ich, dass die Follikel, welche bereits abgeschnïrt sind, sich lange wegen ihrer grossen Derbheit erhalten, während die zarten primordialen Anlagen längst zerflossen sind. IIat man nun eimmal diese zarten Bildungen gesehen, so begreift man sogleich, dass von Isolationsversuchen nicht gar viel zu erwarten ist, weil der Zug diese Gebilde alsbald zerfliessen lässt. Man begreift, warum Chromsäure und Alkohol diese zarten Bildungen zur Unkenntlichkeit einschrumplen lassen, so dass es am gerathensten erscheint, wo möĝ̣lich frisch zu untersuchen, was ja, wenn es möglich, immer die beste Methode bleibt. Als ich einmal ein sehr schönes Präjparat mit deutlichsten Epithelialzellen und schärfster Begrenzunğ vor mir hatte in einer $0,1 \%$ Lösung von sauren chromsaurem Kali, wünschte ich dasselbe zu conserviren, und brachte der Vorsicht halber auf der Spitze eines feinen zugespitzten Glasstälchens eine Spur Glycerins, das ich zur Conservirung anderer Präparate bereits als treflich erprobt hatte, hinzı, musste aher zu meinem Leidwesen sehen, wie mein Gebilde zu einem nichtigen, unkenntlichen Truimmerhaufen zusammensank. Dies lag offenbar an dem starken endosmotischen Strome, den das Glycerin aus den zarten Zellen zu sich erregte. Gehen wir nunmehr nach Beweis der Exi- 
stenz prinırdialer zelliger scharfumgrenzter Follikelanlagen, aus denen sich die Gust'schen Bläschen bilden, zu cinem genaueren Studium jener Anlagen iiber.

Auch die oberflächlichste Betrachtung zeiggt ausnahmslos, dass nächst der scharfabgegrenzten Oberfläche der Anlagge eine Schicht blasser, kernlıaltiger, durch gegenscitigen Druck sich oft polygonal alpplattender Zellen gefunden wird, welche sich von den Epithelialzellen des jungen GraAf'schen Follikels meist wenig oder niclit unterscheiden, es sei denn durch elwas grössere Zartheit und Blasse aller Theile. I m Inneren der primordialen Follikelanlagen sielıt man aber hier und da besonders deutlich in denjenigen Theilen derselhen, die das Streben der Alsschnürung bereits zeigen, meist bedeutend grössere, rundlich ovale Zellen mit of scharfer Umgrenzung, zartkörnigem Protoplasma, kugelrundem, wasserklarem Kernblaschen, das ein stark lichtlurechendes Körperchen beherberğt. Nimmt man das specifisch eigonthümliche, nicht näher beschreibliche Ansehen aller dieser Theile, ihre Grössenverłäilınisse hinzu, so lıahen wir es im Inneren der in Abschnürung begriffenen Tlıeile der Follikelanlagen mit zarten schönen Zellen zu thun, die von den Eizellen in den jungen evidenten Follikeln sich in Nichts unterscheiden. In der That, wenn wir dieselbe Zelle, welche später siclı im abgeschinirten Follikel findet, mit demselben Charakter schon in ihm finden, wenn er sich noclı nicht ganz alıgeschuiirt hat, ja wenn er erst das beginnende Streben der Sonderung zeigt. so muissen wir zugehen, dass das Ei bereits da ist, ehe der Follikel sich ausgebildet hat. Wenn nun alıer diejenigen feingranulirten grösseren Zellen im Inneren der primorlialen Follikelanlaggen für Eier angesprochen werden dürfen, wenn die Follikelanlage sich eben zur Abschnürung anschickt, so ist es nothwendig zuzugeben, dass auch die anderen gleichbeschaffenen grösseren feingranluirten Zellen Eier seien, obwohl die Follikelanlage um sie noch kein deutliches Sonderungshestreben zeigt. Sehr gut überzeugt man sich auch noch durch eine andere Mcthode von dem eigentlichen Sachverhalte. Sonderbarer Weise verträgt es der frische Eierstock, in einem erwirmten Zimmer hingelegt, einzutrocknen, ohne dass die Structur dadurch so zerstört wird, um nicht noch äusserst werthvolle Präparate zu liefern. Mit einem scharfen Rasirmesser schmeidel man feine Lamellen, was selır leicht geht, befeuchtet sie mit einer Lösung von $1 \%$ saurem chromsaurem Kali. Im Anfange treten die primordialen Follikelanlagen mit einer Schı̉rfe lıcrvor, wie durch keine andere Methode, allmählich nehmen sie aber, doch erst nach längerer Zeil, wieder ihr zarteres blasses Ansehen an. An solclıen dünneren primordialen Anlagen sielit man, wie die Eier in einem Canale liegen, so dass wir es also, was der crste Anblick der primordialen Follikelanlagen vermuthen lässt, mit Schläuclıen zu thun lıaben. Das Epithel zeiğ natuirlich nicht mehr so regelmissige Beschaffenheit, doch ist es vollkommen deutlich und ich empfehle deshall, Jedem, der sich schnell in der Sache bis zu einem gewissen Grade orientiren will, diese Methode (Taf. I. Fig. 8.). Hier sicht man Schläuche, theils angeschnitten ( (t. (\&), lheils der Länge nach $(b, c, d)$, theils schief $(e)$, theils quer $(f, g)$ durchschnitten. Auch gewahır 
man hier und da sehr instructive Práparate für den Abschnürungsprocess (s. dieselbe Fig. d. $\&$ ). Ich halte es demgemass fur bewiesen, dass im Inneren der primordialen Follikelanlagen Eier vorhanden sind, lange ehe sich der GraAfsche Follikel gebildet hat und dass diese feinkörnigen Eier umhült sind von den kleineren blassen, kaum granulirten Epithelialzellen der scharfumgrenzten Follikelanlagen. Ich halte es für bewiesen, dass die Eier ursprünglich in mannichfach gestalteten Schläuchen enthalten sind, welche durch Abschnïrung GraAf'sche Follikel bilken.

Ehe wir nun weiter gehen, um nach der Herkunft und Abstammung der Eier zu forschen, wird es zwecknässig sein, vorher den Process der Abschnürung genauer zu verfolgen.

Das Zusanmenhaften der Follikel, welches noch stattfindet, wenn sie bereits vollständig ausgebildet und ganz von dem als membrana propria anzusprechenden Contour umschlossen sind, so wie die noch inniger zusammenhaftenden Follikelanlagen zeigen, dass es sich hier nicht darmm handeln kann, dass innerhall, der primordialen Follikelanlagen hier und da Zellenhaufen sich zusammenballen, un einen Follikel zu erzeugen, weil sonst das so häufige Zusammenhängen aller Follikel nicht zu begreifen wäre.

Um in der Angelegenheit der Abschnüung ins Reine zu kommen, muss man möglichst dünne, am besten isolirte Anlagen wählen (Taf. I. Fig. 6.). An diesem evidenten Schlauche sieht man an tler Stelle, wo die Theilung vor sich gehen soll, eine ganz seichte Einschniırung, welche am einfachsten aus dem Wachsthum der Eier erklät wird, welche die Theile auftreiben, in denen sie liegen. An dieser Einknickungsstelle vermag das Epithel, nicht behindert wie an anderen Orten durch den Gegendruck der wachsenden Eier, stärker zu wuchern und erhebt sich so zur Bildung einer Scheidewand zwischen beiden Eiern (Fig. 8. No. a. $\beta$. und No. $d . \beta$. .) Sobald dic Zellen der einen Seite denen der andern logegnen, was hier heinahe der Fall ist, braucht nichts weiter zu geschehen, als dass sich ein Fortsatz der membrana propria zwischen beiden Eiern von einer Seite zur anderen hinschiebt, was ich direct beobachtet habe und später genauer beschreiben will. Ist die Scheidewand zwischen beiden Eiern nur von einer Lage Zellen zusanınengesetzt, und trennen siclı die Follikel dann, so muss einer cine Stelle haben, wo noch keine Zellen sind. So erkiärt sich die Existenz der beiden Pole der Follikel. Es sind die beiden Mbschnürungsstellen. Ist der Follikel durch Alsschniirung einer stumpfen cylindrischen blindendigenden Follikelanlage entstanden, so hat er natïrlich nachher nur einen Pol, was mir nicht selten vorzukommen schien (Taf. I. Fig. 2.). Auf die Bildung der membrana propria werde ich indessen noch specieller zuriickkommen.

In dem gedachten sicher zu constatirenden Falle unzweifelhafter Abschnürung der Follikel von den primordialen Anlagen reducirt sich also rer Vorgang im Princip darauf, dass eine zellige Scheidewand zwischen die Eier von der Peripherie der primordialen Follikelanlage her 
sich einschiebt. Das ist ein Vorgang, der viele Analogien in der Entwicklungsgeschichte hat. So theilt sich der Herzsack durch das von unten nach oben wachsende septum ventriculorum, durch die valvula foraminis ovalis in linke und rechte Hälfte. So zerfalli der unpaare truncus arteriosus durch eine von der Wand aufsprossende Scheidewand in die spattere Pulnonalarterie und Aorta. Somit stossen wir hier nur auf einen eigenthümlichen Fall der Scheidungr von Organhöhlen. Man begreift, wie also durch L'mwachsung der noch von dem Epithel der prinordialen Anlagen unberïhrten Theile des Eies der Zellenmantel, die sogenannte spätere memlrana gramılosa s. cellnlosa entsteht. Kein Fall zeigt evidenter den Vorgang der Linwachsung, als diejenigen jungen Follikel, die wie der früher beschriebene Taf. I. Fig. I., eine noch unvollendete membrana grumulosa haben, die offenlar das Ei erst noch umwaclisen muss, um vollständig̣ zu werlen.

Noch bleibt uns aber Rechenschaft alszulegen, warum die ursprünglich mit breiten Flächen und vielen Zellen sich innigst berührenden Follikelanlagen später, wenn der Process der Alsschnürung wie in Taf. I. Fig. 4. fast vollendet ist, nur noch in Punkten sich beriihren wie zwei Kugeln. Auf den ersten Blick will es scheinen, als ol, die Erklärung auf der Hand lïge. Denn wenn aus den ursprünglichen Follikelanlagen zunachst polygonale Massen hervorgehen, die sich später in Kugeln umwandeln, so könnte, da sich Kugeln unmöglich anders als in Punkten berühren, nur noch eine Schwierigkeit in der Erklärung der Art des Entstehens der kugligen aus der polygonalen Form des Follikels vorhanden sein. Zunächst ist es klar, dass eine abgeschlossene Masse, welche aus hallfflussigen Theilen besteht (den Zelten mit ihrem Inhalte) und umschlossen wird ron einer membranösen Bildung, aus physikalischen Grünlen die Kugelform anzunehmen streben nuss, wenn im Innern der Masse der Druck der Fliissigkeit, hervorgebracht durch Wachsthum von Ei und Epithel, zunimmt. Jede irgendwie gestaltete aber elastische Blase wird bei Erfüllung derselhen mit fluissigen oder halbflüssigen Theilen bei hohem Druck eine Gestalt annehmen, die von der Kugel um so weniger alıweicht, je stärker der innere Druck ist. Dieses Naturgesetz ist hier unzweifelhaft im Spiel : aber es ist nicht die alleinige Ursache des Vorganges. Die Sache ist folgende:

Zunächst habe ich bei Katzen von $6-7$ Wochen, also zu einer Zeit. wo sich in tieferen Theilen des Eierstocks keine ganz jungen, sondern sehr vorgeschrittene schöne GraAfsche Follikel finden, nicht selten Commissuren wahrgenommen, welche zwei auch drei Follikel mit einander stetig verbanden und als Fortsetzungen der membranae cellulosue anzusehen waren, indem die Zellen der Commissuren mit denen dieser Membran übereinstimmten und sich stetig in sie fortsetzten. Solche Commissuren trifft man um so eher, je jünger noch die Follikel sind, um so weniger, je weiter sie sich vorgeschritten zeigen. Da ferner in den tieferen Theilen des Eierstocks zu jener Zeit unzweifelhaft keine jungen Follikel entstehen und nichts darauf al)zielendes in diesen Commissuren wahrgenommen werden konnte, wogegen auch der Umstand sjricht. 
dass nach einem allgemeinen Gesetz unmittelbar zusanmenhängende Follikel auf nahe derselben Entwicklungsstufe stelien muissen, so hann ich nur folgern, dass die zelligen Commissuren früher oder später obliteriren. Das ist ja üherhaupt die Eigenthimlichkeit der Epithelzellen des Graaf'schen Follikels, welche die Eizelle umschliessen, deren Organisation eine durch die Zeugung unendliche Dauer bestimmt ist, dass sie in dem gellen Körper zum Untergang bestimmt sind. Diese Eigenthümlichkeit zeigen somit diese Zellen schon früher in denjenigen Theilen der Follikelanlagen, welche nicht bei der ersten Bildung in die Formation des Follikels aufgenommen worden sind.

Diese Vorgänge konımen luei dem Entstehen der primordialen Follikelbildungen, ich kann nicht daran zweifeln, allgemeiner vor und unterstuitzen die Absonderung der prinordialen Follikelanlagen. Man betrachte z. B. Taf. I. Fig. 8.

Dies Präparat war isolirt. Es ist ganz frisch und wurde mit saurem chromsaurem Kali von $0,1 \%$ untersucht; darum sind die Zellen so angeschwollen. Man sieht an dieser zelligen Follikelanlage das Bestreben der Absclmiirung. Betrachtet man nun die Einbiegungsstelle, so sieht man in diese eine Zelle eingeschoben, welche gerade die Einbiegung ausfüllt. Ihr ausserer Rand setzt sich stetig in den Contour der Follikelanlage fort. Aber ebenso làsst sich der Contour des Schlauches so verfolgen, lass diese Zelle ausgeschlossen bleibt (Fig. 9. a.). Man könnte allerdings die Zelle $(a)$ auch als Kern des Drusenschlauches, der hier erhalten wäre, deuten. Man betrachte Taf. I. Figur 10. Hier sieht man zwei schöne Follikel, welche noch dicht zusammenliegen. Auf der einen Seite $(a)$ erstreckt sich ein tiefer dreiechiger Spalt zwischen sie, greift aber nicht durch, sondern setzt sich als Linie fort zur entgegengesetzten Seite, wo noch stetig dêr Contour des einen Follikels sanft nach aussen gebogen in den des andern übergeht (b). Da wo der Contour des einen hier in den des andern sich fortsetzt, schiebt sich in die bleibende kleine Lücke, welche auf der anderen Seite grösser ist und durch Fasermasse erfiillt, ein sehr kleines Zellchen ein, von dem es im höchsten Grade wahrscheinlich ist, dass es zu der primordialen Follikelanlage gehörte, im Wachsthum zuruichgeblieben ist, um später zu obliteriren $(b)$. So glaube ich auch, dass bei Praparaten, wie Taf. I. Fig. 7 (c) die den primordiaIen Anlagen noch aufsitzenden oft langen Hälse der jungen Follikel, später obliteriren. Dass in diesen rückbleibenden Resten sich neue Eier bilden sollten, ist darum nicht anzunehmen, weil die Eier auf andere Weise sich bilden, d. h. so dass erst das Ei und dann die primordiale Follikelanlage erscheint, wie das später zur Genüge bewiesen werden soll. Bemerken darf ich indessen, dass die eben erst obliterirten Zellenmassen auch wieder sichtbar gemacht werden können. Wenn man z. B. einen Haufen scheinbar von einander isolirter, sich nur berührender Follikel betrachtet und dann etwas kaustisches Ammoniak zu einem frischen Präparate hinzubringt, so kommen oft plötzlich die Zellenzüge zum Vorschein, die vorher nicht mehr sichtbar wie die ursprüngliche Follikelanlage es doch ist, jetzt abermals wieder die Substanzen andeuten, 
durch welche ursprünglich die Follikel zusammenhangen. Wiewolıl die Beantwortung dieser Fraye keine in der Sache sehr wesentliche Bedeutung hat, so dient sie doch dazı, den Modus der Abschnürung weiter zu beleuchten.

Wir sind indess mit der Betrachtung dieses Processes noch nicht zu Ende. Ich habe weitere Thatsachen zu melden, die besonders geeignet sind, den Vorgang zu erlautern. Man betrachte zu dem Ende Taf. I. Fig. 11. Diese aus schönen polygonalen Zellen bestehende mächtige Anlage trägt, ähnlich wie der rundköpfige Cactus aussehend, aufsitzende, in Bildung und Abschnuirung begriffene Follikel von verschicdener Entwicklungsstufe. Die Bildung zeigt einen glänzenden, dicken Randcontour. Man betrachte den unteren Rand a des Präparates: hier sieht man an drei Stellen die Zellen auseinandergewichen, an zweien (b) um die.Tiefe einer Zelle, an einer um melır ( $c$. Zwischen diese an Rande auseinanderweichenden Zellen schiebt sich aber gleich einem Keilmeisel eine stark lichtbrechende Substanz ein, welche mit dem stark lichtbrechenden Contour der ganzen Bildung zusamnenhängt. Man bemerkt, dass diese sepla, um sie so zu nennen, bald tiefer, bald weniger tief in die Follikelanlage sich lineinschieben, da der Durchschnitt eines solchen in (i) mitten in der Bildung bemerkt wird, der aller Wahrscheinlichlieit nach von der entgegengesetzten Seite vorgedrungen ist. Ausgezeichnet schön sieht man die septa angedeutet an der primordialen Follikelanlage Taf. II. Fig. 6. «.; bei $\alpha$, glaube ich, sieht man von oben auf ein sich einsenkendes septum. Bei $\beta$ ist der Schlauch angeschnitten und zeight in seiner Höhle die körnigen Dottermassen eines oder mehrerer Eier. Die beiden andern Schläuche von sehr verschiedener Grösse haben exquisites Epithel, wie der vorhergehende. Um tiefere Einschnitte zu constatiren als diese siehe Taf. I. Fig. 12. Hier bemerkt man einen måssig tiefen Einschnitt bei $a$, dann einen breiten mit bereits faserigem Inlalt, (ler sich in zwei Einschnitte spaltet $(b)$. Der den Einschnitten dieser Seite entsprechende Contour auf der entgegengesetzten ist vollkommen scharf und glatt. Erst weiter unten zeigt sich wieder eine, wie es scheint, schiefliegende Spaltung (c). Bei dem Priparate Taf. I. Fig. 7. ( $x$; sieht man einen sehr tiefen Einschnitt, über dessen Beginn sich aber noch eine scharfe Linie von einer Follikelanlage zur anderen davon getrennten an dieser Stelle hinzielıt. Man vergleiche endlich, um Dasselbe mit anderen Methoden zu constatiren, das aufgeweichte Prijparat Fig. 8. $a \gamma$. Man kann sich demgemäss den Vorgang wohl einfach so versinnlichen, dass man sich vorstellt, es wüchsen von der Peripherie der Follikelanlagen membranöse septa, etwa ähnlich wie bei einer Amphibienlunge hinein. Da man nun überall und stets den entstandenen Spalt, den eindringenden Keil von schönem Epithel umgeben findet, so ist daraus zu schliessen, dass er sich in demselben Maasse, als er in die Follikelanlage vordringt, mit Ejpithel sogleich durch Vermehrung der Epithelialzellen iiberzieht. Dass dies vorkommt, kann niclıt bezreifelt werden, da die Follikelanlagen wenigstens später, wenn sie evilente Eier entlalten, Hohlräume umschliessen, wie wir bereits bewiesen haben und noch weiter constatiren werden, und ['f] ̈̈ ge er, Eierstöcke. 
da ja beim jungen Follikel sellsst ein Theil des septum urspriinglich frei von Epithelialzellen sein kann, womit also gesagt ist, dass durch dieses Wachsthum der septa die Follikel sich wesentlich abgrenzen. Man könnte sich denken, dass diese Thatsachen nicht nothwendig als tichter Spaltungsprocess gedleutet werlen missen, weil sich ebenso wohl annehmen liesse, class aus ursprüngliclı winzigen Anlagen einzelne Theile stäker hervorsprossen, deren Interstitien als Spalten erscheinen.

Bedenkit man aber, dlass die primordialen Follikelanlagen ursprünglich oft grosse zusammenhängende Zellenmassen darstellen (Taf. II. Fig. 6.), aus denen später gesonderte Follikel entstehen, so kann es sich nur um Obliteration odler Spaltung, odler um beides gleichzeitig handeln. Die Spaltung ist für die letzten Abschnürungsstadien nicht zu läugnen, $\mathbf{l}$. h. für diejenigen, wo die Follikel jetzt noch punktförmig zusammenhängen, um später auseinanderzugehen. Der Process der Spaltung ist nicht in Abrede zu stellen, wo wie in Taf. I. Fig. : $a$. und Fig. 8. d. $\gamma$. nach der Anorknung der Zellen eine entstehende Spaltung evident ist. Nichts desto weniger möchte ich nicht läugnen, lass solche primordiale Anlagen von Follikeln, deren Zellen zu einer gewaltigen Vegetation für lange Zeit bestimmt sind, durch Wucherungen Auswüchse treiben. Es ist dies vielmehr ganz wahrscheinlich.

Durch alle diese Processe alser gehen aus ten primortialen Anlagen die allerwunderlichsten und sonderbarsten Gestaltungen hervor, die anfänglich den Forscher selır verwirren.

Ich glaube nunmehr den Leser darüber ins Klare gesetzt zu lıaben, dass sich die GraAf'schen Follikel durch Alsschnïrung aus den primordialen scharflegrenzten aus Epithelzellen und Eiern hestehenden Anlagen herausbilden und zwar nach den Gesetzen, wie sie soeben dargestellt worden sind.

Noch bleibt uns aber eine sehr wichtige Aufgabe zu lösen übrig: Woher kommen und wie entstehen die Eier, welche wir im Innern der primordialen Anlagen gefunden haben?

Das ist eine Frage, deren Entscheidung bei clem Kallse aus verschiedenen Gründen nicht leicht ist, wảhrend ich lie Abschnürungsprocesse bei keinem Thiere so schön in ihren Gesetzen studiren konnte als gerade bei diesem.

Diese Schwierigkeiten haben zuerst ihren Grund in der ganz ausserordentlichen Zartheit der Eier, welche sogar in den bereits abgeschnürten Follikeln nicht lange dem Angriffe der besten Untersuchungsflüssigkeit widerstehen. Dies ist bei anderen Thieren, z. B. den Katzen, nicht so, sondern hier sind die Eier derber und lassen sich sogar in Glycerin, wenn sie vorher passend behandelt wurden, recht gut conserviren. Aussertem gelingt es schrwer, sie in jüngeren Zustande zu isoliren, indem diese leicht zerfliesslichen Bildungen begreiflich bei jedem Zuge, der die Follikelanlagen auseinanderzureissen strebt, zerstört werden. Ausserdem erhält man die Eierstöcke des Kálbes nicht jung genug. wo noch die Eibildung im lebhaftesten Gange ist und dlas Bindegewebe weniger derb erscheint; - denn die Thiere werden ja 8-14. Tage 
nach der Geburt in der hiesigen Gegend des Niederrheins geschlachtet. Auch dieser Uebelstand ist natiorlich bei den Katzen oder anderen Thieren nicht vorhanden. An Schnitten aber hindert die einem gewissen Entwicklungsstadium zukommende grosse Blässe der Eier an der Untersuchung, so dass sie sogar in jungen frischen Follikeln oft nicht mit der nothwendigen und wünschenswerthen Bestimmtheit mit allen ihren wesentlichen Theilen wahrgenommen werden können. Nichtsdestoweniger habe ich keine Mühe und keinen Zeitverlust gescheut, um iiber die hier vorliegende wichtigste Frage auch beim Kalbe ins Reine zu kommen, was mir endlich auch gelungen ist.

Wenn man einen feinen Schnitt, der am besten vertical auf die Oberfliche des Eierstocks gerichtet wird, mit einer Lösung von saurem chromsaurem Kali von $0,1 \%-0,5 \%$ befeuchtet, so klärt sich nach einigen $(\ddot{0}-10)$ Minuten das Praparat auf, und hellweiss treten die Follikelanlagen und bereits fertigen Follikel hervor. Durch die starke Aufschweliung der Epithelialzellen der GraAf'schen Follikel aber wird, wie schon frïher hemerht, das Ei comprimirt und scheint nun slảrker hervorzutreten als ein feinkörniger Haufen, der das Keimbläschen umschliesst. Man suche nun an einem feinen Schnitte nach einer Stelle, wo eine Follikelkette vorliegt, die eben nahezu die Absclinürung vollendet hat. Man weiss, dass die Pole der Follikel an den Berührungs- oder Abschniirungsstellen derselben liegen. Hier wird man denn bald bei der Verfolgung des Eicontours finden, dass die körnige Masse oft scharf abgegrenzt von einem Follikel sich durch deı Pol in die hörnige Dottermasse des nächsten Follikels fortsetzt. Wenn man einmal auf diese Erscheinung aufnerksam geworden ist, sieht man sie fast überall an vorliegenden Follikelketten, so dass an der Constanz der Erscheinung unter den obwaltenden Verhältnissen kein Zweifel sein kann. Wenn man Flïssigkeiten von einer Concentration anwendet, bei der die Epithelialzellen des Grasf'schen Follikels wenig oder gar nicht anschwellen und das Ei als pralle Kugel in dlem Follikel liegt, sieht man die Erscheinung nicht. Daraus folgt also, dass, sobald das Ei comprimirt wird, der Gehalt desselben sich leicht aus einem Follikel in den anderen ergiesst, und dann die Eier durch 3, 4. und mehr Follikel eine zusammenhängende Masse darstellen: feinkörnige in Innern der Follikel liegende Kuggeln, die durch körnige die Follikelpole durchsetzende Zipfel miteinander in continuirlicher Verbindung stehen. Diese Thatsache zeigt, dass lange noch eine Communication der Follikelhëhlen vorhanden ist, welche ein Uebertreten des Dotters aus einem Follikel in den nischstfolgrenden gestattet, wenn das aussere Ansehen der Abschnürung sclion eine fast vollhommene Sonderung vorspiegelt. Bei genauerer Betrachtung der Eicommissuren, welche aus einem Follikel in den anderen durch die Pole übergehen, fällt oft sehr die Schärfe der Begrenzung der Zipfel auf, welche von beiden Polen des Eies ausgehen, um es mit dem folgenden und rorlıergehenden zu verbinden. Es gewinnt somit den Anschein, dass die Itöhlen der Follikel, deren Al)schnürungsprocess nahezu vollendet ist, doch noch durch besondere Bildungen offen communi- 
ciren. Eine solche Eikette bietet demgemäss mulatis mutandis cine grosse Aehnlichkeit nit einem nit vielen Embryonen erfülten Horne des uterns bicornis des Kaninchens oder des Hundes u. dergl. mehr. Hat man ein solches Präparat von Follikelketten ror sich und betrachtet man jene oft scharfe Begrenzung der Zipfel, welche ununterbrochen aus einem Follikel in den andern übergehend die Eier mit einander verbinden, so drängt sich die Vermuthung auf, dass dieses Zusammenlängen der Eier wohl auf keine scheinhare, sondern eine wirkliche Zusanmengehörigkeit hinweise.

Wie es sich hiermit verhält, lehrt das weitere Studium der Beziehungen des Eies im Grasf'schen Follikel zu seiner Ungebung. Bei ter Untersuchung ganz frischer Eierstocksschnitte in einer Lösung von chemisch reinem saurem chromsaurem Kali, deren Concentration schwanken kann von $0,1 \%$ bis $0,5 \%$, sielıt man den Eicontour sich in einen evidenten bald breiten bald sclmalen Zipfel fortsetzen $(a)$, welcher offenbar aus dem Follikel herauskommt und sich merkwiirdiger Weise in einen oft sehr langen und weit zu verfolgenden körnigen zarten Strang (b) fortsetzt (Taf. I. Fig. 13.a), der ungemein sanfte Contouren hat, abwechselnd dicker und dünner wird, als ob feinkörnige Kugeln dicht hintereinander aufgereiht, und sich innigst beriihrend das Gebilde darstellten. Im Innern der Kugeln erscheint eine hellere Stelle und an guten Präparaten erweist siclı diese hervorgebracht durch ein Bläsclıen, kugelrund, wasserklar, versehen mit einem kleinen mässig scharfbegrenzten, mảssig stark lichıbrechencken soliden Körperchen. Diese Kugeln haben das specifisclıe Anselıen von jungen Eiern in allen ihren Bestandtheilen. Da aber ein solcher Zellenzug sich geradenwegs in einen Follikel verfolgen lảsst, so dass eine der Kugeln des Zuges das Follikelei repräsentirt, so ist es unmöglich, daran żu zweifeln, dass diese feinkörnig̣en Kugeln, die hinter einander aufgereiht liegen, ả chte primordiale Eier sind.

Um über die Natur dieser primordialen Eier und Eiketten indessen vollkommener ins Klare zu kommen, obwohl bei anderen Thieren diese Untersuchung, so bei Hund und Katze, viel leichter ist, liess ich mich doch keine Mỉhe vertriessen und suchte nach Anfertigung feiner Schnitte mit scharfen Nadeln Bruchstücke solcher Eiketten zu isoliren. Die Untersuchungsflüssigkeit war eine Lösung von saurem chromsaurem Kali, deren Concentration 1,0\% betrug. In Taf. II. Fig. 1. sieht man eine solche allerdings an einer Stelle verletzte Eikette. Sic erweist sich zunächst nach aussen an den unverselırten Stelleı durch einen sehr scharfen, aber ganz ausserordentlich zarten Contour abgegrenzt, welcher von einer Eikugel auf the andere direct übergeht. Ob dieser Contour einer Membran entspricht, lässt siclı an diesem Präparate nicht entscheiden. Bei den Katzen will ich beweisen, dass die primordialen Eiketten hereits von einer frisch sehr zarten Membran umschlossen sind, so dass es also auch hier beim Kalbe so sein wird. Das Protoplasma der Eikugehn liess sich sehr schön an der Verletzungsstelle studiren, wo ein Theil ausgeflossen war und sehr feine dunkle Körnchen darbot, zwischen denen kleinere 
und grössere helle, hlare, homogene Kugeln, wohl Eiweisskugeln lagen (Taf. II. Fig. 1. a). Verdünnte Essigsäure, welche die Keimbliaschen etwas stärker hervortreten liess, bewirkte cin Erblassen dieser von mir als Eiweisskugeln bezeichneten Bildungen, so dass sie nicht wohl als Fetttröpfchen oder Kerne angesprochen werden konnten. Die grössten dieser Eiweisskugeln erreichten etwa die halbe Grösse der Keimbläschen. Das Keimblaisclıen (k) war 0,0125 Mn. „uross. wasserklar, kugelrund, scharf und ziemlich derb contourirt und zeigte ein starlier lichtlorechendes Körperchen, den Keimfleck $(f)$, der an jüngeren Eiern des Kallıes etwas cigentluünlich Mattes in seinem Glanze hat, in dem er von anderen Kernen übertroffen wird. Die Grösse des Keinfleckes betrug 0,0030 Mm. Ich habe wohl daran gedacht, im Angesicht so mancher Controverse über die Bildung der thierischen Eier, ob was mir vorlage nicht vielleicht ein feinster Drüsenschlauch mit zartem Epithel wảre, in dem erst die membranlosen Eikuggeln sich befänden. Aber ebenso sehr habe ich vor Augen, wie vorsichtig man mit der Annahme von Zellen besonders: in der heutigen Zeit sein muss, wo die wesentlichen Charaktere der Zelle auf Protoplasma unıl Kernblåschen reducirt worden sind. Bedenkt man nun, eine wie wenig charakteristisclie Masse nach Aussehen, chemischer Beschaffenheit, Mengenverhältniss zum Kern das Protoplasma ist, erinnert man sich, wie leiclıt im Protoplasma eine Eiweisskugel, eine Vacuole gesehen werden kann, so liegt es auf der Hand, dass, wenn hier auch die mikroskopisclıe Routine nachlilft, im speciellen Falle doch sehr grosse Schwierigkeiten entstehen können. Nichts ist entscheidend, als die Entwicklung. So muss ich behaupten, dass sich nicht anatomisch, nur physiologisch d. h. durch ihre Leistungen die Zelle als das charakterisirt, was sie ist. Bei Betrachtung meines Präparates aber kann es Niemandem einfallen hier Zellchen zu selıen. Es sind feinliörnige, kernhaltige, zusanmenhaltende Zellen: „Eiketten." Jetzt wird uns das Verhalten des Zusamnenhängens der Eier von einem Follikel zum anderen sowie die Bedeutung der Follikelpole weitrr klar. Die Eizipfel, welche als Commissuren die Eier der Follikel verhinden, werden durch dic ursprungliche Zellmembran der Eier gebildet, welche an der Abschnirungsstelle sich stark verjüngt hat. Contrahirt sich dann im Follikel der membranlose Dotter, so scheinen in den Follikelketten die Eier gesondert. Schwellen aber durch Wasserimbibition die Epithelialzellen des stratum granulosum, so treibt der Druck den Dotter auseinander, so dass er sich dann in die Zipfel ergiesst und so die noch vorhandene Commissur mit seinen Körnern gleichsaun durclı Selbstinjection sichtbar macht.

Wenden wir uns nun zu den Eiketten, welche sich in die Follikel fortsetzen, olne sellsst in diesen zu liegen. Die ausserordentliche Länge der körnigen Eiketten, die regrelmässige Abwechselung weiter und enger Stellen, die Existenz von Keimblisclıen älınlichen Bildungen in ilnnen, die Kleinheit der Follikel, oft erst aus ein paar Epithelialzellen bestehenı, welclıe stots nur ein kleines Ei umschliessen, sichert gegen den Verdacht, dass wir etwa hier ausgeflossenes in einen Canal ausgetretenes Dotterprotoplasma für eine Eiliette genommen hatten. 
Was dem Beobachter nun zunąchst bei der Verfolgung der Eiketten auffallt, ist, dass es oft bei Untersuchung mit den diluirten Flüssigkeiten des sauren chromsauren Kali's den Anschein hat, als ol, die extrafolliculären Theile derselben frei im Eierstocksparenchyne lägen. Bei genauerer Betrachtung bemerkt man aber, dass das faserige Eierstocksstroma nicht his an die Eihette heranreicht, sondern dass ein lıeller Zwischenraun zwischen ausserem Eicontour und dem faserigen Stroma bleibt, und die Eiketten folglich nicht gleichsam in das faserige Eierstocksstroma eingekittet sind. Sie liegen also in Canälen, welche die Eierstockssulstanz durchziehen. Hier und da sieht man auch an der Wand dieses Canales kleine zarte Zellchen vorspringen, so dass es demnß̈chst sich um Schläuche mit zartem Epithel handelt. in denen die Eiketten liegen. Die Ursache, dass man dies zarte Epithel nicht deutlich genugg walırnimnt, liegt wie gesagt in der Untersuchungsflussigkeit, indem getrocknete und dann wieder in saurem chromsaurem Kali von 1\% aufgeweichte Praparate das Epithel ganz vorziiglich zeigen (Taf. I. Fig. 8.). Dass dies so ist und diese Schläuche sogar eine membrana propriı haben, das kann ich direct nicht blos bei dem Kalbe, sondern auch und hier noch besser bei der Katze heweisen.

Welche Bezichung hat nun dieses Epithel zu dem der Grasf'schen Follikel? Denkt man, dass später, sobald die Bildung der Follikel beginnt, die Eier von dichten Epithelialschichten umhiullt sind, dass in ilmen selbst nichts von Zellenbildung jemals zu sehen ist, dass auch die Epithelialzellen der membrana gramulosa nicht in den Eiketten liegen, sondern die Eiketten umhïillen, so hann man sich unmöglich die Sache von vornherein anders denken, als dass in den Eischläuchen vorhandenes zartes Epithel plützlich mächtig zu wuchern beginnt, wenn um die Eier sich die Epithelialmäntel bilden sollen, welche wir als stratum gramulosum s. cellulosum bezeichnet haben. Glücklicherweise bin ich im Stande, directe Beweise für meine Schlussfolgerung beizubringen. Oefter gelingt es an Schnitten bei Verfolgung des Contoures des Eihettenschlauclies, der ein vorspringendes zartes Plattenepithel zeigt, plötzlich in ununterbrochener Folge an Stellen zu kommen, wo diese Bläschen stärker hervortreten, grösser und grösser, ja c ylindris ch werden, um endlich in sehr lange schmale Cylinderzellen ïberzugehen. Sie sind sehr schief gestellt, so dass sie mit den auf dem Randcontour des Schlauches aufsitzenden Theilen viel weiter von dem mit unentwickelteren Epithel versehenen Eischlauche entfernt sind, als ihr anderes freies in den Schlauchcanal gekehrtes Ende. Gleich den Fingern zweier gegeneinander gekehrter sonst symmetrisch gehaltener IIände, welche eine Kugel umfassen, legen sie sich um die Eizellen (Taf. II. Fig. 2.). Das vorstehende Prảparat ist von einem frischen Kalbseierstock. Die Untersuchungsflïssigheit war saures chromsaures Kali von 1\%. Die Cylinderepithelien sclıeinen mir ziemlich locker mit ihren Seiten zusammenzuhängen, als ob sie gleich Kornälıren aus der Wand des Schlauches hervorgewachsen wären. In dem vorliegenden Präparate scheint der Schlauch in einer Spitze blind zu endigen. Doch könnte das auch Täuschung sein. Denn ich 
habe nicht selten im Eierstocke derartige nit feinkörnigen Massen im Innern erfüllte und aut lange Strecken mit Cylinderepithelien besetzte Schläuche angetroflen.

Der geduldige Leser wird wohl gleich mir, als ich auf diese Erscheinung aufmerksan geworden war, sagen, was in aller Welt nun Schlauche mit Cylinderepithel auftauchen, da doch die Grasf'schen Follikel Plattenepithel haben, was ebenfalls für die primordialen Follikelanlagen von uns angenommen und beschrieben worden ist. Gleichwohl müssen wir uns vor den Thatsachen beugen, deren Complication nicht wenig dazu beigetragen hat, mir die Lösung dieser intrikaten Räthsel auf das Furchtharste zu erschweren. Wenn die Zeichnung, was ich auf das Bestimmteste versichern hann, genau ist, wenn das Präjarat, welches vorliegt, vom Eierstock gewonnen ist, was absolut feststeht, so wird mir jeder Mensch zugeben, dass das hier Gezeichnete ein Schlauch ist, der Cylinderepithelien und dazu noch recht lange besitzt. Niemand kann daran denken, dass ein Blut- oder ein Lymphgefaiss oder sonst eine Gewebebildung zu irgend einer Zeit der Entwicklung vorliege. Hätte ich diese Verhältnisse nur einmal und nicht offter gesehen, wăren sie von mir nicht bei Katzen elsenso wie bei Kälbern wahrgenommen worden, so hätte man glauben können, dass es sich hier einmal um eine abnorme Entwicklungr des Epitheles zu Cylinderepithel handele. Dies scheint mir nicht mehr gestattet. - Haben wir nun ferner auf unzweifelhafte Weise dargethan, dass die GraAf'schen Follikel (lurch Al)schnurung aus den primordialen Follikelanlagen hervorgehen, welche oft Plattenepithel besitzen, d. h. solche Epithelzellen, bei denen keinerlei Riclıtungsverschiedenheit für die Zelle wahrgenommen werden kann, so bleibt kein anderer Ausweg als zuzugeben, dass bei der Entwicklung des Epithels der primordialen Follikelanlagen aus den kileinen Zellen der Eikettenschläuche eine Periode existirt, wo die Schläuche Gylinderepithelien besitzen, welche sich durch Theilung später in Plattenepithel umwandeln müssen. Auch hier bin ich im Stande directe Beobachtungen mitzutheilen, welche diesen Uebergang unzweifelhaft constatiren.

Es sind mir nämlich Bildungen vorgekommen ähnlich derjenigen, welche in Taf. II. Fig. 2. dargestellt ist, nur mit dem Unterschiede, dass statt des cỵlindrischen Schlauches mit Cylinderepithel ein rundlicher, sehr grosser Zellenhaufen vorhanden war, der an allen Seiten scharf umgrenzt schien ausser an einer, wo eine Eikette aus demselben hervortrat. Diese Kapsel aus vielschichtigem Epithel zeigte nun theils cylindrische. theils aber auch schon viele rundliche Zellen scheinbar ohne bestimmtes Gesetz durch einander liegend. Sehr schön sieht man die Verschiedenheit des Epitheles an ein und demsellsen Schlauche in Taf. I. Fig. 8. So hat der Schlauch $a$ bei $\delta$ offenbar Plattenepithel, welches einzugehen bestimmt ist in den sich hier eben zur Bildung durch Abschnirung anschickenden Grasf'schen Follikel. Bei $\varepsilon$ aber isl ein Epithel vorhanden, welches schon allerdings niedrige Cylinderzellen zeigt. Noch unzweifelhafter ist bei $\lambda$ Cylinderepithel vorhanden. In dem Schlauche $b$ sielıt man bei " Cylincler- 
epithel, welches sich allmählich nach dem entgegengesetzten Ende in Plattenejithel umgestaltet. Der Schlauch $d$ zeigt uns eine Art Epithel, welches oft mitten inne steht zwischen Cylinder- und Plattenepithel. Dieser Schlauch scheint zugleich anzudeuten, wie wohl die cylindrische Zelle zum Unwachsen der Eier henutzt wird. Das Wachsthum dieser Zellen gestattet es, dass sie durch Verlängerung von einer Schlauchseite zur anderen hinüber kommen. Wenn eine solche Cylinderzelle dann kleine runde Zellen in sich entwickelt, so würde der Anschein entstehen, wie man es in Fig. $d(\beta)$ wahrnimmt. Auf diese getrochneten Präparate wuirde ich kein grosses Gewicht legen, wenn ich nicht an frischen dasselbe gesehen häte.

Wir kommen nunmehr auf eine wichtige Frage, die ich bisher unerörtert gelassen habe, welche sich aber der Leser bereits wohl selbst vorgelegt hat. Es erscheint auffallend, dass an verschiedenen Stellen die primordialen Follikelanlagen ein vielschichtiges Epithel darboten. da doch die jungen Follikel nur einschichtiges besitzen. Bedenkt man indessen, dass, wie ich später zeigen werde, die Eier sich durch Knospung vermehren, worlurch sie zwischen die lockern Epithelialschichten eindringen können, so dass also das vielschichtige Epithel nicht ganz zur Umschliessung des gerade sichtharen Eies verwandt werden muss, erinnert man sich, dass wir eine Obliteration von Zellenmassen bei dem Aufhau der Follikel als höchst wahrscheinlich liennen gelernt haben, so bietet dieser Umstand; wie ich glaube, keinerlei Schwierigheiten dar. Er erklät aber, wie es kommt, dass man nicht selten in offenbaren Follikelanlagen, an denen in Abschnürung begriffene Follikel vorhanden sind, keine Eier wahrnimnit, entweder weil sie noch nicht in diesellen weiter sprossend hineinw uchsen, oder weil diese oft sehr zarten Bildungen durch die dicken Epithelschichten nicht mehr erkannt werden hönnen. Als allggemeine Regel gilt es, dass die primordialen Eier in der Mitte der oft cylindrischen primordialen Follikelanlagen sich befinden, wie man an Querschnitten derselben sieht (Taf. I. Fig. 8). Diese zeigen ein zuweilen vielschichtiges Epithel, in dessen Mitte ein Ei liegt, als eine mit schwärzlichen Körnchen erfüllte Zelle, mit Keimbläschen und Keimfleck, welche sich auffallend von den glänzenden kaum granulirten viel kleineren hellen Epithelialzellen abhebt. Die Kleinheit und ganze Beschaffenheit der Eier beweist, dass es sich nicht um einen Grasf'schen Follikel handeln kann, der bei solchem Durchmesser grössere, ausgezeichnet entwickelte, schöne Eier enthält. Nach alledem ist es mir in hohem Grade wahrscheinlich, dass die nicht zu Eiern, sondern zu Epithelzellen des Graaf'schen Follikels bestimmten Zellen der primordialen Follikelanlage eine gewisse Selbständigkeit der Vegetation den Eiern gegenüber haben, indem man die evidenten Follikelanlagen oft in feinere Stränge von Zellen verfolgen kann, die dünner sind als die in den Schläuchen enthaltenen jungen Eier. Stellt man sich vor, dass diese dünnen Zellsprossen wuchernd dicker werden. Hohlraume in sich erzeugen, die mit denen der primordialen Follikelnassen, aus welchen sie hervorwuchsen, und in denen bereits Eier sind, sich in Verbindung setzen, so begreift man, dlass nachträglich Eier in diese Gänge hereinwachsen könnten. 
Wenn diese Vorstellung auch nicht mit vollkommener Strenge bewiesen werten kann, so zeigt sie doch, dass jene Thatsachen mit unsern Anschanungen nicht in Widerspruch gerathen.

Der Fortschritt in der Erkenntniss, den wir auf Grund des zuletzt Erörterten gemacht haben, lässt sich also dahin aussprechen, dass in denjenigen Theilen der. Eischlauche, welche grössere Eiketten enthalten, als Einleitung zur Erzengung prinordialer Follikelanlagren eine mächtige Wucherung des Epithels zu constatiren ist, wobei verschieden gestaltete Zellhildungen wahrgenommen werden. Diese Wucherung unwächst die Eiketten und sondert sich spaiter durch den beschriebenen Process der Abschnürung zu Follikieln.

Es bleibt uns nun endlich noch die Erledigung der Frage, wie die Eier und die Eischläuche entstehen, un unsere Aufgahe über die Genese der Eier gelöst zı haben. Zır Beantwortung dieser Frage bein Kalbe fertigt man von frischen Eicrstocke feine Schnilte an und untersucht sie mit einer Lösung von saurem chromsaurem Kali von $0, \bar{b}-1,0 \%$, oder sucht auch aus der Gegend der Oberfläche des Eicrstocks Schläuche zu isoliren. Sclinilte thaten mir bessere Dienste und es kan zuweilen vor, dass wegen Schiefe des Schnittes ein Eischllauch weit aus dem Eierstock ling, wie Taf. II. Fig. 3.

An diesem äusserst instructiven Präparate, welches ich bei 4.00 maliger Vergrösserung mit aller erdenklichen Sorgfalt vermittelst der camera gezeichnet habe, indem iclı von Zeit zı Zeit meine slärksten und besten Objective zu Hülfe nalım, sieht man nun, dass der Schlauch frei blind, stunipf und etwas angeschwollen endet. Diese blinde Enclung ist der Oberfläche des Eierstocks zugekehrt und liegt dicht unter dem periloneum, wovon ich später handeln will; sein entgegengesetztes Ende verliert sich in dem Stroma des Eierstoclissegmentes, aus welchem dieser Schlauch nach dem Schnitt ganz von selbst, was nicht so selten geschicht, hing. Er muss sich wie ein Finger aus einen Handschuh bei dem Schnitt aus der Substanz des Grundgewebes gezogen haben. Das ungemein Wichtige, was nun sofort in die Augen fillt, ist dass in dem blinden Ende, welches ich das Keimfach des Schlauches nennen will, ausserordentlich viel kleinere Bläschen getroffen werden, als auf dem entgegengesetzten noch sichtbaren Theile des Eischlauches. Zwischen beiden Extremen erscheinen in steliger Folge alle Uebergänge, so dass wir nicht daran zweifeln dürfen, hier die Entwicklungsgeschichte der Eier vor uns zu haben.

Beginnen wir mit den grossen Zellen. Sie tragen ganz den Charakter der Eier unserer Eiketten und hängen evident aneinander. Zwei Ketten sieht man in dem Sclılauche lieg̣en, welche etwas um einander gewunden sind. Da ich das Präparal mit einer Lösıng von 0, 1\%” behandelt hatte, so waren die Bläschen etwas grösser und runder, als sie es wohl sonst wären; doch traten darum die Zellchen mit grosser Deutlichkeit hervor. Man sieht nämlich in einzelnen die Keimbläschen und den Keimfleck vollkommen deutlich. Der aussere Contour der Eilietten ist absolut scharf. Geht man in der Richtung nach dem Keimfach an den Eiketten entlang, so 
nehmen die primordialen Eier erst kaum an Grösse ab und sind nahezu gleich. Erst wo die sanfte kolhige Anschwellung beginnt, nehınen ziemlich rasch die Eier an Grösse ab, um alsbald in ein Lager zahlreicher Zellen der verschiedensten Grösse überzugehen. Diese Zellen liegen dicht gedraingt eine an der andern in dem Keimfache, so dass hier eine Sonderung zu Eiketten durchaus nicht wahrzunehmen ist. Die Sache muss man sich mit den Eiketten, wenn es möglich ist, den Beweis zu liefern, dass sie sich durch Knospung vermehren, was später geschehen wirl, demnach so vorstellen, dass aus einem Lager kleiner Zellen, die das Keimfach bilden, Eifäden oder Eiketten hervorsprossen. Welche Veränderungen nun gehen mit den Eiern vor bei dieser starken Alınahme ihrer Grösse in dem Keimfache? Am stärksten sieht man den ziemlich stark granulirten Dotter abnehmen, als ob schliesslich nur das Keimbläschen übrig bliebe, das in einer Körnchenınasse schwämme. Das Keimbläschen wird nach dem äussersten blinden Ende des Keinfaches zu immer kleiner und hleiner und sinkt zu einer winzigen Grösse herab. Denn bei sehr scharfer Einstellung und Vertiefung in das Praparat wollte es mir scheinen, als ol noch hleinere Blasshen, die an der Grenze der Sichtbarkit ständen, an aussersten Rande des Eischlauches gelegen wären. Die feingranulirte scheinbare Dottermasse, die zwischen den kleinsten Keimbläschen im äussersten blinden Ende des Schlauches gefunden wird, ist nur sehr spärlich oder gar nicht mehr vorhanden. Die Blaschen sellsst haben ausser, dass sie rund und scharfbegrenzt sind, nichts Bemerkenswerthes mehr. Ein Kernliörperchen, Andeutung des spätern Keimfleckes, habe ich, vielleicht der Schichtung der Zellen des sonst sehr klaren und guten Präparates halber, nicht mit Sicherheit wahrnehmen können. Das ist die Entwicklung des Eies vom Kalbe von seinem ersten erreiclıbaren Anfange an.

Nicht immer sind indessen die Schläuche so mächtig, wie der gezeichnete, sondern zuweilen viel dünner; auch sind sie nicht immer so vollgepfropft mit Eiern, sondern enthalten diese wohl auch viel sparlicher. Solche Schliuche sind aber, wenn es gelingt sie zu isoliren, ganz ausserordentlich instructiv (Taf. II. Fig. 4.). Diesen Schlauch erhielt ich, inden ich mit einem scharfen Rasirmesser einen der Oberfläche des Kalbseierstocks paralleten feinen Schnitt machte, um ihn dann zu untersuchen. Der Schlauch hing ganz von selhst heraus, zeigte wunderbarer Weise sogar einen sehr scharfen Querschnitt $(a)$, der sich mir etwas zukehrte und eine feingranulirte Masse darbot, in welcher von deutlichen Zellen ebensowenig als von einem Canale etwas zu sehen war. Erst allmählich beginnt eine deutlich zellige Structur aufzutreten bei $b$, um ein aus rundlichen Bläschen bestehendes etwas glänzencles Epithel zu lilden, das an allen andern Theilen des Schlauches sichtbar ist und mit eminenter Schärfe einen hellen Canal abgrenzt, der äusserst spitz bei $c$ beginnend allmählich weiter wird, hierbei aber wechselnde Schwankungen seines Durchnessers bemerken lässt. Der äussere Randcontour des Schlauches ist vollkommen scharf und zeigt nirgends eine bindegewebige Auflagerung, welche bei dem Schlauche noch in geringem Maasse vorhanden war, der in Taf. II. Fig. 3 al)gebildet und vorher 
besprochen worden ist. In dem Schlauchcanal erscheinen zwar spälich, aber darunı desto deutlicher wahrnehmbar frei bewegliche Bläschen, welche in regelmässiger Folg̣e un so grö̈sser erscheinen, je weiter sie von dem dünneren Schlauchendle entfernt liegen. Dass diese Blisschen Eizellen oder wenigstens Muttereizellen sind, daran dürfte nicht zu zweifeln sein, naclı Allen, was wir bis jetzt kennen gelernt haben. Ich habe kein Präparat erhalten, bei dem ich uur lie ersten Stadien so exquisit deutlich håtte sehen können.

Beginnen wir mit den jüngsten demonstrirbaren Zuständen im verjüngten Schlauchende. Hier sieht man in dem feinkörnigen Protoplasma, in welchem undeutliche Zellcontouren hier und da erscheinen, was wohl in einem stattgehal,ten Druck gegen das obere Ende seinen Grund finden dürfte, äusserst winzige Bläschen, die ein Kernkörperchen als ein glänzendes Pünktchen wahrnehmen lassen (Taf. II. Fig. 4. $d d$.). Das Blasschen ist wasserklar, zeigt einen deutlichen stark hervortretenden Contour; das ist Alles. Diese Bläschen - che ich für die primordialen Mutterzellen der Eier halte, inden ich den Contour des Bläschens als den Ausdruck eines feinen Protoplasmabeleges ansehe - scheinen anfänglich in der feinkörnigen Ejpithelialmasse des liier verjüngten Schlauchendes zu stecken. Diese Anfangszustände sind von geringerer Grösse als die Epithelialzellen der Eischläuche, die ungefähr mit denen der jungen Grust'schen Follikel im Mittel übereinstimmen (Taf. I. Fig. 8.). Ehe aber noch das genannte Bläschen, das eigentlich, um die Wahrheit zu sagen, wie ein kleiner Zellkern mit Kernkörperchen aussicht, jene Grösse der Epithelialzellen erreicht hat, ist es abgestossen in dem Canale zu finden und wie es scheint vollkommen frei (s. die Fig. a. a. O. e). Das Bläschen ist elliptisch und enthält auch ein elliptisches Kernkörperchen. In einiger Entfernung von diesem Blåschen, immer weiter entfernt von dem verjünten Ende $a$ liegt wieder ein elliptisclıes Blischen (Taf. II. Fig. 4 f) ganz beschaffen wie das vorhergehende, nur mehr als doppelt so gross und jetzt die Epithelialzellen des Schlauches bereits an Grösse übertreffend. Sein Inhalt ist wasserklar, sein Kernkörperchen stark lichtbrechend. Der Randcontour ist sehr scharf, glänzend und zeigt noch keine messluare Dicke. Abermals in weiterer Entfernung kommt wieder ein Bläschen y. Dies erscheint grösser als das vorhergehende; aber es ist weniger elliptisch und der Randcontour hat jetzt eine entschiedene Dicke, welche ich für die erste evidente Anlage des Dotters der Eimutterzelle halte. Dieser dicke Randcontour ist glänzend und umgilıt das innere wasserklare Blaschen (Keimbläschen', welches einen stark lichtbrechenden, mehr rundlichen Kernkörper enthält 'den Keimfleck der Eizelle). Von dem Schlauchtheile, der die Zelle $g$ beherbergt, bis zu dem etwas verjüngten Theile $h$ sah man keine deutlichen Eibildungen, obwohl ich blasse undeutliche Contouren, die grösseren Bläschen angehören konnten, bemerkte (i). Gehen wir ülser lie etwas eingeschniirte Stelle $i$ des Schlauches hinaus, so schwillt er plötzlich mächtig an und zeigt bauchige Erweiterungen $(k k)$. Im Innern dieser erweiterten Stelle liegen nun - daran kann man nicht zweifeln - die entschiedensten Eier in grösserer Menge, von etwas ovaler Forın, deutlich granulirteın 
Dotter, schönem Keimbläschen mit Keimfleck. Ob hier schon die Bildung der unthüllenden membrana gramulosa begann, konnte ich mit Sicherheit nicht constatiren, doch war es mir wahrscheinlich, weil die Grösse der ovalen Bildungen nahezu übereinstimmte mit der eines kleinen isolirten Follikels aus demselben Eierstocke (Taf. II. Fig. ̈̈.). Da wir bereits wissen, wie die Follikel sich bilden, so ist hier weiter keine Schwierigkeit vorhanden. Nur ein Umstand rerdient noch Erwahnung. Wenn man nämlich das Keimbläschen des primordialen Eies im Schlauche $(g)$ mit dem Keimbläschen $(l$ oder besser $m)$ des Grasf'schen Follikels (Taf. II. Fig. 5.) beziiglich der Grösse vergleicht, so bemerkt man, dass das Keimbläschen im Gusaf'schen Follikel etwas kleiner als das des prinordialen Eies ist, während das ganze Ei im GraAf'schen Follikel jenes an Grösse allerdings sehr uibertrifft. Ebenso ist der Keimfleck $u$ (Taf. II. Fig. 4.) in dem Ei des Follikels entschieden hleiner als der Keimfleck $o$ in dem primordialen Ei $g$. Das ist ein Punkt, der mir viel Unruhe gemacht hat. Nachdem ich aber erfahren hatte, was spater genauer zu erörtern ist, dass diese primordialen Eier sich in einem späteren Stadium durch Sprossung vermehren, wodurch dann die Eiketten entstehen, konnte der Sachverhalt nicht mehr auffallend odler unerklärlich erscheinen. Hierzu liommt dann, dass auch die Keimbläschen bei gleich grossen Eiern nicht immer gleich gross gefunden werden. Ich kann diese Abweichungen, die man an demselben Object auf derselben Objectplatte constatiren kann, nicht durch Artefactlildung erklären. Im Allgemeinen schienen mir die alkalischen Flüssigkeiten das Keimbläschen aufzuscliwellen, saure es zu contrahiren. Die Alkalescenz ist aber in dem Blute und folglich auch in dem Parenchymsaft der Gewebe ein inconstanter Factor, der stark durch die zufallige Zusammensetzung der Nahrungsmittel becinflusst wird. Es herrscht demgemass hier eiı gewisser Spielraum in den Grössenverhältniss zwischen Ei und Keimblåschen. Ausserdem muss ich auch für den Keimfleck die Bemerkung machen, dass er nicht allezeit in den Keimbläschen gleich grross erscheint und besonders nach Säurezusatz zu einem oft grossen Körper sich ausbildet, vermuthlich durch Coagulation eiweissartiger Stoffe, die aus der in dem Keimbläschen vorhandenen Lösung auf das Kernkörperchen sich niederschlagen. Darum aber etwa, wie bereits geschehen ist, den Keimfleck überhaupt für ein Artefact zu erklären, das kann ich darum nicht zugeben, weil man an den frischesten Follikeln, die aus dem noch lebendigen Thier (Katze) genommen und in hmmor aquens, Blutserum oder Eierstocksflüssigkeit untersucht werden, diesen Keimfleck ausgezeichnet schön sieht und weil el endlich, besonders bei Katzen, sich später in eine schöne feingranulirte sclıarf umgrenzte Kugel umwandelt, die Niemand für ein Kunstproduct erklären wirl, welcher sie einmal gesehen hat. Solche regelmässige Bildungen entstehen eben, wie die Erfahrung lehrt, durch Niederschlage und dergleichen mehr, niemals. Unser Schlauch (Fig. 4) scheint sich auf den ersten Blick ferner wesentlich von Schlauch Fig. 3 zu unterscheiden. Man muss indessen zunächst nie vergessen, dass es sich hier nicht um Drüsen handelt, die wie etwa die Lıenerkứm'schen Schlauche lange in immer derselben Weise 
persistiren, sondern um Bildungen, deren Epithelien zu den gewaltigsten Metamorphosen bestimmt sind, so dass diese Schläuche eine wahrhaft proteusartige Beschaflenheit in gewissem Sinne haben. Alle Thatsachen weisen darauf hin, dass zuerst in dem Keimfach die IIutterzellen der Eier entstehen und sich bis zu einem bestimmten Punkte vergrössern. Das ist gleichsan der erste primordiale Zeitraum der Eientwicklung. Dann mit deın Beginn des zweiten Zeitraumes beginnen die Mutterzellen der Eier durch Sprossung sich zu vermehren. In dem diinnen hier liegenden Schlauche ist von der Stelle $a$ bis Stelle $h$ nur der erste Zeitraum vertreten; von $h$ nach $l_{i}$ zu wahr'scheinlich der zweite. Wie steht es mit dem in Fig. 3 abgebildeten Schlauche? Zu dem Ende muss ich vorgreifend einstweilen bemerken, dass das Wachsthum der Eier und die Follikelbildung in den Schläuchen an allen Stellen schliesslich stattfindet, so dass also endlich auch die Theile $a b$ des Schlauches (Fig. 4.) grosse Eier, vielleicht auch Eiketten enthalten werden, und spater sogar Follikel. Das kann ich bei der Katze ganz bestimnt beweisen. Wir haben dengemass in Fig. 3 nur einen weiter vorgerückten Zustand. Der erste primordiale Zeitraum ist auf eine ganz kleine Schlauchstrecke beschränkt und wird auch diese vielleicht später ganz verlassen. Ein Unterschied in beiden Schliuchen liegt noch in der schönen Entwicklung des Epitheles bei dem Schlauche (Fig. 4), während in dem andern (Fig. 3) hiervon Nichts deutlich zu sehen ist. Dies erkläre ich mir entweder aus der Untersuchungsfliissigheit (saures chromsaures Kali), welches stets das Epithel der Eischläuche sehr erblassen lässt, oder daraus, dass die dünne Bindegewebschicht bei dem Schlauch der Fig. 3 in etwas hinderte, wihrend der Schlauch in Fig. 4. absolut isolirt war und in humor aqueus untersucht wurde. Vielleicht erleidet auch das Epithcl im Laufe der Entwicklung eine Unänderung, die ja bereits ron uns theilweise besprochen wurde.

Das vorliegende Präparat der Fig. 4, welches mit solcher Klarheit eine Reihe wichtiger Verhältnisse zeigte, habe ich mit der grössten Aufmerksamkeit während vier Stunden sturdirt und es mit der äussersten Sorgfalt und Genauigkeit mit Hülfe eines Zerss'schen Prisma's alygezeichnet. Ich hatte mir den Stand des Zeichenpultes und den Stand des Mikroskopes durch eine Linie auf dem Arbeitstisch genau bemerkt, um die Vergrösserung des Bildes zu bestimmen. Leider fand ich den Tag darauf durch den Diener den Tisch abgewaschen, so dass ich nicht im Stande bin, die absoluten Grössen der einzelnen Theile anzugeben. Nur aus dem kleinen Grasf'schen Follikel, der eine einschichtige membrana gramulosa besilzt und den ich auf denselben Objectglase hatte und ebenso abzeichnete, lässt sich ein annähernder Schluss auf die Vergrösserung machen. Ich hoffe nicht, dass mir Jemand einen Vorwurf daraus nuacht, dass ich dennoch das Präparat vorlege, wenn er ljedenkt, dass ich keinen Schluss daraus ziehe, der die Kenntniss der absoluten Grösse voraussetzt. Ausserdem muss ich bemerken, dass es nicht leicht ist, solche Präparate zu erhalten. Das Studium der Entwicklung der Eier werde ich genater bei der Katze verfolgen, wo die Untersuchung viel leichter ist als bei dem Kalhe. 
Wenden wir uns zu der Betrachtung der Schlauchhiillen. An dem Keimfach, welches frei dicht unter dem Peritonealepithel liegt, ist ein zarter Contour, über welchen keine Bindegewebefaser mehr hinzieht (Taf. II. Fig. 3.). Zu beiden Seiten des Schlauches aber sieht man Bindegewebezüge demselben aufgelagert, doch an den verschiedenen Stellen zum Theil von demselben al)gehoben. Unter diesem Bindegewebe erscheint aber ein derber, scharfer, stark Itervortretender Contour, oflenbar der Ausdruck einer Membran, da der Contour an einzelnen Stellen weder die Eier noch das Bindegewebe beriihrt und doch unverändert da ist. Ich spreche deshall, den Eischläuchen eine membrana propria ohne Bedenken zu. Bei Katzen ist es mir gelungen, diese Membran allein darzustellen, so dass kein Zweifel mehr übrig bleibt. Wie sich aus der Zeichnung ergibt, scheint diese Membran innen glatt und trägt nur hier und da ein längliches. kernartiges Körperchen oder spindelförmiges Zellchen, über dessen histiologische Aufiassung ich nichts Besonderes beibringen kann.

Es blieb mir endlich noch die Erörterung der Lage der Eischlåuche in dem Eierstocke zu beschreiben. Während die inneren Enden in rerschiedener Richtung die Substanz des Eierstockes durchziehen, durch Wucherung des Epithels die primordialen Follikelanlagen bildend, erhehen sichı die Eischläuche des Organes und liegen mit dem blinden Ende des Keimfaches nackt an der Oberfläche unter dem Peritonealepithel. Weil die Schläuche des Kalbes oft, aber nicht immer, etwas schief gegen die Oberflache des Organs emporsteigen, in Ebenen, welche nan sich durch die lange Achse des Ellipsoides gelegt denken kann, das die Oberfläche des Eierstocks beim Kallue in Allgemeinen darstellt, so muss man die Schnitte am besten in diesen Richtungen führen, um die Köpfe der Eischläuche frei auf der Oberfläche des Eierstocks encligen zu sehen.

Welches Verhalten hat nun diese wunderbare Oberfliche, diese Quelle endlosen Lebens? Will nan derselben ein Epithel zusprechen, so muss man meist winzige Zellchen, welche entweder bereits einem Keimfach angehören, oder aus denen ein Keimfach, vielleicht auch noch Anderes. bei dem Wachsthum des Organes sich bilden kann, als Epithel bezeichnen. Bei der grossen Kleinheit dieser Bildungen und weil solches Epithel nirgends anders wieder vorkommt, ist es gerathener zu sagen, es besitze der Kalbseierstock kein Epithel, sondern sei nackt. Bei diesem Ausspruche wird man daran denken, dass doch in den Compendien der Anatonie gesagt wird, wie das peritoneum den Eierstock überziche und mit einer sogenannten tunica albuginea ovariorum fest rerwachsen sei. Diese sogenannte tunica albuginea der Anatomen ist meine nackte oder mit winzigem unregelmässigem Epithel belegte Oberfläche. Yon einer Imnica kann hier keine Rede sein, weil eine tunica eine Haut ist oder doch eine einigermassen als besondere Bildung sich manifestirende Schicht. Ich meine aber, dass diese Auffassungr am besten verlassen wird, weil es den Thatsachen doch gar zu viel Zwang anthun heisst, wenn inan Haute annimmt, wo keine sind. 
Ueber die Beziehung der albuginea der Anatonen zu dem peritoneum herrscht gegenwärtig in der Wissenschaft keine Klarheit und richtige Vorstellung.

So sagt einer unserer ausgezeichnetsten Histiologen GenLacı (s. Handl)uch der allgemeinen u. speciellen Gewebelehre des menschlichen Körpers von Dr. Jos. Glikacn. Wien 1 s60. pag. 390): "Die Eierstöcke sind nicht vollständigg von dem Peritoneun überzogen, sondern der untere Rand, wo auch die Blutgefässe eintreten, ist frei davon. Der Peritonealülerzug der Ovarien ist innig mit der unterliegenden tunicu propria, einer fibrösen sehr festen Ilaut, verwachsen, deren Dicke $0,3^{\prime \prime \prime}$ beträgt. Diese Membran bestelit aus straflen, innig untereinander geflochtenen Bindegewebefasern und wird von den eintretenden Blutgefassen einfach durchbohrt u. s. w."

Wenn man Thiere untersucht, bei denen wie beim Kalle der Eierstock nicht in einer sogenannten fast ganz z.ugewachsenen Peritonealtasche (Hund, Katze) liegt, deren Natur und Entwicklung mir durchaus noch nicht hinreichend aufgeklart scheint, so dass auch die Deutung des hier vorhandenen Eierstocksepitheles als Epithel des Peritoneuns oder der albuginca zweifelhaft wird, so gelangt man zu dem Resultate, dass eine innige Verwachsung zwischen albuginea und perilonenm nicht existirt. Wenn man Präparate trocknet oder sonst in contrahirende Flüssigkeiten legt, so mag ein Sclınitt dann so aussehen, als ob das periloneum auf die albuginea festgewachsen wäre. Nimmt man aber frische Vertikalschnitte vom Eierstocke, nachdem die Peritonealtasche sorgfältigst entfernt wurde, welche denselben normal zum grossen Theile stets beleckt und den mit Fimbrien besetzten Trichter des ostium abdominale tubac dem Organe zukelırt, dann kann man die ganz gewöhnliche Wahrnehmung machen, dass meistens das perilonenm fehlt, dass es sich abgelöst hat von der albuginea, die allerdings innig mit dem Eierstock verwachsen ist, weil sie elsen nichts als die Oberfläche des Organes bildet. Diese albnginea ist aber so scharf abgegrenzt, dass man nicht wohl denken kann, es sei das peritoneum abgerissen. Zuweilen aber ist man so glücklich mit dem frischen Schnitt das locker über die albuginea hinziehende Häutchen des periloneum zu erhalten und Präparate zur Ansicht zu bekommen wie das abgebildete, welche keinen Zweifel lassen, dass zwischen dem peritouenm und der sogenannten tunica albuginea der Autoren ein Raum ist, und von einem Aufgewachsensein des peritoneum auf den Eierstock also im Allgemeinen schwerlich die Rede sein kann (Taf. II. Fig. 10.). Das Merkwürdigste über dieses Verhalten des peritoneums beim Kalbe ist aber seine Structur, die gar nicht mit dem übereinstimmt, was man als dlas Schema für seröse Häute aufstellt. So sagt wiederum GenLacu in Uebereinstimmung mit der jetzt giiltigen Theorie :

„Die histiologische Grundlage der serösen IIåute bildet Bindegewebe etc. (Er unterscheidet seröses und subseröses Gewebe und untersucht an getrockneten Präparaten).... Es gehört mit zu den wesentlichen Eigenschaften der serösen Häute, dass dieselben an ihrer freien. 
der Körperhöhle zugewandten Fläche von Epithelialzellen bedecht sind . . . N Nach Tonn und Bowmax (Physiological anatomy pag. 130) sitzt das Epithelium der serösen Hăute auf einer durchsichtigen ausserordentlich feinen structurlosen Membran auf; es gelang mir jedoch nie, diese Membran zu Gesicht zu bekommen.« (s. Gerlacı a. a. O. p. 196. 197. 198. 200.).

Genlacii glaubt sodann die Ansicht Rudoupu's zu widerlegen, welcher den serösen Hăuten alle Blutgefässe absprach, indem er zeight, dass die stärkeren Zweige dem subserösen Gewebe zukommen. (s. noch Rudolpm, Grundriss der Physiologie. Vol. 1. pag. 101.). - Geruach weist ferner in Uebereinstimmung mit der herrschenden Theorie den serösen Häuten Lymphgefảsse und Nerven zu.

Ich habe nun zu dieser Theorie einige sehr wesentliche, mindestens modificirende Bemerkungen zu machen, die mir indessen für die gesammte Lehre von den serösen Häuten bedenklich genug erscheinen. Ich habe nicht speciell und methodisch die serösen Häute an den verschiedenen Stellen des Körpers untersucht, um die allgemeine Unrichtigkeit obigger Angaben zu behaupten; ich kann nur mit Bestinmtheit sagen, dass das den Eierstock überziehende peritoneum sich jenem Schema nicht fügt.

Aus was nämlich besteht denn dieses peritoneum, welches über den Eierstock hingespannt ist, ohne mit ihm verwachsen zu sein?

Aus einer einzigen Lage schöner polygonaler, feingranulirter, kernhaltiger Zellen, die dichtgedrängt aneinander liegend eine stetige Haut darstellen. Nichts weiter! - (Taf. II. Fig. 10.). Beim Zuge und Druck sieht man, wie erstaunlich fest diese Zellen an einander gekittet sincl, was zur Annahme einer structurlosen derben Membran veranlassen liönnte. Yon dieser habe ich aber nie etwas gesehen und kann also ihre Annahme durch meine Wahrnelınıungen nicht rechtfertigen. Doch möchte ich die Möglichkeit ihrer Existenz nicht anzweifeln. Aus dieser Thatsache, die leicht und sicher zu constatiren ist, folgt, dass hier also das peritoneum keine Blutgefässe, keine Lymphgefässe und wohl auch keine Nerven haben dürfte, weil innerhalb einer nur aus Epithel bestehenden Membran solche Gebilde nicht verlaufen. Für die Nerven müsste wenigstens ein bindegewebiges Stroma da sein, aus dem sie in das Epithel hineingingen, um in ihm ihr Ende zu finden. Ist dieses merkwürdige Verhalten der serösen Hăute nunmehr in Einem Falle sicher constatirt, so werden alle früheren Angaben verdächtig, weil beim Trocknen natürlich die seröse Haut mit den unterliegenden Partien zusammenpappt oder durch Härtungsmethoden darauf gedrängt und geschweisst wird. Bestätigt sich aber die Voraussetzung nicht, dass die hier am Eierstock gefundene eine allgemeine Erscheinung ist, so liesse sich allerdings gerade für diesen ein solches Verhalten des peritoneum lyegreifen. Denn der Eierstock ist ein Organ von sehr variabeler Gestalt, welches bald hier bald dort in verschiedenster Weise durch die wachsenden Grusf'schen Follikel. die ja oft eine gewaltige Grösse erreichen, anschwillt. Man begreift, (lass durch die ziemlich feste Peri- 
tonealhülle diese Veränderungen der Gestalt behindert und einzelne Theile ıles periloneum, welche gerade über der wachsenden Partic liegen, starker gezerrt und gespannt wirden, als wenn die ganze Peritonealmembran sich auf dem Eicrstock hin- und lıerschieben liann. Es wäre interessant zu wissen, wie sich die Sache für die pleura pulmonalis verhält und welche Veränderungen die Zellen der serosa crleiden, bei den gewaltigen periodischen Ausdehnungen der Oberfläche dieses Organes. Ich finde nirgends diese Sache behandelt. Diejenigen Organe. welche wie die Nieren, Leber, das Gehirn u. s. w. weniger starke Vergrösserungen und Verkleinerungen ihrer Oberfläche wahrnelımen lassen, nögen eine innig aufliegende serosa haben, die sogar durch die ewige Ruhe an das Parenchym des Organes, das sie überzielıt, adlıárirt. Wie man bis jetzt auch immer nach diesen Verhalten des peritoneum beim Kalbe sich die Sache vorstellen möge, sovịel geht daraus hervor, dass der bindegewebige Theil der serosa nichts ilır Wesentliches sein kann, weil er auch fehlen darf. Daraus aber fliessen vicle Consequenzen, die ich theils bereits angedeutet, theils von jedem einigermassen mit der Histiologie Vertrauten gezogen werden können, weil sie sich von sclbst verstehen.

Es wird mir vielleicht durch folgende, auf physiologischer Basis ruhende Betraclitung gelingen, die Fachgenossen zu der Auffassung zu bekehren, dass zu dem Wesen einer serösen Haut nichts weiter gehöre als eine Epithelschicht, die vielleicht auf einer structurlosen Membran aufsitzt. Olne zu verkennen, dass durch das Vorhandensein einer serösen Membran gar mannichfache Vortheile für die thierische Organisation entspringen, darf man doch unzweifellaft als die wesentlichste Bedeutung die ansprechen, eine seröse Flüssigkeil in die Höhlen des Körpers zu secerniren. Diese Eigenschaft ist eine wesentliche, denn sie geht der Membran niemals ab. Die wesentliche physiologische Bedeutung der serösen Menbran konmt folglich durchaus überein mit der wesentlichen der Druisen und zwar derjenigen, welche ein Secret liefern, das von den serum sumgnimis nur wenig, und zwar melı durch die Concentration als die chemische Qualität der Lösung verschieden ist, wie bei dem der Tlıłanendıüise, der Speicheldrüsen der Mundes, der Labdrüsen, der Bauchspeicheldrüse und anderer mehr. In Hinsicht der physiologischen Bedeutung stimmen also die Driusen mit der serosa durchaus iberein. Müsste es uns nun nicht Wunder nehmen, einen wesentlichen Unterschied in ihrer histiologischen Structur wahrzunehmen? Die wesentliche Structur einer ächten Secretionsdrise setzt voraus eine oder mehre Lagen von Epithel, welches gewöhnlich Plattenepithel ist, ganz wie es die serosa hat, aufsitzend auf einer structurlosen Haut, so wie sie fur die serosa von den genannten Forschern Tond und Bowмаx angenommen. also wohl auch beohachtet worden ist. Ob die Epithelialschichten nun in einer Ebene liegren oder ob sie durch Ausstiilpung die verschiedensten Flächen bilden, das ändert an ihrer Bedeutung doch nichts, da diese eine Qualität der Substanz ist und unabhängig ron der geometrischen Lagerung derselben oder ihrer Gestalt. Wir finden nun die ächte Secretionsdrüise stets eingekeilt in eine Bindegervebe genannte Sul)- 
stanz, aus der sie sich wie die Finger aus dem Handschulı bald ausziehen lăsst, bald aber åuch dies nicht ggestattet, weil die Colıăsion eine zu innige ist. In diesem Bindegewebe verlaufen die Blutgefässe, welche durch dasselbe hindurchsicliern lassen den Ernährungssaft, der zu dem Drisenepithel weiter filtrirt, es ernährt und lösliche Stoffe aus demselhen aufnimmt, um sie in die Drüsencanảle fortzuschwemmen. In demsellsen Bindegewebe verlaufen die Lymphgefässe und die Nerven. Wenn es nun auch wahr ist, dass die scharfe Sonderung zwischen Bindegewebe und Epithel besonders in der neuesten Zeit ernsthafte Anfechtungen erlitten hat, denen aber noch die Entwicklungsgeschichte mit gewichtigen Thatsachen entgegensteht und welche durch eine Vergleichung der chemischen Zusammenselzung der Hauptsubstanz des Bindegewebes mit dem Epithel mindestens gar keine Unterstuitzung finden, so dürften wir doch in keiner Zukunft angefochten werden, wenn wir sagen, dass die wesentlichen Theile der Secretionsdrüsen diejenigen Bildungen sind, welche wir heute Drüsenepithelien nennen mit Einschluss einer structurlosen Membran, die wir als lunica mropia bezeiclınen. Wollte man die freilich für die Ausübung der Function sehr wesentliche Blut- und Lynphgefässe und Nerven führende Bindegewebesubstanz, in und auf welche die epitheliale Driisenmembran gekittet ist (man denke z. B. an die sehr kurzen einfachen Schleimdruisen der (rachea) als integrirenden und wesentlichen Theil zu der Drüse rechnen,so müsste man diesen auch der Muskel- und Nervenfaser, der Nervenzelle, die alle in Blutgefasse und Nervenfasern tragendes Bindegewebe eingekittet sind, beilegen, was doch noch Niemandem eingefallen ist. Welche Verschiedenheit bestände nun noch zwischen Epithelialschicht der serosa und der gleichen der Secretionsdrüse, wenn man von der geometrischen Gestalt absieht, welche dieselbe hat, da sie in den Drüsen selbst so unendlichen Schwankungen unterliegen und sogar convex gegen den Canal der Druise sein kann. Lässt sich nicht die Epithelialschicht der serosa an einzelnen Stellen, z. B. dem Eierstock isoliren, inden sie hier mit dem unterliegenden Parenchym des Organes gar nicht zusammenhängt, sondern durch einen wohl mit einer capillaren Schicht von Flüssigkeit erfüllten Raum von ihm getrennt ist; lassen sich an manchen Stellen nicht ebenfalls die Secretionsdrüsen unmöglich von dem Bindegewebe isoliren, wie dies vielleicht an manchen Stellen für die seröse Membran stattfinden wird? Welches Recht bleibt also noch das unter derselben gelegene Bindegewebe mit seinen Blut- und Lymphgefassen und seinen Nerven der serösen Nembran zuzuschreiben, statt dem Organe welches es umhüllt, mit dessen interstitiellem Bindegewebe es unzweifelhaft und immer und ohne Ausnahme zusammenhängt?

Wer da meint, dass hier noch ein Widerspruch bestehe, da doch die anderen Secretionsdruisen sich durch Wucherungen des Hornblattes oder des Drüsenblattes bildeten, den erinnere ich an (len Grasf'schen Follikel. Entwicheln sich doch gleich dem periloneun nach Allem, was wir wissen, die Geschlechtsdruisen aus der Anlage des mittleren Keimblattes, und entsteht doch die Blase des Grasf'schen Follikels in dem Eierslock als eine Drüse, deren Wände in einen 
geschlossenen Raum eine seröse Flüssigkeit absondern, weshalb ich geneigt bin, die membrana gramulosa für eine seröse Haut zu erklaren. Aus der Entwicklungsgeschichıte kann also ein Einwand nicht entnommen werden.

Nachdem ferner in den serösen Flüssigkeiten eigenthünliche Albuminate, sowic solche besondere Stoffe nachgewiesen sind, welche im Blute bis jetzt nicht gefunden wurden. so wirl man auch nicht melır die serosa als ein einfaches Filter betrachten können oder die seröse Flüissigkeit als ein blosses Transsudat. Mit demselben Rechte könnte das dann auch für das Secret der Bauchspeicheldrüse, der Thränendrüse und anderer angenommen werden. -

Wer aber endlich behaupten wollte, dass der serösen Membran eine Fàhigkeit zukomme, welche die Drüsen nicht besảssen, nänılich die auch Stoffe zu resorbiren, dem erwidere ich, dass Niemand die Unfahigkeit der ruhenden Drüse, Stoffe von der secernirenden Oberfläche aus zu resorbiren, erwiesen hat. In Gegentheil zeigt die Erfahrung ja wenigstens in einem eclatanten Falle, dass z. B. Galle, welche sich ein wenig staut und unter etwas stirlieren hydrostati. schen Druck geräth, ganz leicht den Weg rückwảits durch die Leberzellen in das Blut findet. Und man muss in der That nicht aus dem Auge verlieren, dass die Ursache, welche den Filtrationsstrom aus dem Blut durch die secernirenden Zellen treilu, eine ganz andere ist als diejenige, welche den Uebergang in umgekehrter Richtung lewirlit. Dort ist es der periodisch wirkende Blutdruck, wie wohl für vicle Fälle ferner nicht zu bezweifeln sein dürfte, hier ist es die Diffusion verschiedenartig zusammengesetzter Flüssickiciten diesseits und jenseits der secernirenden Membran.

So kann ich nicht mehr zweifeln, dass die richtige Auffassung der serösen Hłute darin besteht, sie zu den Drüsen zu stellen, indem sie theils geschlossene, theils mit Ausführungsgảngen versehene grewaltige Blasen darstellen ron mannichfachster Gestalt, gleichsam modificirte Follikel von ungeheurer Grösse. Wenn ich von einem Ausführungsgang rede, so darf ich mich auf das ostium abdominale der Iuba oder einen Schlitz in der Peritonealtasche des Eierstocks, den ich bei Hunden und Kaninchen gesehen habe, berufen, durch welchen wenigstens zu gewissen Zeiten unzweifelhaft ein Strom seröser Flüssigkeit sich aus dem Abdomen in die luba ergiesst. Dieser unserer Auffassung gemäss erkläre ich die serösen Membranen für Drüsen, und bezeichne als wesentliche Theile eine Epithelschicht, die vielleicht auf einer structurlosen Membran, der tunica propria der serösen Drüse aufsitzt.

Denzufolge glaube ich, dass Jeder nach ruhiger Abw'igung aller Umstande meiner Auffassung den Vorzug geben wird vor der bisherigen, mit welcher sie freilich, wenn auch zuın Theil nur scheinbar in einem grellen Contraste steht. Die Sache ist aber nicht gleiclıgültig; denn nur richtige Auffassung und Klarheit iber die Bedeutung der einzelnen Organe sichert unserer Wissenschaft den wahren Fortschritt. 
Es bleilst mir noch eine Bemerkung. Zuweilen schien es mir, als ob an einzelnen Stellen ein zelliger Fortsatz von den peritoneum sich in das ovarium einsenkte. Doch konnte ich hieriber beim Kalbe, von dessen Eierstock das peritoneum fast stets abgleitet, wenn er frisch ist, nicht Gewissheit erlangen. Iclı werde später auf diesen Umstand noch cinmal zurückkommen. Jedenfalls ändert er an unserer Auffassung nichts, da die Zellsprossung einer Drüse also, gleichsan eine weitere Ausstülpung, den Charahter derselben nicht anficht.

Naclutem ich nunmehr die Beschaffenheit der Eischläuche und besonders die Lage des Keimfaches erörtert habe, ist eine Frage, welche sich sehr auflrängt, die, ob sich auch junge Eier im Innern des Eicrstochs bilden, oder ob nur die stumpfen, blinden, an der Oberfläche mündenden Theile hierzu făhig sind. Bei dem Kalbe ist das nicht leicht zu entscheiden, weil wegen der Grösse des Eierstocks die Schłäuche zu lang sind und auch nicht regelmässigg genug liegen, entlich in zu spärlicher, relativer, viclleicht sogar absoluter Nenge in dem Organe vorkommen, als dass sich an einen Schnitte immer oder doch gewöhnlich eine gesetzmassige und constante Verschiedenheit in den der Oberfläche näheren und mehr von ihı entfernten Theilen herausstellte. Bei der Katze indessen, wo das Zwischenparenchym der Schläuche so spärlich ist, überzeugt man sich leicht, dass die Eier sich unzweifelhaft nur an der Oherfläche bilden, da in der Ticfe niemals ganz kleine, sich eben entwickélnde Follikel neben den grossen in einer gegelıenen Entwicklungsperiode gefunden werden. während man an der Oberfläche, so lange die Eibildungsperiode überhaupt dauert, stets die jüngsten Zustände auffinden kann. Mit hoher Wahrscheinlichleit wird man also sagen dlürfen, dass jene Succession inmer grösserer Eihildungen, welche. von der Oberflache des Organs ausgehend, naclı der Tiefe vorschreitet, ein allgemeines Naturgesetz repräsentire.

Wir wären indessen mit unserer Entwicklungsgeschichte noclı nicht zu Ende, sondern weiter gehend müsste man eimmal fragen, was aus den Eischläuchen wird und zweitens, woher sie stammen und wie sie sich gebildet lıaben. Auf die erste Frage lässt sich Antwort geben, da es klar ist, dass, was für das cine $\mathbf{E i}$ gilt, auch für das andere gelten muss. Demgemäss werden sich schliesslich alle Eischläuche in Follikel umwandeln. Ich kann diesen Satz sehr gut und bestimmt bei den Katzen constatiren, welche in jedem Lebensalter auf das Verhalten der Eierstöcke naturlich gleich leicht untersucht werden können. was ja für das Kalb nicht grilt, da wir hier an die Zeit gebunden sind, wo die Kälber geschlachtet werden, die in Bonn einen sehr kleinen Zeitraum umfasst, von dem iclı glaube, dass er sich erstreckt von dem achten bis etwa 20sten Tage nach der Geburt. Doch ist Letzteres schon eine Seltenheit. Man kann sich in diesen Dingen natülich auf die Angalen, die genacht werden, aus naheliegenden Grüden nicht verlassen. Demgemäss ist es auch schwierig, dic andcre Frage zu beantworten, weil man elıen das Material zur Untersuchung nicht haben kann. Denn nan braucht neugeborene Thiere, oder Embryonen. 
Doch will ich nicht verschweigen, dass man oft Schlauche (Taf. II. Fig. 7. 8. 9,) im Eierstock von verschiedener Grösse findet, die sich leichter als die besclrrichenen isoliren lassen. Sie sind erfüllt von einer feinkörnigen zarten Masse, in welcher helle grösscre und kleinere Kerne bemerkt werden. Das Ganze erinuert an emlryonales Gewebe. Demnach ist ron membranwandigen Zellen in solchen Schläuchen nichts zu sehen. Was man aher an ihnen sehr gut wahrnimmt, das ist eine feine, einfach contourirte, structurlose Membran, welche die cmbryonalen Zellen umhitllt und vielleicht also als membrana propria angesprochen werten diurfte. Man sieht diese Bildungen von bald grösserer, bald geringerer Dicke. Eines ist es aber. welches es wahrscheinlich macht, dass dieselben ganz junge Dritsenmassen sind. Man kann diese Bildungen, welche dann sehr schmal erscheinen, oft bis in die Oberfläche des Eierstocks verfolgen, wo sie in einem kugligen Köpfchen, welches aus eben solchen embryonalen Zellen besteht, enden. Diese Schläuche sind in hohem Grade vergảnglich, so dass sie nur an frischen Prăparaten, die man mit saurem chromsaurem Kali untersucht, mit Evidenz demonstrirt werden können. Alle Versuclıe, dieselben zu conserviren, sind mir durchaus misslungen, was in gleicher Weise für die Eischläuche, weniger für die primordialen Follikelanlagen gilt. Bei Katzen aber lassen sich auch die Eischläuche, wie wir spater sehen werden, ihrer grösseren Derbheit halber gut in Glycerin conserviren.

Solche durchschnittene embryonale Schläuche, durchschnittene Sprossen von primordialen Follikelanlagen sind also bisher für die ersten Anlagen der Follikel gehalten worden; unzweifelhaft ebenfalls die knopfförnigen Anschwellungen jener genannten feinliörnigen cnłbryonalen Schläuche, so wie auch Querschnitte grösserer primordialer Follikelanlagen. Ist es einmal unzweifelhaft festgestellt, dass der Graaf'scheFollikel sich durch Abschniirung von Schläuchen bildet, in denen lange vor dem Abschnürungsprocess die nit ihren wesentlichen Theilen schon versehenen Eier enthalten sind und weiss man, dass schon vor der Zeit der Abschnürung das Ei ganz anders aussieht als die Epithelialzelle der primordialen Follikelanlagen, die es an Grösse sehr übertrifft, so kann man nicht mehr dem Glauben Raum geben, dass irgend ein rundliclıes Zellhäufchen, welches aus gleich beschaffenen Zellen zusammengesetzt ist, die Anlage eines Follikels sei. Man wird zu dieser Annahme sich um so weniger zu verstehen geneigt sein, wenn man im Stande ist, die Bedeutung solcher Zellhäufchen in anderer Weise befrierligend zu erklären. Iclı glaube, dass nunmehr ein Zweifel in der Sache nicht weiter gerechtfertigt ist und werle durch eine sehr genaue chronologische Untersuchung der Entwicklung der Driisenschlauche des Eierstocks der Katze die obigen Sätze nochmals feststellen mit belehrenden Modificationen und neuen Thatsachen, die eben bei der Katze sehr leicht, bei dem Kalbe sehr schwer zu ermitteln sind.

Es ist also der GradF'sche Follikel nicht das Bildungsorgan des Säugethiereies; sondern dies entsteht ganz wie bei niederen Thieren genseinschattlich mit andern Eiern in dem blinden Ende eines Driisenschlauches. Was soll nun der Grasr'sclie Zellenmantel, oder welche Bedeutung 
miissen wir ihm zusprechen? Man kann, glaube ich, hierauf nach meinen Untersuchungen eine ganz plausibele Antwort gelsen.

Einmal sieht man, dass die jüngsten Eizellen an der Oberfläche des ovarimm sich befinden, während die immer grö̈sseren Eier in immer tieferen Theilen des Schlauches gelegen sind, welche sellsst auch ferner von der Oberflache in dem Eierstocke sich befinden. Nun zeigt uns ferner die vergleichende Anatomie, dass die Eier sich meist nach der dem blinden Schlauchende entgegengesetzten Seite bewegen. Folglich nuisste am hilus ovariorum ein Ausfuhrungsgang für die Eierstocksdrüse existiren, der alser eben nicht vorhanden ist. So bleibt also nichts ubrig, als dass das Ei, wenn es nicht untergehen soll, was aber vielen doch beschieden ist, wie ich mich unzweifelhaft überzeugt habe, sich einen Weg durch das derbe Gewebe zur Oberfläche des Organes bahne. Das Ei selbst aber hat kieine Bewegungsorgane, die ihm Platz machen, und es ist nicht nöthig, besondere wunderbare Verschiebungen der Eier und jungen Follikel, wo sie auch im Eierstock liegen, anzunehmen, um zu begreifen, wie der Follikel schliesslich an der Oberfliche erscheint. Das Ei hat eine mächtige Entwicklung erreicht, ohne dass das Epithel des Guar'schen Follikels aufgehört zu haben braucht, aus nur einer Zellenschicht zu bestehen. Yon einer gewissen Zeit ab beginnt aber eine starkere Wucherung des Epitheles, wobei einzelne Zellen des stralum gramulosum auf derjenigen Hemisphäre, wo der discus proligerus entstehen soll, ganz gewaltige Dimensionen annehmen, so dass sie nahezu halb so gross wie das Ei sind, das bereits eine zona pellucida aufzulegen begonnen hat. In der Hemisphäre, wo die kleineren Zellen liegen, entsteht nun ein halbmondförmiger Schlitz, der von Zellen der membrana gramulosu ganz begrenzt ist. Die Zellenwucherungen auf der dem discus entsprechenden Seité werden immer stărker, so dass die eine Ilalbkugel des Follikels ganz von Zellen erfüllt ist, die andere aber von der Flissigkeit des Guasf'schen Follikels oder dem liquor folliculi und nur eine niedrige Epithelialschicht enthält. Die solide Hemisphäre birgt in ihren Zellenmassen das Ei, welches nahezu in der Mitte des Follikels jetzt gelegen ist. Der Druck der Fluissigkieit, welche von dem Epithel des Gra.sf'schen Follikels secernirt wird, dehnt allnählich mehr und mehr denselben aus und zwar so lange, bis endlich die Blase an der Oberflache des Eierstoches sichtbar wird. Da die Grast'schen Follikel so gross werden können, dass ihr Durchmesser gleichkommt dem Abstand der entgegengesetzten Oberflichen des ovarium von einander, so begreift man, lass bei solcher Ausdehnung der Blase jedes Ei. wo es auch immer im Eierstock seinen juingsten Follikelzustand haben mag, schliesslich nicht durch Wanderung des Follikels, sondern durch seine Schwellung zu der Oherfliche geführt werden kann, wobei es die obere d. I. die der Oberfläche des Eierstocks zugekehrto IIemisphäre emporhebt, da es in diese festgewachsen ist. Dieses Anschwellen des Follikels, welches wohl wesentlich durch den stetigen Secretionsdruck bedingt ist, findet unter folgenden bemerkenswerthen Umstanden statt. Zunächst sieht man an Schnitten durch den Eierstock von Kälbern oder Kühen, dass die 
GraAf'schen Follikel meist nicht ganz, rund sind, sondlern mit einem stumpfen Keg̣el in der Richtung nach der Oberfläche des Eierstocks endigen. Das begreift sich; denn offenhar ist der Widerstand, welcher sich der wachsenden Blase darstellt, grvösser von der Tiefe und den Seiten als von der Oberfläche des Organes her. Bei Hunden und Katzen hahe ich diese Kegelspitzen der GraAf'schen Follikel zuweilen hesonders schön geschen. Es ist ja natiurlich, dass man sie nur bemerken kann, wenn der Schnitt durch sie geht. Ich hahe sogar junge Folliliel mit solchen conischen Ausbuchtungen isolirt. Denkt man aber an die oft lederartige Derblicit des Eierstocksstroma's, so dürfte vielleicht doch der Secretionsdluck als nicht ausreichend erscheinen, um Weg zu bahnen nach der Oberfliche. Freilich darf man nicht veruressen, dass nach den Versuchen von C. Linwig der Druck der Secretion in den Speicheldrüisen den gleichzeitigen in der Arteria carotis übersteigen kann, der doch eine sehr grosse Kraft reprasentirt. Trotzdem hat die Natur diesen Process der Bahnbrechung für das Ei, wozu der Giras'sche Follikel berufen ist, nicht ausschliesslich der Kraft des Secretionstruckes übertragen, sondern gleichzeitig, vielleicht durch den Druck erzeugt, einen anderen Vorgang̣ angeregt, der die Ausdehnung des Graaf'schen Follikels wesentlich begünstigen muss. So lange nåmlich der Process der Follikelbildung an den nomalen jugendlichen Eicrstöclien noch in der ersten Periode bleilı, sehen dieselben von aussen, wenn ilıre Blutgefässe nicht mit Blut stark erfüllt sind, fast ebenso blass fleischfarben aus wie der Uterus, nur durch einen Stich ins Gelbliche von ihm unterschieden. Mit zunehmendem Alter vermchrt sich die gelbliche Farbe besonders an gewissen Stellen des Organes. Dass diese gelbe Farbe eine Beziehung zu dem eigentlichen Druisengewebe hat, geht daraus hervor, dass die kleinen Säugethiere, welche kleine Eierstöcke lıaben, also viel Drüsengewebe und wenig Stroma, bei weitem intensiver gelb gefärbte Ovarien besitzen als die grossen Säuger, bei denen das Stroma über die Drüsensubstanz überwiegt. So finde ich die Eierstöckie aller Neugebornen blass, mit einem sehr schwachen Stich ins Gelbe; aber sehr bald erscheint die gelbe Farbe bei der Ratte, der Maus, dem Kaninchen, der Katze und ist bei diesen Thieren wie es scheint um so stärker wảhrend des mannbaren Alters vertreten, je fruchtharer sic sintl. Die Kaninchen haben demgemåss oft Eierstöcke, die sich an gelber Farbe von einem corpus luteum desselben Thieres nur wenig unterscheiden. Die Kuh aber, rlie Stute, der Hund, der Mensch haben im erwachsenen Zustande blasse grauweissgelbliche Ovarien, an denen hier und da gelbe Flecke erscheinen. Da die gelbe Farbe intensiv oft schon hei ganz jungen Thieren gefunden wird, die noch sehr kleine, aber mit blossen Auge sichtbare Follikel darbieten, so kann man sie nicht etwa von Rudimenten gelber Körper ableiten. Untersucht man die Ursache dieser Färbung mit dem Mikroskope an Schnitten, so zeigt sich, dass die gelben Stellen bei durchfallendem Licht absolut schwarz erscheinen, bei auffallendem weisslich glänzend. Sie werden durch zahllose Moleküle hervorgerufen, die in das Gewebe des Organes abgelagert sind. Diese Körnchen wurden von anorganischen Såuren und Essigsłure wenigrstens in kürzerer Zeit nichı 
verändert; für kohlensaure Alkalien gilt dasselbe. Ich weiss, dass diese Körnchen in kohlensaurem Kali sich Tagrelang fast unverändert erlıalten. Ein Theil dieser Körnchen wird aber von Aether aufgelöst. Gleichwohl habe ich bei langer Behandlung von Eierstöcken (Kaninchen) mit Aether die Körnchen nicht ganz entfernen können, was wohl einen ähnlichen Grund hat wie die Resistenz, welche die unveränderten Milchkügelchen dem Aether darbieten. Galle scheint ebenfalls einen Theil derselben aufzulösen, da dieselbe das Eierstocksgewebe auffallend klar durch Verminderung der vorhandenen Trühung macht. Als Reagens ist aber die Galle darum doch nicht viel werth, weil sie die Contouren der Zellen so blass werden lässt, dass sie kaum mehr wahrgenommen werden können. Nehme ich zu alledem hinzu. dass wenn man gelbe Eierstöcke zerkleinert, sie mit Aether schüttelt und dann den Aether in Wasser giesst, Fettaugen erscheinen, so kann man wohl nicht daran zweifeln, dass in den gelben Eierstöcken reichliche Mengen von Fett in Form einer an lestimmten Stellen besonders stark abgelagerten Emulsion vorhanden sind. Welches sind diese Stellen? Beim jungen Thiere - am schönsten überzeugt man sich hiervon bei jungen Hunden oder Katzen 3-6 Wochen nach der Geburt - beginnt die Fettinfiltration in den Innern des Eierstocks. Hier sieht man die Körnchen ahgelagert rings um die Kerne der Bindegewebezellen, deren Zïgen folgend, um gegen die Olserfläche des Organes mit zunehmendem Alter immer mehr emporzustecigen. Zu einer gewissen Zeit ist deslıall, die schlaucherfiillte Oberflache ganz frei von dieser Emulsion. Aber in demsellsen Maasse als die Schläuche sich von innen nach aussen in Follikel umwandeln, umkreist sie bald ein fetterfiiltes Gewehe. In einen schwarzen Mlantel sieht man deshalh die etwas grösseren Follikel bei durchfallendem Licht eingehiullt. Dieser Mantel entspricht nicht der membrana gramulosa, welche klar bleibt, sondern dem rings um den Follikel liegenden durch das Wachstlıum dessellsen verdichteten Gewelse. An der Follikelgrenze schneidet die Fettregion scharf ab, nicht aber in umgekehrter Richtung, sondern erstreckt sich hier allmählich weiter theils diffus theils in Zuigen in die Substanz des Eierstochs. Diese Emulsion nun hindert die Untersuchung sehr und es ist ein Glück, dass sie gerade an den Stellen, wo die jungen Schlauche mit den waclısenden Eiern liegen, bei dem normalen Eierstock nicht gefunden wird. Ich sage bei dem normalen. Denn wenn ich junge Thiere, z. B. Katzen, welche noch Säuglinge waren, unnittelhar schlachtete und untersuchte, nachdem sie der Mutter entzogen waren, so zeigte sich stets das Verhältniss in der angegebenen Weise. Wenn wir aber rersucht hatten, durch Einspritzen ron Kuhmilch die neugebornen Thierchen zu erhalten, so konnte ich fast sicher sein, dass der Eierstock nach 2-3 Tagen in allen Theilen von einer Emulsion ibersiet war, die oft solche Dichte hatte, dass alle Untersuchung nutzlos ward, weil man der zahllosen Körnchen halber nichts gut sehen konnte. Welche Bedeutung lıat nun jene Fettinfiltration des Eierstocks, die besonclers in den Portionen desselben, wo junge Follikel wachsen, in grösserer Menge gefunden wirt? Einmal liann man daran denken, dass es sich um einen Process regressiver Melamorphose 
der Gewebe handelt, der eine Lösung derselben bewirken soll. Denn wo Follikel wachsen, da muss Platz geschafft werden. Es ist deshalb nicht unwahrscheinlich, dass der Vorgang alınlich der Metamorphose der corpora lutea als eine sogenannte fettige auf Gewebelösung hinzielende Degeneration aufzufassen sei.

Man kann aber auch noch eine andere Vorstellung als zulassig anerkennen. Denn mit hoher Wahrscheinlichkeit wird durch die Zeugungsthätigkeit, die Bereitung der Keime, eine bedeutende Fettmenge des Körpers consumirt, wie aus den Fettansammlungen bei castrirten weiblichen Individuen und bei solchen, deren Zeugungsthätigkeit authört, hervorzuggehen scheint. Direct sieht man diese Fettaufnahme am besten nicht allein in dem Dotter des Hühnereies, sondern auch in dem Dotter von Säugethieren und zwar am schönsten bei der Katze, wo oft recht viel grosse und zahllose kleine Augen eines gellblichen Fettes wahrzunehmen sind. Wenn nun diese bedeutenden Fettmengen nicht aus Albuminaten entstehen, so müssen sie ron aussen her in das Ei transsudiren, also vorher in das Eierstocksparenchym abgelagert werlen. Dass beide Vorgảnge hier gleichzeitig vorhanden sind, ist sehr wahrscheinlich; doch liann man einen strengen Beweis nicht erloringen.

Meiner Auffassung zufolge ist also die Bedeutung des Gratr'schen Follikels nicht darin zu suchen, dass er die erste Bildung der Eier übernimmt, welche viehmehr in den Eisclıläuchen vor sich geht, sondern darin, dass er als Sprengorgan des Eierstockis zu betrachten ist, welches dem Ei den Weg an die Oberflache bahnen muss.

Bei der Oeffnung der Grasf'schen Follikeln soll nach der jetzt herrschenden Ansicht normal ein Bluterguss in die Höhle derselben erfolgen. Ich habe hierüber folgende Beobachtungen gesammelt, die mich bestimmen zu glauben, dass dem nicht so ist. Ich will keinen grossen Werth darauf legen, dass bei der Untersuchung schön entwickelter geller Körjer aus den Eierstock der Kuh Blutresiduen im Innern der kleinen noch vorhandenen Follikelhöhle gewöhnlich vernisst werden. Wohl aber muss ich darauf Gewicht leģen, dass, wenn man frische corpora lutea bei Kaninchen, Hunden, Katzen untersucht, unmittelbar nachdem die Eier in die tubae entlassen sind, in welchen ich sie aufsuchte und auffand, dann niemals, sage niemals ein Bluterguss gefunden wird, wenn man das Thier lebendig auflindet, das Abdonıen vorsichtig öffnet und das Ovarium ausschneidet. Wenn man aber die Kaninchen durch einen Schlag auf den Kopf oder durch Durchschneidung des Ilalses tödtet, so wird man fast inmmer die frischen corpora lutea mit Blut erfüllt finden. Ich habe diesen Gegenstand oft genug untersucht und die Sache stets so gefunden. Ich stele deshall, nicht an zu behaupten, dass bei den allgemeinen, dem Tod rorausgehenden Convulsionen, welche das Blut aus den Extremitaten treiben, durch die starken Füllungen der Blutgefässe in Innern des Körper's Zerreissungen der zarten Capillaren eintreten, welche sich soeben in der Substanz des sich entwickelnden gelben Körpers ausbildeten und zum Theil noch in der Entstehung begriffen sind. Es ist dieser Blut- 
erğuss indessen keine den gelben Körper allein zukommende Erscheinung, sondern sehr oft habe ich bei Kälbern die jungen Grasfschen Follikel von 3- ̈ Mm. Durchmesser ganz von dunklem Blnte erfült gefunden, was unzweifelhaft pathologisch ist und aller Wahrscheinlichkeit nach einen alınlichen Grund wie die Extravasate in den gellsen Körper hat.

Man hat in Ovarien und zwar in Residuen der gelben Körper allerdings Haenatoidinkrystalle zu finden geglaubt und auch wohl wirklich gefunden, welche zweifellos durch ein Blutextravasat bedingt waren. Man wird aber daraus, dass in irgend einem Organe selbst öfters Haematoidinkrystalle sich finden, nicht zu dem Schlusse berechtigt sein können, dass in demselben die Entstehung von Blutextravasaten eine normale Erscheinung sei. Im Gegentheil, wenn man sicht, dass bei gesunden Thieren diese Extravasate niemals vorkommen, leicht aber bei denselben durch gewisse stärkere Kreislaufsstörungen bedingt werden, und zwar nicht blos in gelben Körpern, sondern auch in jungen Grasf'schen Follikeln, so wird man zu dem Schlusse berechtigt sein, dass der normale Vorgang der Oeffnung des Follikels ohne jede Blutung vor sich gehe. Dass nachı alledem die stark bluterfüllten Höhlen der Graf'schen Follikel und der corpora lutea der geschlachteten Schweine keine andere Bedeutung als die von Artefacten haben, dürfte nicht länger zu bezweifeln sein.

Und in der That, bei jeder Ansicht, die nan von der resorbirenden Fähigkeit der serosa des peritoncum haben mag, ist es doch klar, dass ein Bluterguss. der bei der Oeffnung des Follikels erfolgt, nothwendig auclı in das cavum peritonei stattfinden muss, woruber aber Niemand noch Etwas luerichtet hat, sowie ich selbst niemals etwas derartiges beobachten konnte. Grössere Blutergüsse aus den Ovarien sind pathologisch allerdings beim Menschen constatirt; aber dann aúch nit sehr schlimmen Consequenzen. -

Es bleil)t mir übrig, endlich noch über das Stroma des Eierstocks mit seinen Gefassen u. s. w. einige Bemerkungen zu machen.

Auf unzweifelhafte Weise habe ich mich überzeugt, dass wenigstens bein Kalbe und hier wenigstens an gewissen Stellen lange dünne Fasern vorkommen, welche einen schwach granulirten Inhalt haben und hier und da einen schönen ovalen Kern beherbergen. Diese Faserzellen liegen ziemlich lose aber vielfach durcheinander geflochten nebeneinander und lassen sich sehr schön studiren, wenn man den Eierstock 12 Stunden in Alkohol von 4.0\% härtet, dann schneidet, nach GerL.acu's Methode scliwach mit Carmin färbt und in Glycerin untersucht. Nicht verschweigen darf ich, dass zuweilen ein von einer primordialen Follikelanlage ausgehender Fortsatz sich immer mehr und mehr verjüngte, um schliesslich ganz ähnlich den eben beschriebenen zu werden, denen er sich beigesellte, um sich in ihnen zu verlieren. Neben diesen langen Fasern kommen aber auch rundliche, dicht aneinander gedrängte Blăschen in Eierstocke vor, ausgezeichnet durch eine derbe Ungrenzung, innerhalb deren hellem Inneren ein Kern nicht wahrgenommen werden kann. Ich bin geneigt, das helle Innere für den Kern an- 
zusehen, die derbe Umgrenzung aher für den Ausdruck einer sehr diunnen Protoplasmaschicht, durch welche die verschiedenen Zellen aneinander gehittet werden. Wenn der Eierstock mit Fett infiltrirt wird, dann bleiben gewöhnlich, oder vielleicht immer die hellen Raume unluerührt und nur was zwischen denselben ist, wird von der Emulsion erfüllt gefunden. Olggleich diese rundlich-polygonalen Zellchen so verkittet sind, dass es sehr schwer möglich ist, sie zu isoliren, so glaube ich doch nicht, durch durchschnittene Fasern der oben beschriebenen Art getäuscht worden zu sein, weil ich solche isolirte allerdings mit Fett infiltrirte Zellen untersuchen konnte.

In diesen Stroma, das also loald aus langen dünnen Faserzellen, bald aus kleinen runden Zellchen besteht, finden sich die Blutgelässe, an denen ich lieine besonderen Eigenthünlichkeiten gesehen habe, die sie etwa von den Blutgefassen anderer Orte unterschieden. Die Arterien erstrecken sich im Allgemeinen vom hilus gegen die Oberfliche des Organes und haben hierbei häufig einen korkzieherartig gewundenen Verlauf. Die Capillaren sind gebaut wie überall. Die kleinen Venen zeigten mir eine Eigenthümlichkeit, die ich erwähnen will, weil sie bei der Untersuchung des Drüsengewebes zu Täuschungen Veranlassung geben könnte. An frisch getödteten Thieren und zwar an dem Kalbe sah ich die kleinen noch von Blut erfülten Venen oft alswechselnd weit und dann rasch wieder eng und dann wieder weit werden. Ich möchte glauben, dass dies durch ungleichmässige Füllung des Gefłsses und ungleichmässigen auf dasselbe ausgeuibten Druck bedingt war. So lange man an frischen Pr'tiparaten untersucht, hat dieser Unıstand gar kieine Bedeutung; denn die Blutgefảsse sehen den Drüsenschlauchen so total unähnlich in jeder Beziehung, dass Niemand auch nur einen Moment sich tauschen kann. Das zarte, weissglänzende, etwas feinkörnige, schwach getrübte Ansehen der eigenthümlichen Drüsenmassen des Eierstocks mit ihren besondern Zellen hebt sich vor (len streifigen, durchsichtigen, oft mit rothem Blut gefülten oder offenbar leeren Blutcanălen mit eindringlicher Charakteristik dem Auge hervor. Sobald man aber Reagentien anwendel, ist die Sache anders. Der Farbstoff der Blutzellen kann ausgezogen werden; sie sellsst können aufschwellen und sich zu Kugeln zusammenballen; die weissen Zellen, welche oft eine beträchtliche Grösse erreichen und feine Granulation darbieten, könnten Eilbildunģen vorspiegeln; bei Untersuchung in Glycerin verschwindet sehr das streifige Ansehen des Bindegewebes und die Existenz weiter und enger Stellen des Canales könnte gerade als Beweis angesehen werden, dass man kein Blutgefäs vor sich habe. - Ich halse geglaulst auf diesen Punht aufmerksam machen zu müssen, der bei Holzessig- und Carminpräjaraten zu beachten ist. - Da ich fast immer beim Kallse frisch untersuchte, so bin ich durch derartig̣e Täuschungen sicher nicht in die Irre gefuilırt worden.

Was die Lymphgefässe und Nerven des Eierstocks betriff, so kann ich darüber nichts 
Neues beibringen. In dem oberflächlichen Theile des Eierstocks habe ich sogar niemals Bildungen angetrolfen, die ich als Nervenfasern hätte ansprechen mögen.

In neuerer Zeit hat man noch einen bestimmten Gewebselemente in dem Eierstocke Aufinerksamkeit zugewandt, nämlich den glatten Muskelfasern. Obwohl ich nicht direct und absichtlich nach diesen Bildungen suchte, so habe ich doch so viele Schnitte angefertigt und mit so verschiedenen Methoden untersucht, dass mir solche Elemente wie glatte Muskelfasern, welche nachzuweisen keine allzubesondere Schwierigkeit darbietet, nicht wohl hätten entgehen können. Habe ich doch oft genug die schönsten glatten Muskelfasern an den Blutgefässen des Eierstocks wahrnehmen können, in dem Stroma aber niemals, werler bei dem Kallbe, noch dem Hunde, noch dem Kaninchen, noch der Katze u.s.w. Wenn man hier mit Reagentien an die Untersuchung geht, so wird man wohl auch einmal eine spindelförmige Zelle mit länglichem Kerngebilde finden. Aber eines ist nicht zu vergessen. Solche Bildungen können Bindegewebefasern des Eierstockes sein und werden von mir für solche aus folgendem Grunde gehalten. Wenn man nämlich mit Blutserun oder humor aqueus oder der Flüssigkeit eines Grasf'schen Follikels den Eierstock untersucht, so zeigt die Muskelfaser in der media der Arterien einen exquisiten Glanz, eine homogene Beschaffenheit, eine deutlich grünliche Färbung, die ihren Grund in den optischen Eigenschaften des Muskels findet. Hiervon aber ist die Erscheinung der Eierstocksfasern sehr verschieden, indem sie mit heller, farbloser, höchstens einige Körnchen enthaltender Flüssigkeit gefüllt scheinen und nirgends jenen Glanz und stark lichtbrechende Eigenthümlichkeit zeigen, wie man das an der Muskelfaser der media sieht. Ich bin deshall der Ansicht, dass in dem Stroma des Eierstocks, welches ich so oft vor mir hatte, keine Muskelfasern vorkommen. Den eigentlichen Eierstockskern habe ich seltener untersucht, so dass ich diesen von der gemachten Behauptung anszunehmen genöthigt bin. - 


\section{Raubthiere.}

\section{Katze.}

Ich beginne mit der Untersuchung der Eierstöcke junger Katzen.

Als Ausgangspunkt unserer Erörterungen wähle ich den Drüsenschlauch eines 3 Wochen alten Thieres (s. Taf. III. Fig. 1.), dessen Eierstock in einer concentrirten Lösung chemisch reiner Oxalsäure gehärtet worden war. In dieser Flüssigkeit wird das Gewebe nach einigen Stunden so resistent, dass es sich gut schneiden lässt. Auch isoliren sich dann bereits die Drüsenschläuche oft sehr schön. Liegt das Präparat länger, so wird die Isolation schwieriger. Aber nach 5-6 Tagen eignet es sich wiederum zu Isolationsversuchen. Die Epithelialgebilde mit Einschluss der Kerne und Membranen behalten ihre scharfen Contouren; nur das Protoplasma wird körniger und dunkler als es sonst ist. Da die Drüsenschläuche im Allgemeinen direct aus dem Innern nach aussen verlaufen, so erhält man am leichtesten ein gutes Präiparat, wenn die Schnitte vertical auf die Oberfläche des Organes in irgend einer Richtung geführt werden. Hat man mehre recht feine Lamellen gemacht, so versucht man mit scharfen Nadeln, während das Präparat in concentrirter Oxalsäure liegt, Schläuche zu isoliren, was nicht besonders schwierig ist. Auf diese Weise ist das Präparat gewonnen, welches ich in Taf. III. Fig. 1 mit Hülfe der Camera abgezeichnet habe. Dasselbe war ganz frei und nur noch unten durch einige Bindegewebefasern mit einem grösseren Gewebefragmente verbunden. Günstigerweise hing der Schlauch noch an einer abgehobenen Epitheliallage der äusseren Eierstocksoberfläche. Dieses Anhaften war so innig, dass es erhalten blieb, obwohl ich das wichtige Präparat wenigstens zehnmal umkehrte, um es von allen Seiten zu studiren.

Dieser Schlauch $(b)$ zeigt nun zunächst, dass er von der Oberfläche des Eierstocks nach der Tiefe an Dicke sehr schnell und bedeutend zunimmt. Der Querdurchmesser misst an der oberen dünnsten Stelle $0,0054 \mathrm{Mm}$., an seiner dicksten, wo er sich bei $d$ spaltet, aber $0,0234 \mathrm{Mm}$., so dass er also um das 4fache zugenommen hat. Gleichwohl ist der Schlauch sehr kurz und misst von seinem Anfang bei $e$ bis zur Spaltungsstelle $c^{n} 0,0720 \mathrm{Mm}$. Daraus geht hervor, 
dass er nur dreimal so lang als dick ist, wenn man die Stelle stärksten Querschnittes zum Vergleiche wählt, während er $13 \mathrm{mal}$ so lang als dick ist, wenn die Stelle kleinsten Querschnittes zum Vergleiche herangezogen wirl. Dieser Schlauch zeigt eine sehr scharfe Al)grenzung, welche, wie ich beweisen werde, der Austruck einer Haut, (ler membrana propria desselben ist. An einzelnen Stellen bemerlit man in dieser Membran kernartige Auflagerungen (s. die Fig. frf.), welche von aussen aufzusitzen scheinen. Dass diese Sclılauclıe eine membrana propria haben, davon überzeugt man sich, wenn eine Stelle derselben sich entleert hat, so dass dann die Haut von einer Schlauchepithelpartie zur anderen sich durchsichtig hinspannt. Die Menuran erscheint fast structurlos, von nicht messl)arer Dicke, aber wie ihre Resistenz beweis't, nicht ganz geringer Festigkeit.

Wenclet man seine Aufmerksamkeit dem Inhalte des Schlauches zu, so bemerkt man, dass überall der mombrana propria kleine Zellchen mit Kernen und Kernkörperchen aufsitzen. Ihre etwas schwankende Grösse betragt ca. 0,0036 Mm. in der mittleren Partie des Schlauches, wenn man die kurze Achse des Ellipsoides, welches diese Zellen darstellen, misst. Nach den dünneren Partien zu sind sie noch etwas kleiner, nach der dickeren zu werden sic zum Theil wenigstens etwas grösser. Diese Zellchen sind das Epithel des Schlanches, vergleichbar dem Plattenepithel, welches wir bei dem Kalbsschlauclie (s. Taf. I. Fig. 8 und Taf. II. Fig. 4.) kennen gelernt haben. Ganz wie dort, nur rascher auf einancler folgend, hegen nun in dem Canale des Schlauches cigenthümlich gebildete Zellen, an denen sofort das auffältt, dass sie sehr verschiedlen an Grösse sind. Ausserdem zeigt sich auch hier ein bestimmtes Gesetz, welches diese Zunahme der Grösse beherrscht, indem die Zellen im Centralcanale un so berleutender erscheinen, je weiter sie von dem verjuingten Schlauchende entfernt sind, so dass man auch hier die Entwicklungsgeschichte der Eier oder doch der Eimutterzellen vor sich hat. Beginnen wir mit Erörterung des blinden Endes $e$. Dieses scheint an dem vorgelegten Schlauche nicht blind, sondern offen zu sein. Ich habe aber Präparate erhalten, die in anderer Beziehung weniger instructiv als das vorliegencle waren, wohl aber den schmalen Schlauchtheil mit stumpf endigender Spitze mir darboten. In diesem Ende, dem Keimfach, liegt wiederum eine sehr zartgranulirte Masse (bei $\iota)$, in welcher man kieine deutlichen Zellen oder Bläschenbildungen wahrnimmi. Sehr bald aber bemerkt man, wenn man sich etwas weiter in der Richtung nach dem dickeren Ende des Schlauches bewegt (bei $b$ ), kleine etwas ovale Bläschen, zwischen denen ein sehr spärliches Protoplasma zu sein scheint. Die jüngsten Zustände lieser Bläschen sind sehr blasse Bildungen, von zarter Umgrenzung und ohne deutliches Kernkörperchen. Alsbalı bildlet sich ein schärferer Contour des Kernbläschens und ein kleines stark lichtbrechendes Körperchen erscheint in demselben. Im Querdurchmesser misst das Bläschen ca. 0,0036 Mm., im Längendurchmesser 0,00ð4. Mm., das Kernkörperchen nicht ganz 0,0009 Mm. Diese Zahlen beanspruchen nur einen relativen Werth, weil man zu bericksichtigen hat, dass die Wirkung 
der concentrirten Oxalsäure die normalen Grössenverhältnisse etwas verändert. Auf diesem Stadium sieht nun das Gebilde den eigentlichen Epithelialzellen des Schlauches wenigstens bei der Untersuchung mit Oxalsäure sehr ähnlich. Rasch aber nimmt das Blaischen an Grösse zu, wobei es in mehr Protoplasma eingebettet erscheint (s. Taf. III. Fig. I. d.). Es misst in seinem Querdurchmesser jetzt 0,0054 Mm., in seinen Längendurchmesser 0,0090 $\mathrm{Mm}$. Der Kern hat sich ebenfalls etwas vergrössert. Hierauf aher beginnt ein rasches Wachsthum, wobei das Bläschen in allen Theilen bedeutend zunelımend mehr rundlich wird und eine deutliclıe Unlagerung von scharf abgegrenztem Protoplasma darbietet, so dass wir es nunınelır mit ciner sehr schönen Zelle zu thun haben (s. die Fig. \&). Unsere Zelle, die Eimutterzelle, misst jetzt 0,0162 Mm. im Längendurchmesser, während das Ausmaass im Querdurclımesser 0,014.4 Mm. beträgt. Man sieht, dass, während vorher der Längen- zum Querdurchmesser sich verhielt wie 5:3, das Verhåltniss jetzt auf 9:8 gestiegen ist. Das Keimblaschen misst in seinem Längendurchmesser 0,0144 Mm., im Querdurchmesser 0,0126 $\mathrm{Mm}$., so dass demnach die ganze Eizelle das Keimbläschen an Grösse nur wenig übertrifft. Der Keimfleck nisst jetzt 0,0027 Mm. An dem Aussehen der Eimutterzelle $(\varepsilon)$ ist selbst in concentrirter Oxalsaure zu constatiren, dass der Dotter fein granulirt, das Keimbläschen durchsiclıtig weiss, der Keimfleck stark lichtbrechend solide aussieht. Auf diese Zelle folgen zwei andere fast gleichgrosse, milten im Canal liegende, welche wiederum die vorhergehende an Ausmaass übertreffen. Die Eimutterzelle ( $\lambda$, misst im längsten Durchmesser 0,0216 Mm., in kürzeren (sie ist offenbar etwas durch die andern Zellen gedrückt) 0,0162 $\mathrm{Mm}$. Das Keimbläschen hat ein Ausmaass von 0,0 I80 $\mathrm{Mm}$. im langen, von 0,0144 Mm. im queren Durchmesser. Die Grösse des Keimflecks im kürzesten Durchmesser beträgt 0,0036 Mm. Man sieht, dass demgemäss alle Theile der Eier an Grösse zugenommen haben. Der Dotter ist immer noch als ein schmaler, aber scharf umgrenzter Ring zu bemerken, der eine zarte Granulation darbietet. Wenn man die beiden grossen Eizellen $\lambda$. genau auf ihren Contour prüf, so sieht es ganz so aus, als ob sie zusammenhingen. Wir werden sogleich darauf zurückkommen. Es wird nunmehr an der Zeit sein, der Entwicklung der Eier genauer nachzuforschen, indem wir dieselben aus den Schläuchen zu isoliren suchen, um sie in Albumin oder humor aqueus zu untersuchen; denn es ist wichtig, die möglichst normalen Verhältnisse wahrzunehmen. Nachdem man sich an Verticalsclınitten iiberzeugt lıat, dass die Schläuche wesentlich von innen nach aussen gegen die Oberflache verlaufen und neben den beschriebenen schönen grossen Zellen ähnliche in den Eierstocksstroma nicht vorkommen, sondern nur im Inneren der Schläuche, verfährt man zur Isolirung der Eizellen folgendermassen. Der Peritonealuberzug des ovarium eines eben getödteten Kätzchens von 1-3 Wochen wird sorgfältig und vorsichtig losgelöst, darauf mit einem scharfen Rasirmesser ein Schnitt geführt, welcher parallel der Oberfläche des Organes verläuft, also vicle Drüsenschläuche quer durchschneiden muss. Darauf fasst man mit den Fingerspitzen das ovarium, befeuchtet 
daś Rasirmesser mit luımor aqueus oder Albumin und fährt leicht drückend mit der Schneide über die angefertigte Schnittfläche, wodurch die Schläuche ihren Inhalt auf das Messer entleeren. Man kehrt dann nit einem in lumor aqueus befeuchteten zarten Pinselchen die Theile auf das Objectglas, welches mit drei kleinen Wachströpfchen benetzt wurde, um den Druck des Deckglases von den zarten Bildungen abzuhalten. Nun untersucht man, da die Isolation der Theile es gestattet, mit recht starken Vergrösserungen. Man sieht hier und da cylindrische Zellenmassen den Inhalt der entleerten tubuli repräsentiren, der nun alle verschiedenen Stadien der Eientwicklung darbietet. Die Zellen, aus denen diese Massen bestehen, sind theils solche, wie ich sie in den Figuren 2-14 dargestellt, theils protoplasmaartige Massen in spärlicher Menge mit wasserhellen ungemein zarten Kernen von verschiedener Grösse, in denen theils ein Kernkörperchen sichtbar ist, theils nicht wahrgenommen werden kann. Dass diese letzten Zustände die Anfangsbeschaffenheit der Eimutterzellen darbieten, ist nach der Fig. I, so wie nach dem, was wir beim Kallse kennen gelernt haben, füglich nicht zu bezweifeln. Theilungen der blassen Kerne scheinen vorhanden. Beginnen wir indessen unsere genaue Untersuchung mit den schärfer charakterisirten isolirten Zellenbildungen aus den Schlauchtheilen der Eierstocksoberfläche. Bei Untersuchung mit den genannten Flüssigkeiten zeigt die primordiale Eimutterzelle bereits ihren eigenthiintlichen Charakter: Dotter, Keimblaschen, Keimfleck sind scharf bemerkbare Gebilde. Die kleine Zelle (Taf. III. Fig. 2.) misst in Längendurchmesser 0,0 26 Mm., in Querdurchmesser 0,0108 $\mathrm{Mm}$., so dass also der mitllere Durchmesser 0,0117 $\mathrm{Mm}$. betrüge. Das Keimbläschen misst in seinem Lảngendurchmesser 0,0099 Mm., in seinem Querdurchmesser 0,00\$ $1 \mathrm{Mm}$., folglich im mittleren Durchmesser 0,0090 $\mathrm{Mm}$. Die Grösse des Keimflečks beträgt 0,0027 Mm. Daraus geht also hervor, dass das Keimbläschen dreimal so gross als der Keimfleck ist, während sich der Durchmesser des Keimbläschens zu dem ganzen Ei verhält wie $90: 117$ oder nahe wie 3:4. Die Fig. 3 zeigt einen etwas weiter vorgeschrittenen Zustand. Das runde Ei misst 0,0126 Mm., das Keimbläschen 0,0090 Mm., der etwas längliche Keimfleck in seinem schmalen Querdurchmesser 0,0027, in seinem Längendurchmesser $0,0036 \mathrm{Mm}$. Hier tritt uns also die bemerkenswerthe Thatsache entgegen, dass ein etwas grö̈sseres Ei ein mit ihm gleich grosses Keimbläschen besitzt, aber einen grösseren Keimfleck. Taf. III. Fig. 4 zeigt uns eine Eizelle ron 0,0189 in der Länge, 0,0144 Mm. in der Quere, so dlass der mittlere Durchmesser 0,0166 Mm. ausmachen würde. Das Keimbläschen misst 0,0135 $\mathrm{Mm}$. in der Breite, 0,0144 $\mathrm{Mm}$. in der Länge, also im Mittel 0,0140 Mm. Der Keimfleck misst in der Länge 0,0036 $\mathrm{Mm}$. Derselbe ist also kaum etwas grösser als der des vorhergehenden etwas kleineren Eies, währent das Keimbläschen allerdings viel stärker erscheint. Der Durclımesser des letzteren verhält sich zum Durchmesser des ganzen Eies jetzt wie 0,0140:0,0166 oder nahe wie 7:8. Das weiter in Fig. 3 folgende noch grössere Ei hat einen Durchmesser von 0,0162 Mm. in der Breite, von 0,0 180 Mm. in der Länge, also im Mittel 
$0,0171 \mathrm{Mm}$. Das nahezu runde Keimblaschen misst $0,144 \mathrm{Mm}$, der Keinfleck 0,004:3 im Mittel. Alle Theile hahen zugenommen. Das Verhältniss des Keimblåschen-Durchmessers zum Eidurchmesser ist nahe unverändert geblieben. Gehen wir weiter zu immer grösseren Eiern. Die Zelle (Fig. 8. b) misst in der Lange 0,0216 $\mathrm{Mm}$., in der Quere 0,0162 Mu.; im Mittel lueträgt der Durchmesser also 0,0189 Mm. Das Keimblischen misst in der Lainge 0,0162 $11 \mathrm{~m}$. in der Breite 0.014.4 Mm., also im mittleren Durchmesser 0,01:3 Mm. Alle Theile, nit Ausnahme des Keimfleckes, haben an Grösse zugenommen. Das Verhältniss des KeimblischienDurchmessers zu dem Eidurchmesser ist jetıt nahezu wie $\ddot{3}: 6$, oder es hat dasselle abgenonmen. Aus diesen Zahlen ergibt sich ein constantes Resultat trotz ihrer sonstigen scheinharen Abweichungen von einem allgeneinen Gesetze. Von einer gewissen Zeil al, nämlich steigt jenes Zahlenverhältniss, d. h. der Durchmesser des Keimbläschens, zu den Durchmesser des gesammten Eies, erreicht ein Maximum und nimmt dann wieder ab. Dieses eine Maximum liegt bei einer Eigrösse von ca. 0,0170 Mn. Mit andern Worten heisst dies, dass vor dieser Zeit das Keimblåschen stärker w'achst als der Dotter, eine Thatsache, die man ülurigens luei dem Eischlauche aus dem Kalbe ohne Weiteres deutlich siehı.

Bei anderen Eiem von 0,0216 Mm. in der Lange, 0,0162 Mm. in der Quere, also im Mitiel von 0,0189 Mm. misst das Keimbläschen 0,01 \&4 in der Länge, 0,0126 Mln. in der Breite, also im Mittel 0,013\%. Der Keimfleck betragt im Mittel 0,004.3 $\mathrm{Mm}$. Dieses Ei war eben so gross wie das vorhergehende; sein Keimblischen aber ist um ein Geringes kleiner als das von jenem. Das Verháltniss des Durchmessers des Keimblaschens zum Durchmesser des ganzen Eies hat wieder etwas alggenommen.

Das abermals grössere $\mathrm{Ei}$ in Fig. $10 \mathrm{misst}$ in der Länge 0,0225 $\mathrm{Mm}$., in der Breite $0,0216 \mathrm{Mm}$., also im Mittel $0,0220 \mathrm{Mm}$. Das Keimbläschen hat einen Durchmesser von 0,014.4 Mm. in der Lănge, 0,0126 $\mathrm{Mm}$. in der Breite, also 0,0133 $\mathrm{Mm}$. im Mittel. Demgemäss hat sich das Keimbläschen nicht merkbar verğrössert, obwohl das Ei doch wieder etwas das vorhergehende im Durchmesser übertrillt. Folglich ist das Verhaltniss des Keimblaschenrlurchmessers zum Durchmesser des Eies wieder gesunken.

Untersuchen wir weiter ein etwas grösseres Ei (s. Fig. 11). Es misst 0,0360 Mn. in der Lange, 0,0234 Mm. in der Breite, also im mittleren Durclmesser 0,0297 $\mathrm{Mm}$. Das Keimb) äschen misst 0,014.4 Mm. in der Länge, 0,0135 Mm. in der Breite, also 0,014.0 Mm. im Mittel. Der Keimfleck beträgt im Mittel 0,0043̈ Mm. Folglich verhalten sich die Zuwachse des Keimbläschendurchmessers zu dem des Eies wie $\ddot{3}: 77$. Man sicht also, dass bei Eiern von der angegebenen Grösse ein ganz rapides Wachsthum des Dotters gegen das Keimblaschen und noch mehr gegen den Keimfleck eintritl, der sich nur wenig verłndert.

Grössere Eier als die untersuchten lassen sich ohne Zuhülfenalıme von Reaggentien nicht mehr isoliren. Die Zahlen haben aber dann nur einen relativen Werth. 
Betrachten wir nach Erörterung der Grössenverhältnisse nunmehr das Aussehen der verschiedenen Bestandtheile des Eies.

Wenn wir nit dem Protoplasma begginnen, so bemerken wir eine sanftglänzende, blassgrüunlich gefärbte, fast hyaline, aber bei Vertiefung in das Object verschwommen granulirte Substanz. So verhält es sich bei den jungen Eiern. Dieses Protoplasma ist so scharf abgegrenzt, dass man sofort geneigt ist, an die Existenz einer Membran zu glauben. Man wird darin bestärkt, wenn einmal ein Ei, was häufig vorkomnt, an einer Stelle verletzt ist (s. Taf. III. Fig. 6. a). An dem mit a bezeichneten Unfangtheil tritt das Protoplasma wie eine zähe Flüssigkeit hervor und sieht wirklich nackt aus, was an den andern Stellen nicht der Fall ist. Ich werde aber bessere Gründe noch für die Existenz von Membranen an diesen jungen Zellen beibringen. Das Protoplasma bleibt wesentlich so bis zu Eiern von der Grösse des in Fig. 11 dargestellten. In diesen bemerkt man nur cin paar kleine Körnchen. Mit der beginnenden Dotterbildung wird aber auch das Ei, welches mächtig wächst, durchsichtiger und verliert den urspruinglichen Glanz seines Protoplasma's, welches so allmählich in eine weissliche zăhfliissige mit Dotterkörnchen nehr oder weniger erfülte Masse sich umwandelt. Eine Membran ist jetzt sicher rorhanden. Das Protoplasma der primordialen Eier wird durch Säuren stets coagulirt, durch Alkalien blässer und glanzloser, durch Iol' gell gefärlts, durch carninsaures Ammoniak sehr schön intensiv roth. Wurden diese primordialen Zellen er'st in Oxalsäure gehärtet, dann nach Gerlacı's Methode mit Carmin gefäl,t, so kann man sie besonders in etwas verdünntem Glycerin vorzüglich mit allen ihren Bestandtheilen conserviren. Yon Zellen habe ich innerhalb des frischen Protoplasmas niemals auch nur eine Spur gesehen. Wenn man aber Reagentien; besonders Säuren, anwendet, treten Gerinnsel auf, die oft in Faiden gleich einem Maschenwerk das Protoplasma und das Innere des Keimbläschens durchsetzen. Wer ohne gehörige Umsicht solche Bildungen zu Gesicht bekommt, kann wohl die Entdeckung machen. dass das Keimblasschen oder das Ei eine Epithelschicht habe oder ein Zellenhaufen sei und dergleichen mehr. Jedenfalls ist es aber nicht besonders zu verwundern, wenn Jemand, der in den Vorurtheilen der vorhandenen Doctrinen über den Eierstock befangen ist, solche Präparate für junge Follikel hålt. Hierzu könnte er um so eher geneight sein, weil sonderbarer Weise Essigsäure den im frischen Zustande so zarten Contour rasch in eine derbe starre Linie unwandelt, die dann eine membrana propria des jungen Follikels vorspiegelt. Ich glaube, dass die Erscheinung einfach durch die stark fallende Wirkung, welche Essigsäure auf eine Sulsstanz des Dotters ausubt, bedingt ist. Dieser Einfluss kann sich in der blossliegenden Oberfläche des Eies am meisten bemerkbar machen. Im frischen Zustande aber ist von alledem ebensowenig Etwas zu sehen als in der Zeiclınung und es wird auch Niemand versucht sein, an solchen frischen offenbaren Zellen etwas Anderes zu suchen als Protoplasma, Kern und Kernkörperchen. Doch kommen wir hierauf noch hestimmter zurück. Was nun ferner das Keimblasschen betriff, so 
ist dies in allen Stadien der Entwicklıng wasserklar und ohne jede Spur von Granulation. Frisch erscheint sein Contour zwar selır zart. aber doch auch sehr bestimnt. Der Keimfleck bildet ein stets nur ein fach, niemals doppelt vorhandenes solides Körperchen, das hej den jungen Eiern nicht immer scharf begrenzt ist, sondern eine gewisse Unregelmassigkeit seiner Oberfläche darbietet. Ebenso ist es auffallend, dass der Keimfleck bei gleichğ’ossen Eiern von ziemlich verschiedenem Ausmaasse sein liann, was seinen Grund in einem Umstande findel, den ich nachher genauer erörtern werde. Je alter aber das Ei wirl, um so mehr nühert er sich der runden Gestalt. Da er die bei Weitem kleinste wesentliche Bildung des Eies ist, so waichst er natürlich am langsamsten. Später geht aus den Keimfleck in den nahezu reifen Eie eine schöne feingranulirte Kugel hervor. Nach der Lage des Keimfleckes in Fig. 7, b. und Fig. I0 bei den jungen Eiern darf man schliessen, dass er wahrscheinlich der Keimblaischenmembran anliegt.

Wenn man solche Eier, wie die bis dahin beschriebenen in einem warmen Zimmer von ca. $20^{\circ} \mathrm{R}$. in Albumin oder humor aqueus längere Zeit betrachtet, nachdem sie aus den lebendigen Thieren eben entnommen worden sind, wird man die Bemerkung leiclst machen, dass sie ihre Gestalt verändern. Bald sielit man, dass alle diese Zellen mit ein em B ewegungsvermögen begabt sind.

Zuerst bemerkte ich das Phänomen, als ich eine biscuitförmige, den bisher beschriebenen gleich beschaffene Zelle, welche ein Kernblaschen hatte, betrachtete und gewahrte, dass sie sehr bald wieder rund geworden war. Diese Zelle setzte nun in humor aquens, welchen ich aus dem Auge desselben Kätzchens entnommen hatte, ihre Bewegungen fort. Zuerst erschien an einem Ende des Eies eine Einschnurung, welche durch einen im Vergleich zum Aequator der Kugel äusserst kleinen Parallelkreis umgrenzt war. Diese Strictur war sehr scharf und verwandelte das $\mathrm{Ei}$ in zwei an einander hängende Kugeln. Es sah aus, als wollte ein winziges rundes Zellchen auf dem grossen knospend hervorwachsen. Während die Strictur so scharf blieb, wuchs nun sletig das kleine Bläschen, während das grosse entsprechend an Volum abnahm. Dies ging so fort, bis endlich das kleine Blasschen dem anderen gleich geworlen war. Ja sogar hierbei sollte es nicht bleiben, sondern immerfort wachsend sahen wir das ursprünglich kleinere Bläschen zum grösseren werden, das ursprünglich grössere zum kleineren, bis es schliesslich auf Null heralggekommen war. Odel man könnte den Vorgang auch so beschreiben, dass man sagte, es sei an einem Pole der Kugel eine Einschniirung entstanden, welche tief und scharf einschneidend in der Richtung der Meridiane sehr langsam uber das Ei hinlief. Es ist übrigens bemerkenswerth, dass das Keimbläschen bei dieser Bewegung durch die Strictur mit dem in Fluss gerathenen Protoplasma hindurchschlupfte. Das Ganze macht dann den Eindruck, als ob ein Theil der Zelle sich contrahire, um seinen I $n$ halt durch die bestehende Strictur in den anderen Theil langsam hinzutreiben. Zuweilen sind diese Contractionen nicht derartig, 
dass sich scharfe ringförmige Stricturen bilden, sondern dass eine ganze Hemisphäre der Kugel sich stark zusammenzicht und hierbei bedeutend verlangert; dann haben solche Eier Fortsätze, welche Bewegungen machen (s. Fig. 9, Fig. 8, Fig. 7, Fig. 5). Wenn die Membran des Eies an einer Stelle (Fig. 6. a) verletzt ist, so zeigt hier das ausgetretene Protoplasma doch noch Bewegung, indem es in sich zusanmenhält. Das Ganze macht den Eindruck wie eine langsame Bewegung von Wellen. welche in einer zahflussigen Masse erzeugt werden. Auch an unverletzt erscheinenden Eiern sicht man solche Oscillationen am Rande oft hin und her gehen. Die Verschiedenheit der Gestalt, welche die Zellen bej diesen Bewegungen durch Ein- und Abschnürungen annehmen, ist eine so ausserordentliche, dass die Gestalt des Eies charakteristisch zu sein auflı̈rt. Ich habe darauf Acht gegehen, ob das Keimbläschen sich auch bewegt, da es zuweilen aussieht, als ob das Ei hin- und herschwankt, weil ein lebendiges contractiles Wesen in ihm sich hin- und herschieht. Ich vermochte das aber nicht mit Bestimmtheit zu entscheiden, wahrend ich die selbstandige Bewegung des Protoplasma's wohl behaupten darf. Ich habe diese sichtbaren Lebensäusserungen drei Stunden lang auf dem Objectglase in lumor aqueus und Albumin anhalten sehen. Mehrmals ist es mir sogar vorgekommen, dass das Ei durch diese Bewegungen seinen Platz veränderte und aus dem beträchılich grossen Gesichtsfelde sich forthegab. Es können demgemảss durch diese Contractionen Ortsbewegungen wirklich hervorgebracht werden. Die ganze Erscheinung hat sehr viel Aelınlichkeit mit den Bewegungen einer Gregarine, wie man sie in den Hoden von Lumbricus terrestris findet. Ich habe die kleinere, solitä lebende, noch weniger granulirte Form im Auge.

Bei der Betrachtung solcher grösserer Eizellen wie sie in den Figuren $7-10$ abgebildet sind, beobachtete ich nun einen höchst wunderbaren Vorg̣ang. Dieser hestand darin, dass die Strictur, die an einem Pole des Eies angefangen und ein kleines Bläschen abgeschnurt hatte, weiter gehend etwas vor der Nitte der Zelle innehielt und wie es schien durch eine starke Verengerung das Keimbläschen, welches zum Theil durch diese geschliupft war, durchschnitt. Zwei Keimbläschen wurden dann unzweifelhaft geschen, von denen das abgeschnürte kleiner war als dasjenige, von den es abgetrennt worden. Beide neuen Keimbläschen hingen nicht mehr zusammen, erschienen aber kugelrund. Der Keimfleck war unverändert in dem urspriinglichen Blaschen zuriickgeblieben. Doch kaum hatte ich Zeit gehabt, mich hiervon zu überzeugen, so erschien plötzlich in dem neuentstandenen zweiten abgeschnürten vollkommen durchsichtigen Keinıbläschen, weit entfernt von dem alten Keimfleck, ein plötzlicher Niederschlag, als ein neuer. Dieser zeigte dieselbe lichtlbrechende Beschaffenheit, denselben Glanz, dieselhe eigenthümliche Umgrenzung. Sicher war nur ein neuer entstanden und ausser ihm Nichts von Körnchen u. s. w. zu sehen. Das Ëinzige, wodurch er sich von dem alten Keimfleck unterschierl, war, dass er viel kleiner erschien, indem siclı sein Durchmesser zu dem des alten etwa wie $1: 3$ verhielt. 
Einmal sah ich in älnlicher Weise eine der primordialen Zellen sich in 4 Abtheilungen abschnüren, wobei aber nur in einem der entstandenen Keimblasclien sich ein neuer Fleck bildete, wàlırend in den anderen keiner erschien.

Hätte man nun diese verschiedenen Stadien neben cinander unter den Mikroskope gaehabt, so würde Niemand daran gezweifelt haben, dass es sich lier un eine Vermelı'ung ron Zellen durch einen Theilungs- oder Knospungsprocess lıandle. Die Bewegungen der Ureier scheinen demnach nichts weiter als Bestrebungen der Zellen zur Alssclinürung bestinnuter Theile odler zur Vermehrung. Nan könnte zwar dic Vermutlung aufstellen, dass der unzweifellaft von mir mit aller erdenklichen Sclıärfe beobachtete Vorgang - denn es lıandelte sich uı eine einzige durchsichtige, vollkommen isolirte, in humor aqueus schwimmende Zelle unter eineu ausgezeichneten Mikroskope - ein pathologischer oder abnormer Process gewesen sei. Wenn man aber erwågt, dass ich die Beobachtung cines neu entstehenden Keimfleckes maclite, so hat dieser Einwand gar wenig für sich. Was wäre in der That dann noch sicher, wenn man hicran zweifeln wollte, wo die Succession von Vorgăngen an derselben Stelle beobachtet ist, während sonst solche Successionen von verschiedenen Zellen benulzt werden, un die Vermehrung durch Theilung zu constatiren. Dass dieser Vorgang einen abnormen Verlauf unter den abnormen Verhältnissen nehmen könne, will ich indessen gern zugeben.

Aber ich kann überzeugendere Grïnde beibringen. Man loctrachte die Figuren 12, 13 und 14 auf Taf. III. Frisch ist das Praparat aus deu ganz lebendigen Eierstock erhalten. Die Zellen zeigten eine geringe Bewegung, wahhrend sie in humor aquens schwamuen. Bei Hunden sicht man leicht bis zu 6 spontan beweglicle Zellen an cinander hängen. Könnte Jemand behaupten, dass diese Zellen bloss zusammenkleben? Dann müsste doch ein scliarfer Contour zwischen beiden Zellen hingehen, von dem ich bei Fig, 12 Nichts sehen konnte. Fig. 12, 1.3 und 14 repräsentiren die verschiedenen Stadien des Alsschıirungsprocesses.

Es gibt aber schliesslich eine Mlethode, die allem Zweifel ein Ende macht. Um námlich die primordialen Zellen bequem zu isoliren, thut man gut, den ganz frische» Eicrstock ein paar Stunden in concentrirle Oxalsaure zu legen, dann eine Lamelle aus den oberflächliclıen Regionen des Organes abzutragen und mit scharfen Nadeln in concentrirter Oxalsaíre zu zerzupfen. In reicher Menge schwimmen dann dic in ihren wesentlichen Theilen gut erhaltenen Zellen in der Flüssigkeit und können bequem studirt werden. Nur eine starke Granulation unterscheidet die Zellen wesentlich von dem normalen Zustande. Sie halsen wahrscheinlich durch gegenseitigen Druck oder Bewegung die wundersamsten Formen angenonuen. Zunächst wird man bald Zellen finden, an denen die Existenz einer Membran niclit in Alredle gestellt werden kann (Fig. 15). Hier hat sich bei $a, a, a$ das Protoplasma von der Hatt der Zelle zuríckgezogen. Bei einiger Aufmerksamkeit wrd es aber nicht fehlen, bald auch solchı Zellen zu sehen, welche zwei Kerne besitzen und theils keine, theils eine geringe Einschniirung darbieten (Taf. III. Fig. 16 
und Fig. 17\%. Fernere Präparate demonstriren selır woit vorgeschrittene Einschnurungen (Taf. III. Fig. 18). Endlich findet man auclı solche Bildungen, bei denen der Alsschnürungsprocess ganz vollendet ist bis auf die Zellemmembran, die noch von einer Zelle auf die andere übergeht. Nach Betrachtung dieser oft wohl wegren Fältelung leicht streifigen Hant bleilht kein Zweifel mehr, lass hier schöne grrosse kernhaltige Zellen, welche Menbranen besitzen, einen ächten Zellentheilungsprocess durchmachen. Nienand wird dies bezweifeln. (Taf. III. Fig. 19 u. 20).

Wenn hier noch ein Bedenken bleiben hann, so ist es das, ob diese sich theilenden Zellen wirklich Eier oder doch Mutterzellen der Eier sind. Die ganze folgende Untersuchung wird die Antwort auf diesen Zweifel geben. Kurz resünirt concentrirt sich diese darin, dass, wenn man von mit gesättigter Oxalsäurelösung gehärteten Eierstöcken Querschnitte anfertigt und sie dann entweder so in Glycerin oder jener Flüssiglieit untersucht, die beschriebenen grossen Zellen sich nur da im Eierstock funden, wo die Ei- und Follikelbildung vor sich geht, also gegen die Oberfläche zu und nicht im Kerne des Organes, mit einem Worte in allen Regionen oberhall, der bereits fertigen Follikel, nienals in den nach innen von dieson gelegenen Theilen. Man überzengt sich, dass diese Zellen in dichten Massen den wesentlichen Inhalt der Drüsenschläuche bilden; es ist leicht zu sehen, dass sie sich schliesslich alle nach Umhüllung mit einem Mantel kleiner Zellen in Grusf'sche Folliliel umwandeln, die sich von den Schläuchen früher oder später abschnirren. Diese zweifellose Wahrheit kann ich, wie man auch immer sich wenden und drehen magr, nicht anders douten, als dass die genannten grossen unter der Oberflache des Eierstockes entstehenden Zellen wirklich Eier oder doch Mutterzellen derselben, also Ureier sind. In Laufe der Untersuchung hoffe ich soll jedler Zweifel schwinden. Dass diese Zellen sich aber durch einen ächten Theilungsprocess vermehren, das ist iber alle Anfechtung festgestellt. Um dom Leser eine weitere Ansichıt solcher verschiedener primordialer Eier zu gewähren, füge ich noch die Präparate hinzu, welche sich auf Taf. III. Fig. 21 bis 28 alggebildet finden. Dieselben sind von einem Kätzchen entnommen, das drei Wochen alt war.

Der von mir hier abermals fuir das Säugethier aufgestellte Bildungsmodus der Eier lässt sich demnach kurz so definiren, dass wir zwei Perioden der primordialen Oogenese aufstellen. Die erste umfasst die Zeit, in welcher winzige Kerne in feinkörnigem Protoplasma gelegen, rinen Theil desselben hald als verschwindend diinne Schicht auf sich ablagern, so dass zunächst ein scharfumgrenztes Blisschen entsteht, welches alsbalı in den Schlauchcanal fällt. Ich lasse es dahingestellt sein, ol, jenes zarte, kerntragende Protoplasma doch schliesslich aus winzigen, vielleicht sogar mit zartesten Membranen ausgestatteten Zellchen besteht, deren Kerne nahe so gross wie die ganze Zelle sind. Unser Zellchen wächst in dem Canal weiter, indem sein Protoplasina zunimmt und etwas körnig wird, ähnlich dem späteren Dotter. Eine Unlagerung von Dotter um das Keimblaischen findot nicht statt, sondern der spätere Dotter 
ist das durch Wachsthum vermehrte Protoplasma. Das Urei hat eine Membran. Es kommt hierauf der zweite primordiale Zeitraum. Die Ureier vermehren sich durch Ausstiilpung hei gleichzeitig stattfindender Kerntheilung. Sie bilden hierdurch oft sehr mächtig aufgehaufte, in dem ursprünglichen Schlauche liegende Zellenunassen, welche durch die Membranen der Mutterzellen zusanmengehalten werden.

Ich bin nicht der Erste, welcher diesen merkwürdigen Bildungsnodus thierischer Eier gefunden hat. Freilich an weitentlegener Stelle des Thicrreichs beschreilot G. Muissien bei gewissen Helminthen einen Process der Eibildung, der deu allgemeinen Plane nach mit dem von mir für das Säugethierei aufgestellten ganz ausserordentlich nahe übereinstimmt. Messsven unterscheidet offenhar auch zwei Eibildungsperioden in den Ovariumschlauchen. Inı blinden Ende bilden sich kleine Zellchen. Diese wachsen bis zu einer bestimnten Grösse. Es sind die Ureier. Jedes der grösser gewordenen Ureier erzeugt dann durch Ausstülpung bei gleichzeitig eintretender Kerntheilung aus sich Knospen von Tochterzellen, die noch lange mit einander zusammenhängen. Wenn sie sich geschieden hahen, so kann man die Trennungsstelle, wo die Eihaut fehlt, an dem durch Druck ausfliessenden Protoplasma crkennen. Alles das ist im Wesentlichen von vielen gewichtigen Autorititen in Zweifel gezogen worden. Ich selbst habe zwar diese Verhältnisse nicht untersucht, glaube mich aber dennoch berechtigt, auf Grund der selbst von den Gegnern Messswer's gemachten Zeichnungen, sowie in Rüchsicht auf die so ảhnlichen Verhältnisse der Säugethiere meine Ansicht aussprechen zu dürfen.

Man sagt, dass die Eitrauben Messsxen's durch Zusammenpappen erzeugt sind. Wenn Kugeln aber in einem Schlauche zusammenliegen, so werden sie sich da am innigsten und stärksten berühren, wo sie am meisten abgeflacht sind; da am schw'ichsten, wo dies an wenigsten der Fall ist. Wenn die nackten Eier klebrig wären, so würden die Oberflachen, welche sich am innigsten berühren, am besten aneinander haften müssen. Hier ist es nun aber gerade umgekehrt. Die Eier kleben da zusammen, wo sie sich sicher am schwichsten beriihren, weil sie an dieser Stelle spitz sind. Denn eine nachgiebige von aussen überall gedrickte Kugel wird da den kleinsten Krümmungsradius haben, wo der Druck selbst ron aussen ein Minimum ist. Die Ansicht der Gegner Messsxer's miisste also dieser Stelle eine besondere Beschaffenheit beilegen. Meine Eiketten hängen nun weniger wegen ihrer Klebrigkeit als wegen der verhandenen Membran der Mutterzellen zusammen. So wird es denn auch wohl bei Meissner's Eitrauben sein. Derselbe Forscher behauptet, dass man an einzelnen isolirten seiner Eizellen die nackte Stelle demonstriren könne, womit das Ei der Mutterzelle aufsass. Man hat das in Zwveifel gezogen. Ich habe mich hiervon bei Katzen ganz entschieden überzeugt. An der betreffenden Stelle gewahrt man das nackte Protoplasma, welches nicht wie der Rand einer mit Flüssigkeit gefüllten Blase, sondern wie eine teigige Masse von unregelmässiger Oberfläche aussieht. Beobachtet man nun, wie an dieser Stelle das Protoplasma bei 
seinen Strönungen hervortritt, sarcodeartige Bewegungen macht, sich zurückzieht, um dann wieder imner an derselben Stelle hervorzukommen, so kann man niclit zweifelhaft bleiben, dass hier die Menbran des Eies ein Loch hat. Wir brauchen das in der That nicht mehr wahrscheinlich zu machen. Wir haben es festgestellt, indem wir den Nachwcis lieferten, dass bei den durch Theilung entstandenen Ureiern die Mutterzellenmembran sich von einer Tochterzelle auf die andere fortsetzt. Ich bin deslıall ganz geneigt, Messsven's Ansicht für wohl mit der Wahrheit übereinstimmend anzusehen, weil sie auf einem Gesetze basirt, das wenigstens für die Säugethiere buchstablich wahr ist. Der Hauptgrund der Gegner war ja aber, dass Messsen's Gesetz in offenem Widerspruch mit den bis jetzt bekannten Principien der Eiloildung bei den Thieren stehe.

Ich wüsste bei ruhiger Erwägung nur noch einen Einwand, den man gegen mich und Meıssin erhelen liönute und welcher etwas ungezwungener den von uns beiden gefundenen Thatsachen sich anzupassen scheint. Es ist das ein Einwand, auf welchen Mancher besonders bei der Untersuchung des Eierstocks der Katze leicht geführt werden könnte. Man würde sich denken, dass in den grossen Eisäcken feine äusserst zarte Schläuche liegen, welche gleichsam aus dem Keimfach durch die wachsenden Eier ausgestiilpt worden sind und weiter durch diese und ihr Wachsthum zu secundären Divertikeln hie und da erweitert werden. Dann wảre also die scheinbare Eimembran nur die propria zarter Drüsenschläuche, iu welchen die nackiten Eidotter lägen. Hiergegen ist nun Folgendes zu bemerken. Membranen kommt in der ptlanzlichen und thierischen Histiologie eine sellständige, ron Zellen unabhängige Vegetation nicht zu, sondern sie sind entweder Ausscheidungsproducte von Zellen oder verảnderte Zellensulsstanz. Demgemäss müssten, wenn man nicht abermals zu ganz paradoxen Annahmen sich versteigen will, diese Schlauchmembranen entweder durch die Eier sellst ausgeschieden sein oder durch andere Zellen, die keine Eier wären, sondern eine Art Epithel der innern zarten Eischläuche darstellten. An isolirten Eiketten nit Membranen sieht man aber zu einer gewissen Zeit der Entwickelung weder frisch noch mit Reagentien eine Spur ron Epithel auf der über die Eidotter hingehenden Membran. Ich habe darnach mit aller Sorgfalt gespälıt (Taf. III. Figg. 12, 18, 19, 20). Man kann auch nicht sagen, dass wegren der Zartheit das möglicherweise vorhandene Epithel nicht zu sehen sei. Denn wenn sich die Eier stark bewegen, so rollt das Keimblasschen oft an der Periplerie herum, sich innigst und ohne dass ein bemerkbarer Raum übrig blieb, auf weite Strecken so anlegend, dass der äussere Eicontour nit dem des Keimblischens in ein e Linie zusammenfliesst. Es besitzen also zu einer gewissen Zeit der Entwickelung der Ureier, welche bereits eine sehr bedeutende Ausbildung erlangt haben, die Eiketten in sich kein Epithel, sondern sind einfach nichts als was sie auf den ersten Blick scheinen : aneinanderhängende schöne grosse Zellen. Niemand hat auch bei den von Merssxer intersuchten Thieren an den Eitrauben etwas wie Kerne oder Zellchen und dergheichen an dem 
Innern des Eicontours jenals wahrgenommen. Somit muss man zugeben, dass die Membran ein Ausscheidungsproduct der Ureier ist. Will man dieses nun einen innern Eischlauch oder Zellmembran der Eier nennen, so ist das gleichgültig. Dem Wesen nach hat man es mit einer Bildung zu thun, welche man von einer Zellmembran zu unterscheiden nicht melır berechtfertigt ist. Demgenıass bin ich der Ansicht, dass der von Meıssaen bei gewissen Itelninthen, von mir bei den Săugethieren anfgestellte Bildungsmodus thierischer Eier als feststehende Thatsache zu betrachten ist. Die Discussion kehrt sich also um, indem aufs Nene diejenigen Arten der Eizeugung in dem Thierreich revidirt werden müssen, bei welchen es scheint, als ob erst das Keimblasschen entstehe, welches sich nachher mit Dottersubstanz umltiillt, um das Ei $\mathrm{zu}$ bilden. Es ist wahr, dass die Schwierigkeiten für die Erklarung der wunderlaren Eigenschaften des Eies ausserordentliche sind; es ist nicht zu lảugnen, dass wir deshall, auf Thatsachen gefasst sein dürfen, welche dem menschlichen Geiste paradox erscheinen. Bei der Discussion der hier vorliegenden Frage handelt es sich natürlich nur um die Entstehung der wesentlichen Eitheile, so dass der Nahrungstotter ausser Betracht bleibt.

Gerade aber bei vorurtheilsloser Erwägung der Thatsachen wird die jetzl so beliebte Theorie, dass sich erst das Keimbläschen des thierischen Eies bilde, um sich dann mit Dotter, der an einer andern Stelle erzeugt ist, zu überzichen, höchst unwalırscheinlich.

Ich lege sehr viel Werth darauf, dass hei den Pflanzen, deren wesentliche Wachsthums- und Zeugungsgesetze eine so tiefe Uebereinstimmung mit denen der Thicre darbicten, die Ureier ganz wie andere Zellen entstehen und sich auch theilen können. Ich muss sehr betonen, dass an verschiedenen Stellen des Thierreichs ebenfalls ein Modus der Oogenese nachgewiesen ist, demzufolge der Dotter nichts weiter als entwickelteres durch die Eigenthätigkeit des Eies gebildetes Zellenprotoplasma ist. Nur wenn die Eier memlsranlos sind, dann wird es sehr schwer sein zu lıeweisen, dass die Dottermassen der sich berülıenden Eizellen doch gesondert sind, und nur sclieinl)ar eine zusammenfliessende Masse darstellen. Es ist demgemäss, wenn man sein Ürtheil auf die gut constatirten Thatsachen hasirt, vielmehr äusserst wahrscheinlich, dass niemals cin $\mathrm{Ei}$ anders entstehe, als durch cine aus innerer Kraft erfolgende Entwicklung eines winzigen Zellchens, dessen Protoplasma ursprünglich von verschwindender Menge ist. Dies anzunchmen ist darum gestattet, weil eine allmähliche Zunahme (lesselben von den geringsten Spuren an nachgewiesen werden kiann. Die Dotterstöche der Trematoden u. s. w. hier heranzuziehen, ist darum nicht gestattet, weil diese Organe nur Nahrungsdotter licfern, also durchaus nichts mit dem ächten Eidotter zu schaffen haben.

Was bleibt nun noch übrig, um es mir und Metssxem entgegenzustellen? Entstehen etwa die vielen im Keimfach liegenden hleinen Zellchen (sogenannte Keimbläschenj nichı durch Zellenvermehrung? Leiten sie sich durch einen anderen Process aus der ursprünglichen lieinhlaut her? Niemand wird dies glauben wollen. Welche Schwierigkeit besteht also darin, dass Zellen, an 
denen schon der Eicharakter deutlich herrortritt, sich doch noch zu theilen fortfalıren. Es ist dies kein in mechanischer Bezichung absurder Vorgang. Deun denkt man sich die Uratome, welche die Eiorganisation darstellen, sich vermehrend, so kann diese Vermehrung so stark sein, dass von einer gewissen Zeit ab zwei gleiclı vollkommene Organisationen daraus gemacht werden könnten. Wenn man auf einem Bilıle imner denselben Punkt, auf dieselbe Weise mit derselben Farbe bemalte, so dass es eine gewisse Dicke erhielte, dann liessen sich durch Schnitte, welche parallel der Flache des Bildes verlaufen, beliebig viele absolut identische, gleich organisirte Bilder oder Naturhörper herstellen. Es gibt indessen Thatsachen, auf die ich mich berufen könnte.

Was ist der Generationswechsel anders, als lass, freilich nach der Zeugung, die aus einem Eie sich entwickelnde Organisation sich in viele identische spaltet, die für sich fortwachsend der Reife zustreben? Hier gehen aus einem ächten Ei viele Individuen herror, welche dem zeugenden Organismus gleich sind. Dass bei niederen Pflanzen eine Theilung von Eimutterzellen beobachtet ist, habe ich bereits bemerht. Ol, nun diese sich theilenden Zellen Membranen haben oder nicht, das kann, scheint mir, wenig wesentliches Gewicht halsen, weil die Menulsran eben kein wesentliclıes und unveräusserliches Attribut der pflanzlichen und thierischen Zellen ist.

Gehen wir in unsern Erörterungen weiter. Der Schlauch, den ich in Taf. III. Fig. 1 dem Leser vorlege, ist sehr schmal, schwilt aber nach unten zu mehr an, obwohl er immer nur eine Reihe von Eiern hintereinander enthält. Dieses ist aber nicht immer, ja nicht einmal gewöhnlich der Fall, wenn man Katzen von 14. Tagen bis 3 Wochen untersucht. Meist haben die Schläuche dann durch gewaltige Vermehrung der Eier sich bedentend vergrössert und sincl, weil sie nreist wegen des kleinen Eierstocks nicht lang sein können und aus einem noch spăter zu erörternden Grunde zu kurzen dicken Säcken geworden (s. Taf IV. Fig. b̈). Dies Präparat ist von einer gesunden jungen Katze, deren Eierstock frisch sofort in concentrirte Oxalsaure gelegt worden war. Ein auf die Oberfläche des Organes angefertigter Verticalschnitt wurde dann mit scharfen Nadeln sanft auseinandergezogen und der vorliegende an einer Stelle noch mit einem Eierstocksfragment zusammenhängende Drüsensack gefunden. Das Nikioskop ist auf die Oberfläche des Schlauches stets eingestellt gewesen, weil natürlich so grosse Zellen von selbst den Blick von dem Inneren abhalten. Neben diesem Schlauche lag ein denselben nach unten umhüllender Sack von ganz derselben Gestalt, wie sie die Inhaltsmasse darbot. Derselbe war streifig, mit Kernen besetzt und schien mir eine bindegewebige Membran darzustellen, welche als äussere Umhiullung zu der hier noch vorhandenen (s. Taf. IV. Fig. ̋̈. a.) mem. brana propria hinzuliam.

Ein andrer ähnlicher Sack, der nicht isolirt, sondern an einem Schnitte, aber sehr deutlich zu sehen war, ist der in Taf. IV. Fig. I abgebildete. Es scheint, dass er angeschnitten ist, weil nan Hohlräume in ihm olne Weiteres deutlich wahrnimmt. Dieser Schlanch ist von 
dem Ovarium einer 4. Wochen alten Katze. Der Eierstock hatte 12 Stunden in concentrirter Oxalsåure gelegen. Er war absolut frisch ja lebendig in die Ilärtungsllüssig̣cheit gelegt worden. Diese Schläuche haben nun vieles Eigenthümliche. Zunächst sieht man balı, dass diese Säcke die Epithelialkugeln, welche offenbar unter einander zusammenhängen, nicht wie gewöhnliches Epithel enthalten. Denn offenhar sitzen diese mächtigen Zellen gar nichıt dem Schlauche auf, sondern berühren ihn nur hier und da, als ob in dem Hohlrame dessellsen Haufen von Eiern, in mannichfacher Weise zusammenhäingend, gesondert lägen. Dies stinumt auch ganz gut mit unsern bisherigen Erfahrungen und mit den Thatsachen der vergleichenden Inatomie. Denn wir sahıen, wenigstens äusserst deutlich beim Kalbe, die jungen Eizellchen von winziger Kleinheit bereits in den Schlauchcanal abfallen, so dass bei spaterem starlien Wachsthum des Eies und üppiger Sprossbildung dann solche eigenthümliche Zellenhaufen, die in sich mannichfach anastomosirend zusammenhängen, gebildet würden (s. Taf. H. Figg 1). Zweifellos überzeugt man sich sogar an Oxalsäırepräparaten wie an den vorliegenden der Taf. IV. Fig. I, dass zwischen den Eiketten Raume sind, in denen aber nichts ist als Wasser. Hieraus erhläre ich es mir, wie es kommt, dass, wenn man an besten einen frischen Eierstock durch einen mit der Oberfliche parallelen Schnitt blosslegt, also einen im Algemeinen senlirecht auf den Verlauf der Schläuche gefülrten Schnitt führt, dieser sofort ron einem oft grossen Tropfen einer wasserklaren Flussigkeit ähnlich der des Grasf'schen Follikels iiberflossen ist. Dennoch haben solche Eierstöcke sicher noch lieinen einzigen Grasf'schen Follikel, in dem bereits eine Ansamn:lung des liquor vorhanden wäre. An Schnitten von Oxalsiure- oder Carminpräjaraten, die auf die oben gedachte Weise angefertigt wurden und die zierlichsten Bilder gehen, sieht man dann an oft doppelt so grossen Scllauchen als den vorliegenden, falls der Schnilt durch dieselben ging, sehr grosse Räume im Innern. Diese werden durchzogen von den sich haufig spaltenden Eiketten, die gleich einem Netzwerke mit verschieden grossen Interstitien den Sack erfitlen. Hier und da haften allerdings einzelne der grossen Zellen inniger der inneren Oberfliche des Schlauches an, was wir alsbald genauer zu crörtern haben.

Während dieser Process der Eiwucherungen stattfindet, leitet sich aber gleichzeitig. besonders ron den tieferen Stellen des Schlauches her, die Bildung der Follikel ein, welche die Verhältnisse weiter oft sehr complicirt, wie wir sogleich selıen wolten. Ganz hesonders entwickelt sich das kleine Schlauchepithel stärker an denjenigen Stellen, wo der Process der Follikelbildung elsen im Gange ist. Von der membrana propria aber wächst ein Fortsatz als Nembran in die Höhle des Schlauches hinein, unı denselben in ein Fächerwerk zu spalten, das die Eiketten sondert. Diesen Ausspruch stüze ich durch folgende Thatsachen.

I. Ich halse Prijparate von entwickelteren sehr grossen Sajcken, welche in Oxalsdiure gebärtet und in Carmin gefärbt waren, untersucht, und bei einzelnen Schılachen die Eier etwas contrahirt gefunden, so dass sie sich von der membruna propria des Schlauches entfernt hatten. 
Hierbei sah ich, wie von der membrana propria aus unzweifelhaft Membranen sich zwischen je zwei Eiern fortsetzten. Es entspringen also sepla von der membrana propria. ähnlich wie bei einer Amphilbienlunge, nur dass unsere sipta eben structurlose Membranen sind, welche an einem Eiersack zu einer gewissen Zeit ein Ganzes bilden und stetig unter einander communiciren.

II. Bei einigen Eiersäcken, wie dem in Taf. IV. Fig. 1, sieht man von solchen Membranen durchaus Nichts. Bei andern aber durchzicht eine oder mehre solche von der äusseren Innica propria ausgehend in irgend einer Richtung den Eisack, so dass dann zwei oder mehre Abtheilungen dessellen entstehen können.

Man sieht mit einem Worte von dem einen Grenzzustande an, der noch lieine derartigen sepla unzweifelhaft nachweisen lăsst, die Zustände verschiedenster Ausbildung der intermediären Scheidewände.

III. Häufig gelingt es besonders an in Oxalsiure gehärteten, in Carmin gefärbten und dann in Glycerin untersuchten isolirten Drüsenmassen Präiparate zu erhalten, welche aus 2, 3 oder f und mehr Eiern bestehen, die erst von einer Menulsan umlüillt sind. Diese trägt nach innen ein zartes Epithel und setzt sich stetig fort auf die membrana propria eines jungen Follikels, in clem nur ein Ei ist.

IV. Ich habe Präparate erhalten, welche aus einer Reihe kugliger Körper ijunger entstehender Follikel bestanden, die in einer structurlosen Haut lagen, ohne dass noch ein Fortsatz derselben einen Follikel von dem anderen getrennt hatte $(\mathrm{s}$. Taf. IV. Fig. 3. m.p.). Es sind mir endlich aneinanderhängende Follikel vorgekommen, bei denen eine membrana propria zwischen zwei Follikeln unzweifelhaft vorhanden war.

Es ist dennach unmöglich daran zu zweifeln, dass von der ursprünglichen membrana propria aus häutige sepla hervorgehen, um die Eilietten in secundäre immer kleinere Partien zu spalten.

Es fragt sich nunmelır ferner, wie man sich diesen Vorgang des Wachsthums einer structurlosen Membran gleichsam in Itohlräume und Gänge vorzustellen hahe.

Nach Allem, was man weiss, kommt solchen Membranen eine sellsstandige Existenz nicht zu, sondern sie sind das Prorluct einer Zellenausscheidung oder doch einer verinderten Zellensubstanz. Die directe Erforschung des eigentlichen Sachverhaltes ist, wie sich Jeder in der Ilistiologie einigermassen Erfahrene denken kann, nicht leicht. Gleichwohl müssen wir uns von dem Borlen der thatsächlichen Erfahrung aus auf die Frage Antwort zu geben suchen. Ich glaube auch, dass ich das in einigermassen befriedigender Weise im Stande bin.

Zunächst ist zu constatiren, dass fast immer den membranösen Septen ein Beleg hleiner Zellchen zuliommt, welche sehr nahe oder ganz mit den Zellen der spätern membrana gramulosu übereinstimmen. Daraus folgt also bereits, dass ein von Zellen unabhångiges Wachsthum der 
membrana propria nicht angenommen zu werden braucht. An einzelnen Stellen allerdings, wie bei jenem Follikel des Kalbes (Taf. I. Fig. I) fehlte an einem nicht unbetrachtlichen Theil des Kugelumfanges das Epithel. Dennoch war eine so scharfe Umgrenzung des Eies an dieser Stelle vorhanden, welche ilırer Lage und Beschaffenheit nach nicht als Eimembran grerleutet werden konnte. Hier schlug ich vor, sich die Sache so zu denken, dass das Protoplasma der Zellen sich in einer ganz diinnen Schicht iiler das Ei ergossen hätte. Die andere Möglichlieit, welche zur Erklärung vorlag, war die, Zellen von solcher Kleinheit anzunehmen, dass sie mil den heutigen mikroskopischen Hülfsmitteln nicht mehr deutlich nachgewiesen werden könuen. Un sich eine Torstellung zu machen, wio nun in den Eischläuchen die kleinen Epithelzellen sich zwischen die Eier einschieben, siche die Taf. IV. Fig. 4. Dieses Präparat war yanz. isolirt. Man sieht zwei aus ihrer Membran gefallene Eikugeln, zwischen welche sich ein Zellchen $a$ einschiebt, das mit einem andern Zellchen $b$ anastomosirt. Das Prajparat ist ron einen 18 Tage alten Kätzchen, und zwar von einem Eierstocke, (ler in concentrirter Oxalsäure gelegen hatte. In den Eiern konnte ich absolut Nichts von Zellen schen; denn natijrlich wird man geneigt sein zu argwöhnen, dass $a$ und $b$ Bindegewebezellen wàren, und ich für ein li $i$ gehalten, was ein kleiner Grasf'scher Follikel sei. Das kann ich nicht zugelsen. Denu uı zu sehen, ob in den Kugeln $c c$ Zellen oder auch nur kernartige Gebilde sind, dazu bedarf es keiner besontlern Virtuosităt. Wenn man nun sieht, wie solche kleine Zellen an dem Rande der Schlauche innen aufsitzen (s. Taf. IV. Fig. 2. « und Taf. III. Fig. 1. d), wenn man weiss, dass die Eier ursprünglich zusammenhïngende Massen bilden, dass sie spatter von Epithel umhuillt sind und von einander gesonderte Graxi sche Follikel darstellen, dass niemals in den Eicrn. wohl aber auf ihnen die Bildung von kleinen Zellchen wahrgenommen wird (Taf. III. Fig. 27 u. 28), so ist gar keine andere Möglichkeit da, als tlass die Eier von tlen kleinen Zellen umwachsen werden. Diese Umwachsung beginnt inmer wesentlich von unten (s. Taf. IV. Fig. I und 2), da die Schlauchpartie A der Oberfliche des Eierstocks zugekehıt ist, während die dichere Partie $\boldsymbol{B}$ tief in dem Organ steckt. Jeder Schnitt zeigt das. Zu gewissen Zeiten mag durch die majchtigen Wucherungen der Eier nach Resorption odler Verdrangung der Fliissigkeit in Schlauche eine gleichsam solide Zellenmasse (Taf. IV. Fig. I. 5) entstehen, indem die Eier dann, was ich beobachtete, dicht gerlrängt wie ein Epithel an einander liegen. Man kann sich nun recht grut denken, wie zwischen sie Zellen hinein wachsen und alle umhüllen. Da die Unwrachsung ron den peripherischen nach den centralen, d. h. den der Achse des Schlauches näheren Theilen vorschreitet, so wird eine Zeit existiren, wo in der Mitte des Schlauches noch nicht umwachsene Eiketten liegen, wåhrend diese an der Peripherie des Schlauches schon zum Theil umhiullt sind. Auch kann wohl zu dieser Zeit noch Flussigkeit in den Interstitien zwischen den einzelnen centralen Eiketten zurückgeblieben sein (Taf. IV. Fig. 2). In dieser Durchgangsperiode sicht es also aus, als ob wieder einige Eizellen an der Peripherie des Schlauches ansässen, was auch 
wirklich wahr ist, aher seinen Grund in der statgehabten von der Peripherie ausgegangenen Umwachsung finclet. Man darf aber nicht vergessen, dass die Eier meist noch innig zusammenhängen, wenn die Follikellbildung. d. l. die Unwachsung beginnt. Denunach werden also zunächst die am Schlauche peripherisch liegenden Eiketten umhiillt. Indem die membrana propria und Bindegewebe zwischen die kleinen, die Eiketten verkittenden Zellchen hineinwuchern, müssen sich nothwendig wegen des fortdauernden Zusammenhaltens der Eier Schläuche bilden, die innen Eiketten enthalten und ein kleinzelliges Epithel so wie eine membrana propria mit Bindegewebeauflagerung lesitzen. Man könnte sich also denken, dass diese bindegeweligen septa von aussen nach innen die membrana propria einstülpen. Wenn man die kerntragende membrano propria als eine dem Bindegewebe angehörende Bilkung bei den Drüsen anzusehen sich erlaubt, so würde unser Vorgang sich noch einfacher erklaren, inden wir uns denken. dass bei Uuwwcherung der peripherischen Eiketten mit kleinen Epithelialzellen feine Bindegewebezijge spaltend zwischen diese kleinen Zellen dringen, während die Eiketten noch zusammenlaften, um diese eine propria anlagern und auf djese Weise einen Knauel von anastomosirenden tmbulis erzeugen, aus denen dann durch einfache Quertheilung die Gruar'schen Follikel entstehen. Auf diese Weise begreift man die sonderbaren Bilder, welche man oft im Eierstock elhålt, nåmlich Knåuel von Eiketten, die noch nicht umvachsen sind, sondern von einem lilaren liqunr ungeben werden und sich nach vielen Richtunğen in anastomosirende varjeöse Schläuche verfolgen lassen, welche in Bindegewebe eingebettet liegen. Das explicirte Schema des reducirten ursprüglichen Drüsensackes lief demgemäss darauf hinaus, dass von einem centralen kleinen Raume aus sich viele radiär gestellte schmale Seitencanäle, welche untereinander anastomosiren fortsetzten. Das so ggebildete Höhlensystem, welches von kileinen Epillıelialzellen ausgelileidet ist, enthielte dann die untereinander meist innig zusammenhängenden Eimassen. Indem die centrale Höhe mit ilıren Inhalte immer mehr in das peripherische Canalsystem aufgenommen wird, verschwindel sie endlich ganz, um ein Convolut von anastomosirenden Schläuchen zu bilden, welche durclı einfache Querabschnirung in Folliliel zerfallen. Ich bin nach einem langen und genauen Studium fest überzeugt, dass diese Darstellung ten wahren Vorgang mit grösster Genauigheit präicisirt (s. Taf. IV. Fig. I, 2, 3, $\ddot{3}$ ).

Weil dieser Abschnilungsprocess wesentlich von unten nach oben, d. I. von innen nach der Oberfläche des Eierstocks zu. weniger intensiv von den peripherischen nach den centralen (d. h, der Achse des Schlauches nähern) Theilen vorschreitel, und weil die Eier im Schlauche fortfahren zu wachsen und sich zu vermehren, wird der letztere immer unförmlicher, dicker und kürzer. Man begreift, dass durch dieses Wachsthum die Eizellen immer ståsker aneinandergepresst werden, so dass sie dann die sonderbarsten Gestalten besitzen hönnen. In diesem Zeitraun halien wir folglich hier und da noch zusammenlängende Follikel, zwischen denen sich mehr oder weniger reichliches Binılegewehe entwickelt hat. Man sielıt mit andern 
Worten jetzt vor sich ein Flechtwerk aus Graar'schen Follikeln, welche durch Membranen von aussen abgeschlossen werden. Man sehe Taf. IV. Fig. 3. Man bemerkit sehr schön die membrana propria (m. p.). Später scheint der dünne Schlauch $A$ (Taf. IV. Fig. 2) zu obliteriren oder auch zur Follikelbildung verwandt zu werden, denn in der $\ddot{3} .-6$. Woche nach der Gelurt ist Nichts mehr von ihm zu sehen; statt der Schlikuche sind Follikehhaufen vorhanden wie in Taf. IV. Fig. 3.

Alle diese Thatsachen, welche sich auf die Existenz der Schlauche, die Entwichlung des Eies und die Abschnürung der GraAf'schen Follikel, die schliessliche Unwandlung der gesammten Schlauche in letztere beziehen, sind leicht zu constatiren, wenn man meine Methoden in Anwendung bringt. Es ist nur ein Punkt, der bei der Katze ausserordentlich schwierigr ist und fast alle Zeit, die ich der Untersuchung zuwandte, in Anspruch nahm, das ist die Entstehungِ der membrana granulosa in dem Ei oder ausserhalb des Eies. Vielleicht liegt dies an einem zu weit getriebenen Skepticismus meinerseits.

Wenn man aber einmal die Eiketten sieht, das heisst jene aneinander hägenden perlschnurartig aufgereihten schönen Zelken, zusammengehalten durch eine Membran, die von einem Ei auf das andere übergeht, wenn man dannn wieder Präparate vor sich bekommt, welche perlschnurartig aufgereihte aneinander hängende Follikel darstellen, so beschleicht Einen der Verdacht, dass die membrana granulosa durch eine Art freier Zellbildung an der Wand des Eies sich bilde, sodass die zweifellos nachgewiesenen, die Eier wirklich umwachsenden Zellen als junge Bindegewebezellen zu deuten wären. Ich habe keine Miihe gespart, um hierin Sicherheit zu erlangen. Ich muss jenen Verdacht als unbegründet zurückiveisen.

Fassen wir noch einmal die wesentlichen Gründe zusammen, um ihren Werth zu würdigen.

1) Die aneinander hängenden grossen Zellen der Eischläuche, welche ich als Ureier angesprochen habe, sind keine feinste Schläuche und haben wenigstens zu einer gewissen Zeit, die eine bereits sehr vorgeschrittene Entwicklung der Eier anzeigt, absolut und unzweifellaft kein Epithel.

2) Wenn man frisch oder nach Behandlung mit concentrirter Oxalsäure oder kohlensaurem Kali und Iodwasser die isolirten Eizellen und Eiketten untersucht, so erscheinen kleine Zellchen niemals nach innen vom Eicontour, sondern nach aussen, indem sie ihm aufsitzen (s. Taf. III. Fig. 27. 28.). Niemand wird zweifeln, dass dieser Zellenliranz der membrana gramulosa angehört. Håufig sieht man nun, wie in vorstehendem Falle ausgezeichnet schön die Alıschnürungsstelle des Eies (s. Taf. III. Fig. 28), um welches, nicht in welchem die Zellen der membrana granulosa liegen.

3) Wenn man dünnere Schläuche wählt, besonders von jüngeren Thieren, in denen ein Ei hinter dem andern liegt, so sieht man am innern Ende die Follikel einfach durch Abschnü- 
rung des letzten Schlauchendes entstelıen. Da man diesen glatten, nicht varicösen Schlauch oft lis an die Oberflache verfolgen kann, um sich zı überzeugen, dass er zu einem Keimfach, d. h. zu Epithel tragenden Schlauchtheilen führt, in denen Eier liegen, so muss man zugeben, dass der Follikel entstanden ist, indem das Ei hier ein Stiich Schlauch als Umhiillung mithekam.

4) Bei dünnen Schläuchen wie in Taf. III. Fig. 1. sieht man das Epithel des Schlauches, in den dir Eier liegen, gerades Weges sich fortsetzen in das Epithel eines späteren Folliliels, welcher noch nicht ganz fertig ist, weil das Ei noch nicht ganz umwachsen wurde.

3) Es komnt häufig vor, dass zwei, nicht selten, dass drei, in einzelnen Futlen sogar, dass vier Eier in einem jungen Follikel liegen und sich innig berühren. Wenn das Epithel eines solchen Follikels mit dem Epithel evidenter Follikeln noch stetig zusammenhängt, was man elenfalls zu beobachten Gelegenheit hat, so ist es nicht begreiflich, wie dasselbe im Innern der Eier entstanden sein sollte, die (loch innerhalb des Epithelkranzes liegen.

6) Die vergleichende Anatomie lehrt, dass im Thierreich (ich habe hier nur die WirbelIosen im Auge, deren Ovarien leichter zu untersuchen und besser bekannt sind als die der Wirbelthiere, bei denen an vielen Stellen eine genaue Revision der weillichen Sexualdrüsen statttinden muss) (in Ei wohl die mannichfachsten Auflagerungen erfahren kann, niemals aber aus eigener Kraft durch einen Act freier Zellbildung rin Epithel entwickelt.

7) Wollte man die von nir als Ureier bezeichneten Bildungen für Mutterzellen ansehen, in denen vielleicht urplötzlich durch eine endogene Zellenvermehrung viele kleine und eine grosse Zolle geschaflen würden, welche den jungen Grus'schen Follikel constituirten, so waire das wieder in Widerspruche mit den hekannten Thatsachen der vergleichenden Anatomic. Denn die Mutterzelle, aus welcher ein Gruar'scher Follikel entstände, würde sich so entwickeln, wie es sonst nur die achten Eier thun. Die Eier sellsst aber entstanden durch einen Act, wie er bis jetzt im Thierreiche nicht bekannt ist. Bei meiner Auffassung findet die vollkommenste Analogie bis in dic feinsten Nüancen statt. In der That darf man nicht vergessen. dass die Verschiedenheiten der Bildungen zwischen höheren und niederen Thieren sich erst im Laufe der spateren Entwicklung entfalten, walırend in den ursprünglichsten Grundlagen der thierischen Organisation cine so tiefe Uebereinstimmung her'scht.

Alle Thatsachen weisen somit theils mit Nothwendigheit, theils mit einer sehr grossen Wahrscheinlichkeit auf das eine Gesetz hin, demzufolge die membrana gramulosa eine dem Ei aufgelagerte Bildung ist.

Wir hahen diesen Satz bei den Wiederkäuern verhältnissmåssig leichter beweisen können.

Wenn ich diesen schwierigsten Punlit der ganzen Untersuchung als entschieden ansehe, so bleibt mir noch eine wichtige Erörterung über die Veränderungen. welche das eigentliche Drisengewelye des Eierstocks allmällich nach der Gelourt erleidet. Durch diese Untersuchung 
wird mit Sicherheit festgestellt werlen, welcher als der frühere, welcher als der spaztere Zustand aufgefasst werden muss.

Unmittelbar nach der Geburt ist das Eierstocksgewelse so zart, dass ich mit meinen Reagentien nicht in Stande war, mir deutliche Präparate zu verschaffen. Kolılensaures liali, Holzessig, Alkohol, Chromsăure, Sublimat, Oxalsäure, Oxaläther, humor aquens, Allsumin liessen mich sammt und sonders im Stiche. Ich bedaure, das chromsaure Kali damals nicht in der richtigen Concentration als eine so ausgezeichnete Untersuchungsflüssigkeit für den Eierstock gekannt zu haben. Selbst jetzt weiss ich noch nicht gewiss, ob dieses Reagens fuir den Katzeneierstock so vorzüglich wie für den rles Kalbes ist; doch möchte ich es vermuthen. Denn als ich nach Abschluss der Untersuchung der Katzenovarien mit Oxalsäure auch beim Kalbe zu arbeiten begann, musste ich mich überzeugen, wie schlecht sich dieses Reagens hier erwies, nachdem es mir dort so gute Dienste gethan hatte.

Ist das junge Kätzchen 8 Tage alt, so geben frische Schnitte in luumor aquens ziemlich gute Bilder. Besser wirkt schon eine kurze Hartung in diluirten Holzessig, der zweckmåssig noch etwas gefarbt ist, weil dadurch die jungen Schläuche gelblich werden. Ganz schöne Bilder erhält man, wenn entweder Holzessig oder diluirtes Glycerin als Untersuchungsflissigkeit genommen werden. Man sieht die Schläuche meist sehr diunn und lang von innen gegen die Oberfläche des Eierstocks emporsteigen und häufig durch oft sehr kurze und dünne Anastomosen mit einander in Verbindung stehen. Die Schlauche zeigen eine zarte Mosaik kleiner kernhaltiger Zellen und hier und da grössere in ihrem Inneren. Dic kleinen Zellen lassen schwer eine Membran unterscheiden, was wohl in dem Iolzessig seinen Grund hat; denn mehrmals glaube ich mit Bestimmtheit eine Algrenzung der Epithelialzellen durch zarte Contouren erkannt zu haben. Die Kernbläschen der Epithelialzellen sind deutlich.

Ob die Schläuche bereits jetzt eine membrama propria haben, kann ich nicht sagen; doch scheint es, nach der scharfen Abgrenzung gegen das Stroma zu urtheilen, der Fall zu sein. Isolationsversuche sind mir in dieser Periode gewöhnlich misslungen. Diese Schlauche, welche weit in die Tiefe des Eierstocks, oft bis über den halben Abstand von der Oberflache zum Centrum herabreichen, sind schon innen dicker als aussen und zeigen in Alschnürung begriffene Follikel. Gewöhnlich ist es jetzt Regel, dass das innere duinne Schlauchende sich zu einem Follikel abschnürt. So geht es eine Zeitlang fort, wobei also eine Reihe von jungen Grasf'schen Blaschen entsteht, die hinter einander in der Richtung eines Radius vector liegen, der aus dem Mittelpunkt des Ellipsoids nach der Oberflache gezogen wird. Die tiefer gelegenen dieser jungen Follikel sind grösser und weiter entwickelt als die oberflachlicheren. Das verstelıt sich nach dem Vorigen von selbst. Ausserdem findet man, dass die tieferen auf demselben Radius vector liegenden weiter aus einander gerückt und durch mehr Stroma geschieden werden als die oberflächlicheren. Auch dies ist leicht zu begreifen. Denn die letzteren sind diejenigen, welche 
sich erst elen al,geschniurt haben. Wahrend diese Sonderungsprocesse am inneren Ende des diunnen Schlauches stattfinden, wishst aber die andere Schlauchpartie mit rapider Geschwindigkeit besonders in die Dicke. Zwei bis drei Wochen nach der Geburt, also innerhalb \& bis 14. Tagen, sind aus jenen dünnen tubuli, deren Querschnitt mit dem diunnen Theile des Schlauches in Taf. III. Fig. 1. oder Taf. IV. Fig. 2. nahezu iulsereinkonnut, häufig schon so gewaltige Säcke geworlen, wie die in Taf. IV. Fiğ. 5. oder Taf. IV. Fig. I. Leicht sieht man, dass diese Verdickung durch das Wachstlum des Epitheles, insonderheit aber der Eier bedingt ist. Der Abschniirungsprocess der Follikel schreitet immer von innen nach aussen an den dicken Schlauche vorwairts, sodass derselbe am Ende der vierten Woche gewöhnlich den ganzen Schlauch consumirt hat. Die oberflachlichen in Bildung begriffenen Follikel hängen dann nur noch ahnlich einem Epithel zusammen. Auch sie sondern sich später, indem Bindegewebe sich zwischen ihnen entwickelt, welches in Laufe des Wachsthums reichlicher auftritt und lie Follikel immer mehr auseinander treibt. Wenn die Schläuche nahezu bis auf die äussersten Theile sich in Follikel umgewandelt haben, so erluilt man bei Verticalschnitten in Oxalsaiture gehairteter Ovarien of Prijparate, wie eines in Taf. V. Fig. I. abgelbildet ist. Dasselbe war so vollhommen aus der angefertigten Lamelle isolirt, wie es die Zeichnung angibt. Nur seillich sah man bei $x x$ noch einige Bindlegewchefasern anhaften. Die vorliegende Bildung ist der obere Rest eines Schlauches, der hier oft grosse keulenförmige Zellen besitzt. welche mit fadenförnigen Zipfeln von der Wand des Canales kommen. Diese Keulen sieht man von sehr verschiedener, aber oft so bedeutender Grösse, wie sie in Taf. III. Fig. 24. dargestellı ist. In diesem Falle liegen die grossen Zellen stark gegen cinander gepresst, polygonal abgeflachlt zusammen, immer noch die kuppelfốrmige Wölbung des stumpfen blinden Endes eines Drisenschlauches nachahmend. Noch etwas spaiter bemerkt man gleich gruppirte rundliche Körper, welche aber bei genauerer Untersuclıung sich nunmehr als junge Follikel erweisen, sodass sich also um jene grossen Zellen später eine Schicht kleinerer bildet. Demgemäss ist es wahrscheinlich, dass die in Taf. V. Fig. 1. abgebildeten Keulen Eier sind, welche länger der Wand des Schlauches anhafteten als dies sonst gechieht, vielleicht weil wegen der Füllung desselben mit Eiern und Follikeln das Abfallen in den Canalraum verzögert worden ist. Die Gestalt ist ja für die Eier nichts Charakteristisches. Ich habe aber auch an den beweglichen Ureiern solche Fortsaitze gesehen, welche mit den Stielen der Keulen iibereinstinmen. Oft erscheinen in dem bald kurzen, hald langen Stiele Querstriche, welche auf eine Alıschnürung hindeuten $(k, h)$. Bei $h$ bemerkt man einen solchen sockelähnlichen Vorsprung, der frïher sicher eine muthmassliche Eizelle kelchartig trug.

Bereits in der vierten Woche sieht man die diunnen gegen die Oberfliche gewandten Schlauchzipfel meist nicht mehr, sei es, dass sie ohliterirten, sei es, dass sie ganz in die Bildung der Follikel mit aufgenommen wurden. Jetzt ist die Zeit vorbei, um die Entstehung der Eier und Graaf'schen Bläschen zu studiren oder die Existenz der Schläuche zu constatiren. Dieser 
Zustand ist gewöhnlich $3-6$ Wochen nach der Geburt erreicht. In dieser Zeit ist noch hein wasserhaltiger Follikel bei der Katze zu beobachten. Auch besteht die membrama gramulosa höchstens aus ein paar Zellenschichten. Wohl aber ist oft das Ei bereits sehr entwickelt. Von jetzt ab geschieht nichts weiter, als dass die Follikel mit den Eiern wachsen. Ich habe die Katzeneierstöcke im 2., 3., 4., 3., 6., 7., 8., 9. Monate untersucht und nichts als Stroma nit eingebetteten, oft sehr entwickelten Follikeln und Eiern gefunden. Im ganzen ersten Jahre konnte ich junge Follikelketten nicht wieder nachweisen, sollass in diesem Zeitraume an eine Neubildung nicht zu denken ist. Derselbe reift nur die Producte der ersten Eizeugungsperiode, welche so schnell abläuft, (lass eigentlich nur 14 Tage innerlialb des ersten Jahres zu ilırer Wahrnehmung sich besonders eignen.

Ehe wir zur genaueren Betrachtung dieser langen Periode übergehen, müssen wir noch einige wesentliche Punkte aus den ersten Zeitraume hesprechen. Wie entstelıen die Eischläuche? Welches ist ihre Matrix oder entbehren sie derselben?

Unter allen von uns erörterten Thatsachen ist es eine, welche ganz besonders geeignet scheint, auf die Lösung dieser Fragen hinzuleiten. Soviel sieht man sogrleiclı an jedem Verticalschnitt des Eierstocks, dass an der Oberflïche stets die jüngsten Zustände gefunden werden, welche bei der gerade stattfindenden Pliase der Entwicklung überhaupt vorkommen. Das ist, glaube ich, der richtige Ausdruck für den Sachverhalt. Denn er gestattet, dass unter der Oberfläche keine jüngsten Zustände vorhanden zu sein brauchen, sowie in der Tiefe sehr jugendliche angetroffen werden können. Das Wesentliche des ron mir gefundenen Gesetzes ist der Unterschied in dem Verhalten der oberflächlichen und tieferen Partien. Verfolgt man nun den Schlauch nach dem Innern des Organes, wozu man Anfangs, geleitet durch die Analogie nit dem Hoden, geneigt ist, so schliesst derselhe bald ab, weil sich die Follikel abschnüren und einen über sich wieder geschlossenen Schlauch zurücklassen. Studirt man die muthmasslich aus einem tubulus entstandenen Follikelzuge bis tief in den Kern des Ovariums, so ist eben nichts weiter als reichliches Stroma zu bemerken, das die Follikel von einander abgrenzt. Geht man aber in der Richtung nach der Oberfliche an den Schlauchen entlang, so verfolgt man sie bis dicht unter dieselbe, wo sie schnell zu erstaunlicher Feinheit herabsinken, sodass sie wohl ungefahr unit dem Durchmesser einer Primitivnervenfaser übereinstinmen. Iclı habe das nicht blos an Schnitten, sondern exquisit deutlich an isolirten Präparaten gesehen, sorlass kein Zweifel nögglich ist. Dieser "Schlauchzipfel«, welcher in concentrirter Oxalsaure gehartet wurde, ist seh" scharf begrenzt, etwas glänzend und mit derselben Masse erfüllt, wie ich sie bei dem Präparate Taf. III. Fig. 1. « abgebildet habe. Diese Schlauchzipfel, entsprechend dem blinden wichtigen Ende der Ovarien der niederen Thiere, sind geschlossen, indem sie stumpf zugespitzt endigen. Ich hahe das an isolirten Präparaten recht deutlich gesehen. Zuweilen kommen diese Zipfel aber beträchtlich stärker vor und sind dann mit schönen Keimbläschen dicht angefültt. Wenı 
an isolirten Schliuchen noch Fragmente des bei der Katze vorhandenen Eierstocksepitheles haften, sieht man nun, dass unbedingt der Contour des Schlauches sich bis zur Epithelialgrenze erstreckt (Taf. III. Fig. 1.). Das Gleiche lehren Verticalschnitte. Bald laufen diese feinen Schläuche gerade auf direct gegen das Epithel, balı kriechen sie erst unter ihm her, um sich demselben innigst anzuschmiegren. Sehr balı überzeugt man sich hiervon an Präparaten, die in Oxalsäure gehärtet waren, dann mit Carmin gefäbt wurden, um in Glycerin untersucht zu werden. Betrachten wir nun das Epithel des Eierstocks der Katze. Dieses Thier hat bekanntlich wie der Hund eine wie es scheint geschlossene Peritonealtasche, wenn man von einer, vielleicht zwei kleinen Oeffnungen in dieser absieht. Die natürlichste Deutung - ich kann es nicht läugnen - ist, dass man diese Tasche als Analogon der tunica vaginalis propria testis ansicht. Demgemảss wäre das Epithel des Eierstocks der Katze als Peritonealepithel aufzufassen. Freilich darf man nicht überschen, dass in diese Tasche sich die tuba öffnet, deren Epithel ja sonst auch allmảhlich in das des Peritoneums übergeht. Eine bestimmte Grenze zwischen ächtem Peritonealepithel und solchem, das bereits den weiblichen Geschleclıtsorganen zugehört, kann nicht gezogen werden. Leider habe ich den Eierstock der Katze fast immer an solchen Präparaten studirt, welche in Reagentien gelegen hatten, weil frisch mit ihm wenig anzufangen ist. Ich konnte auch später, als es mir wünschenswerth wurde, noch einmal an frischen Präparaten die Charaktere der Epithelialschicht zu studiren, nicht dazu kommen, weil sich zu dieser Zeit keine jungen Kätzchen mehr auftreiben liessen. Meine Pråparate aber, die nach Oxalsäurehärtung entweder gleich in verdiinntes Glycerin gelegt oder vorler mit Carmin behandelt waren, sind so ausgezeichnet gut conservirt, die Zellen so scharf contourirt, die Kerne überall so deutlich und durchaus nicht erblasst, dass ich hierdurch allerdings einige sehr wesentliche Punkte in unserer Frage entscheiden konnte. An vielen Stellen ist eine scharfe Grenze zwischen der Epithelschicht und dem Eierstocksstroma vorhanden. Es macht den Eindruck, als ob ganz winzige Zellchen ein Stratum an der Oberfläche bilden, auf welchem das Epithel aufsảsse. An sehr vielen Stellen aber bemerkt nıan, wie die Schlauchzipfel in das Epithel gehen. Das Praparat (Taf. III. Fig. 1.) sieht täuschend so aus, als oh die Schläuche aus dem Epithel gezogen wären, ta in diesem Lücken erscheinen, die offenbar so breit sind wic der Querschnitt der Schlåuche. Wenn man ferner einen feinen Schnitt macht, der parallel mit der Oberfläche des Ovariums verläuft und ihn von seiner freien Fläche betrachtet, welche die zierliche Mosaik der Peritonealzellen zeigt, so sicht man hier und da runde kleine und viel grössere (als der Querschnitt der Epithelzellen) Löcher, welche eine derbere Begrenzung haben, als sie den anderen Zellen zukommt. Zuweilen sind diese rundlichen ausgezeichneten Theile des Epitheles von einer feingranulirten Masse, zuweilen von einer gewaltigen Zelle erfüllt, welche viermal und mehr an Durchnıesser den der anderen benachbarten Zellen übertrifft. Untersucht man die Beschaffenheit ker Epithelialzellen an Querschnitten, so finclet man die verschiedensten Zellengestalten. 
Die schönste Cylinderzelle mit scheinbarem Ausläufer, sowie sehr grosse hugelrunde Zellen kommen eintrüchtig nebeneinander in demselhen Epithelialstratum vor. Birn- und spindelförmige, kleinere und grössere, mit einem und mehren Kernen versehene, lassen sich nachweisen. An einzelnen Stellen ist das Epithelialstratum scheinbar nur aus einer Zellenschicht zusanmengesetzt und grenzt sich scharf gegen das Stronıa ab; an der anderen Stelle sind melıre Lagren verschieden gestalteter Zellen vorhanden. Hier sieht es dann oft so aus, als ob sie sich in einer Schicht vom Epithel loslösen wollten, um dann dem Eierstock anzugehören, d. h. sich auf ihn abzulagern. An vielen Stellen ist aber ein Uebergang von den äusseren Epitlelialzellen des Eierstocks in Zellen des Stroma's nicht zu läugnen, vor allen Dingen nicht ein Zusammenhang zwischen dem Stratum des Epithels und den Schlïuchen, in welchen die Eier entstelien. Im Laufe der Entwicklung trennt sich wieder das epitheliale Stratum von den Schlauchen uncl kein bestimmtes Merkmal weist mehr darauf hin, dass fiüher ein Zusammenhang vorhanden war.

Welche Deutung darf man diesen Thatsachen beilegen? Dic Sache ist zu wichtig, als dass ich es wagen möchte, den so wahrscheinlichen Schluss zu ziehen, der eigentlich auf der Hand liegt. Die Frage drehet sich offenbar darum, ob die Schlauche bei der ersten Entstehung so wie andere Drüsen einfach aus dem äusseren Epithel hervorsprossten oder erst später in dieses hineinwuchsen. Wenn sich bei der Untersuchung nicht ganz besondere Verhiltnisse herausstellen, so dürfte die Entscheidung der vorgelegten Alternative durch die directe Beobachtung ihre grossen Schwierigkeiten haben. Wir sind vor der Hand darauf angewiesen, an einer wahrscheinlichen Entscheidung uns genügen zu lassen.

Was bis jetzı von der ersten Entwickelung der Geschlechtsorgane bekannt ist, gribt keinen ausreichenden Anhalt. Denn die WoLfF'schen Körper sind mit Sicherheit noch von keinem Keimblatt abgeleitet. Ob aus ihnen ausser den Ausfülırungsgängen der Sexualdrüsen auch die Anlage des Hodens und des Eierstocks entsteht, ist nicht sicher ermittelt. Man kann nur so viel mit Rücksicht auf die Lage der primordialen Eierstöcke sagen, dass sie sich allerdings aus einer Wucherung der Zellen, welche die Höhle der gespaltenen Seitenplatten überziehen, erklären liessen.

Wenden wir uns zu einer Betrachtung der vergleichend-anatomischen Verhältnisse. Wenn man bedenkt, wie unendlich mannichfaltig die Lage der Organe zu einander in der Thierwelt angeordnet ist, so dass nur diejenigen constant vereinigt vorkommen, welche wesentlich durch Function und Entwicklung zusammengehören, wie der Darmcanal, das Maul und der After, der Darmcanal und die Leber, das Herz und die Blutgefasse. das Gehirn und die Sinnesorgane, das centrale Nervensystem und die peripherischen Nervenfasern u. s. w., so muss es Wunder nehmen, dass fast ausnahmslos im gesammten Thierreich die Eierstöclie in der Bauchhöhle liegen oder doch in einem anatomischen Zusammenhange mit ilır stehen, wenn iilserhaupt 
eine vorhanden ist. Allerdings sind Thatsachen nachgewiesen, welche der Anschaung, dass ein Theil des Peritonemi's dic Matrix der thierischen Keime sei, zu widersprechen scheinen. So z. B. entwickeln sich bei gewissen Thicren (Anthozoen), welche allerdings der Bauchhöhle enthehren, die Geschlechtsorgane anf der tusseren Körperoherfläche. Denkt man aber daran, dass die Wourf'schen Körper ursprïnglich unmittelbar unter dem Hornblatı, d. h. derjenigen Schicht des Blastoderma's liegen, aus welcher spiter das Epithel der busscren Körperoberfläche entsteht, erwägt man, dass derjenige Theil der Seitenplatten, aus dem sich dic ächten Geschlechtsdiüsen entwickeln, sich früh von diesen ablösen könnte, um bei der späteren Entwicklung unter der ausseren Haut liegen zu hleiben, so begreift man, dass jene vereinzelte Thatsache weder für noch gegen beweisend ist, was für alle ähnlichen gilt. Der Nachdruck ist offenlar auf die so ganz gewöhnlich in der gesammten Thierwelt rorkommende innige Beziehung der Bauchhöhle zu den Geschlechtsdrüsen zu legen, welche mir nicht ohne tiefe Bedeutung zu sein scheint.

Wenn demgemäss die Epithelschicht, welche das Ovariun der Katze überzieht, dem Peritoneum angehört und ein Zusammenhang der Schliuche nit diesem in gewissen Entwicklungsperioden anch bei denjenigen Thieren sich darthun lisst, deren Eicrstock von der Peritonealtasche nur zum Theil bedeckt ist, so wird man kaum lainger zweifeln können, dass die Bauchhaut die Matrix sej, aus welcher dic Geschlechtshliusen hervorsprossen. Dann wire das Ei einc Zelle des Peritoneum's und der Grasf'sche Follikel eine von diesem abgeschnürte seröse Blase. Allerdings mag dieses dusserst merkwïrdig ersclieinen. Aber was kam uns noch wundern, nachdem es zwcifellos ist, dass die äussere Hornschicht des Körpers mit den Haaren und Niggeln -aus einer Lage mit Gehirn und Rirckenmark sich entwickelt? Ich habe mich hiervon an Querschnitten der Keimhaut itberzengt.

Wie man auch immer diesc Verhältnisse auffassen möge, so bleiltt doch die Thatsache sicher, dass die jüngsten Drisenelemente stets an der äussersten Oberflache des Eierstockes liegen. Das Vorhandensein ciner im Allgemeinen zusammenhäingenden Schicht gleich einer Matrix unter dem Peritonemm kann ich meinen Beobachtungen nach nicht bestätigen. Denn einmal habe ich mit Sicherheit das Ilinaufreichen der Schlauche bis und in das Epithel des Katzen- und Hundecierstoclies nachgewiesen. Sorlann ist bereits ron mir festgestellt worlen, dass die Schliuche bein Kalbe in derjenggen Entwicklungsperiode, welche eine Beziehung des Peritoneum's zu denselben zu constatiren nicht melır gestattet, als gesonderte Gebilde bis an die Oberfläche des Ovarium's heranreichen und das Peritoneun unmittelbar berühren. Zwischen diesen Schlauchen ist hier und da ein streifiges Wesen zu bemerken. welches sich bis dicht unter die Oberfliche erhebt und als interstitielles Bindegewebe am natülichsten gedeutet wird. Es gibt aber Perioden in der Entwicklung, in welchen dic scharfe Sondermg zwischen 
Eierstock und Peritoneum nicht dasein mag. Auf diese Verhältnisse bezieht sich indessen dic soelsen gemachte Erörterung nicht.

Diese eigenthümlichen Gesetze wurden von mir nicht erwartet, weil ich mich Anfangr: durch die jetzt gültige Lehre leiten liess, class die reiferen Follikel der Oberfläche des Eierstockes näher liegen als die jüngeren. Ausserdem schien es wohl nach Analogie mit dem lloden wahrscheinlicher, dass die Schläuche gleichsam von innen nach aussen sprossten. un sich an der Oberfläche abzuschnüren. Ferner konnte man es paradox finden, dass die Gusa'schen Follikel später die Stellen passiren müssen, wo das junge Drüsengewelse lieğ. Die Tlıatsachren haben sich für diese Voraussetzungen nicht entschieden, weil diese letzteren zum theil auf unwahren Theorien berulten.

Denn es ist nicht erwiesen, dass bei den Hodencanàlen eine Sprossung von innen nach aussen stattfindet. Diese Drüse verhält sich von den andern in einem Punkte sehr verschieden. Ihre wirklichen Ausführungsgänge sind nicht die Stämme, aus welchen die Samencanäle gleich Aesten hervorwuchsen, sondern nelen den lubuli seminiferi selbständig erzengte Bildungen, welche sich erst später mit jenen in Verbindung setzen. Die Matrix des IIodens liönnte deshall) ebenfalls an der Oberflache des Organes sein, wo ja auch die jüngsten Zustände des Drüsengewebes sich im Allgemeinen vorfinden.

Ferner braucht das Ei und der Grasf'sche Follikel bei dem Platzen dessellen nicht jene jungen Bildungen zu passiren, weil sie eben zu dieser Zeit längst verschwunden sind. Es haben sich dieselben in Follikel umgewandelt. Durch mehr oder weniger reichliches Stroma auseinander getrieben finden wir sie jetzt nahezu gleichförmig im Eierstock vertheilt, was fast streng für alle Schichten gilt, welche überall gleich weit von der Oberfliche entfernt sind. Nachdem wir bis dahin die Entstehung der Eier und die Umwandlung der Schläuche erörtert haben, bleibt es uns ïbrig, den wesentlichen Elementen des Eierstockes, nämlich dem Grasr'schen Follikel und dem Ei, in ihrer ferneren Ausbildung weiter zu folgen.

Ich beginne mit dem Ersteren. Nachdem die junge membraua grauulosa sich gebildet hat, wächst das Ei sehr stark. Doch bleibt sie selbst lange eine dünne Schicht, welche das bereits weit vorgeschrittene Ovulum überzieht. Gleichwohl findet wihrend der Vergrösserung des Eies eine stetige Zellenvermehrung der membrana graunlosa statt. Wenn man diese grösseren jungen Follikel ansieht (s. Taf. IV. Figg. 6-9.), so ist mancher ejgenthümliche Umstand hervorzuheben. Der glänzende Ring, welcher sie umgibt, ist an den meisten nicht geschlossen, sondern enthält grössere oder lileinere Lücken, wie dies z. B. in Fig. 9. Taf. IV. sehr auffallend erscheint. Was ist dieser Ring? Untersucht man mit humor aqueus, so ist nichts als eine stark glänzende Masse zu sehen, welche wie ein Zellkern das Licht bricht. Bringt man Säuren hinzu, so trübt sich der Ring. Es erscheinen hier und da kleinere und grössere kreisförmige Contouren in ihm. Diese haben aber nicht die Schärfe und Bestimmtheit, welche noth- 
wendig ist. um über die Existenz von Zellen mit Sicherheit zu entscheiden. Darf man diesen Ring für Bindegrewebe erklaren? Gegen diese Deutung sprechen folgende Thatsachen.

Zunäclsst sehe ich bei dem besten Willen mit den vorzüglichsten Linsen an der Peripherie des Eillotters (s. Fig. $T$ und Fig. 9. b. p.) keine Spur einer Zelle, die ich als der membraua graumlosa angehörig deuten könnte. Eine solche ist sellıst da nicht zu erkennen. wo der glänzende Ring fehlı, mag man nun frisch mil humor aqueus oder mit verdünnter Essigsăure untersuchen. Man könnte allerdings eiuwenden wollen, dass aus dem Praparate eine ausserordentliche Verdiunnung des Ringes ableithar sei, die aber noch ausreiche, um durch die starke Lichtbrechung die Wahrnehmung des zarten Epithels zu hindern. Dieser Einwand hat darum wenig Gewicht, weil man das Keimbläschen durch die dickste Schicht des Ringes mit der vollendetsten Klarheit sielıt. Das einzig Denlbare wäre, dass die Epithelialzellen der membrana gramulosa durch den Druck des stark wachsenden Eies obliterirten und sich auflösten. Hierfür könnte die Thatsache sprechen, dass bei dem Hühnerei Aehnliches rorkömmt, da dessen ursprügliches Epithel schwindet.

Was den Beobachter aher ferner abmahnt, den glänzenden Ring für Bindegewebe zu lıalten, ist, dass bei juingern Follikeln einzelne Zellen der offenbaren membrau gramulosa jenen eigenthümlichen Glanz zu zeigen anfangen und mehr und mehr eine scheinlore zusammenfliessende Nasse z.u bilden (Taf. IV. Fig. 8.). Da das Präparat ganz isolirt war, so erscheint es ungerechtfertigt, die drei glainzend gewordenen Zellen als angelagertes Bindegewebe statt als Epithel zu bezeichnen, das dem lier sehr sparlichen strutum granulosum angehört. An anderen Stellen (Taf. IV. Fig. 7. r. r.) zeigt der Ring noch auf grösseren Strecken nach innen vorspringende, den Epithelzellen ähnliche kuglige Herrorragungen. Offenbar liegt hier ein weiter entwickelter Zustand vor. Der Unterschied in der Grösse der Follikel verleiht dieser Vorstellung eine Stiitze.

Was ferner abmahnt, den glanzenden Ring fir Bindegewebe zu halten, ist die Thatsache, dass an noch grösseren isolirten Follikeln sclıöne Zellen der membrama grauulosa sich steti: in diesen Ring vertolgen lassen. Es sieht so aus, als ol) das Epithel sich aus demselben erhöbe. Hiermit in Uebereinstimmung erscheint es, dass in denselben llaasse, als die Follikel an Grösse zunehmen und eine membrana gramulosa mit vielen schönen Zellen sich ausbildet, auch der lichte Ring immer mehr und schliesslich ganz verschwindet. Als wichtig ist hier ferner hervorzuheben, dass gerade diese mit glanzenden Ringen versehenen jungen Follikel unit äusserster Leichtigkeit sich isoliren lassen. Fast bei jedeın Schnitt sieht man sie deshall, ohne dass man zu zerzupfen braucht, in der Untersuchungsflüssigkeit herumschwimmen. Stets sind sie scharf begrenzt und zeigen nirgend faserige Fortsätze oder dergleichen, wodurch ein Zusammenhang mit Bindegewelse angedeutet wäre.

Die entschiedenste Thatsache ist aber folgende: Ich habe nach Härtung des Eierstoclies 
in Oxalsăure und Untersuchung isolirter Fragmente Praparate erhalten, leei welchen die un die Eier wachsenden Epithelien sich erst zur Sonderung in Follikel anschickten, greichwohl aber bereits aus ganz verschwindend kleinen Zellehen bestanden _s. Taf. V. Fig. 3. . Unzweifelhaft bilden diese dichtgedrảngten ausserordentlich kleinen Blasschen nach der Abschnürung den crwảhnten glänzenden Ring. Auch hier weise ich den Verdacht, dass die gezeichneten Kug̣eln keine Eier, sondern Follikicl seien, zurück.

Nach alle dem muss man diese Verhältnisse folggendermassen auffassen. Solsald die Vorbereitung der membrana gramulosa zur Erzeugung jener gewaltigen Epithelmassen anhelu, welche spater das Innere des grossen Graaf'schen Follikels erfiillen, verlieren die Zellen derselben ihr zartes durchsichtiges Ausselıen, werden glinzend und brechen das Licht wie Zellkerne. Dies ist durch eine starke Vermehrung der in den Zellen vorhandenen Kernmassen bedingt. Es bleibt uns die eigenthümliche Veränderung der Dicke des glinzenden Ringes zu erklären übrig.

Nachdem die Follikel sich gebildet haben, wächst das Ei viel schneller als die membrama gramulosa. Das ist unzweifelhaft. Denn wenn alle Theile derselben sich in den drei Dimensionen des Raumes eben so stark als das Ei ausdehnten, dürfte nicht nach einiger Zeit das Verhältniss des Eihalbmessers zur miltleren Dicke der membrana gramlosa sich rergrössert haben, wie dies doch in der That der-Fall war. Wenn dieses in radiarer Richtung langsame Wachsthum der membrama gramlosa nicht minder träge in der Flaiche vor sich geht. so müssen die Erscheinungen sich so gestalten, wie man sie wahrnimmt. Das stark wachsende Ei dehnt die Epithelialblase, in welcher es stecht, sehı aus. Die Rảume zwischen den Epithelien müssen folglich zunehmen. Deshalb gewinnt es of den Anschein. als ob die membrama gramlosa nur rudinent air vorhanden wäre. Man beğreift, dass an den Follikelpolen, wo das Epithel fehlt, die zellenlose Stelle sich ebenfalls vergröössern muss. Es ist deshall) eine auffallende Bestatigung unserer Ansicht, dass immer nur an einer oder zweien sich aber nahe gregenüberliegenden Peripherietheilen der Ring unterbrochen ist (s. Taf. IV. Fï. 6. 7. 9.).

Ich kann indessen die Erörterung dieser Prånarate nicht verlassen, olne aul' das Zellenhäufchen (Taf. IV. Fig. 9. a.) zurückzukommen, das man bisher wohl olıne Weiteres für einen GraAf'schen Follikel gehalten hätte. Eine gewisse Bercehtigung könnte darin gesucht werden, dass dieses Häufchen innig dem evidenten Grasf'schen Bläschen $(b)$ anhaftete. Denn als ich das Deckglas drückte, sah ich wohl, wie zwischen beiden Bildungen ein Zusammenhang existire. Was will man aus diesen Zellenhäufchen machen? -

Wir haben bei dem Kalbe auf die unzweifelhafteste Weise gesehen, dass die Grasf'schen Follikel durch Abschnürung von Schlauchen entstehen; wir konnten auf das Bestimnteste crweisen, dass die mit ihren wesentlichen Theilen ausgerüsteten ziennlich entwickelten Eier hereits vor der Bildung der Follikel in zusammenhängenden Nassen da sind; wir vermochten 
dies auch Alles bei der Katze festzustellen. Folglich missten wir zwei Arten der Ei- und Follikelhildung zugehen, weun wir das Zcllenhäufchen für ein junges Grasf'sches Blisschen ansehen wollten. Hierzu glauben wir uns aber tlarum nicht berechtigt, weil wir einen Uebergang solcher Zellenhäufclien in ächte Follikel nienals wahınchmen liomten. Niemals wurde in ihnen eine Zelle mit grossem klaren Blischen bemerkt, wie sie die Eier besitzen. Aus diesem Grunde grlaube ich, dass diese Iläufchen Zellenüh)erbleibsel der Schlảuche sind, welche zum Theil ähnlichre Metamorphosen wie ihre Schwesterzellen durchmachen und zuweilen sogar ebenfalls kleine glänzende Ringe zu bilden beginnen. Wir haben bewiesen, dass nicht die gesammten Epithelialmassen der Eischläuche zum Aufbau der Follikel verwandt werden, sondern zum Theil obliteriren. Wir fanden diese vergänglichen Theile von sehı verschiedener Gestalt. Warum sollten sie in einem Parenchyn, in welchem sich Kugehn gegeneinander abgrenzen, in den bleibenden Zwischentiumen nicht auch rundlich gestaltet sein können?

Der Leser wirl aber nicht verkennen, dass solche Verhallnisse an Verwickelung ihres Gleichen suchen, welche nur die belarrlichste Ausdauer und die unbefangenste Erwảgung richtigg zu deuten und zu begreifen ermöglicht.

Gehen wir in unserer Betrachtung der wachseuden membrana gramlosa weiter, so zeigt es sich, dass sie lange ein im Vergleich zum Ei sehr dünner Ring bleilt, der anfänglich solide erscheint und bei der Katze sich erst spät mit Wassel fullt. Die Grössenzunalıme der Zellen der membrama gramulosa ist eine oft sehr bedeutende, indem sie um das vier- bis sechsfache an Durchmesser die in den jüngsten Follikeln iibertreffen können.

Meist błeihen die Graar'schen Blischen der Katze runcl. Dociı habe ich sie auch cylindrisch gefunden, vermuthlich wenn sich einmal der Ausdehnung der membrana granalosa in bestimmter Richtung ein kleinerer Widerstand entgegensetzte (s. Taf. IV. Fig. II.). Das Prảparat war vollkoumen aus dem Eierstock einer jungen Katze isolirt, der einen Tag in concentrirter Oxalsăure gelegen hatte, nachdem er ganz frisch aus dem eben getödteten Thiere entfernt worden war. Indem ich die Flüssigheit in slarke Strönıung versetzte, sah ich, wie dieser sonderbar gestaltete Follikel um die verschiedensten Achsen rotirend und mir alle Seiten zukichrend in der That dic Auffassung rechtfertigte, die man bei der unmittellıaren Anschauung des Präparates sofort gewann. Seine Umgrenzung war durchaus scharf.

Es bleibt uns endlich noch in dem Entwicklungsleben der Grasf'schen Follikel ein Vorgang zu beschreiben, der nur von einem höheren Gesichtspunkte aus verstanden werden kann.

Wenn man nämlich die Zahıl und Grösse der jungen Follikel aus einem dicken Schlauche des Ovariums einer drei Wochen alten Katze bestimmt und ebenso den Durchmesser des reifen GraAf'schen Bläschens ermittelı, so kommt man zu dem Resultate, dass, wenn auch nur einer der dickeren Schläuche alle seine Follikel zur Reife brächte, bereits nur für diese in dem Eierstock kein Platz mehr sein wiirle. Ferner sieht man leicht, dass cine Anlage wie z. B. Taf. IV. 
Fig. 2) bereits mehr Gratr'sche Blaschen elzengt als eine Katze jalurlich Eier alusitosst. Icll schätze die Zahl derselben in Jahre auf ungefahr zwanzig, da sine fruclıthare Katze zweimal, höchstens dreinal werfen kann. Die Zahl ist absichılich zu hoch gecnommen worlen. In dicken Schläuchen sind aber oft viel mehr als zwanzig Eier enthatten (s. Taf. IV. Fig. : j). Nun liegen diese Schläuche dicht gedrängt in den Ovarien nebeneinander, so dass häufiğ das zwischenbefindliche Bindegewebe auf ein Minimum reducirt, ja fast geselwwunden ist. Wir sehen mithin einen Ueberfluss an Zeugungsstoff vorlanden, der wahrhaft staunenswerth ersicheint. Man könnte deshalb zweifelhaft werden, ob die beobacbteten Follikelbildungen nicht andere Bedeutung hätten, als diejenige, welche wir ilmen beilegten. Aber man betrachte Taf. IV. Fig. 2. Wer kann laugnen, dass $\gamma \gamma$ junge Gratr'sche Blaschen sind? Wer wird rersuchen wollen, die dlarüber liegenden Bildungen für etwas anderes zu erklären? Wo will man aufhören, die Existenz der Eier zuzugelıen, es sei denn in dem Ende (A) des Keinfaches? Welches Bedenken kann noch bleilen, wenn wir diese bei Katzen von drei Wochen so teicht nachznweisenden Bildungen bei Thieren ron 4-3 Wochen nicht mehr finden, wohl aber an ihrer Stelle Haufen Grasf'scher Bläschen, von denen einzehe bereits stark in der Entwicklung vorausgeeilt sind? Ilier muss das Vorurtheil vor der Thatsache verstummen.

Entstehen doch auch im Hoden Milliarden von Spermatozoen und ist es doch sclıliesslich nur ein wahrhaft verschwindender Bruchtheil, der seine Bestimnung erreicht.

Man hat sich bereits fruher die hier anfgeworfenen Fragen zu beantworten gesuchl. Die Einen meinten, dass die jungen Follikel lange bestehen bleiben und also fur das ganze Leben ausreichen. Gleichwohl erkannte man, dass während des crwachsenen Alter's neue nachgebildet werden müssen, weil währond desselben Follihel im allerjüngsten Zustande unzweifelhaft vorkommen. Auch ich halte die Neubildung für sicher, da ich auch bei erwachsenen Thieren noch den Abschnïrungsprocess beobachten konnte. Weiss man, mit welch ausserordentlicher Geschwindigkeit die jungen GraAF'schen Bläschen sich bilden, in wie kurzer Zeit die kleinen zu beträchtlicher Grösse heranwachsen, erwägt man, wie zahlreich sie im Vergleich zu den wenigen Eiern sind, welche während eines Jahres die Ovarien verlassen, so kann man sich kaum der Ueberzeugung erwehren, dass viele in dem Eierstock zu Grunde gehen. Es ist das sogar eine Nothwendigkeit, wenn man die Zahl der während des Lebens eines Thieres ausgestossenen und der im spätesten Alter im Eierstock noch rorlandenen Eicr nit denjenigen vergleicht. welche sich wahrend der fruhesten Jugend darin vorfinden. Bedlenkt man, dass eine Katze ungefähr 10 Jahre alt wird und innerhall, dieser Zeit höchstens 200 Eier die Orarien verlassen haben, welche in der Jugend viele Tausende entlielten, so muss man, weil bei sehr alten Katzen nur noch sehr wenige Follikel zu finden sind, den Schlıss zielıen, dass vicle während des Lehens in dem Eicrstocke zu Grunde gehen. Die Plıvsiologie muss diesen Process einen normalen nennen. Denn danit nur ein einziger Follikel reifen könne. mussen viele verderlben, weil alle zu 
Grunde gehen wïrden, wenn die Natur sie gleichnlissig in der Entwicklung beguinstigte. Es gibt viele Beispiele derartiger Naturerscheinungen, welche für den philosophischen Forscher von ungemeinem Interesse sind. So entwickeln sich, un ein Beispiel aus der Pflanzenwelt zu wälen, in dem Embryosacke von Citrus nur zwei bis drei Keime, olwohl bis hundert Embryonen darin enthalten sind, die aber, weil sie keinen Platz zum Wachsthum finden, verliummern. Bei Ardisia excelsa bildet sich auf dem nit zahlreichen Samenknospen ausgerüsteten Samenträger inmer nur eine zum Samen. Bei den Lebermoosen und anderen Pflanzen sind ahnliche Verhailtnisse bekannt.

Ich kann auch durch directe Beobachtung die Auflösung vieler Follikel in Eierstocke bestitigen. Ich konnte bereits bei dem Kalbe den Process schildern, der ausgezeichnet schön bei der Katze zu sehen ist. Durch die beschriebene fettige Entartung werden die Follikel mit Epithel und Ei ergrilfen; allmählich klärt sich das Gewebe des Grasf'schen Błảschens wieder auf; seine Structur ist aber undeutlicher geworden, und schliesslich deuten nur hellere runde Flecken die Stelle an, wo ein Follikel lag. Dieser Vorgang ist nicht bei der urspriinglichen Follikelbildung in den Schlauchen zu sehen. Er tritt erst nach der Alschnurung auf. Bereits im dritten und vierten Monate nach der Geburt ist die Zahl der Follikel eine so kleine geworlen. dass sie sich, auch wenn man die Vergrösserung der Ovarien in Betracht zieht, keineswegs aus dieser erkłären lässt. Ich konnte sogar dann noch den Lösungsprocess beobachten, wenn das Ei bereits in Follikel eine mächtige zona pellncida besass. Ich habe gesehen, wie dieses sellst sich unter besonders merkwïrdigen Erscheinungen auflöste. Wenn man nämlich innerhall der Periode der Follikelreifung untersucht, so wird man sehr gewöhnlich an frischen mit humor äqueus untersuchten Schnitten unter den schönen normalen Eiern einzelne finclen; die folgente Eigenthimlichkeit zeigen. Die :ona pellucida scheint oft stark aufgeschwollen und verdickt; wenigstens ist der weisse Hof um das Ei ganz alnnorm breit. Dieselbe steht wenig oder sehr viel von dem Dotter ab, sodass dann zwei Eier statt eines in dem Innern Platz fainden. Jener liegt entweder als scharf begrenzte dunkle Kugel in dem Raume orler zeigt einen unregelmåssigen Contour, als ob von aussen nach innen eine Lösung gleichsam die Oberflache der Dotterkugel anfressend vorschritte. Oft sieht man dann die letztere in zwei, drei, vier und mehr Partien zerfallen, die ähnlich wie ein in Furchung begriffenes Ei aussehen, obwohl Alles beweist, dass es sich nicht um eine Gewebeneubildung, sondern um einen Zerfall handelt. Das Merkwürdigste aber, was ich bei dieser Verflüssigung des Dotters als lösenden Factor kennen lernte, waren Zellen, welche den in der Zonahöhle liegenden Körnerkugeln an verschiedenen Stellen aufsassen, etwa wie ein Pilz dem Organismus, auf welchem er schnarozt. Ich liahe diese Zellen hier zu $6-8$ in Arbeit gefunden und war auch im Stande zu constatiren, woher dieselben kamen. An verschiedenen Stellen sıeht man mit ausgezeichneter Klarheit dic Zellen der membrana gramulosa durch die zona pellucida Fortsätze schichen. Diese letzleren sind balıl sehr schmal. lıald zienulich hreit, d. h. können etwa den dritten Theil des Durchmessers einer 
mittelgrossen Zelle der memlrana gramulosa und melır erreichen. Oft stehen diese Fortsaitze mit Blasschen in Verbindung, welche sich im Innern der Eihöhle befinden und den inneren Contour der zona pellucida herühren. In diesen Falle stellen also jene Fortsłize einfache Zellenconlmissuren dar. Nlit der Lösung der peripherischen Tlıeile des Dotters schıinen jene inneren Zellen später, von der zoma sich entfernend und ihren Fortsatz verlassend, ein selhststindiges Leben zu führen. Ich werde auf diese Verhältnisse noch einnal zurückiommen. wenn wir dic weitere Entwicklung des Eies verfolgen. So viel ist lilar, dass diese Processe im gewissen Sinne abnorm sind, weil sie auf eine Lösung der bereits fast reifen Eier hinzielen. Da an den schönsten, kräftigsten, jugendlichsten Katzen im November und December, also in vierten lis zehnten Lebensmonate, diese Erscheinungen ganz gewöhnlich von mir wahrgenonmen wurlen. so darf man wohl ohne Bedenken zugeben, dass wir den zeitlichen Verlauf und den Morlus dieser Processe demonstrirt haben, deren Existenz bereits durch andere Betrachtungren als zweifellos erliannt wurde. Es handelt sich also hier $1 \mathrm{~m}$ die eigenthümliche Thatsaclıe, (lass einc im Grunde krankhafte Erscheinung als nothwendiges Glied in das Bereich des gesunden Lehens sich einfiigt.

Ich wende mich endlich zu der Betrachtung ler Entwicklung des Eies. Wenn wir mit iem Keimflecke beginnen, den wir im Anfange als eine solicle ziemlich stark lichtbrechende Masse von nicht immer sehr regelmässiger Begrenzung kennen gelernt laben, so ist zu bemerken, dass dieser auf allen Stadien der Entwicklung constant vorhanden ist und leei dler Katze niemals doppelt vorkonmt. Derselbe wachst stetig und ninmt hierbei immer melır eine kugelförmige Gestalt an, bis er endlich ganz rund geworden ist. Beidieser Umwandlung rerandlert er seine Beschaffenheit derart, dass er ein feingranulirtes Wesen zeigt und dann ganz aussieht wie ein mit körnigem Protoplasma erfülltes Blasschen. Der Keimfleck scheint in den kleinen Eiern der Peripherie des Keimbläschens anzuliegen. Bei den reifen aber bezweifle ich, dass er sich anderswo als in der Mitte des Keimbläschens befinde. Denn bei den vielen reifen Katzeneiern, welche mir zu Gesicht gekommen sind, habe ich doch stets den Keimfleck nahe der Mitte des Keimbläschens und niemals am Rande desselben gesehen. Elsenso rerhielt es sich, wenn ich isolirte Keimblaschen untersuchte (s. Taf. IV. Fig. 10.). Wenn der Keimfleck dennoch excentrisch liegt, so müssen beim Katzenei Verhältnisse alınlich wie bei dem gellen Hühnerdotter vorhanden sein, denen zu Folge das Keimbläschen immer dieselbe Hemisphäre nach oben kehrt.

Das Keimbläschen des Katzeneies wächst ebenfalls bis zur Reife des Eies langsan voran, um schliesslich eine ganz bedeutende Grösse zu erreichen (s. Taf. V. Fig. 7.). Die Zeichnung ist genau 530 mal grösser als das Object. Das Keimblảschen rerindert seine optische Beschaffenheit niemals. Stets ist es wasserklar, ohne jede Spur von Körnchen, sehr scharf, wenn auch zart begrenzt und fast immer liugelrund. Essigsiure bringt in demselben Gerinnsel hervor, die ein Netzwerk bilden, so dass zuweilen der Anschein entsteht. als bestainde das Bläschen aus zelligen Răumen, was natürlich Täuschung ist. Nan sieht das Keimbläschen vom 
Katzenei fast immer gut und zwar am besten, wenn das Prajparat frisclı ist und in limmor aqueus untersucht wird. Nur in einer gewissen Periode, welche nahe der Bildung der jungen Follikel liegt, ist in dem starkglanzonden Ei das Keimblaschen oft schwer zu bemerken. Alkalien schwellen es sehr stark auf, Säuren scheinen es zu verkleinern. Das Keimblaschen liegt in entwickelteren Katzenei zienlich in der Mitte. So verhijlt es sich mit Gewissheit, so lange der dichter gewordene mit Fett erfülte Dotter nicht alle Beohachtung unmöglich macht. Dies geschieht aber erst, nachılem das Ei nahezu seine volliommene Grösse erreicht hat. Denı anfangs ist es dann noch durchsichtig. Niemals sah ich bei den wrösseren Eiern das Keimb) lischen am Rancle der zona liegen. Nienals habe ich in einem Eie, welehes die zono pellncila bereits besass, zwei Keimblischen wahrgenonmen. Ich bin überzeugh, dass dies nienals vorkommt.

Ich wende mich zu dem Dot ter. Ifier habe ich einige Verhảltnisse zu erörtern. die bis jetzt wenig oder gar nicht berichsichtigt worden und vielleicht doch von grosser Bedleutung sein mögen. So lange nänlich die Durchsichtigkeit des Eies eine Beobachtung uberhaupt gestattet - und dieser Zeitraum reicht fast über die ganze Entwiclilung - spricht sich constant uit höchster Entschiedenheit e.in Gegensatz in tem Verhalten der peripherischen und centralen Dotterschichten aus. Dies ist natülich bei den allerjüngsten Eiern, die eben nur verschwindende Protoplasmamengen besitzen, noch nicht zu bemerken. Der Unterschied tritt aber schon bei sehr kleinen Eiern auf, welche noch lieinem Grasf'schen Follikel anzugehören scheinen s. Taf. V. Fig. 4. u. 5.). Diese Verschiedenheit offenhart sich zuerst in einem hlassen ringförmigen Hof, der scharf umg̣renzt das Keimbläschen umgibt. Legt man die Eier in Oxalșiure. so tritt dieser Hof mil einem geringen Glanz hervor .s. Taf. V. Fig. 4. u. "̈. h. h.); ja es ist mir zu wiederholten Malen gelungen, an aufgerissenen Eiern das Keimblischen mit diesem scharf begrenzten Hofe herausschauen zu sehen (s. Taf. V. Fịg. ̈̈. h h.). Es sieht aus, als ob eine Zelle in einer Hutterzelle lage, in welcher sie durch freje Zellbildung entstanden wäre. Ich kann nicht zugeben, dass ich hier junge Grasr'sche Follikel vor mir ggehabt, bei denen ich etwa den anfangenden Dotter für den Hof des Keimblasschens gehalten und die membrama gramulosa irrthümlich als Dotter gedeutet hätte. Ich misste Alles, was ich geschen, verläugnen, wenn ich dies glauben sollte. Denn weder frisch noch nach Anwendung von Reagentien vermochte ich innerhall, dieses muthmasslichen Dotters die Spur einer Zelle oder eines molens zu locolsachten. Bei weiterem Wachsthum des Eies wird der innere Hof feinkörnig und rerliert die scharfe Ungrenzung, während umgekeht die Peripherie des Eies unter der Zellenmembran hỵalin und last so klar als das Keimblischen wird/s. Taf. III. Fiğ. 12.). Dies Präparat war ganz frisch und lag in hnunor aiquens. Hier konnte nun gar kein Zweifel bleiben, dass diese Bildungen keine Graaf'schen Follikel scien, weil eben heine Spur einer membroma grammlosa in den alsolut durchsichtigen peripherischen Theilen der Zelle wahrzunehmen war. 
Nachılem aber das Ei grösser geworden ist, hellı sich wieder der Hof un das Keimbläschen auf und scheint bei den grössten noch durchsichtigen Eiern liejne Körnchen mehr zu enthalten (s. Taf. V. Fig. 7.). Es ist also ein mehrmaliges Schwanken in dem Gegensat\% der Schichten während der Entwicklung zu beobachten, inden bald der innere Dotter, bald der äussere körnig orler lyalin ist. Was aber hierbei sehr hervorgehohen werden muss, das ist die ausserordentlich scharfe Begrenzung des breiten Ilofes um das Keimblaschen, so dass es oft aussieht als sei hier der Abschluss für eine hyaline Kugel, die in dem äusseren Dotter steckit. Dieser letztere hat sich aber mit Körnchen und Fettröpfchen erfiillt, welche mil zunehnmender Reife sich vermehren und oft an der Peripheric an schwächsten entwichelt sind (s. Taf. V. Fig. 7 u. 8.j. Dieser hörnige Dolter stellt gleichsam cine Fitterung der zona dar, in welcher die helle Kugel mit ihrem Keimbläschen sich befindet. Weil dieses Terhältuiss constant bei allen Eiern der Katze und des Kallses vorkommt, will ich einen Namen fur diese Dolterverschiedenheit vorschlagen, indem ich den Keimbläschenhof als in n e ren, den peripherischen körnigen Hof als äusseren Dotter bezeichne. Untersucht man genauer die Grenze zwischen beiden Dotterschichten, so findet man diese oft so scharf, dass man an die Existenz cincr Membran glauben möchte, welche aber wohl nicht vorhanden ist. Verfolgt man die Peripheric des inneren Dotters, so benterkt man, dass diese nicht ganz rund erscheint. sondern eine strahlige Besclıafenheit hat. Man sicht mit anderen Worten, wie Fortsäize mit scharfer $\Lambda$ bgrenzung, an verschiedenen doch nicht zahlreichen Stellen von den inneren Dotter ausgelien und bis zur zona pellucida reichen. Mlan könnte dies auch so auflassen, dass man sagte, es bestinde in Eic um das Keimbläschen eine Höhle, welche durch radiär verlaufende sich allmatlılich verjüngende Canäle mit der zona pellucida zu communiciren scheint (s. Taf. V. Fig T.).

Bei der Reifung des Eies füllt sich der Dotter inmer dichter mit Körnchen. wïhrend die Fettbläschen sehr gross werden, so dass das reife Katzenci ein ganz merkwürdiges Ansehen gewinnt. Ich glaube dasselbe hierdurch von allen anderen mir bekannt gewordenen Eiern der Säugethiere unterscheiden zu können. Diese grobe Fettemulsion mit zahllosen Dolterkörnchıen behindert aber die Einsicht in das Innere des Eies vollständig, so dass ich nicht zu sagren weiss, wie sich bei den vollkommen reifen Eiern das Keimblaschen, der Keimfleck und der innere Dotter verhält.

Die Verhältnisse, welche sich auf die beiden Dolterschichten bezielıen, halte ich darum für wichtig, weil es möglich wäire, dass nach der Befruchtung der äussere Dotter gelöst wird und die flüssige Masse bildet, welche den befruchteten, die Eihöhle nicht mehr ganz erfüllenden Dotter umgibt. Da der Bildungsdotter körnig ist, so nüsste man annehmen, dass auch der innere im reifen Zustancle wieder Granula besitzt. Wenn ein solches Verhatten. welches man nicht sicher widerlegen kann, wirklich vorhanden wäre, dann könnten wir auch dem Săugethierei einen Nahrungstotter zusprechen. Nan tarf nicht vergessen, dass die Existenz 
der Dotterschichten in Saugethierei unzweifelhaft ist und deshall Beachtung und Erklärung. verlangt. Man weiss aber ferner, dass auch der gelle Hülınerdotter wăhrend der Entwicklung der Keimhaut sich in sehr grosser. Venge zu einer klaren Fliissigkeit löst, welche die membrana vilelli aufbläht.

Ich wende mich endlich zur Erörterunğ der Eih üllen. Wir haben uns überzeugt, dass die primordialen Eier eine hyaline, sehr dünne und wie es nach Anwendung von Reagentien scheint, ziemlich feste Membran besitzen, die zuweilen wohl wegen feinster Fältchen eine schwache Längsstreifung zeigt. Nachdem der Grasf'sche Follikel sich gebildet liat, sieht man an wohlerhaltenen Präparaten das Ei von oft so scharfer Begrenzung, dass kein Grund vorhanden ist, die Existenz der Membran hier wieder in Abrede zu stellen. Aber wenn das Ei von nur Einer Zellenschiclıt in ganz jungen Follikeln iberzogen wird, haften diese Zellen innigst an der Oberflache der Jembran fest, während besonders nach Härtung in Oxalsăure die runden Dotter sellsst scharf umgrenzt aus der Eihaut fallen können.

Man weiss, dass später die membrana gramulosa auf der dicken derben Hülle des Eies festsitzt. Diese spătere Kapsel, zona pellucida genannt, grenzt sich zu jeder Zeit scharf gegen (len Dotter ab. Ueber ihre Entwicklung und Abstammung ist wenig bekannt. Ist die zona pellucida eine Verdickung des primordialen chorion? Wie entsteht diese Verdickung? Ist die sona pellucida eine secundäre Aullagerung auf das primordiale chorion? Wird diese Auflagerung oder Verdickung vom Ei odler den Zellen der membrana granulosa gebildet? Erhält sich das primordiale chorion neben der zona pellucida odler ist dies nicht der Fall?

Was ich von Thatsachen beizubringen habe ist Folgendes. Die zoua pellucida entsteht erst nachdem das Ei eine sehr bedeutende Grösse erlangt hat. Dass diese Bildung so spät anhebt, scheint seinen guten Grund darin zu finden, dass die Existenz einer so derhen Membran dem starken Wachsthum des Eies gewiss hinclerlich sein müsste.

Die zona pellucida entsteht nun nicht etwa so, dass eine weiche Masse von der späteren Diche jener zona sich un das Ei bildet. Ganz allmählich wird der anfangs sehr dünne Hof immer stäker und breiter. Stets ist seine innere Oberfläche sclıarf, seine äussere unregelmässig. Stets haften dieser hier und da Zellchen der membrana granulosa an. Gleichwohl ist es eine besondere Eigenthümlichkeit des Katzeneies, dass es sich leicht von allen Zellen isoliren lässt. Wann und mil welchen Reagentien man auch immer die zona pellucida untersuchen mag, so zeiğt sie doch niemals eine deutliche Structur. Im jüngeren Zustande und bei grösseres Dünne hat sie indessen eine beträchtlichere Dichte und bricht das Licht etwas stärker als später, wo sie klar wie Milchglas aussieht. Eine gewisse Differenzirung ist indessen der zona pellucilla nicht ganz ahzusprechen.

Zuweilen nämlich erscheint sie mit prächtiger concentrischer Schichtung, was ich nach Behandlung mit Eisenchlorid und ef was Chlorwasserstoffsaure beobachtete. Ob dieses Reagens 
constant so wirkt, weiss ich nicht zu sagen, weil ich dies zu untersuchen bisher noch keine Zeit gefunden habe.

Stets aber sicht man auch an den frischesten Präparaten, die in der Eierstoctisfliissigkeit, in humor aquens oder Albumin untersucht werden, eine zarte Streifung, welche in radiärer Richtung die zona pellucida durchsetzt.

Tritt man nun an die Beantwortungr der Frage heran, wie die zona entstelre, so kanu darauf auch von mir keine entscheidende Antwort gegeben werden. Es bleiben uns nur Wahrscheinlichkeitsgründe. Die Entstehung so dicker Zellhüllen ist in der thierischen Histiologie noch nicht mit hinreichender Genauigkeit studirt. Wohl aber war dies in dem Pflanzenreiche möglich. Hier stellt es sich als allgemeines Gesetz heraus, dass eine solche Menıloran durch Ablagerung auf die imnere Oberfläche entsteht, so dass also die äussersten Schichten die ältesten sind. Würde das Ei die zona pellucida bilden, so muisste sie von aussen nach imen wachsen. Stammt sie aber von den Zellen der membrana gramulosu, so wiirde sic von innen nach aussen, also gleichsam durch Auflagerung zunehmen. Welcher von beiden Vorgangen ist der wahısscheinlichere? Erwägt man, dass bei dem Säugethierei ein primordiales choriou von mir bewiesen wurde, dass die zona nach innen in stets gleicher Weise äusserst scharf sich abschliesst, während die äussere Oherfläche stets unregelmässig beschaffen erscheint und selten deutlich von den aufliegenden Zellen der membraua gramulosa sich aljgrenzt, so dürfte die Vorstellungy, dass die zona pellucida eine Bildung der membraua gramulosa sei, mehr fiur sich haben, als die gegenwärtige Annahme, welche sie als Product der Eithätigkeit auffasst. Denn fur die letztere Auffassung findet man in den Thatsachen gar keinen Anhalt. Nie konnte ich beim Siugethierei etwas sehen, was z. B. auf eine Umwandlung der peripherischen Dotterschichten in zona pellucida bezogen werden lionnte, wie das doch bei gewissen Thieren. z. B. den Gasteropoden nachgewiesen wurde. Nimmt nan unsere wahrscheinliche Auffassung an, so ist die zona pellucida ein Auflagerungsproduct und besteht entweder aus verwachsenen erl)lassten Zellen der membrana graminsa, oder würde durch Ausscheilung dieser Zellen, also indirect durch eine Unwandlung ilırer Substanz gebildet. Das Wesentliche in der Fıage ist offenbar, ob die zoua zu den Ei hinzugekommen ist oder einen genuinen Theil desselben darstellt.

Mit meiner Auffassung stimmt es gut ïlerein, dass wenigstens zu einer gewissen Zeit die radiären Streifen der zoma in die radiùr sich stellenden gestreckten Zellen der membramu granulosa sich fortsetzen. Weiss nan ferner, dass die radiären Zellen in die zona prellucida Fortsätze senden, so ist der Modus dargelegt, wie die Beziehung der Zellen der membrana grauulosa zu der :ona zu denken sei; es wirl gewiss, dass wenigstens einzelne Theile der zona durch Zellensulstanz gebildet sind, welche von der membranu gramulosa stanmit. Dieser Anschauung gemäss bestände die zoua aus dichtgedrängten stäbchen, die als abgeschnürte Enden rylindrischer Fortsätze ron Epithelialzellen des Follikels aufgefasst werlen nuissten. 
Ob nun das primordiale chorion persistirt oder zu Grunde geht, kann ich mit Gewissheit nicht entscheiden. Es scheint mir nur cine hohe innere Wahrscheinlichkeit dafiir vorzuliegen, dass jene primordiale Membran persistire. Ich weiss recht gut, dass viele ausgezeichnete Forscher beniilıt gewesen sind, diese nachzuweisen und ihre Nichtexistenz aus der zähen Gallertheschafłenheit des Dotters folıerten. Aher es könnte derselbe diese Beschaffenheit haben und das innere chovion doch vorhanden sein. Die Frage ist so schwierig. dass man auf Grund der directen Beobachtung vor der Hand zu keinem Schlusse berechtigt ist. Die Wahırscheinlichkeit der Persistenz liegt mir nämlich darin, dass wegen jener membranösen Zipfel, welche von einem Ei zum andern, von einem Follikel zu dem anderen wenigstens ul’* sprünglich sich hinspannen, mit Nothwendigkeit eine Miliropyle entstehen müsste, welche die zona pellucida und auch viclleicht die Zellen des discus durchsetzt. Jedenfalls begreift man ohne Weiteres, wie bei der Auflagerung der zona pellucida auf das Ei zwei ausgezeichnete Punkte da sein können. Dies sind die Abschnürungsstellen, welche, wenn sich die Zipfel noch einige Zeit erhalten, offen bleihen miissen. Die Entstehung der Mikropyle ist dann eine innere Nothwendigkeit, die von keinem Zufalle abhänght. So viel ist wenigstens klar, dass wenn zu der Zeit, wo die zona pellucida sich aushildet, die Zipfel noch existiren, sie durch die Ausdehnung des Eies allmählich immer mehr durch die zona gezogén werden. Sie muissen auf diese Weise für das Offenbleiben einer odler zweier Stellen sorgen. Wie ein cylindrischer Canal eine rundliche Höhlenwand allmählich bilden kann, sieht man ja recht schön an dem durfus Cuvieri, welcher in die Wand der Atrien bei der Entwicklung des Herzens aufgenommen wird.

Was lässt sich nun mit Rüchsicht auf die Mikropyle an der zoua pellucida normal erscheinender Eier darthun? - Iclı habe zuweilen bei der Katze im Profil einen Hohlraum zu sehen geglaubt, der als runder Canal die zona durchsetzte. Gegen diesen schien sich einer von jenen Canälen aus dem inneren Dotter zu erheben. Es sah aus, als führe das Loch unmittelbar in den inneren Dotter. Die Contouren der zoua pellucida sind sellsst nach aussen von solcher Zartheit, dass man einsieht, wie ein ebenso contourirter Canal, der sie durchsetzt, nur mit Schwierigkeit wahrgenommen werden kann. Zuweilen aber liegt in der muthmasslichen Mikropyle ein Zellenfortsatz, der nach innen und aussen mit einer entschiedenen Zelle zusammenhängt (s. Taf. V. Fig. 8.).

Dass das eine dieser Bläschen innerhall). das andere ausserhalb der sona pellucida sich befinden. daran kann bei der Grösse der Verhältnisse kein Zweifel sein. Es erhebt sich nur der Verdacht, ob dies Doppelblaschen nicht vielleicht das Keimbläschen des Eies ist: welches durch einen bei der Isolation dessellıen entstandenen Riss hinausschlüpfen wollte und plötzlich festgeklemmt wurde. In der That vermochte ich bei diesem Ei durch den dichten Dotter das Keimbläschen nicht zu erkennen. Ich kann aber mit Sicherheit behaupten, dass diese Erklärung nicht stichlıaltig ist. 
Denn einmal war an dem Ei von einem Risse oder einer Verletzung durchaus Nichts zu sehen. Es seigte die schärfsten Ungrenzungen auf allen Theilen der zona pellncida. Das Keimbläschen hat ferner bei der Katze nie zwei Kerne, die siclı aber in den Doppellılaschen finden. Ich habe sodann öfter eben solche Doppelblàschen, wenn auclı beträchtlich kleiner zu mehren in der zona stecken sehen. Ich konnte endlich diese Doppell,basclien an Eiern wahınehmen, in denen die Existenz des Keimbläschıens sehr deutlich zu constatiren war. Was die Variationen dieser eigenthümlichen Erscheinung betriflt, so habe ich zu bemerken, dass der Canal bald weiter, bald enger, bald länger, bald kürzer ist, während die Zwillingszzellen bald] grösser, bald kleiner ersclıeinen. Man sieht wohl melıre kleine Zwillingszellenpaare in derselben zona, niclıt aber zwei grosse wie die in der Taf. V. Figg. 6. 7 algavebildeten. Es sind mir endlich Fälle vorgekommen, wo in dem Canal der zoua eine grosse Zelle lag, die dicker als die mächtige zona pellucida war, innen den Dotter aufsass und nach aussen über dem äusseren Rand der zona hervorragte, um lier mit auderen gleichbeschaffenen schönen grossen Zcllen der membrana granulosa zusammenzuhängen (s. Taf. V. Fig. 7.). Dies Ei zeigte das Keimbläschen exquisit deutlich, sowie man auch den innern Dotter gewalırte, der sich hell bis zu der Zelle im Loche der zona pellucida hinzog. Diese verschiedenen Erscheinungen sind wolıl nur Entwicklungsphasen eines und desselben Processes. Man könnte sich denken, dass durclı Wachsthum der Zwillingszellen der Canal sich verkürzt und erweitert, um endlich zu schwinden, so dass die Oeffnung nun eine der Zwillingszellen aufnimmt. Da die innere nirgends befestigt wird als an der äusseren, diese aber mit den benachbarten Zellen des cumulus proligerus zusammengelittet ist, so hebt die äussere die innere empor, was noch durch die Dickenzunahme der zona befördert werden muss.

Wenn man zugibt, dass diese Verhältnisse normale sind, woran zu zweifeln wegen der Beschaffenheit der Eier kein Grund rorliegt, so folgt aus den gemeldeten Thatsachen jedenfalls, dass in der dicken derben Kapsel des Säugethiereies grössere Löcher oder Canäle demonstrirt werlen können. Diese sind ausreichend weit, um eine ganze Garbe von Spermatozoen lin. durchzulassen. Kann man ein grösseres Loch constatiren, so scheint es nur einfach vorhanden zu sein. Ich habe es wenigstens auf der entgegengesetzten Seite, was ich eigentlich erwartet lıătte, niemals mit Bestimmtheit wahrgenonmen. Darunı könnte es aber dochı existiren. Denı es gehört zur Wahruehnung oflenbar das grosse Gluick, dass bei den Isolationsversuchen gerade die Stellen des discus, an denen die beiden Zwillingspaare lıängen, gleichzeitig unverletzt bleiben.

Da nun die Spundzellen ein Ganzes mit denen der membrana gramilosa ausmaclien, welche gleichsam als Haut die äussere Oherfliche des Eies überziehen, so begrreift man, dass irgend eine Ursache, welche die Zellenschicht über dem Eie heht, zugleich den Spund mit lıervorzieht. 
Die Eier, hei welchen ich diese Thatsachen nachweisen konnte, besassen nahezu die Grösse der reifen. Weil nun eine orler nrehre Oefinungen in der derben zona pellucida zum Einlassen des männlichen Samens vorlanden sein müssen. so werden wir wohl nichts zu wagen haben, wenn wir dem entdeckten Loche seinen ihm zukommenden Namen Miliropyle geben, und es als das Samenthor des Eies auffassen.

Wenn die Zwillingszellen mit ilırer Commissur sich länger bis zum Bersten des Grata'sclien Follikels erlıalten sollten, so nuisste man eine Zerreissung der Commissur oder Lösung der äusseren oder inneren Zwillingszelle sich vorstellen, um das Entstelıen eines Loches zu begreifen. Fasst man aber die verschiedenen Erscheinumgen der Zwillingszellen nur als Entwicklungszustände auf, die nach demselben Ziele linsteuern, so enpfiehlt sich, meine ich, die früher vorgetragene Ansicht, durch grosse Einfachlıeit als die wahıscheinlichere. Der vollgültige Beweis wird erst durch Nachweis dersellıen Verhaltnisse bei dem aus dem Eierstocke entlassenen Eie geliefert werden können. Da aher bein Platzen des Follikels sich möglicherweise gleich der Spund aus der Mikropyle heht, so diufte vielleicht auch ferner der directe Nachweis derselben unmöglich sein.

Die wahrscheinlichste Erklärung der Miliropylenhildung ist die, sich vorzustellen, dass die in die zona vorstrebenden Sprossen der Zellen der membrama gramulosa sie an einer orler mehren Stellen. welche schwächer sincl, durchlırechen. Wir hahen die Vermuthung aufgestellt. dass diese Stellen mit dem Mlsschnüungspole zusammenfallen. Die Thatsache, dass in einem geschlossenen Parenchym eine Zelle in den Raum der anderen hineinwaichst, ist auch im Pflanzenreiche beobachtet. So bei Robimia riscosa (s. Scmacut, Der Baum. 1860. pg. 204.).

Ich labe endlich noch einige Bemerkungen ïber die Nethoden zu machen, mit Hülfe deren die Mikropyle zu denıonstriren ist. Wenn man die frischen Eierstöcke halbwächsiger Katzen wählt und feine Lamellen mit scharfen Nadeln sanft in hrmor aqueus zerzupft, so wird man dann fast immer mehrere Eier isolirt in der Flissigkeit finden. Nan sucht erst mit schwacher Vergrösserung die passenden stellen. Es ist eine sehr bemerkenswerthe Erscheinung. dass die Eier der Katze sich so leicht isoliren, so dass höclıstens ein paar Epithelzellen noch der Oberfäche der zona anhaften. Bei keinem von mir untersuchten Thiere sind diese Verhăltnisse so günstigr. Hierzu kommt dann ohendrein, dass man bei Untersuchung nicht alter, sondern halbwächsiger Katzen oft eine ganze Schaar ron Eiern isolirt findet, unter denen einzelne sind, an denen man hei einiger Aufnerksamkeit die in der zoma steckenden Zwillinge gewahren wird. Wenn viele die Erschoinung nicht zeigen, so ist dies einmal aus ihrer Lagerung und sodann dadurclı zu erklären, dass nit der Entfernung der Zellen der membrana granulosa ron der sona bei den Isolationsversuchen auch oft die Zwillingszellen zerstört werden. -

Ich habe somit die wichtigsten mir bekannt gewordenen Thatsachen üloer das Leben 
im Eierstocke der jungen Katzen geschildert. Spaiter werde ich noch einmal bei der Betrachtung der Thätiglieit in den Ovarien älterer Thiere auf dasselbe Thier zurückliommen.

Da ich diesem die genaueste Kenntniss vieler wichtiger Thatsachen ühor dic Oogrenese verdanke, so ist es wohl hier am Platze, zum Schlısse unsern Blick zu einem Vergleiche des Săugethiereies mit den Eiern oder weiblichen Keimen der anderen Organismen zu wenden.

Richtet unan sein Augenmerk auf die Pflanzen, so gestalten sich die Verlualtunisse bei den Kryptogamen sehr einfach, indem das Ei stets eine evidente Zelle reprisentirt. Bei deu Phanerogamen ist ohne Bedenken das sogenannte (allerdings doppelt vorhandene) Keimbläs(hen als der weibliche Keim aufzufassen, welcher die entschiedensten Charaktere einer Zelle an sich trägt. Fuxke erklärt den Embryosack als das Analogon der thierischen Eier (Physsiologie III. p. 4.2.). Der Embryosack der phaneroganıen Pflanze ist das Organ, in welchem das Ei, d. I. diejenige Zelle, aus welcher der Embryo sich aufbaut, entsteht. Dasjenigge Organ, in denen das Säugethierei gebildet wird, sind die Schläuche, welche vor der Hand nicht nit dem Embryosack der Phanerogamen parallelisirt werden dürfen. Denı es ist nicht erwiesen, dass jerler von ihnen das Product einer Mutterzelle ist, wie dies für den Embryosack mit allen seinen Theilen Geltung hat. Man kann auch den Grasf'schen Follikel mit seinem ganzen Inhalte nicht. dem Embryosacke der Phanerogamen vergleichen, weil jener nicht aus e in er Zelle seine Abstammung herleitet, und nicht das Bildungsorgan des Eies ist, das er enthailt. Wenn also auch der Embryosack der höheren Pflanzen das Ei bildet, so ist el darum doch sclhst das Ei nichıl. Ausserdem ist das Ei stets Eine Zelle, der Embryosack stets ein aus melıren Zellen hestehendes Organ. Nur wenn es wahr wảe, dass das reife Saugethierei, nachden sein Keimbluschen verschwunden ist, durch freie Zellbildung ein neues erzeugt, olıne dass hierhei die Befruchtung im Spiele ist, würde der Vergleich mit dem Embryosack sich rechtfertigen lassen. Wer möclıte aber für diese Thatsachen die Bürgschaft übernehmen? Ein Unstand, der ferner gar nichı ohne Gewicht bei der vorliegenden Frage ist, liegt in der Existen\% zweier Keimblischen in deu Embryosack, die oft von einer Membran umschlossen sind. Darum wảre es möğlich, dass dlieso Membran die ursprüngliche Mutterzelle andeutete, aus welcher jene ovula entstinden.

Ich werde später Verhältnisse zu besprechen haben, welche dem Fivik'sclien Vergleiche einige Berechtigung geben. Doch kannte Froke diese Verhiltnisse nicht und konute sie darum nicht im Augre haben.

Vergleicht man das Säugethierei mit den Eiern anderer Thiere, so ist keinerlei Schwierigkeit vorhanden. In Wahrheit iberrascht uns eine fast monotone Gesetzmässigkeit. Stets ist fler Bildungsdotter mit dem Keimblischen eine Zelle; stets lraben sogar diese einzelnen Theile aller thierischen Eier eine grosse Uebereinstimmung darin, dass der Keimfleck solide, das Keimbläschen wasserklar, der Dotter granulirt ist. Nur wenn man die Auflagerungen lietrachtet, welche die Natur den verschiedenen Eiern mitgilh, wird der Vergleich schwierig. Es 
ist das selbstverständlich. Denn eben die Verschiedenheit beweist, dass es sich um Variationen eines Thema's handelt, welches den verschiedenartigen Lebensverhältnissen der Thiere angepasst wird.

Von jeher hat die Vergleichung des Vogeleies mit dem Säugethierei die Forscher viel heschaffligt und man ist heute uber viele in gewissen Sinne allerdings unwesentliche Punkte noch durchaus nicht in Klaren.

Meine Ansicht in dieser Frage greht dahin, dass, so lange die Entwicklungsgeschichte des Vogeleies wie bis jetzt so gut wie unbeliannt ist, jerle Discussion illusorisch erscheint. Denn was nuitzen luftige Theorien, welche der nachste Tag mit einigen Thatsachen iiber den Haufen bläst. - Wer auf Grund eigner Untersuchungen sich ein überzeugendes Urtheil verschafft hat, für den licgt natiirlich die Sache anders.

In Grossen und Ganzen lässt sich aus allen diesen Betrachtungen aber dennoch der befriedigende Schluss ziehen, dass die wesentlichen Theile der Eier in der gesammten Thierwelt unfehlbar dieselben sind.

\section{II I.}

Die Untersuchungen, welche ich bis dahin mitgetheilt habe, sind die vollstandigsten. welche-ich besitze. Man hat bemerkt, wie gewaltig dic Metamorphosen sind, welche das ächte Driisengewebe des Eierstocks zu durchlaufen hat, wie scheinhar verschieden die Bildungen sich erweisen, welche in den Eierstöcken verschiedener Süugethiere vorkommen. Demgemäss ist es ohne Weiteres begreiflich, dass man kein durchschlagendes Urtheil aus einer beschrankten Zahl von Präparaten sich bilden kann; sondern nur eine bis in die feinsten Einzelheiten dlurchgeführte Forschung gibt vollgültigen Anhalt. Was ich iiber den Hund mitzutheilen habe. stiitzt sich noch auf ausführlichere Untersuchungen, die aber älter sind, als diejenigen bei Katze und Kalb, weshalls sie anch mit andern vielleicht weniger guten Untersuchungsflüssigkeiten angestellt wurden.

Ich behandelte den jungen Hunderierstock mit Holzessig ron mittlerer Concentration. Leicht sieht man dann die langen feingranulirten Schlacuche, welche von Plattenepithelien besetzt gefunden wurden, das aus kleinen rundlichen Zellchen mit Kernen besteht und keine besonderen weiteren Eigenthümlichkeiten darbietet.

Hier und da sieht man diese Schläuche varikös angescliwollen nit oft sehr starken Einschnïrungen. In jeder Erweiterung bemerkt man eine rmolliche, feingranulirte, mit einem 
hellen Bläschen versehene Zelle, von der es nicht zweifellıft sein hann, dass sie das Ei des jungen in Abschnürung begriffenen Follikels darstellt. Die in deı dünneren Sclıăuclien hintereinander liegenden Eier hăngen sehr innig zusammen, so dass der junge Hunı ganz besonders geeignet zur Demonstration dieser Bildungen ist. Inden iclı ganz so wie bei dem Katzenovarium verfuhr, verschaflte ich mir die Elemente (ler Drüsensclılauche (s. Taf. V. Fig. I 2. u. b. c.). Hier sieht man sechs zusammenhängende Eier, welche aber etwas anders als die von der Katze oder dem Kalbe aussehen. Sie erscheinen nicht mit dunklen Körnchen gefült und hahen einen schwachen Glanz; das Protoplasma ist, ohne sehr grannlirt zu sein. doch so diclıt, dass die sichere Wahrnehmung des Keimfleckes, nicht des Keimbläschens gestört wird.

An diesen Eiern habe ich nun auch wiedler die eigentlümlichen Bewegungen greselıen, was darum besonders instructiv war, weil sich eine Beziehung der Bewegung zur Langasachse der Kette im Allgemeinen wenigstens für die Lage der an den Zellen entstehenden Stricturen herausstellte. Die scharfe Einschniirung, die aber oft sehr rasch verschwand und nicht so nachhaltig wie bei den Katzeneiern war, lag immer nahezu senkrecht zur Längsaclıse der Eikette. Höchst interessant erschien es, wie die Strictur die Stelle, wo die Eier zusanmenhängen, bis auf ein Minimum verengte, so dass ich jeden Augenblick erwartete, es würrle hier die Kette zerbrechen. Das geschah aber nicht, sondern obwohl nur noch eine punktförmige Berührung ibrig geblieben war, erschlaffte die Strictur dann wieder, so dass nachher die Eier abermals durch recht breite Flächen mit cinander zusammenhingen, aber stets varicös eingeschnürt blieben. - Auch an isolirten Zellen habe ich diesen ähnliche Bewegrungen wahrgenommen.

Aus alledem ergibt sich demgemäss, dass bei dem Hunde die allgemeinen Bildungsgesetze der Eier und GraAf'schen Follikel dieselben sein müssen wie bei den vorher betrachteten Thieren.

Ausser dem Kalbe, der Katze und dem Hunde habe ich noch die Eierstöcke anderer Thiere, besonders die des Kaninchens und des Fuchses untersucht und bei diesen zweifellose Driisenschläuche nachzuweisen vermocht. Da es mir aber bisher an Zeit gefehlt hat, eine bis in die äussersten Details durchgeführte Entwicklungsgeschichte des ächten Drüsengewebes herzustellen, so glaube ich, in Hinblick auf die vielfachen Metamorphosen des Ovarialgewebes es vorziehen zu müssen, wenn ich diese Untersuchungsfragmente hier nicht bespreche. 


\section{Der Mensch.}

Brtrotu sagt in einem Aufsatz über fötales Druisengewebe in Schilddrüsengeschwülsten (s. Mrlera's Archiv für Anatomie und Physiologie. 1836. S. I44.) : „Ich kann nicht unterlassen, hier noch zu erwilınen, dass auch an Eierstocksgeschwiilsten wahrscheinlich ähnliche Gebilde wie die beschriebenen vorkommen, was ich mit um so grösserer Bestimmtheit hehaupte, als ich noch ror Kurzem, bei einem frischen kaum viermonatlichen weiblichen menschlichen Fötus die Entwicklung der Grask'schen Follikel durch Alsschnürung von langen cylindrischen Schläuchen auf?s unzweifelhafteste heol,achtete habe." Die hier von Bubrotı gemachten ausserst wichtigen Angaben stimmen durchaus mit dem überein, was wir bis dahin bei Săıgethieren so verschiedener Ordnung auf das Sicherste haben ernitteln können. Es diurfte also keinem Zweifel unterliegen, dass bei dem Menschen die Bildung der Eier ganz denselhen Gesetzen gehorcht, wie sie ron mir fiur die Säugethiere festgestellt worden sind. Mir sellost ist es leider hier in Bonn nicht gelungen, mir einen frischen menschlichen Fötus ron dem angegebenen Alter zu verschaffen. Einmal labe ich den Eierstock eines siebenjahligen Maidchens zur Untersuchung erinalten, olıne dass iclı in Stande gewesen wảre, efwas anderes als junge Grasf'sche Follikel, welche durch ziemlich reichliches Stroma geschieden waren, nachzuweisen. Freilich muss ich bemerken, dass ich zu der Zeit dieser Untersuchung noch nicht so vertraut ınit den Lösungen war, welche ain hesten zu der Darstellung des jungen Dritsengewebes benutzt werden. Nichts desto weniger schliesse ich aus der Entfernung der kleinen Follikel von einander, in Uebereinstimmung mit den bei der Katze gemachten Erfahrungen, dass der Abschnuirungsprocess sowie die Eibildung zur Zeit meiner Untersuchung also im siebenten Lebensjahre längst alggeschlossen ist. Als bemerkenswerth hebe ich aus meinen Untersuchungen an den menschlichen Ovarien hervor, dass ich nirgends Häufchen kleiner gleichbeschaffener Zellen wahırnehmen konnte. Stets liess sich in den jüngsten Follikein das Ei nit Dotter, Keimbläschen und Keiunfeck bemerken. Niemals war die centrale Zelle des jungen Follikels denen der mem- 
brana granulosa gleichbeschaffen. Der Zeitraum der Follikel- und Eireifung, welcher bei der Katze nicht ganz ein Jahr dauert, erstreckt sich beim Menschen von den Perioden des intrauterinen Lebens bis zum vierzehnten, fünfzehnten, ja zwanzigsten Lebensjahr. An keiner Stelle fincle ich aufinerksam gemacht auf die unvergleichlich wunderbare Thatsache, dass ein menschliches Ei vierzehn, ja zwanzig Jahre braucht, bis es von den ersten Anfangen ausgehend den Zustand der Reife erreicht. Dennoch ist das menschliche Ei wie das der Säugethiere ein Gebilde, welches nur unter den günstigsten Verhälnissen bei schärfster Aufmerksamkeit von dem unlsewaffneten Auge noch wahrgenommen werden kann. Diese Thatsache erscheint um so bedeutungsvoller, wenn man bedenkt, dass nach der Befruchtung der menschliche Körper mit fast allen seinen wesentlichen Bestandtheilen in vielleicht weniger als vier Wochen sich aus dem Ei entwickelt hat. Es ist nun sehr schwierig zu bestimmen, ob in der Zeit des mannbaren Alters die Geschwindigkeit der Entwicklung der Eier eine grössere sei. Jedenfalls hat es etwas Paradoxes sich vorzustellen, dass die Eier des Menschen und mancher Thiere das eine Mal Jahrzehende gebrauchen bis sie reifen, das andere Mal aber in ganz kurzer Zeit sich entwickeln. Unzweifelhaft liegt hierin eine grosse Verschiedenheit der weiblichen von der männlichen Organisation, indem der Same sich in ausserordentlich kurzer Zeit wieder zu erzeugen vermag. Vielleicht ist dies die Ursache, warum den Männern die geschlechtliche Ausschweifung so gefahrlich ist. Denn bei ihnen ist die Menge des gebildeten Zeugungsmateriales ausserdem noch indirect der Willkür unterworfen, weil bald nach jeder Samenentleerung neues Secret den Hoden erfüllt. 


\section{Der Eierstock der erwachsenen Thiere.}

Durch die Untersuchung der Ovarien junger Sängethiere haben wir eine Reihe von Thatsachen kennen gelernt, welche uns einen wichtigen Fingerzeig für die Erforschung des Bildungslebens an die Hand geben, in sofern sich das letztere auf die Neubildung der Eier und GraAf'schen Follikel bezieht. Es ist von uns festgestellt worden, rlass die Entwicklung der Eier in den Schläuchen, so wie die Abschnürung der Grasf'schen Follikel bei Katzen auf einen Zeitraum von etwa drei Wochen nach der Geburt sich beschränkt. Wenigstens besitzen die Drüsenmassen zu dieser Zeit denjenigen Grad der Derbheit, welcher sie der mikroskopischen Untersuchung zugänglich macht. Wenn es also wahırscheinlich oder doch möglich ist, dass bei dem erwachsenen Thiere die Neubildıng der Eier unıl Follikel mit noch grösserer Geschwindigkeit von Statten geht, so liegt es auf ler Hand, dass ein ganz besonderes Glück dazu gehört, die Ovarien nicht blos gerade in der richtigen Periode zu treffen, sondern auch die geeignete Stelle des Organes für die Untersuchung vor sich zu bekommen. Die meisten Forscher pflegten bisher, wenn sie die Entstehung der männlichen und weiblichen Keime ermilteln wollten, die Zeit der Brunst zu wăhlen. Eine einfache Ueberlegung zeigt aber, dass dieser Gesichtspunkt im Allgemeinen nicht gerechtfertigt werden kann. Niemand wird daran zweifeln, dass die wahre Bedeutung der Brunst. sich auf die Begattung beziehe, d. h. auf die Befruchtung des reifen Eies. Wie wenig die Bildıng der jungen Eier so wie der Grasf'schen Follikel mit der Brunst zu thun hat, gelıt ja bereits mit eindringlicher Klarheit daraus hervor, dass die Früchte in Mutterleibe schon die Keime erzeugen. Es kann also wohl einmal die Neubildung der Eier mit der Brunst zusammenfallen. Eine Nothwendigkeit liegt aber hierfür offenbar nicht vor.

Leider habe ich bei diesen so schwierigen und so zeitraubenden sich iber mehre Jahre erstreckendeu Untersuchungen noch nicht Musse gefunden, um bei ein und demselben erwachsenen Thiere Monat für Monat den Eierstock auf die periodischen Veränderungen seines Drïsengewebes griindlichst zu durchforschen. 
Gleichwohl verschaffte ich mir nach Untersuchung alter Katzen und Hunde die sichere Gewissheit, dass nicht blos Eier und Grasf' sche Follikel neu gebildet worden, sondern dass auch der Modus der Entwicklung von dem bei jungen Thieren beobachteten nicht rerschieden ist.

Zur Begründung dieses Ausspruches habe ich folgende Thatsache hervorzuhelen. Bei einer erwachsenen Katze, welche vor einigen Tagen (Ende April) geworfen hatte, fand ich den Eierstock sehr durchtränkt mit parenchymatöser Flissigkeit. Nach Anfertigung von Schnitten, die mit dem Rasirmesser erhalten waren, liessen sich die einzelnen Gewebselenente des Organes in humor aqueus mit ungewöhnlicher Leichtigkeit nach den bekannten Methoden isoliren. Hierbei erhielt ich viele Praparate, von denen ich eines, welches am instructivsten war, in Taf. IV. Fig. 3, mittheile. Um die Kernbildungen der Zellen schärfer wahrzunehmen, batte ich zu der Untersuchungsflüssigkeit des humor aqueus noch einen Tropfen verdiunnter Essigsäure fliessen lassen. Das Präparat war vollkommen isolirt. Nirgends haftete ihm eine Bindegewebefaser oder dergleichen Aehnliches an. Da Prof. Scinacnt zufällig in mein Arbeitszinmer kam, nachdem ich diese wichtige Bildung dargestellt hatte, ersuchte ich denselben, dieselbe zu zeiclsnen, ohne ihm irgend einen Aufschluss über die Bedeutung zu geben. Nach seiner Darstellung, welche, wie das bei einem so erfahrenen Forscher nicht anders zu erwarten ist, sehr naturgetreu vermittelst der Camera ausgeführt wurde, habe ich den Stich anfertigen lassen. Auf diese Weise ist es möglich gewesen, dass meine Vorstellung über die Deutung des Präparates bei der Zeichnung gar keinen Einfluss ausgeübt hat.

An diesem Präparate bemerkt man mit der vollendetsten Sicherheit, dass die jungen Graaf'schen Follikel, welche sich meist innig berühren, perlschnurartig in einem durchsichtigen structurlosen Schlauche stecken. Ausgezeichnet schön sicht man diese Memlyan besonders an zwei Stellen. An der einen spannt sie sich durchsichtig von einem Follikel auf den anderen etwas entfernteren hin (s. Taf. IV. Fig. 3. p.). An der anderen Stelle beobachtet man die ïber den abgelösten Follikel hinaus ragenden durchsichtigen structurlosen Fetzen.

Die hier vorliegende Bildung ist nun absolut dieselbe, wie man sie aus den Eierstöcken junger Kätzchen drei bis vier Wochen nach der Geburt ganz gewöhnlich erhält.

Da man aber bei halbwächsigen Katzen stets unsonst nach so jungen Follikeln, die in langen Ketten zusammenhängen, suchen wird, indem bei ihnen nur ältere Zustände sich vorfinden, so kann es keinen Zweifel unterliegen, dass bei erwachsenen Katzen zu gewissen Zeiten junge Eier und Follikel sich auf's Neue erzeugen. Denkt man nun daran, dass eine Bildung, wie die vorliegende Follikelkette bei jungen Thieren sich in etwa drei Wochen aus den Schläuchen erzeugt, so würde der April. vielleicht sogar der März die Zeit andeuten, in welcher die vorliegenden Follikelketten zuerst angelegt worden wären. Hieraus würde also die \%eil des Frühjahrs sich als diejenige ergeben, in welcher die Neuhildung der ächten Geschlechts- 
organe der weiblichen Katze zweifellos vorhanden ist. Da nun wahrend des Sommers zwei Epochen der Eireifung im Allgemeinen bei der Katze bemerkt werden, so ist die Möglichkeit nicht in Abrede zu stellen, dass auch zweimal eine Neuentwichlung von Eiern und Follikeln rorkommt. Wenn ich erwachsene Katzen in October, November und December untersuchte, so fand ich die Follikel durch Bindegewebe geschieden. In diese Zeit scheint also die Neubildung der Eier und Follikel nicht zu fallen. Steht es aber fest, dass bei jungen Thieren nur unmittelbar nach der Geluurt, bei erwachsenen nur während des Frühlings und Sommers ganz junges Drisengewebe nachgewiesen werden kann, so folgt hieraus mit Bestimmtheit, dass wie bei den Pflanzen periodisch die Blïthen erscheinen, so auch bei den Säugethieren periodisch die eigentlichen Ovarien entstehen, um die Keime zu bilden, welche zu ihrer vollkommenen Reife oft sehr lange Zeit beanspruchen. Ich habe allerdings den Modus der Neubildungen von Eiern und Grasf'schen Follikeln bei der erwachsenen Katze bis jetzt in allen Stadien noch nicht verfolgen können. Wenn es von vorn herein im höchsten Gradle wahrscheinlich ist, dass die hier geltenden Entwicklungsgesetze dieselben wie bei jungen Thieren sein werden, so erhebt sich dies fast zur Gewissheit, da es mir nachzuweisen gelungen ist, dass bei erwachsenen Hündinnen während des Sommers Follikel durch Abschnürung cylindrischer Schlauche in der bekannten Weise gebildet werden.

Wenden wir uns zur Betrachtung der Ovarien erwachsener Iliindinnen, welche in der wärmeren Jahreszeit von mir untersucht worden sind. Es waren dieses allerdings meine ersten Untersuchungen, welche ich gern in manchen Beziehungen weiter durchgeführt wünschen möchte. Aber dieser Gegenstand ist von einer so ausserordentlichen Ausdehnung und beansprucht so viel oft schwer zu beschaffendes Material und Zeit, dass ich noch einige Jahre hătte verbringen können, ehe die Publication möglich greworden wäre.

Entnimmt man den Eierstock aus dem Abdomen der soehen getödteten Hündin und benutzt den humor aqueus desselben Thieres als Untersuchungsfliissigkeit, so gewahrt man an Schnitten, welche von der Oberfläche der Ovarien entnommen sind, die starkglänzenden etwas grünlich gefärbten Drisenschlänche. Es ist nothwendig, dass man auch hier durch drei niedrige auf der Objectplatte angebrachte Wachströpfchen den Druck des Deckglases abhalte. Die Drüsensclıläuche verlaufen in verschiedenen Richtungen und sind deshalb bald schief, bald quer, bald der Länge nach in ein und derselben Lamelle durchschnitten. Mit ausserster Schärfe grenzen sich die starliglänzenden Cylinder gegen das Stroma ab. Bei genauerer Betrachtung bemerkt man, so lange frische Präparate untersucht werden, einen sowohl an Quer- als Lảngsschnitten nit eminenter Schärfe hervortretenden wasserklaren Canal. Die ausserordentliche Evidenz dieses Canales könnte die Vermuthung nahe legen, dass es sich hier um ein Blutgefäss. nicht abej um einen Driisenschlauch handele. Obwohl ich mit Sicherheit weiss, dass kein IIistiologe, der auch nur mit einem Blick diese Bildung gesehen hat, an ein Blutgefass denken 
kann, so will ich denuoch die speciellen Gründe auscinandersetzen, welche Jedem beweisend sein werden.

Sehr häufig habe ich Präparate vor mir gehabt, deren Blutgefasse stark mit Blut crfiillt waren, ohne dass in dem Canal der glänzenden Schläuclie, deren Wand von der des Blutçefässes durchaus verschieden ist, die Spur eines Blutkörperchens walırgenommen werden honnte. Sodann sieht man sowohl an Längs- als Querschnitten, wie die Epithelialggelsilde weit in deu Canal vorspringen, so dass im Querschnitt der Canal als vielstrahliger Schllitz erscheint. Dio hier erscheinenden Buchten sind oft sehr tief (s. Taf. V. Fig. 10.b.). Solch einen Anblick garwährt kein durchschnittenes Blıtgefìss.

Wenn man nun die Wand der Schläuche betrachtet und ihre Dicke mit dem Querschnitl des gesammten lubus vergleicht, so ergilıt sich, dass man es nit einer Arterie zu thun haloen witrde, falls es sich um ein Blutgefass handeln sollte. An der Arterie sieht man aber, wenn der frische Eierstocksschnitt mit humor aqueus behandelt worden ist, die ringförmigen Muslielfasern einzeln mit ausgezeichneter Klarheil. Längs des Arteriencanals erscheint das streifige Gewebe der Intima. Niemals grenzt sich die Arterie sellsst nach aussen scharf gegen das Stroma ab. Nichts von alledem gilt für die Wand des Drüsenschlauches.

Nehme ich hinzu, dass an einzelnen Stellen des Canales zuweilen ein oder sogar nuelıe grosse Zellen bemerkt werden, die alle Charaktere thierischıe Eier an sich tragen, nämlich feinkörniges Protoplasma, rundes scharfbegrenztes wasserklares Kerublischen mit einem soliden. stark lichtbrechenden Körperchen, so wird es vollionmen unhegreillich, wie es sich bei den frisch untersuchten Präparaten um ein Blutgefäss handeln sollte.

Man bemerkt nun weiter, wie an solchen Stellen, welche einen kleinen IJaufen von Eiern enthalten, die glånzende Epithelialwand zu einem spitzen Hügel sich nach dem Canalraum erhebt, zwischen die Eier wie ein keilförmiger Fortsatz eindringt, um dieselben von einander zu sondern. So lange die Prảparate frisclı sind und in hmuor aqueus untersucht werden, gibt es gar kein schöneres Object, un die aus der Canalwand aussprossenden, die Eier trennenden Scheidewände gleichsam in flagranti zu beobachten. An Querschnitten der Schläuche habe ich mich auch überzeugt, dass bis vier und vielleicht mehr Eier auf ein und (lemselben Querschnitt des Canals gelagert sein können.

Nichts desto weniger bemerkt man in den Schläuchen erwachsener Hunde die Eier wenig zahlreich. Es findet demgenı̉ss hier alıgemein ein Verlıăltuiss statt, wie man es älınlich bei manchen dünnen Schläuchen des Kalbes wahrnimnı, in denen nur hier und da durch grössere Zwischenräume getrennt einzelne Eier bemerkit werden (s. Taf. II. Fig. 4.).

Nachdem die Schcidewände zwischen den Eiern sich ausgel)ildet haben, erscheint der Schlauch varikös angeschwollen. Bei dem Hunde bemerkte ich nun, dass die Eluenen, in wolchen die später erfolgte Alsschnürung vor sich gelıt, selır oft schief, d. h. nicht rechtwinklig 
zur Achse des Schlauches liegen. Waren die Eier in dem Canale ziemlich dicht lintereinander aufgereiht, so entsteht später ein mit abwechselnden Erweiterungen und Verengerungen versehener Drusenschlauch. Liegen aber die Eier weit entfernt von einander, so entwickelt sich haufig in dem blinden inneren Ende des Ovarientuluus der Graaf'sche Follikel, ohne sich von der Drüsenröhre zu sondern. Diese läuft meist in der Richtung nach der Oberfläche des Ovariums weiter. Auf diese Weise erklären sich die langgestielten rundköpfigen Kolben, welche man bei den erwachsenen Hündinnen besonders an der Grenze zwischen der derbfaserigen Ovarialrinde und dem weicheren Ilark des Ovariums wahrnimmt. Die Stiele dieser Kolben gehen im Allgemeinen nach der Oberflache des Eierstockes, die runden Köpfe aber, welche die Eier enthalten, sind in den weicheren Kern gebettet und können sich also leicht ausdelınen (s. Taf. V. Fig. 11.).

So lange man mit humor aqueus untersucht, zeigen die Wände der Drüsenschläuche einen so starken Glanz, dlass sic fast wie eine homogene Masse erscheinen, in welcher sich die Epithelialzellen nicht deutlich von einander abgrenzen. Die ganze Erscheinung ist durchaus mit jenem glänzenden Ringe übereinstimmend, welcher in einer gewissen Periode die membrana gromulosa des jungen Katzenfollikels darstellt. Wenn man aber hier verdiunnte Essigsaure anwendet, so treten die meist kleinen rundlichen kernhaltigen Epithelialzellen in der Wand des Drüsenschlauches mit vollkommener Deutlichkeit hervor (s. Taf. V. Fig. 9., Zur Wahrnehmung der Epithelialzellen der Drüsenschläuche hat mir oft folgende Methode sehr gute Dienste gethan. Der frische Schnitt eines Eierstockes wurde auf dem Objectglas so lange init verdunnter Essigsaure immer ernenert behandelt, bis die anfänglich entstandene Trübung des Gewebes wieder vollkommen verschwunden war. Setzt man hierauf allnı̈hlich Ammoniak hinzu, so erscheinen in dem Augenblick, wo der Neutralilitspunkt überschritten worden und die Untersuchungsflüssigkeit alkalisch reagirt, sämmtliche Schläuche mit grrosser Schärfe und eigenthümlich gelbgrünlicher Färbung, welche das Stroma durchaus nicht darbietet. Ich habe diese eigenthümliche Reaction auch an dem jungen Drijsengewebe des Eierstoches der Katze wahraenommen. Am auffallendsten beobachtet man die Erscheinung an den jungen in Abschnürung begriffenen Follikeln. während die allerjüngsten Drüsenschliuche noch nichts davon zeigen. Es ist bemerkenswerth, dass ein solches Präparat auch in Glycerin auflowahnt jene Färbung beibehält. so dass (lann die gelbgrünen Drüsenmassen vor dem erblassten Stroma stark hervortreten und sehr zierliche Bilder geben. Ich habe diese Reaction allerdings nicht in der Weise variirt, dass ich die Essigsäure bei dem Versuch durch Salpetersäure ersetzte. Nichts desto weniger vermuthe ich, lass es sich hier $u m$ eine Reaction handelt, welche mit der bei Bildung des Xanthoproteïns beobachteten verwandt ist.

Als wichtig in der uns hier besclataftigenden Frage habe ich noch zu erwähnen, dass die schlauche oft in ausserordentlich feine Zipfel sich fortsetzen, deren Querschnitt mit dem dunkel- 
randiger Nervenfasern von einerlei Ordnung ist. Auch bei dem Orarium der erwachsenen Hündin liegen die jüngsten Drüsenelemente im Allgemeinen der Oberfläclıe des Eierstockes näher als die älteren. Ausserden glaube ich einen Zusammenhang der Schlatuche mit dem mächtigen Epithel, welches die Oberfläche des Eierstockes überzieht, auch bei der Hündin wahıgenommen zu haben. Als ich wăhrend eines Sommers diese Untersuchungen bei crwachsenen Hündinnen anstellte, welche zum Theil sicher schon geworfen lratten, fand ich bei den einen die reichsten Schlauchmengen mit spärlichen Follikeln, bei anderen nur variköse, also in $\mathrm{Al}$ )schnürung begriffene gleichbeschaffene Schläuche, bei noch anderen nur Follikel und keine Schläuche. Hieraus folgt nit Nothwendigkeit, dass auch bei dem Hunde periodisch die tulılösen Ovarien entstehen, um die Eier zu bilden und bald zur Erzeugung der Graaf'sclıen Follikel verbraucht $\mathrm{zu}$ werden.

Ausser diesen Thieren untersuchte ich noch besonders die Kuh und das Kaninchen, bei welchen ich mit kleinzelligem Plattenepithel besetzte cylindrische Bildungen fand, in denen hie und da grössere Zellen wahrgenommen wurden, welche die wesentlichen Charalitere thierischer Eier an sich trugen.

Ein einziges Mal ist es mir vergönnt gewesen, den frischen Eierstock eines jungen gesunden Mädchens, welches nach der Entbindung an Verblutung gestorben war, für die Untersuchung zu erhalten. Ich vermochte zu dieser Zeit, in der ich noch nicht die hinreichende Erfahrung hatte, in den schönen Ovarien nur sehr zahlreiche Mengen Graar'scher Follikel, aber keine Schläuche wahrzunehmen. Entweder sind mir die letzteren entgangen, was bei ilırer ausserordentlichen Zartheit und Durchsichtigkeit nicht unmöglich ist, oder es befand sich das Ovarium gerade nicht in der richtigen Phase der Entwicklung. Ich kann nicht daran zweifeln, dass auch heim erwachsenen menschlichen Weibe die Schläuche noch demonstrirt werden. So viel aber glaube ich hervorheben zu müssen, dass man umsonst nach diesen zarten Bildungen in den Ovarien kranker Individuen suchen wird. Denn nur zu deutlich und oft halse ich sogar bei den sonst so lebenszähen jungen Katzen nach geringfügigen Ernährungsstörungen, sofort den Eierstock mit Fettkörnchen infiltrirt gefunden an solchen Stellen, welche bei deın normalen Thiere klar und von deutlicher Structur erscheinen.

Es bleiben mir endlich noch einige Bemerkungen über die Entwicklung der gelben Kö rper übrig. Noch ehe der Grasf'sche Follikel sich zu öllinen beginnt, vermehren sich die Zellen der membrana gramulosa in ausserordentlicher Weise. Dies geschieht, wie schon Lermu hervorhol, durch Zellsprossung. Es entsteht ein Netzwerk, dessen einzelne Fialen ursprünglich von dem liquor folliculi mehr oder weniger auseinander gehalten werden. Die Zellen der membrana gramulosa wachsen nun zur Zeit der Oeffnung des Follikels und erreichen bei Kaninchen, Katzen und Ratten erst einige Tage nach der Entlassung des Eies jene bedeutende Grösse, wie sie fül die Zellen der gelben Körper bekannt ist. Bereits in der Zeit, welche der Oeffnung des Folli- 
kels unnillelhar vorausgeht, werden die Zellen der membrama gramulosa von einer Emulsion feiner Fe!tkörnchen erfüllt. Doch sind dieselben in der Periode der Follikelöffnung noch nicht zahlreich genug, um dem Aıge die gaclbe Farbe darzubieten, wie sie später die membrana grammlosu besitzt. Nach der Entlassung des Eies hat der Follikel eine etwas ins Bräunliche spielende Fleischfarbe. Dies ist wohl hegruindet in den zahlreichen Blutgefässen, welche sich in der Wand des gelben Körpers entwiclielt haben. Beim Kaninchen findet man nach $\ddot{3}-8$ Tagen indessen die gelbe Farbe, welche stets hei diesem Thiere sehr hell bleibt, auf das Entschiedenste ausgesprochen. Drei bis vier Wochen lang lasst sich bei dem Kaninchen die Entwicklung der corpora lulea verfolgen. Dann aber fliessen die Grenzen derselben mit dem Stroma zusammen, weil der Eierstock dieser Thiere stets von den zahlreichsten Rudimenten gelber Körper durchsetzt ist. Da diese die vielfachsten Metamorphosen durchmachen, wobei sie die wesentlichen Drüsenbestandtheile des Eierstockes iiberwuchern, so stellt sich der Untersuchung bei diesem Thiere ein besonders grosses Hinderniss entgegen. Gleichwohl habe ich mich überzeugt, dass bei den erwachsenen Kaninchen die Ovarien sehr zarte, vielfach anastomosirende Schlauche von sehr verschiedenem Durchmesser, der aber oft sehr gering sein kann, darstellen. Wenden wir unsere Betrachtung deshall) den gelben Körpern derjenigen Thiere zu, bei denen die gelbe Farbe niemals durch den ganzen Eierstock sich fortsetzt, und ausserdem besonders lebhaft ist, wie bei dem Hund oder auch wohl der Katze, so ergilst sich, dass von einer gewissen Zeit ab jene mit gellsem Fefl erfüllten Zellen immer noch in rerästelten Zügen zusammenhängend mehr und mehr ihre scharfe Abgrenzung verloren haben. Continuirlich scheint sich das Protoplasma von einer Zelle zur nächst folgenden fortzusetzen. Hierbei bemerkt man, wie die Fettkörnchen in dichter Menge sich um das schöne Kernbläschen der Zelle gruppirt haben, wảhrend die Peripherie eine durchsichtige Masse darstellt. Zuweilen hat es mir scheinen wollen, als sei ein streifiges Wesen in dem peripherischen Protoplasma wahrzunehmen, welches den Zellenziigen die ihnen zukommende Festigkeit verleihen könnte. Es würde sich dann um die Bilklung der Intercellularsubstanz von Bindegewebe handeln, welches aus der Corticalschicht der Zelle durch Differenzirung des Protoplasma's entstanden wäre. Ich habe leider dieses Verhältniss welches für die allgemeine Histiologie von grosser Bedeutung ist, bis jetzt noch nicht genauer verfolgen können, so dass ich deshalb auch nicht mit Sicherheit zu sagen weiss, ob das Bindegewebe des corpns luterm durch Metamorphose der ursprüglichen membrama gramlosa sich liilde, was mir aber wahrscheinlich ist.

Bei Hunden sieht man mehrere Monate nach der Geburt der Jungen noch immer die Reste der gelben Körper in der Gestalt gelber, verästelter, in oflenbarem Zerfall begriffener Zellenziige, welche in dem Stroma des Eierstockes zu liegen scheinen.

Eine äusserst wichıge Frage, die sich so manchem Forscher schon bei der Betrachtung der gewaltigen gelben Körper, die oft fast den ganzen Eierstock einnehmen, aufgedrängt hat: 
ist die, ob es sich hier vielleicht nicht nur um einen Process rücksclireitender Metamorphose, sondern auch um Neubildung von Eiern und Grasf'schen Follikeln handle Von verschiedenen Seiten ist das Letztere mit Bestimmtheit behauptet worden. Auch ich bin indessen der Ansicht, dass die gegenwärtige Lehre, welche den gelben Körper wesentlich mit einem Rüickbildungsprocess in Verbindung bringt, die allein richtige sei. Die Gründe, welche mich zu diesem Ausspruch bestimmen, sind folgende.

Zunächst zeigt es sich, dass bei der ersten Entwicklung der Eier in den Embryonen oder neugebornen Thieren diejenigen Stellen des Eierstockes vollkommen blass und durclısichtig sind, in welchen die jungen Ovarien entstehen. Keine Spur gelber Farbe ist an diesen Orten bemerkbar.

Ferner ergibt sich, dass auch bei denjenigen Thieren, welche wie die Hunde und Katzen nur hie und da Reste von gelben Körpern darbieten, die neu entstehenden Eier und Follikel nicht etwa an bestimmten Stellen des Eierstockes besonders angehåuft ggefunden werden, und an anderen fehlen. Die Neubildungen finden sich vielmelır gleichförmig vertheilt unter der ganzen Oberfläche der Ovarien. Dies könnte nicht der Fall sein, wenn der gelbe Körper der Ausgangspunkt für die Neubildung wäre.

Ich habe ferner mehrmals den Eierstock von Hündinnen untersucht, welche vor einiger Zeit geworfen hatten. Deutlich gewahrte ich die Wucherungen der gelben Körper. Sehr gut konnte ich die Existenz junger Drüsenschläuche beobachten. Diese letzteren waren ziemlich gleichmässig in der Rinde des Eierstockes vertheilt. Nur innerhalb der gelben Körper, die bereits von beträchtlich entwickelten Blutgefässen durchzogen waren, zeigte sich weder von Schläuchen noch von jungen Follikeln eine Spur.

Ein weiterer Grund lässt sich aus dem Verhalten des Vogeleierstockes entnehmen. Denn wenn wirklich von den charakteristischen Bildungen der gelben Körper die Neubildung der Eier ausginge, so würden jene auch bei den Vögeln nicht fehlen, wie das doch der Fall ist. Bei dem Vogel gräbt der Follikel kein Loch in die Substanz des Ovariums, sondern erhebt sich auf dessen Oberfläche zu einer gestielten Beere. Darum braucht bei ihm eine so massenhafte Wucherung zur Beseitigung des Substanzverlustes nicht Statt zu finden, wie das bei dem Săugethiere durchaus nothwendig ist. 


\section{Allgemeine resumirende Betrachtungen.}

In diesem Abschnitte gedenke ich die wesentlichen, bei verschiedenen Thieren und dem Menschen gewonnenen Resultate von einem ganz allgemeinen Gesichtspunkte aus kurz zu erörtern.

Meine Betrachtungen beziehen sich auf die Entstehung der Eier und die Bildung der Follikel. Elre ich die thierische Oogenese behandle, wird es angemessen sein, auf die bei den Pflanzen ermittelten Gesetze zurückzukommen. Bei der so grossen Uebereinstimmung, welclie in beiden Naturreichen herrscht, wenn man an den Modus der Zellenvermehrung und der Zeugung denkt, rechtfertigt sich unser Torhaben von sellsst.

In denjenigen Fallen, welche die Botaniker bis jetzt mit Sicherheit haben feststellen können," hat sich ergeben, dass keine Sporen, kein Ei, kein Befruchtungskörper in organischen Fliissigkieiten, niemals zwischen, sondern stets nur innerhalb bereits vorlıandener Zellen ausgebildet wer(len können. Der Modus der Eibildung ist aber stets ein eigenthuinlicher. Wie es scheint, ist es nicht die Zelltheilung, sondern die sogenannte freie Zellbildung, welcher der Keim seinen Ursprung verdankt. Wir sind zwar bis jetzt nicht mit Bestimmtheit berechtigt, einen tieferen Unterschied zwischen Zelltheilung und freier Zellbildung anzunehmen. Der Umstand aber, dass die von den Botaniliern ermittelten guten Thatsachen auf die freie Zellbildung bei der Keimentstehung hinweisen, fillt sehr schwer in das Gewicht.

Ich kann bei der eminenten Uebereinstimmung, welche die allgemeinen Principien der Zeugung im Pflanzen- und Thierreiche bisher bekundet haben, nicht nachàrücklich genug die Zoologen auf eine eingehendere Beachtung der Gesetze verweisen, welche besonders durch W. Hofmeister und N. Pungsuem für die Entstehung des Kryptogameneies aufgestelt worden sind. Darf ich meine subjective Meinung in dieser Angelegenheit aussprechen, so ist es die, dass eine wesentliche Verschiedenheit bei der ersten Bildung des ächten Eies bei Thieren und Pflanzen nicht existiren wird. (s. W. Hofueıster's Berichte der Kön. Sächs. Gesellschaft der 
Wissenschaften. 22. April 18̈̈4. Zur Morphologie der Moose. p. 9:). - (Prixgsuem. Jalıbuicher der Botanik 18̈8. Morphologie der Oedogonien. p. 1 u. flgal. Die Saprolegnicen. p. 294 u. flgd., ferner a. a. 0. 1860 . Die Coleochaeteen. p. 1 u. flggl. u. s. w.). -

Bei den thierischen Spermatozoen scheint bereits der Process ihrer Entstelıungr auf freier Zellbildung zu beruhen. Ich halte es für angemessen, das Spermatozoon für eine kleine Flimmerzelle zu erklären. Denn einmal zeigen uns zweifellose Thatsachen, dass hei den Pflanzen der männliche Keim so gut wie der weibliche eine Zelle ist. Anderentheils kennt man wohı flimmernde Zellen aber lieine mit Cilien besetzten Kerne. Itierbei darf ich wohl daran erinnern, dass die Beweğung des Samenthiers bei gewissen Thieren, den Tritonen, durclı flossenartige colossale Wimperhaare bewirlit wird.

Wie verhält sich die Sache nun für das thierische Ei? Am genauesten sind die Verhältnisse untersucht, wenn sich dasselle in Schlauchen bildet. In blinden Ende der Röhre liegen dicht gedrängte Bläschen, an denen kaum etwas mehr als ein Contour, der einen hellen klaren Inhalt umschliesst, unterschieden werden liann. Alles spricht dafür, dass diese Blíschen Zellen seien. Das stetige Wachsthum der Dicke des Contours und seine Umwandhung in den späteren Dotter rechtfertigt die Annahme, dass der Contour der kleinen Bliischen im blinden Ende der Eierstoclisröhre als der Ausdruck einer verschwindend diinnen Protoplasmaschicht angesehen werden darf. Der helle Raum in den lileinen Blaschen wäre somit als Keimbläsclien zu deuten. Welches ist der Modus der Oogenese in dem blinden Ende des Ovariums? Ich habe an dem cylindrischen isolirten Inhalt der Katzenovarien oft Bilder vor mir gehabt, bei denen es schien, als ol, zwei blasse Kerne noch biscuitförmig zusammen lingen, während ein sehr feinkörniges Protoplasma sich zwischen sie einschob. Die Verhältnisse sind indessen so ausserordentlich zart und liein, so dass ich grossen Werth auf diese Beolsachtungen nicht lege. Es wăre also immerhin denkbar, dass in dem spärlichen Protoplasma, welches im blinden Orariunende die Keimbläschen der vielleicht membranlosen Zellen von einander sondert, neue Keimbläschen durch freie Zellbildung entständen.

Wenn das aber auch zugegeben werden diurfte, so bliebe doch immer noclı das eigentliche Räthsel ungelöst. Denı wir lraben mit Merssser auf das Entschiedenste den Beweis erbracht, dass die in dem blinden Ovariumende sich bildenden Blaischen keine eigentlichen Eier im strengsten Sinne des Wortes sind, sondern nur die Mutterzellen derselben. Es ist mir elıen so gelungen, den sicheren Naclıweis zu liefern, dass jene Mutterzellen, die von mir sogenannten Ureier, sich durch Sprossung, also durch einen ächten Theilungsprocess vermehren. Die Producte derselben haben wir als ächte Eier ansprechen zu muissen geglaubt, weil wir lieine sichere Thatsaclıe zu ermitteln in Stande waren, welche dieser Auffassung entgegen getreten wäre. Wenn man alver an die bei den Pflanzen bekannten Verhïltnisse denlit, welche uns zeigen, wie in einer Specialnutterzelle bei gleichzeitigem Verschwinden des primären Kernes und Entstehung eines neuen, eine 
der Mutterzelle oft fast gleich grosse Tochterzelle, welche ein Ei ist, durch freie Zellbildung entsteht, so sind auch meine Beobachtungen nicht ganz ausser Stande den muthmasslichen Zeitpunkt anzudeuten, wann in dem durch Sprossung entstandenen Urei der wichtige Act geschieht. Ich habe bereits oben bemerkt, dass zu der Zeit, wo sich die membrana gramulosa um das Ovulum bildet, oft an den ganz frischen isolirten Follikeln ein Keimbläschen umsonst gesucht wird. Es ist gleichgültig, ob man humor aqucus oder Essigsäure bei der Untersuchung anwendet. Das ganze Ei hat zu dieser Zeit ein verschwommen granulirtes glänzendes Ansehen. Es ist nicht unmöglich, dass in diesem Glanze die Ursache liegt, weshalb man das Keimbläschen nicht sieht. Doch ist mir dies wenig wahrscheinlich. Jedenfalls wird die Thatsache mit Entschiedenheit hervorgehoben werden müssen; dass in der Zeit der Anlegung des Follikelepithels um das Ei das Keimbläschen häufig vermisst wird. Es wäre also sehr möglich, dass dies der Augenblick ist, wo die Bildung des ächten Ovulum Platz greift. Demgemäss könnte man sich auch nicht wundern. wenn das Urei ebenfalls durch freie Zellbildung an seiner Wand ein Epithel entwickelte. Dann wäre das Urei vielleicht vergleichbar dem Embryosack der phanerogamen Pflanzen, das Epithel aber dem Endosperm. Bei dem Săugethierei habe ich ein Epithel niemals mit Gewissheit wahrnehmen können. Bei dem Vogelei soll ein solches in gewissen Entwicklungsperioden existiren. Ausserordentlich wichtig wäre es demnach, wenn es festgestellt wäre, ob der gelbe Vogeldotter das Product einer Zelle ist oder nicht. Diese Erörterung ändert an unsern frühern Betrachtungen über die Art der Entstehung der membrana gramulosa durchaus nichts. Diese lagert sich von aussen her auf das Gebilde ab, was jetzt allgemein als Ei angesprochen wird. Das behauptete Verschwinden des Keimbläschens in dem reifen Ei würde nur dann auf freie Zellbildung zu beziehen sein, wenn unabhängig von der Befruchtung und vor derselben ein neuer Kern entständle. Zu einer derartigen Annahme sind wir aber durch nichts berechtigt. Aus alle dem geht allerdings hervor, dass für die Lehre von der Entstehung der thierischen Eier vielleicht noch Fragen von der einschneidendsten Bedeutung zu lösen sind.

Wenn meine Auffassung, wofür manches spricht, richtig ist, so würden also im strengsten Sinne des Wortes die "Eiketten« nur Oogonien sein, in welchen erst durch freie Zellbildung das ächte Ovulum entstände, das aber, weil es gleich den Raum der Mutterzelle wieder ausfüllt und einen dem primăren sehr ähnlichen Kern besitzt, ganz so wie sein Oogonium aussähe.

Füge ich nun zu diesen Ergebnissen meiner Untersuchung noch dies hinzu, dass in mehr oder weniger regelmässigen Perioden die Ovarien bei dem erwachsenen Thiere ähnlich wie die Blithen der Pflanzen sich neu erzengen, so haben wir in kurzer Skizze die wesentlichen Momente hervorgehohen, welche sich auf die fesetze der Oogenese beziehen. 


\section{Geschichtliches.}

Ich beginne mit demjenigen Zeitraum, der auf den Schultern von GraAf; v. Baer, Purhivje, Rud. Wagner steht.

Es ist nicht meine Absicht, eine detaillirte Geschichte über die Entwicklung unserer Kenntnisse in diesem Gebiete zu schreiben, als vielmehr diejenigen Arbeiten hervorzuheben, durch welche ein wesentlicher Fortschritt entweder selbst angebahnt oder secundär angeregt worden ist. Es wird hierbei nicht zu vermeiden sein, dass ich dann auch derjenigen gedenke, deren Forschungen zu den meinigen in einer mehr oder weniger innigen Beziehung stehen. Vor allen sind die Untersuchungen Valestis's hervorzuheben, welche derselbe im Jahre 1838 veröffentlicht hat (s. G. Valextis, Ueber die Entwicklung der Follikel in dem Eierstocke der Såugethiere. Múner's Archiv für Anatomie und Physiologie 1838. S. 526-535.). Nach diesem Forscher entwickelt sich bei den Embryonen der Hoden und Eierstock in ganz derselben Weise. Er sagt:

„Die Grundanlage der Hoden und Ovarien ist ursprünglich durchaus die analoge und beide schreiten eine Zeit lang auf ganz ähnliche Weise vorwärts, bis ein Differenzpunkt eintritt, wo der Eierstock in seinem Fortgange zur Ausbildung einer röhrigen Drüse stille steht und diesen seinen ursprünglichen Charakter bald nur mit immer grösserer Mühe erkennen lasst, wăhrend der Hode in seinem primär ihm vorgezeichneten Entwicklungsgange beharrend bald den reinsten Typus einer röhrigen Drüse erreicht. Das Blastem beider Arten von inneren keimbereitenden Geschlechtstheilen erscheint zuerst als ein langer und schmaler Streif an dem Innenrande der Wourf'schen Körper, concentrirt sich hierauf zu einem mehr oder minder bohnenförmigen Gebilde jederseits und wird mit Leisten und isolirten inneren Höhlungen versehen. Der Hauptausführungsgang entsteht getrennt und entfernt von dem durch Leisten bezeichneten Blastem. So weit geht die Bildung vollkommen gleichmåssig in beiden vor sich. Wenn nun aher in den Leisten des Hodens die Höhlungen der Samencanälchen entstanden, wenn das vas deferens seine ebenfalls selbstständige Höhlung besitzt, so bildet sich ein communicirender, 
seine isolirten Hölıuggen bald erzeugender Mlttelkörper, welcher Samencanälchen und vas deferens vereinigt. In dem Ovarium hingegen nehmen die Leisten den peripherischen Theil des Blastemes ein, während der centrale solit bleibt. Auch die Leisten bilden sich durclı Vermittlung eines wenigstens in spatteren Stadien deutlich erkennbaren Häutungsprocesses zu blinden Röhren um, welche von der línglichen soliden in Centrum befindlichen Masse strahlig ausgehen.".....

"Dass das Ovarium der Säugethiere aus Röhren bestehe, welche grewissermassen doppelt hlind endigen, insofern sie einerseits mit einem saccus coecus an der Peripherie sich schliessen, andererseits mil ihrer Basis an łem soliden, linglichrunden Centralkörper des Eierstockes aufsitzen, sieht man am deutlichsten hei denjerigen Entbryonen, wo die Follikel sich auszubilden schon begonnen haben, beim Fötus des Rindes und des Schales von 3-5" Länge vom Scheitel bis zu dem After. Hier gelingt es sehr oft theils durch feine Perpendikularschnitte, theils durch Zerreissen kleinerer Fragnmente mittelst der Nadel die sehr dünnhäutigen und zarten. an ihrer Jnnentläche mit den zahlreichsten Epithelialkugeh bepflasterten Röhren zur Anschauung zu bringen. Ihr mittlerer Breitendurchmesser beträgt hier 0,04.2 P. Z.. In juingeren Ovarien erzengen die Kleinheif und Weichlıeit des Theiles, so wie die iberaus zahlreichen Köıner fast unïberwindliche Schwierigheiten der Béobachtung. Doch glaube ich auch hier schon isolirte Röhren gesehen zu haben.

Je grösser die Zahl der in diesen Röhren entstehenten Follikel wird, je mehr diese sich intensir ausbilden, um so grö̈sser und in ihren Wandungen dünner werden die Rölıren des Eierstockes, und um so mehr verkleinert sich relativ der solide Centralkörper, bis endlich, wenn eine Menge von Follikeln sich zur Grösse bedeutender Bläschen hervorgebildet haben, die Röhrenformation so zurücligedringt wird, die einzelnen Röhren so ierschoben und durch die wuchernden Follikel aneinandergepresst werden, dass der Nachweis inmer schwieriger und zuletzt gar nicht mehr möglich wird. Doch kiann man mit einiger Geduld die Eierstocksröhren des Fölus nicht nur, sondern auch des Neugebornen von dem Rinde und Schaafe, sowie der Katze und dem Kaninchen noch deutlich nachweisen und isoliren.

Das Gewebe der Eierstocksröhren besteht aus einer sehr feinfaserigen Membran, an deren Innenfliche rundliche, etwas gekörnte Epithelialkugeln sich befinden. In beiden Rüchsichten sind die Gewebstheile denen der Sanıencanailchen von Früchten oder Neugebornen gleichen Alter's sehr ăhnlich.

Die crste Entstehung der Follikel fallt in eine so frühe Zeit der Entwicklung, dass man beim Rindsfötus von 8-10" Länge schon Hunderte derselben in dem Orarium vorfindet. Bald nảmlich, nachdem die Röhre des Eierstockes sich ausgebildet, zeigen sich auch Follikel in ihnen. Gelingt es eine Röhre zu isoliren, so sieht man, dass die Follikel in ihr sich reihenweise lagrernn und wahrscheinlich auch hier wie in den röhrigen Ovarien der Insecten um so mehr an Aus- 
bildung zunehmen, je weiter sie von dem blinden Endtheile der Röhre sich entfernen. Ein solcher Follikel hat im Allgemeinen einen mittleren Durchmesser von 0,000500-0.0012 P. \%. und besteht aus einer äusseren durchsichtigen Hülle membrana folliculi (nicht chorion) und einem sehr körnerreichen Contentum . . . . . «

Hierauf bespricht ValExtix die bekannten Veränderungen der relativen Grössenverhåltnisse der verschiedenen Theile, welche den Follikel zusammensetzen.

Jeder, der einmal diese Verhälnisse sellst gesehen hat, wird zugeben müssen, dass Valentin zuerst unzweifelhaft die Eierstocksröhren der Säugethiere gesehen hat. Dies ggeht bereits daraus hervor, dass er ihre Lage, ihren Verlauf, ihren Ban im Allgemeinen richtig lecschrieben hat.

Ohne dass ich Valextıx's Arbeit kannte, gelangte ich zu denselben Resultaten, wodurch also bereits eine hohe Wahrscheinlichkeit fuir die Richtigkeit unserer Auffassung gegehen ist. Valextix vermuthet, dass die Follikel sich in demsellen Maasse ausbilden, als sie sich von dem blinden Ende des Drüsenrohres entfernen. Da er die Schläuche am Eierstockskerne, so wie an der Oberflache blind endigen lasst, so kann man aus seiner Darstellıng nicht entnehmen, ob die jüngsten Zustände im Centrum des Ovariums oder an dessen Peripherie zu suchen sind. Oflenbar hat er dariiber keine directe Beohachtungen angestellt. Ebenso sind in dem bezeichneten Aufsatze noch keine Andeutungen ïber die Bildungsgesetze der Eier und Follikel vorhanden. Nur um den Sachverhalt zu constatiren erwähne ich dieses. Denn bei der Unendlichkeit der Natur und der Schwierigkeit ihrer Durchforschung kann Niemandem rorgeschrieben werden, bis zu welcher Station er vordringen soll. Jedenfalls wird Valextrs stets das Verdienst bleiben, zuerst den Charakter der inneren weiblichen Geschlechtsorgane festgestellt zu haben. Der Satz, demgemäss die männliche und weibliche Organisation nach demselben Typus angelegt sind, gilt also sogar für diejenigen Theile, durch welche sie sich eigentlich wesentlich unterscheiden.

Alle Forscher, welche nach Valextis den Eierstock untersucht haben, liugnen dic Wahrheit der von ihm mitgetheilten Thatsache; der Einzige, welcher 18 Jahre nach Valextıx's Arbeit durch eine beiläufige Untersuchung sogar bei den menschlichen Fötus dasselbe Princip ivie Valextix entdeclit, ist Bulrotı (s. Tieodor Bılnotı, Ueber fötales Druisengewebe in Schilddrüsengeschwülsten. Müler's Archiv für Anatomie und Physiologie. 1830. pag. 144-149.). BiLlroti erkennt nicht nur das Vorhandensein langer Drüsenschläuche in dem menschlichen Ovarium an, sondern gibt auch kurz den Modus an, wie die GraAf'schen Follikel entstehen. Er sagt, dass sie sich durch Abschnürung von langen cỵlindrischen Schläuchen bilden und hat liermit den Nagel auf den Kopf getroffen. Seine Angabe reducirt sich zwar nur auf ein paar Zeilen ohne alle nähere Begründung, was wohl die Ursache sein mag, dass alle Histiologen jene bedeutungsvolle Bemerliung bis heute ignorirt halsen. Nichts desto weniger wïrde es 
ungerecht sein, wenn wir nicht BıLnотı das Verdienst zugestelien wollten, zuerst wieder nach VALENTIX auf den Chatakter der Eierstocksdrüsen aufmerksant gemacht zu haben. Es bleibt zu bedauern, dass BinLrotı gar nichts Näheres über die Besclaffenheit der Schläuche überhaupt angegeben hat. Man weiss deshall, nicht, ob die Sclıläuche etwa lange cylindrische Zellen sind, ob das sich abschnürende Gebilde, aus dem die Grasf'schen Follikel sich bilden, eine grosse Zelle oder ein Zellenhaufen ist, ob in letzterem schon das Ei gesehen wurde oder nicht und dergl. mehr. Wenn man an die Eiketten denkt, erlangen diese Bemerkungen Bedeutung.

Der Nächste, welcher sich mit dem Eierstock beschäftigt hat, ist O. Spiegeuberg (s. Die, Entwicklung der Eierstocksfollikel und der Eier der Säugethiere. Nachrichten der k. Soc. d. Wissenschaften. Göttingen 1860. 9. Juli. P. 201-208.). Nach Spizgelierg enstehen durch Zelltheilung aus grossen hellen Zellen, die er Keimzellen nennt, Haufchen ron Tochterzellen. Eine von diesen soll sich dann almählich vergrössern und zum Ei ausbilden. Es unterliegt niclıt dem mindesten Zweifel, dass diese Darstellung den wirklichen Verhältnissen nicht entspriclit.

Meine erste Arbeit iiber den Eierstock erschien den 23. Mai 1861 (s. Untersuchungen zur Anatomie und Physiologie der Säugethiere. Allg. med. Centralzeitung.). In dieser heisst es folgendermassen:

„Nach der jetzt allgemein herrschenden Ansicht bestehen die Ovarien der Saugethiere aus einem derben, Blutgefasse und Nerven tragenden Bindegewebestroma in welchem kleine und grosse Blasen (Graar'sche Follikel) liegen. Jede derselben birgt in sich das eigentliche Ei in einer zelligen Schicht, welche als sogenannte membrana gramlosa die innere Oberflache des Follikels austapeziert und einen mit dem liquor folliculi erfüllten Hohlraum umschliesst.

Durch meine Untersuchungen über diesen Gegenstand bin ich dahin geführt worden. diese Ansicht zu berichtigen und zu erweitern, wie sogleich in kurzer Skizze gezeigt werden soll.

Der Eierstock der Säugethiere besteht aus einer grossen Zahl von Röhren, gehört zu den tubulösen Drüsen, ganz wie sein Analogon beim männlichen Thiere, der Hode. Die Dicke der Schläuche variirt bei demselben Individuum, sowie bei verschiedenen Thieren, sehr beträchtlich, und will ich hier nur das hervorheben, dass viele von ihnen von colossaler Grösse. dem blossen Auge bemerkbar sind. Die kleineren Schläuche, die der mikroskopischen Untersuchung am zugänglichsten sind, lassen ein ziemlich grosszelliges Epithel mit Zelliernen erkennen. welches einen in der Mitte des Tubus verlaufenden hellen Canal umschliesst. Die einzelneı Epithelialzellen springen oft stark kugelig in den Röhrencanal ein, wăhrend ihre äusseren Flächen sich zu einem geraden oder leicht (wegen der Krümmung des Schlauches) gebogenen Contour, der äusseren Begrenzung des Schlauches, vereinigen, so dass die Existenz einer membrana propria wahrscheinlich wird. Auch habe ich an grösseren Schläuchen nach Essigsảure- 
zusatz den Contour, welcher der membrama momiu entsprechen wirde, als eine dunkile Linie scharf den Sclilauch begrenzen sehen.

Innerhalb dieser Schlauche entstehen nun die Grasp'schen Follikel, und zwar entwerler viele neben einander in den grossen Schläuchen, orler bei den kleineren auch in einfacher Folge hinter einander. Während der mit Epithel besetzte I) rüsenschlanch noch vollstandig erhalten, nicht etwa durch das Wachsthum der Follikeln resorbirt ist. besitzen, wie man das an isolirten Schläuchen mit aller wünschenswerther Sicherheit sehen kann, die inliegrenden Follikel bereits eine noch einschichtige membrana gramulosa mit mombrana propria folliculi, so wie natürlich das lilare, Kernliörperchen tragende Keimblaschen, welches oft bereits einen evidenten dunkleren Hof, die Anlage des Dotters, erkennen lassst. Bei der Entstehung der Gras:schen Eikapseln kann man an isolirten Schlauchen die Wahrnehmung machen, wie an einer Stelle des Schlauches die Follikel bereits in letztgedachter Weise entwickelt sind, während man bei Entfernung von dieser Stelle immer frühere Stufen-bemerkt, bis zu solchen, wo innerhalls des Tubus nichts weiter als ein helles, kerntragendes Bläsclıen beobachtet wird. Denı entsprechend hat der Schlauch denn auch eine an verschiedener Stelle sehr verschichlene Dicke, inden er um so mehr anschwillt, je grösser und zahılreicher die in ihın entstelıenden Eikapseln sind. An solehen Stellen entspricht jedem der Drüsenschlauchwand anliegenden Follikel eine bauchige Auftreibung des Druisenrolırs. Das habe ich nicht etwa aus nelıreren Präparaten gुefolgert und zu einem Ganzen verbunden, sondern es lisst sich dies an ein und demselben ganz isolirten dïnneren Schlauche wahrnehmen. Durch wiederholte Anderslagerung und Unkehrung des isolirten Schlauches erwächst die Gewissheit, dass dic Follikelbildungen wirklich in seinem Innern sich befinden.

Diese Schläuche hann man nicht allein bei jungen, sondern auch erwachsenen Thieren demonstriren. Ich habe sie bei sehr vielen verschiedenen Säugethieren gesucht und bei keinem vermisst.

Der Grund, warum dic Structur dieses hochwichtigen Organes bis heute vollstänclig unbekannt geblieben ist, liegt einmal in der allgeneinen grossen Schwierigkeit des Gegenstandes, sodann in der Wahl ungüntiger Thiere, oder bei passendem Thiere in der Anwendung unzweckmässiger Untersuchungsuethoden.

In der ausfuhrlichen Abhandlung, in der ich zugleich eine Entwicklungsgeschichte des Säugethiercies und Graar'schen Follikels bringen werde, behalte ich mir vor, diese Verhälnisse auf das Eingehendste zu erörtern,"

In dieser ersten Mlittheilung ist im Wesentlichen einmal wiederum der Lubulöse Charakter der Eierstocksdrüse hervorgehoben und zum ersten Male darauf lingewiesen, dass in den Schläuchen ein regelmässiges Gesetz die Aufeinanderfolge der Eier und Follikel beherrsche. 
Den 8. Januar 1862 veröffentlichte ich abernals in der Centralzeitung eine zweite vorläufigure Mittheilung über denselben Gegenstand. Ich bin genöthigh, auch diese Mitheilung wörtlich dem Leser mitzutheilen, weil sich hieran alsbald wichtige Discussionen knüpen. In dieser Mittheilung heisst es:

„In meiner ersten, in dieser Zeitschırift enthaltenen, vorläufigen Mittheilung vom 2ö. Mai 1861, hatte iclı gezeiğt, dass die Orarien der Säugethiere zu den tubulösen Drüsen gehören und das Versprechen gegeben, genauere Untersuchungen ïber die Entwicklungr der Eier und Grasf'schen Follikel nachzuliefern.

Das guinstigste Thier für die feineren hier in Betracht kommenden Fragen ist die Katze, weshalb das Nachıfolgende zunăchst auf diese zu beziehen ist.

Bci jungen Katzen bestcht in den ersten Wochen nach der Geburt der Eierstock aus dichtgedraingten Schlıuchen, welche meist parallel nebeneinander liegend aus dem Innern gegen die Oberlläche des Orğanes his dicht zum äusseren Epithel heranreichen.

Die Schläuche zeigen zunächst den allgemeinen Charaliter tubulöser Druisen, $d . h$. ein um den stets vorlandenen Centralcanal gelagertes Epithel, welches einer membrana propria aufsitzt. Letztere glaube ich bei entwickelteren Schläuchen nit Bestimntheit isolirt gesehen zu haben. Die Tubuli bicten ferner Verảstelungen dar und anastomosiren nicht selten mit einander. Bereits jetzt erscheinen diese Sclılauclıe von sehr verschiedener Dicke, welche von ca. 0,009 Mm. bis 0,1 Mm. schwankt. Das interstitielle Bindegewebe ist spälich.

Die Beschaffenheit unserer Schlauche ist nach ihrer Dicke verschieden. Diese Verschiedenheit bezieht sich besonders auf ihren Inhalt, l. h. dic Epithelialgelilde derselben. Denn die dickeren Schläuche zeigen neben kleinen, rundlichen Zellen noch viel grössere, welche in den diunneren Tubuli nicht oder doch nur spärlicher bemerkt werden. Da man nun aber alle möglichen Uebergänge zwisclıen den dünnen, kleinzelligen Schlauchen und den dickeren wahrnimmt, so unterliegt es keinem Zweifel, dass die diinneren in Allgemeinen als die jüngeren Zustände angesehen werden muissen. Das geht endlich daraus zur Evidenz hervor, dass bei den jüngsten Thieren die dünnen Schläuche in reichster Menge vorhanden sind, bei zunehmendem Alter aber immer seltener werten, wăhrend nun die dicken Schlauche mit ihren gewaltigen Epiltrelialzellen vorwiegen. Diese Entwicklung des Schlauchinhaltes hat man sich aber im Allgemeinen so vorzustellen, dass jedesnal die verschiedenen Abtheilungen desselben Schlauches Epithelialgebilde von verschieden weit vorgeschrittener Entwicklung zeigen. Das ganz constante Gesetz ist folgendes. Nennen wir das Ende des Schlauches, welches der freien Fläche des Ovariums zugekehrt ist, das àussere und obere, dasjenige, welches in der Tiefe des Organes wurzelt, das innere oder untere, so enthäl das erstere die jüngeren $\mathrm{Zu}$ stände, das letztere die älteren; demgenuảss könnte man auch jenes das jüngere, dieses das altere nennen. Zwischen beiden Stellen aber findet stets ein const ant vorhandener, stetiger 
Uebergang statt, so dass der Schlauch eine Stufenleiter der Entwickelung reprdsentirt. welche die Epithelialgebilde zu durchlaufen lıaben. Da nun alle Theile des Schlauclies der Reifung zustreben, so erlangen gemảss jenes Gesetzes erst die im inneren Ende, dann die im nittleren Stück und endlich die in dem äussersten den Zustand der Reife. Dies lasst begreifen, dass die Untersuchung solcher Schläuche am lehrreichsten und wichtigsten ist, bei welchen das aussere Schlauchende noch die möglich jüngsten, das inner'e die möglich ätesten enthålt. Gerarle diese von mir aufgefundene Stufenleiter, welche dicht hinter einander in regelmässiger Ordnung die auf einander folgenden Zustände der Entwichlung zeigt, ist fur die Untersuchunğ der letzteren unschätzbar, indem sie derselben einen Grad von Sicherheit gibt, den man sonst nur da haben kann, wo man das Wachsen unnittelbar unter dem Mikroskop sieht. An einem wohl isolirten Schlauche von geeigneter Entwicklungsstufe bemerkt man nun im ausseren Ende ein feinkörniges Protoplasma mit klaren Kernen, welche oft in Theilung begriffen sind. Diese kleinen Zellen scheinen nicht durch eine Membran von einander abgegrenzt, haben aber ein sjarliches Protoplasma und sehr verschiedlene Grösse. Nach dem Gesagten findet an dem äusseren Schlauchende eine starke Zellenvermehrung statt, so class hier der Schlauch wohl eine Zeit lang vorwärts wächst. Hiernit bringe ich es in Zusammenhang, dass, während bei dicken Schlauchen das äussere Ende durch eine ganz scharfe, runde Linie wie bei anderen tubulösen Drüsen sich abgrenzt, bei jüngeren Schlauchen eine spindelförmige Verjüngung derselben ganz an der Oberfläche des Ovariums von mir wahrgenommen wurde, welche sich blass gegen das Epithel der letzteren als ein dünner Zipfel verlor. Kehren wir zu der Betraclitıng unseres jungen Ejithels in äusseren Schlauchende zurück. so gewahren wir, dass einzelne von den jungen Zellen stäker wachsen und auch sonst durch bestimmte Charaktere als besondere Gebilde sich bemerkbar machen. Hiermit tritt in der That ein Fundamentalunterschied zwischen den Zellen des Schlauches auf, so dass von jetzt ab zwei Arten unterschieden werden müssen. Der wasserklare Kern der sich vergrössernden Zelle erfüllt sie nahezu ganz, während ihr Protoplasma fast lyalin erscheint und nur eine Spur verwachsener, aber constant und sicher verhandener Granulation walırnehmen lasst. Das Letzere hat sich um den Kern scharf al,gegrenzt, indem allem Anschein nach eine ausserst zarte Membıan sich un dasselbe gebildet hat. Fast gleichzeitig, vielleicht etwas später als diese Umwantllungen, erscheint auchı ein anfangs sehr blasser Niederschlag in dem Kernblaschen, der mucleolus. Die Zelle lat jetzt eine Grösse von 0,0090 Mnı., ihr Kern misst nahe eben so viel, das Kernhörperchen 0,0028 Mm. Diese Zelle ist das junge Ei, d. h. derjenige jüngste Zustand, in welchem alle wesentlichen Charaktere desselben bereits scharf ausgesprochen vorhanden sind. Hiermit ist gleichsam der erste - "primordiale» - Zeitraun der Eientwickelung vollendet. Das Ei wäclıst nun mächtig; dieses bezieht sich besonders auf das Keimblaschen, wahend der Dotter noch langer einen schmalen Ring um das letztere bildet, und der Keimfleck dichter, stärker lichthrechend, 
schärfer begrenzt, von runıllicher For'm erscheint, aber verhältnissmảssig zu den übrigen Eitheilen etwas in seiner Grösse schwankt. Zur Beurtheilung der Grössenverhältnisse in diesem Zeitrame bemerke ich, dass einem Eie von 0,0180 Mm. ein Keimbläschen von 0,0138 MIm. und ein Keimfleck von 0,0038 Mm. zuliommt. Von jetzt ab wichst aber der Dotter stärker. Bei Eiern ron 0,0234. Mm. misst das Keimblaschen 0,0 / 64. Mn., der Keimfleck 0,0043 Mm. In solchen Eiern bemerlit man nm in Dotter sclıon gröbere Körnchen; noch ist keine mentbrama graumlosa rorhanden. Unter den charakteristischen Eigenschaften der jungen Eizellen habe ich, nach Erörterung ihres allgemeinen Ansehens und der verschiedenen Grössenverhältnisse, nun zundichst die anzufuhren, dass sie mit einer sollsststandigen Bewegung begabt sind. Man glaubt eines jener cinzelligen Thicre, eine Gregrarine, vor sich zu sehen. Gewöhnlich bestehen diese Bewegungen in Contractıonen der Zelle und Abschniirungen gewisser bald grösserer bald lileinerer Fragmente. Während durch die Strictur Kern und Protoplasma hindurchschlüpft. wächst die eine Abschnürung auf Kosten der andern, bis eine wieder ganz verschwunden ist. Aler die Eier zeighten sogar Locomotionsluewegungen. Denn eimmal sah ich eine isolirte, zwischen auderen Gewebetheilen liegende Eizelle zu meinem höchsten Erstaunen unter fortwährenden Zusammenziehungen aus dem Gesichtsfelde forthriechen, während die Ruhe aller anderen Partikelchen die vollkommenste Abwesenheit jeder Flïssigkeitsströmung bewies. Hätte ich diese merkwïrdigen Bewegungen nicht an allen Zellen wahrgenommen, sowohl an denen der Katze als des Hundes und erfülten ganz dieselben doch sehr charakteristisch aussehenden Zellen nicht dic Schläuche constant, hätte ich nicht die Entwichlung dieser beweglichen Bildungen vollstandig und lickienlos ror mir, so wiurde ich geglaubt halen, Parasiten ror mir zu sehen. Diese an sich so wunderharen Bewegungen sind nun für die Entscheidungr einiger sehr wichtigen Fragen iilser die Structur des Eies von ausserordentlichem Werthe. Bei den jüngsten Eiem nămlich liegt die äussere Eihaut so dicht an der Oberfläche des Keimbläschens, dass man nicht recht sagen kiann, ob das letztere nur eine recht diclie Membran besitzt oder ob es der Kern einer Zelle ist, deren Wand demselben nahe liegt. Sobald aber das junge Ei sich zu bewegen beginnt, sieht man sofort. wie die Sache ist. Bald hier luald da geräth die auussere Haut ganz dicht an das Keimbläschen. Wo das geschieht, ist dann nur eine selır feine Linie zu sehen, also der Anschein einer dicken Wand des Keimbläschens hier vollständig verschwunden. Da aber das Protoplasma an dieser Stelle ausgevichen ist, hat es auf der entgegengesetzten Seite die äussere Eihaut um so mehr von dem Keimbläschen entfernt.

So hahe ich nicht selten fast zwei Drittel der ausseren Fläche des Keimblaschens der ¿usseren Eihaut absolut anliegen schen, wobei sich also auf dem letzten Drittel das Protoplasma in grösserer, deutlicher Jenge und sichelförmiger Gestalt ansctzle Wenn man sieht, wie die Fliissigkeit des Protoplasma's bei den Bewergungen zwischen das Küimbläschen und die äussere Eihaut cindringt, so liann man sich schwer der Ansicht erwehren, es bestehe eine pri- 
mordiale Dottermembran ron äusserster Feinheit. Wunderbarer Weise lisst Essigsaure dieselbe sehr scharf und derb hervortreten, wahrend sie frisch ungemein zart scin muss. Das hat gewiss daran Schuld, dass junge Eier nit Follikeln verwechsolt worden sind.

Aber jene Bewegungen sind auch mit Bezug auf letztern, Punki, d. lı. die Bildung der membrana gramlosa, unschäzhar, indem ich auch an den grösseren nachten Eiern aus den Schliuchen, bei ilıren Bewegungen, wo der Inhalt strömt und oft die aussere Eihaut an das Keimblaschen zu liegen konmt, niemals eine spur beginnender Zellbildung inı Dòtter wahrgenonımen.

Wir werten nachler sehen, dass die membrana gramulosa eine von aussen spater un das Ei gebildete und nicht von ihm erzeugte Hiille ist.

Endlich bin ich bei den beschriebenen Bewegungen noclı auf eine Thatsache aufmerlisam geworden, welche ich, so merkwürdig sie ist, als fast zweifellos bezeichnen liann, námlich die Vermehrung der jungen, noch nackten Eier durch Theilung. Die Griunde sind folgende: 1, Einmal sah ich einem der jungen, nackten Eier zu, welches in Albumin sich munter beregte. Es hatte einen mässig entwickelten, blassen Dotter, ein schönes, grosses K(inul)läschen mit Keinfleck. Plötzlich stülpte sich ein kleiner Theil des P'rotoplasma's aus, durch eine scharfe Strictur vom übrigen Ei geschieden. Schncll drang das Keimblasschen mit einem Theile durch die Strictur, während der alggeschnuirte Theil inmer fort wuchs, als ob durch Contraction des Eies sein Inhalt durch die Strictur gepresst wuirde. Aber als so das Ei in nalsezu zwei gleiche Abtheilungen sich geschieden hatte, erstaunte ich, zu schen, dass das Keimbläschen an der Stelle der Strictur getrennt war, so dass jetzt in jeder Abtheilung zwei sclıöne, runde, hlare Blasclsen lagen. Wohl gewahrte ich aber deutlich, dass der Keimfleck in der einen Hälfte zurückgeblieben war, so dass die andere Hälfte des Kcimbläschens keinen Keimfleck besass. Kaum latte ich das gesehen, so erschien urplötzlich, wie hingezaubert, in dem zweiten Blasschen ein blasser Niedlerschlag, rundlich, stärker lichtbrechend als alle anderen Theile - ein neu entstandener zweiter Keimfleck. Nun hatte ich zwei biscuitförmig ançinander hängende Zellen vor nir. Niemand würde es geläugnet haben. Sie entstanden aus einer. Das sind Erscheinungen, welche in einigen Augenblicken beendigt sind, etwa wie eine Furchung nach der Befruclitung. 2) Es ist eine ganz gewöhnliche Erscheinung, dass man die Eier zu 2-7 aneinander hängend findel, in nahezu gleicher Grösse. Sie liegen dann oft in einer Reihe hinter cinander, wie die Zellen eines Algenfadens. Natürlich ist jede kugelig angeschwollen. Die Bewegung der Eier in diesen Eiketten ist gewöhnlich so, dass die bereits yorhandenen Stricturen zwischen den Eiern tiefer' werden oder neue entstehen, welche den bereits gel,ildeten parallel sind. 3) Sieht man einzelne isolirte, frische junge Eier, so bemerkt man, dass fast stets eine Stelle der Oberlliche verletzt ist, wo das nackte Protoplasma in wunderlicher Bewegung bald herauskommt, bald wieder zuriickgeht. 
Allem Anschein nach sprossen die Eiketten aus dem Epithel so zum Theil in den Schlauchcanal hinein.

Sobalıl das Ei eine Grösse von ca. 0,024.0 Mm. erreicht hat, sind die Bewegungen nur noch sehr schwach und an den Eiern in den Follikeln habe ich dieselben nicht mehr wahrgenommen. Es ist also wahrscheinlich, dass mit Beginn der Bildung der membrana gramlosa Ruhe eintritt.

Befrachten wir nun unsere Zellen in einem geeigneten Schlauche, so bemerken wir, dass sie in den oberen und wohl auch mittleren Theilen der Wand zunächst dicht gedrängt liegen, wie das schönste Epithel, eine dicht neben der andern, deshalb von polygonaler Gestalt und oft sontlerbarer Form, was bei so grosszelligem Epithel begreiflich ist. Gegen den Canal des Schlauches zu zeigt das Epithel aber gewöhnlich eine Zerklüfung, so dass der Gang durch enge, tiele Buchten in dassellse einzudringen scheint. Das mag einmal in Lockerungen der Epithelzellen von einander seinen Guund haben, welche durch die starken Bewegungen hier an der freien Fläche leichter entstehen liönnen, sowie auch in Wucherungen der Zellen durch Vermelırung, wobei wohl auch Eier in den Hohlraum abfallen. Denn oft sielıt man die Eicr in den Schläuchen wie zahlreiche grosse Kugeln in einem Sacke, welche beim Anschneiden dessellsen herausrollen, wie ich das nicht selten wahrnahm. Hauptsächlich sitzen die Eizellen indessen (ler Wand des Schlauches an, rings um den Canal herum, und verdienen deshall) den Ausdruck Epithel durchaus.

Wenn wir uns ferner den innern Ende des Schlauches nähern, so gewahıren wir constant eine rasche aber stetige Grössenzunahme der Eier und ausserdem ein Auseinanderrïcken derselben, so (lass sie sichı nur noch wenig oder gar nicht mehr berïhren. Dieses Auseinanderweichen hat seinen wesentlichen Grund darin, dass die zweite Zellenart des Schlauches, kleine rundliche Zellen, stärker wuchernd und sich vermehrend, besonders von der Schlauchwand her in die Interstitien zwischen die Eier hineinwachsen. Doch kommen diese kleinen Zellen auch in den anderen Theilen des Schlauches, aber viel sparlicher vor. In jedent Theile beginnen dieselben erst dann so stark zu wuchern, wenn das Ei eine gewisse Grösse uiberschritten hat und die Bildung der membrama gramilosa beginnt. Jene kleinen Zellen sondern sich nun so um die Eier, dass zwar nicht inmer, aber gewöhnlich, eine gegebene Reihe der letzteren eine zellige eylindrische Hiilse erhält, so dass also vom innern Grunde des grossen Schlauches aus durch cine emporwachsende Zellengeneration secundäre Schläuche bei der Katze entstehen, in denen ein Ei dicht hinter dem andern liegt. Das hat wohl seinen Grund in dem Zusammenhaften der Eier in einer Richtung (den Eilietten).

Die Richtung der secundären Schlauche ist im Allgemeinen wie die der primairen in Eierstocke. Doch kommen hier, besonders ganz an der Oberfliche des Organes, Ausnahmen vor. Indem das Epithel der seeundaren Schläche nun in den Raum zwischen zwei Eiern hin- 
einwuchert, werden letztere weiter auseinander getrieben, so dass eine Reihe Grasr'scher Follikel entstanden ist, die hinter einander aufgereiht sind wie eine Perlschnur. Diese lassen sich frisch nicht schwer isoliren. Spaiter scheinen die Follikel sich von einander ahzuschnuren. Ich glaube aber, dass das meist nicht ganz geschieht, da ich sehr oft bei recht entwickelten Follikeln noch zellige Commissuren fand, durch welche sie verbunden waren. Es ist also im Allgemeinen liir jeden Follikel ein praformirter Weg aus den Innern nach der Oberfliche des Eierstockes rorhanden, es liegen aber die reiferen Zustände, wie aus Allem folgt, im Allggemeinen tiefer. Wenn nun eine Scheidewand in den secundären Schläuchen sich mangelhaft orler gar nicht ausgebildet hat, so entsteht ein Follikel, der zwei Ovula l,irgt. Ueberhaupt scheint sich ulic Natur bei demselben Thiere und verschiedenen Thieren manche Freiheit in dem Morlus des Umwachsens der Eier gelassen zu haben.

Es ist also die membrana gramulosa kein Product des Eies, sondern eine accessorische Bildung. Kurz zusammengefasst, sind die Gründe für diese wichtige Tlatsache folgende: Wenn man frisch die Eier aller Grössen, von den kleinsten bis zu solchen, wie sie bereits in den Follikeln stecken. isolirt untersucht, so ist von einer Zellbildung im Dotter nichts zu selien; wenu man eine Schlauchwand isolirt vor sich hat und in den oberen und mittleren Partien erst die ihr aufsitzenden, nackten, schönen Eier dicht gedränğt an einander lieg̨end sielıt, hier und da ron der äussern Schlauchwand durch ein kleines Zellchen getrennt, welches sich cinschiebt; wenn man dann weiter, imnıer nach einer und derselben Richtung, gauz dieselben Eier mił allen wesentlichen Theilen, nur immer grösser erblickt und weiter aus cinander rückend, wålurend nun zahlreichere kleine Zelleu in die entstandenen Interstitien, besonders von der Schlauchwand her, eindringen; wenn man endlich, noch weiter gehend, die Eier noch nicht ganz umwachsen, oft noch an einer Seite nackt findet, und endlich noch weiter in absolut regelmässigger Folge ganz fertige Follikel wahrnimmt, so kann kein Zweifel bestehen bleiben, dass das Ei erst. nackt im Schlauche liegt, eine bei der Katze bedeutende Grösse und Entwickelung erreicht und erst dann durch neu von Aussen hinzukommende Zellen seine membrana gramulosa bildet. In der gedachten Weise verzehren sich die Schläuche endlich ganz.

Rundliche Häufchen kleiner, rundlicher Zellen, welche man im Eierstock findet und, ol)wohl sie nach meinen Beolsachtungen keine evidenten Eier enthalten, wic das bei den ächten Follikeln gleicher Grösse stets der Fall ist, doch bisher für junge Follikel gehalten hat, stehen in einer Beziehung zu der Neubildung der Schláuche, sind zunächst also lieine Follikel. Denn erstens sieht man solche Zellenhaufen, welche viel kleiner oder auch viel grösser als die jüngsten entschiedenen Follikel sind, ohne dlass jene, wie diese, evidente Eier enthalten; zweitens treiben die fraglichen Bildungen oft sehr lange cylindrische Sprossen, in denen ein Canal benerkt wird, (ler mit einer IIöhle in dem kugeligen Zellenhaufen zusammenlıangt, welche IIöhle wohıl bisher für ein Ei angesehen worden ist, und endlich unterscheiden sich drittens die Zellen der 
wahren Follikel von den Zellen dieser primordialen Schlıuche in verschiedenen Punkten. Von diesen primordialen Schläuchen schnüren sich nicht selten küızere oder längere Stiicke ab und können dann wietler rundliche oder längliche Zellhäufchen bilden, die man „Sch la u chknospen“ nennen könnte.

Hiermit ist also der Beweis geliefert, dass Niemand ror nir die Entstehung und erste Entwichlung der Siugethiereier und Grasf'schen Follikel gesehen hat. Denn die Eier entstehen mit allen wesentlichen Theilen, elıe ein Follikel da ist, und naclite Eier in den Schläuchen habe ich zuerst gesehen; zweitens hat man Bildungen für junge Gusıf'sclıe Follikel und Eier gehalten, die weder das eine noch das andere sind.

Nach einer kurzen, ron mir angestellten Uebersicht bei verschiedenen Säugethieren läuft das allgemeine Gesetz ter Entwickelung immer auf dasselbe hinaus. Doch bemerlut man mit Bezıg auf die Länge und Dicke der Schläuche, das Mengenverlabltniss der kleinen und grossen Eier) Zellenart, die Zeit der Bildung der membrana gramulosa um das mehr oder weniger entwickelte Ei, mit Bezug auf absolute Grösse besonders der jungen, nackten Eier, der Natur des Protoplasma's des Drusencpitheles, mit Bezurg auf die Menge des interstitiellen Bindegewebes. also des Reichthums an idnten Drisengewebe in dem Organe, die ausserordentlichsten Verschiedenheiteu, worauf ich nebst vielen anderen erst in meiner ausfühllichen. demnäclıst zu veröflentlichenden Abhandlung eingehen hann."

Ieine dritte Mittheilung erschien in demsellsen Jahre den I. Novenher wiederum in der med. Central-Zeitung. Sie lautet:

"Iı den folgenden Zeilen werde ich dıe Thatsachen, welche ich bereits in dieser Zeitsclırift über die Anatomie und Physiologie der Eierstöcke und Eier s. I. Mitheilung rom 23. Mai 1861 und II. Mittheilung vom 8. Jan. 1862 publicirt habe, als bekannt voraussetzen.

Ich habe bereits in del zweiten vorlảufigen Mittheilung (a. a. O.) darauf hingewiesen, dass an jungeren Schlauchen bei Katzen das aussere Schlauchende sich of gegen das Eierstocksepithel Epithel der äussern Oberfläche des Eierstocks) immer mehr verjüngt, um sich "blass gegen das Epithel als ein diinner Zipfel zu verlieren." Es ist mir jetzt durch Anwendung giunstiger Untersuchungsmethoden gelungen, iiber diesen Unstand von ausserordentlicher Bedeutung in's Klare zu kommen, bei dem es sich um nichts Geringeres als um einen effectiven Zusammeuhang der jungen Schläuche mit dem Epithel der äussern Eierstocksoberfläche handelt, welches ich fortan als ndusseres Ovariumepithel" bezeichnen will.

Die Sache verhälı sich bei jungen Katzen, bei denen ich auch diesen Umstand genauer habe ermitteln liönneu, folgendermaassen:

Das aussere Epithe! des Eierstockes zeigt an verschiedenen Stellen selır verschiedene Beschaffenheit, inden dicke und diinne Schichten kleiner und grosser, rundlicher und cylindrischırZellen getroffen werden können. Jene Schlauchzipfel, welche mit kleinen Zellen erfüllt sind, 
und oft rasch in sehr dicke Schläuche übergehen, setzen sich direct in das Epithel und zwar so fort, dass unzweifelhaft das aussere Schlauchende einen integrirenden Theil des aussern Ovariumepithels bildet. Merkwiurdig ist, dass zuweilen einzelne kleine Zellchen sich noch innerhall, des äussern Ovariumepithels oder dicht darunter zu evidenten Eiern differenziren. Bedenkt man nun, dass die Schläuche an ihrem innern Ende scharf al)geschnilten endigen, indem sich hier, wo die reichsten Drüsenelenente getroffen werden, Gmis sche Follikel abschntiren, wálırend dort an der Oberfläche die jüngsten Zustånde gefunden werden, die in den Schlauchzipfeln und dem Epithel identische sein können, so wird man die Bedeutung der von mir ermittelten neuen Thatsache nicht verkennen."

Die vierte Mittheilung über den gleichen Gegenstand, in derselben Zeitschrift wurde am 8. November publicirt. Folgendes ist der Wortlaut derselben:

„Es ist bis jetzt umsonst nach der Mikropyle des Säugethiereies gesucht worden. Mikropyle heisst bekanntlich der Canal in der Eihaut, durch welchen der männliche Same eindringt, unı sich mit dem Dotter zu vermischen. Wenn nın in ter Eihaut einer oder mehrere Canäle nachgewiesen werden könnten, welche ausreichend weit wïren, um ein oder mehrere Spermatozoiden zu dem Dotter durchzulassen, so bliebe im Allgemeinen immer die Mögliclıkeit, dass aus irgend welchem Grunde nicht diese beobachteten, sondern andere, noch unbekannte die eigentlichen, wahren Mikropylen darstellen. Da nun aber der Befruchtungsvorgang bei dem Săugethierei in flagranti vielleicht niemals oder doch erst nach Ueberwindung der allergrössten Schwierigkeiten direct wird beobachtet werden können, so bleiben wir vor der Hand immer noch auf das Studium des Eierstockseies angewiesen. Bei diesen habe ich nun, nachdem iclı viele Hunderte der Reife nahe Eier geprüft, höchst eigenthümliclıe Anordnungen in und an der zona pellncida entdeckt, von denen es kaum zweifelhaft sein kann, dass sie den Mikropylenapparat des Säugethiereies darstellen.

Ehe der Grasf'sche Zellenmantel sich um das Ei gebildet hat, besitzt dasselbe schon eine durchsichtige, hyaline, ziemlich derbe Membran. Gleichwohl habe ich die Billung einer merklich dicken, glashellen Eihiille, also einer evidenten zona pellucida, erst dann mit Sicherheit wahrnehmen können, nachden sich ein stralmm gramulosum um das Ovulum gebildet lıatte. Die zona pellucida nimmt ganz stetig mit dem Wachsthun des Eies an Dicke zu. Bei der Katze. welche ich auch hier als ausgezeichnetes Object benutzte, ist diese Mentbran im frischen Zustande fast ohne Spur von Structur, ganz wasserklar und demgemäss so durchsichtig, dass das grosse Keimbläschen und die schöne Keinfleckkugel mit der vollendletsten Klarheit gesehen werden. Während oft ein kleiner, zuweilen ein grosser Raum die Dotterkugel von der zona pellncida trennt, sitzen die Zellen der membrana gramlosa der äussern Oberfläche der zona pellucida ganz innig auf und zeigen folgendes merkwürdige Verhalten: Einzelne dieser der Zona aufsitzenden Zellen senden spitze, zuweilen sich theilende Fortsitze in die Zona, welche bis zu 
verschiedener Tiefe eindringen, in cinigen Fällen dieselbe unzweifellaft durchbohren, um in die Eihöhle zu gelangen und den Dotter zu beriihren. So sieht man dann die Zellen auf und in der Zona sitzen wie tief in eine Wand eingetriebene, mit runden Köpfen versehene Nägel. Dies bemerkt man zu der Zeit, wo die Zona schon eine beträchtliche Dicke hat und das Ei nahezu so gross wie ein reifes ist. Dies ist aber nicht Alles, sondern recht häufig sieht man an der innern Oberflache der Zona eine den Zellen des stratum granulosum ahnliche, bald kleine, bald aber auch recht grosse Zelle, welche durch eben solchen Fortsatz mit einer Zelle des stratum gramulosum unzweifelhaft zusammenhangt. Die naturgemasseste Vorstellung ist daher, dass eine oder mehrere Zellen des stratum graimlosum in das Ei durch die Zona hineinknospen. Die Berechtigung, die an der innern Fläche der Zona liegende, dem Dotter aufsitzende oder selbst in ihn eingesenkte Kugel eine Zelle zı nennen, liegt einmal in dem Vorhandensein von scharf begrenztem Protoplasma, in dem ein runder Kern mit Kernkörperchen wahrgenommen wird, und dem entschiedenen Zusammenhang dieser Kugel mit einer Zelle des stratum granulosum, in dem Nachweis zapfenförmiger Auswiichse, welche von den Zellen des letztern in die Zona eindringen, und der hereits bekannten Thatsache, dass diese sich durch Knospung vermehren. Reife Eier, welclıe kenntlich sind an der stralıligen, gegen das Eicentrum convergirenden Anordnung des stratum gramulosum und der Undurchsichtigkeit des Dotters, zeigen diese Verhältnisse weniger deuthich als etwas juingere. Denn mit der erscheinenden Reife werden die Commissurenfortsätze, welche in der Zona liegen, ebenfalls hyalin, während sie vorher fein granulirt und etwas glänzend waren, auch sich durch Iod gelb farbten, was die Zona kaum thut, so dass sie leicht wahrgenommen werden konnten. Die durch die Zona gehende Zellencommissur habe ich oft żiemlich weit gefunden, so dass der Canal hinreichte, um mehrere Spermatozoen neben einander hindurchzulassen. Oft war die Commissur so kurz, dass die äussere Zelle in der zona pellucida lag, gleich wie ein Spund in der Wand eines Fasses steckt. Einmal sogar schien die Commissur so geschwunden, dass in dem Canal eine grosse Zelle lag, welche den Dotter innig berührte und ihrer Grösse wegen noch etwas aussen über die Zona hervorragte. In diesem Falle konnte man also von einem in der Zona befindlichen Loche sprechen, in welchem eine Zelle wie ein Pfropf steckte.

Denkt man nun daran, dass einmal bei der Ausstossung der Eier die Zellen des stratum gramulosum verletzt werden und sodann bekanntlich eigenthümliche Gestaltsveränderungen durchmachen, erinnert man sich, dass Biscuoff bei eben in der Furchung begriffenen Eiern freie Körner im Innern der Ejer von räthselhafter Bedeutung beschreibt, dass diese Körner den Zellkernen meiner in das Ei geknospten Zellen sehr ähnlich sehen, so wäre nichts nöthig, als dass aus irgend einem Grunde die Zellenconmissur reisst, so dass die Spunde aus dem Loche, welches sie bildeten und oflen liielten, lierausfallen können, um das Entstehen einer Mikropyle bei der Ausstossung der Eier aus dem Ovarium oder ihrer Wanderung in den Tuben zu begreifen. 
Die Sache hat aber noch eine andre Seite. Zuweilen habe ich nicht, wie gewölnnlich. eine, sondern mehrere solche Zellen der innern Fläche der zona pelluridu ansitzen und durch Fortsätze mit den Zellen der membrana gramulosa zusammenlıängen sehen. Wird man nun nichıt in gewissem Grade berechtigt sein, zu sagen, dass die Zona ein inneres, freilich sparsanıstes Epithel besitze, ohne dass das Ei aufhört, e in e Zelle zu sein? Ein Blick auf die vergleichende Anatomie wird die Bedeutung dieser Thatsache jedem Morphologen einleuchtend erscheinen lassen. Die specielleren Angaben muss ich meiner grösseren Arbeit überweisen.“

Am 17. November 1862, also nach allen meinen Mittheilungen, fast ein Jalır nach Publication meiner vorläufigen zweiten, in welcher die wichtigsten von nir ermittelten Thatsachen sich vorfinden, erscheint eine Arbeit von Dı. Отто Scınös (Beitrag zur Kenntniss der Anatomie und Physiologie des Eierstockes der Säugethiere. Zeitschrift für wissenschaftliche Zoologie. 12. Bd. 3. Hft. pag. 4.09 u. f.). Diese Arbeit ist bei Weitem die beste. welche seit meinen Mittheilungen uber diesen Gegenstand erschienen ist.

Eine Reihe äusserst wichtiger Thatsachen wird von Scurös mitgetheilt, welche vor meinen Untersuchungen durchaus unbekannt gewesen sind. Scuröx bestätigt das ron mir aufgestellte Gesetz, dass die jüngsten Zustände der Eier und Follikel dicht unter der Oberfläche des Eierstockes gelegen sind. Er zeigt in Uebereinstimmung mit mir, dass die genannten Bildungen im Allgemeinen um so grösser sind, je weiter sie von ler Oberfläche des Eierstockes entfernt liegen. Sciröx behauptet, dass das Ei bereits vorhanden sei, ehe man von einem GraAf'schen Follikel reden könne, ganz so, wie es von mir in Widerspruch mit allem bisher Bekannten entdeckt worden ist. Scunös bestätigt meinen Satz, dass der Follikel nicht das Product einer Mutterzelle sei. Scunös weist nach, dass, so wie ich es entdeckt habe, kleine Zellen die Eier auseinanderdrängen, sie umwachsen und auf diese Weise die membrana granulosa elzeugen. Scrinös findet, in Uebereinstimmung mit meinen Angaben, häufig zwei Eier in einem mit Epithel versehenen schlauchartigen Gebilde. Scпвӧs sind sogar in Uebereinstimmung mit meinen Angaben drei Eier in ein und derselben Epithelialcyste aufgestossen.

Dieses Alles findet sich nun bereits und mehr als dieses in meiner zweiten Mittheilung, welche fast ein ganzes Jahr vor der Scuröx'schen Arbeit publicirt worden ist, wie sich der geneigte Leser einige Seiten vorher überzeugt haben wird. Sogar in dem Jahresbericht von HexLE und Merssaer für 1861 findet sich bereits ein ausfühliches Referat uber diese meine Untersuchungen. Niemand war deshalb mehr erstaunt als ich bei dem Durchlesen der Scmörschen Arbeit zu finden. dass er Alles dem Leser so dargestellt hat, als ob er und nicht ich der Entdecker all dieser Thatsachen wäre. Man muss aber nicht ğlauben, dass den Dr. Scırös meine Arbeiten unbekannt waren, denn obwohl er bei der Betrachtung einer Reihe der wichtigsten Verhältnisse, deren Kenntniss man meinen Untersuchungen verdankt, mit keiner Sylbe meiner Erwáhnung thut, zufallig mit mir dasselbe beste Untersuchungsobject ausmittelt. zufällig sogar 
dieselbe Ueberschrift für seinen Aufsatz nit nir wăhlt, kommt er doch auf mich zu reden, wenn es sich darum handelt, gegen mich zu polemisiren. Wir wenden uns hiermit zur Besprechung dieser Polemik.

Sснвös läugnet die Existenz der von mir behaupteten Schläuche. Nach ihm befinden sich die jungen Eier frei unter der bindegewebigen Albuginea des Ovariums in einer mit dieser parallelen zusammenhängenden gefässlosen Schicht. Da er zugibt, was ganz sicher ist, dass diese Schicht von Bindegewebe durchsetzt wird, so liegt es auf der Hand, dass er einen stetigen Zusammenhang seiner unter der Albuginea des Eierstockes gelegenen Keimzellenlagen nicht bewiesen hat. Dieser Zusammenhang existirt in Wahrheit nicht. Dies wird bewiesen durch die Existenz isolirbarer Schlauche, welche aus dem Ovarium bis an und in das Epithel gehen (s. Taf. III. Fig. 1.). Solche Schnitte, welche parallel mit der Oberfläcle des Eierstockes durch die sogenannte Albuginea oder die unter ihr liegenden Schichten geführt werden, zeigen die quer durchschnittenen kleinen und grösseren Schläuche, welche dann entweder kleine rundliche Zellhăufchen vorspiegeln, in deren Mitte das Keimbläschen liegt oder grössere Follikel, in denen ein bereits evidentes Ei wahrgenommen wird. Der Verticalschnitt beweist sofort, dass die scheinbaren Zellhäufchen durchschnittene Schlăuche sind. Um jene quer durchschnittenen Schläuche erscheint stets ein faseriges Gewebe. Niemand hat auch bis jetzt die für junge Follikel angesprochenen Häufchen von Zellen, welche aber gewöhnlich junge durchschnittene Schläuche waren, anders als in Bindegewebe eingebettet wahrzunehnen vermocht. Hătte Scurös seine Corticalschicht auf die Oberfläche der Albuginea verlegt, so würde ich, ihm so bestimmt entgegen zu treten, keine Veranlassung gehabt haben. Wenn Scunöx seiner Corticalschiclıt die Blutgefüsse abspricht, so stimmt dies sehr gut damit, dass die an dieser Stelle angehäuften Drüsenschläuche wie alle anderen keine Blutgefasse besitzen. Scırös vernuthet, dass die von mir beschriebenen mächtigen Drüisenschläuche, welche gerade bei der Katze dicht gedrängt einer neben dem anderen liegen, Blutgefảsse seien. Er hat selbst aber nachgewiesen, dass an der Stelle, wo meine Schläuche liegen, keine Blutgefässe sind. Dass übrigens zwischen den Schläuchen Capillarschlingen und kleine Gefässe hie und da liegen, habe ich nichts desto weniger an frischen Präparaten deutlich gesehen. Mit Bezug auf diesen Gegenstand bemerke ich, dass die Driisenschläuche und die Blutgefässe im frischen Zustande so wenig Aehnlichkeit haben, dass selbst ein sehr unerfahrener Beobachter sie nicht mit einander verwechseln kann. Wenn Schrös meine naturgetreuen Zeichnıngen ansieht, so wird er nicht länger auf seiner Ansicht bestehen wollen.

Scuröx stellt nun die Behauptung auf - und dies ist ein sehr bemerkenswerther Umstand - dass die Epithelialgebilde des GraAf'schen Follikels sich aus dem bindegewebigen Stroma der Ovarien entwickeln. Dies zeigt mit Evidenz, dass er häufig Umhüllungszellen der Eier vor sich gehabt hat, über welche er zweifelhaft war, ob er sie als Epithel oder als Stroma 
ansprechen solle. Demgenass hat er oft Fortsetzungen der Epithelzellen der membrana granulosa in den Eierstock sich verlieren schen. Man sieht aber, dass wer die Epithelzellen der membrana granulosa sogar für Stroma erklärt, nothwendig auch die Schläuche, welche ähnliche Epithelien haben, unter dieselbe Rubrik bringen muss. Wülde er an der riclitigen Stelle bei Anwendung starker guter Linsen mit feineren Methoden als die seinigen. vor allen Dingen besseren Reagentien an's Werk gegangen sein, so hätte er sich überzeugt, dass jene Züge kleiner Zellen, in welchen hie und da Eier erscheinen, nicht mit dem Stroma zusammenfliessende, sondern gesonderte Bildungen und zwar Röhren sind, in welchen die Eiketten stecken. Bereits der Umstand, dass er öfter zwei ja drei Eier in einer Cyste fand, wie das auch neuerdings von Groнe bestätigt wird, hätte ihm einen Wink geben können. Es konnte ihm nicht verborgen bleiben, dass es bei meiner Vorstellung, welche die Existenz von Röhren voraussetzt, leicht begreiflich ist, wie das zarte Eichen von der Oberflàche des Eierstockes allmählich ausserordentlich tief in die Substanz hinabrückt. Auf welche Weise aber die zahlreichen zarten Zellen aus Scurös's Corticalschicht allmählich durch das derbe lederartige Gewebe der Eierstocksrinde lindurchkommen sollen, ist gar nicht abzusehen. Niemand wird von seiner Erklärung sich befriedigt fühlen, da el der Corticalschicht die Fathigkeit zuschreibt, durch Neuproductionen die Keimzellen nach abwärts, also in einer bestimmten Richtung, zu drücken. während gleichzeitig Bindegewebe sie auseinander treibt. Sie kommen aber doch schliesslich bei alten Hunden durch die derbfaserige Eierstocksrinde in die weiche Markmasse, müssen also trotzdem wohl, wenn Scurös Recht hat, durch jenes Leder sich hinabbohren. Da sich nun viele kleine Eier und Follikel später auch an der Oberfläche ausbilden, so ist, wie aus meinen frühern Auseinandersetzungen sich ergibt, seine Vorstellung überhaupt nicht richtig, wenn er meint, dass jedes Ei aus der Corticalschicht in die Tiefe des Eierstockes wandeln muss, um die membrana gramulosa zu bilden und zu reifen. Die Sache verhält sich eben einfach so, dass die Eierstocksröhren mit dem Keimfache an der Oberfläche des Organes liegen, während die Follikelbildung an dem Schlauch von innen nach aussen vorschreitet. Darum liegen die reifen Zustände tiefer, die jüngeren oberflächlicher. Der Zustand der Reife schreitet aber schliesslich bis zu dem Keimfach vor, so dass auch in diesem endlich Follikel entstehen. Wenn man diese Verhältnisse bei Katzen von Woche zu Woche nach der Geburt bis zum 3. Monat verfolgt, wie ich es gethan habe, so wird man sich von der Richtigkeit meiner Angabe iberzeugen. Freilich versteht es sich von selbst, dass, wenn ein junger, an der Oberfläche des Eierstockes liegender Follikel in Folge der Wasseraufnahme aufschwillı, das Ei nothwendig mit einem Theile des Follikels nach abwärts rücken muss, da nach den Untersuchungen Schröx's das letztere an den verschiedensten Peripherietheilen des GraAf'schen Bläschens seinen Sitz haben kann. Ueber die Variationen in der Lage des cumulus proligerus habe ich selbst keine ausgedehnteren Untersuchungen angestellt.

Bei den erwachsenen Thieren gestaltet sich mit Rücksicht auf die von Scurös ange- 
nommene Wanderung der Eier die Sache meiner Meinung nach muthmasslich so, dass bei der Neubildung der Ovarien ein anfangs sehr dünner Schlauch ganz allmählich von aussen nach innen durch die Eierstocksubstanz vordringt. Bei der Derbheit, welche besonders die Rinde besitzt, ist es daher um so mehr begreiflich, dass man besonders bei erwachsenen Hunden die dünnen Schläuche in den verschiedensten Richtungen und Windungen nach dem weicheren Mark des Eierstocks vordringen sieht. Sobald der Schlauch in demselben angekommen ist. schwillt er auch sofort an. Das Ei wächst, der Follikel bildet sich aus. Für ein solches Vordringen wachsender cylindrischer Sprossen durch viel derbere Massen als das festeste Eierstocksstroma finden wir ein schönes Analogon in der parasitischen Mistelpflanze, welche ihre Wurzeln in den festen Stamm einsenkt, als ob Holz für sie der weichste Boden wàre.

Da Scurox die Schlauche nie gesehen hat, so ist es auch nicht meine Aufgabe, zu discutiren, ob bei der allerersten Anlage derselben in der That eine Umwandlung ron Zellen des Stroma's in ächte Epithelialzellen der Schläuche und der GrasF'schen Follikel wahrzunehmen ist. Ich weiss sehr wohl, dass hesonders in der neueren Zeit immer mehr Beziehungen zwischen den ächten Epithelialbildungen und den sogenannten Bindegewebezellen wahrgenommen worden sind. Niemand kann sich der Bemerkung entziehen, dass Bildungen vorkommen, welche Uebergänge von Bindegewebezellen zu den verschiedensten Gewelsselementen des thierischen Körpers darzustellen scheinen. Könnte man deshall nicht auf die Vermuthung kommen, dass unter die Rubrik der Bindesubstanzen jetzt noch eine Kategorie von kleinen Zellen geworfen wird, aus denen mulatis mutandis gleichsam Alles werden kann, so wie wir ja auch aus den kleinen gleichbeschalfenen Zellen der Keimhaut des Embryo die verschiedenartigsten Gewebselemente durch eigenthimliche Metanorphosen sich herausbilden sehen. Die Botaniker unterscheiden seit lange ein solches Gewebe und nennen es Urparenchym. Wäre es nicht möglich, dass angesichts der oben erwähnten Thatsachen auch in dem thierischen Körper ein solches Urparenchym vorkommt? Jedenfalls würle der Ausdruck Bindegewebe für dasselbe höchst unpassend sein. Ich glaube, dass bei dem gegenwärtigen unentwichelten Zustande der allgemeinen thierischen Histiologie hierauf kine bestimmte Antwort gegeben werden kann.

Ohne Zweifel handelt es sich um eine Frage von sehr grosser Tragaweite. Mir genügt es, die Existenz schlauchartiger Bildungen nachgewiesen zu haben, welche zweifellose Zellen mit allen wesentlichen Charakteren als Epithelien besitzen und in sich die Eier erzeugen.

Ich habe gegen Scurox die Bemerkung ausgesprochen, dass die Mangelhaftigkeit seiner Metlode die Ursache ist, welche ihm die Existenz jener Schläuche entgehen liess. Scurox benutzt Alkohol, dessen Procentgehalt er nicht angilst und legt die frischen Eierstöcke mehre Wochen hinein. Nach seinen Schnitten zu urtheilen sind die Eierstöcke ziemlich stark gehärtet. Der Alkohol ist eine Sulıstanz, welche aul anorganische Salze, sowie Albuminate stark fallend 
wirkt und organischen Zellen mit Begierde Wasser entzieht. Er besitzt also alle Făhigkeiten, um einen so zarten Drüsenschlauch in unkenntliche Trümmer verschrumpfen zu lassen. Ich weiss aus Erfahrung, dass Alkohol sellost in grosser Verdiinnung, also zu 30̈-4.0 Volumprocent und nach Einwirkung von 6-24 Stunden ein schlechtes Härtungsmittel für den Eierstock ist, geschweige denn, wenn man ihn stark wählt und 14. Tage einwirken lässt.

Ausserdem bediente sich Scurröx des chromsauren Kali's. Er vermeidet es wiederum, etwas über die Concentration zu sagen, die bei diesem Reagens gewiss nicht gleichgültig, sondern unendlich wichtig ist. Eben so wenig gibt er an, ob die Krystalle seines doppelt chromsauren Kali's chemisch rein waren, was die in dem Handel vorkommenden oft nicht sind. Dieses ist aber darum nicht einerlei, weil das unreine doppelt chromsaure Kali anders auf die Gewebe wirkt und ausserdem auch eine andere Löslichleit besitzt als die reine Substanz. Was aber die Concentration angeht, so wirkt jede über I procentige Lösung sehr bald, l. l. in Zeit einiger Minuten, derartig, dass die schönste Eikette zu einem unkenntlichen mit coagulirten ineinandergeflossenen Niederschlägen erfüllten Streifen zusanımensinkt. Das saure chromsaure Kali ist ein ausgezeichnetes Reagens für den ganz frischen Eierstock, wenn es chemisch rein ist. Aber wie bei allen Untersuchungsflussigkeiten für thierische Gewebe kommt sehr viel, ja Alles auf die Concentration und die Dauer der Einwirkung an, welche Scıros kaum ungiinstiger håtte wählen können.

Scurös arbeitete endlich auch an frischen Präparaten und bediente sich hier nicht feiner Schnitte, sondern durch Zerzupfen erhaltener Fragmente. Weiss man nun, wie vielfach die langen derben Bindegewehezellen gleich einem Filze die zarten Drüsenmassen umstricken, so begreift man, wie ungünstig las von Scuros angewandte Verfahren ist. Man denke sich ein vielfach aufgerolltes Fischernetz längere Zeit in einem Wasser liegend, so dass Wasserpflanzen in dichter Masse durch die Interstitien des Gewebes hindurchkriechen. Wollte man sich nun einzelne von diesen Pflanzen im Inneren des Netzes verschaffen, so wären Versuche das derbe Netz deshalb zu zerreissen offenbar nothwendig mit einer vollkommenen Zerquetschung der dasselbe durchziehenden zarteren Theile verbunden. Wohl aber lässt sich von Schnitten etwas erwarten, welche mir deshalb auch vorzügliche Dienste erwiesen haben. Wendet man an frischen Präparaten die Isolationsnadel an, so gehört viel Glück und noch mehr Geduld dazu, wenn man ein brauchbares Object erhalten will. Nur nach Einwirkung von Reagentien lässt sich mit Erfolg an die Isolation denken. Dieser Weg ist aber von Scrrös nicht betreten worden.

Obwohl also Scırös nicht behaupten kann, das äusserste Maass nothwendiger Vorsicht bei der Untersuchung beobachtet zu haben, obwohl er nach eigener Angabe nicht weiss, woher die jungen Eier kommen, setzt er sich doch leicht ïher alle meine Angal)en einfach dadurch fort, dass er mir die grobe Täuschung zumuthet, nicht blos Blutgefässe für Drüsenschläuche 
angesprochen, sondern auch an den vasa sanguifera die Entwicklungsgeschichte der Eier und den Process der Follikelbildung erforscht zu haben.

An die Arbeit von Scurox reiht sich die von Kuens, welche allerdings vor der von Scunöx und mir publicirten erschienen ist, al)er nichts Neues loringt. Auch KLEBs fasst die membrana granulosa als aufgelagerte Schicht des Eies auf und verwalıt sich, dass sie nicht durch endogene wandständige Zellbildung sich entwickele. KıEns stützt diese richtige Angabe aber auf unrichtige Beobachtungen. Denn er behauptet, dass die umgebende Zellenschicht des Eies (GraAfscher Follikel, Kapselschichte,) ursprünglich aus spindelförmigen Zellen bestehe, welche von den übrigen Zellen des Stroma sich nicht unterscheiden und gegen dieselhen niemals scharf abgegrenzt sind. Später erst, gegen die Zeit der Reifung (?) des Eies soll diese Formation einen epithelialen Charakter annehmen. Nun weiss man offenbar gar nicht, was er sich unter der Zeit der Reifung denkt. Da nun ursprïnglich in den Schläuchen, noch ehe von einem Follikel die Rede sein kann, sogar sehr schönes Epithel ist (s. Taf. I. Fiǧg. 4, 5, 6, 7, 9, 11 und 12.), da ferner die Schläuche mit eminenter Schärfe sich von dem Stroma alggrenzen, so fehlt den Kuens'schen Beobachtungen die Richtigkeit, um als Unterlage für eine Behauptung zu dienen.

Es bleibt mir endlich noch die Besprechung einer Arbeit von Grone übrig. welche in VIrcnow' Archiv (3. und 4. Heft 1863), also zu einer Zeit erschien, wo der grösste Theil dieses Werkes bereits gedruckt vorlag.

Das Wesentlichste, was in diescr Arbeit sich vorfindet, ist die Behauptung, dass die membrana gramlosa ein Auflagerungsproduct sei, obwohl Gnone, der ebenfalls nicht weiss, woher díe Eier kommen, aus den bei KuEss besprochenen ähnlichen Gründen einen Beweis nicht erbracht hat. Nicht ohne Interesse ist, dass dieser Beobachter Cylinderepithel bei einem Graaf'schen Follikel (?) und ebenso wie alle anderen Neuern das Vorkommen von zwei und drei Eiern in einer mit Epithel ausgekleideten Cyste constatirte. Grone findel mit Kuens glatte Nuskelfasern in dem Nlark und der Rinde des Eierstocks. Für die Katze habe ich dies aber in Abrede gestellt, so weit es sich un die Corticalschicht des Orariums handelt. Die auch von mir gesehenen korkzieherartig gewundenen Arterien bestatigt Grour und knüpft daran einige physiologische Betracbtungen, über welche ich mich nicht aussprechen will.

Groue konnte ebensowenig als seine Vorgảnger die ron Valestrs, BıLnotu und mir gesehenen Schläuche wahrnelmen. was nir begreiflich ist. Denn Grone gebraucht Alkohol und Chromsäure, in welchen er die Ovarien bis zu gehöriger Härtung liegen lässt. Nachdem die zarten wasser reichen Epithelialgebilde zu unkenntlichen Trümmern verschrumpft sind, werden Schnitte angefertigt und mit kanstischen Natron, Essigsäure oder Glycerin aufgehellı. Wenn Grone mit den anderen Beobachtern einmal den Versuch machen will, die evidente Eierstocksröhre eines Nematoden oder anderen Thieres ebenso zu belıandeln, dann dürfte er vielleicht auch 
finden, dass sie siclı in lauter Bindegewebestroma umgewandelt hat. Denn ohne meine Arbeit, was Grone ausdrücklich sagt, auch nur gelesen zu laben, olıne zu bedenken, dass es sich bisher nur un vorläufige Nittheilungen handelte, steht er doch nicht an, meine Sclıläuche für ab-

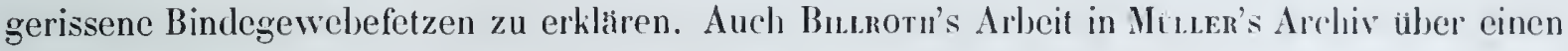
pathologisch-anatonischen Gegenstand kennt der Professor der pathologischen Anatomie Grone nicht. Denn er meint, dass ausser Valextix kein Mensch sonst als ich die Schlabuche halue sehen können.

Wenn man nun ferner in seinem Aufsatze das Keimbliischen eine Zelle genannt findet (s. a. a.0. p. 284.), den Dotter des Säugethiereies (natülich bei Anwendung der Grone'schen Methoden) gedeutet als umgewandelte Zellen der memlirana gramlosa (s. a.a. 0. p. 294.4. 292., welche den Nahrungsstoff für das Keimbläschen alggeben, wenn man hört, dass dieses cine leichtkörnige Beschaffenheit darbiete, dass die mëmbrama propria der jungen Grasł'schen Follikel aus schematischen Zeichnungen der bisherigen Forscher abstrahirt sei und nicht existire (s. a. a.0. p. 26is u. 287.), wenn er die von mir längst ermittelte That sache, dass die jüngeren Zustande unter der Oberfläche, die älteren in der Tiefe des Eierstockes gefunden werlen, selbstandig entdecht, unrichtig aus der Vertheilunğg der Blutgefâsse erklärt und siclı dann darüber wundert, dass Niemand noch diese »bemerkenswerthe“ Wahrheit begründet habe, während ich sie langst sehr bestimmt aus der Entwicklungsgeschichte ableitete, so weiss man. von vielem Anderen abgesehen. genug, um ferner schweigen zu liönnen gegen jeden seiner Angriffe.

Fasst man nun alle neueren Arbeiten uber den Eierstock zusammen, so ist eine Reihe neuer von mir entleckter Thatsachen nicht zu verkennen, für welche alle Forscher eintreten.

Zunächst geben Alle zu, dass die jüngeren Zustünde oberflichlicher, dic älteren tiefer liegen. Alle leiten nicht mehr den Grasp'schen Follikel aus einem Haiufchen kleiner gleichbeschaffener Zellen ab; Alle behaupten mit mir, dass das Ei dasei, ehe man von einem Follikel reden könne. Es herrscht cine mir wirklich auffallende Uebereinstimmung daruiber, dass die membrana gramulosa ein Auflagerungsproduct sei und nicht mit dem Ei in einer Vutterzelle entstanden. Das ist aber, wenn man die Sache ernst nimmıt, der schwerste Theil in der gesammten Untersuchung.

Sehr merkwürdig nuuss es erscheinen, dass während bisher alle Histiologen den Anfang des Graxf'schen Follikels von einem kleinen Haufchen Zellen ableiteten, in dessen Mitte nichts als das Keimbläschen zu sehen war, nunmehr Keiner etwas Derartiges wahrnahm. Hierin sind die Neueren nicht im Rechte. Zufallig gebrauchten sie meist dieselben Reagentien, welche dic jüngsten Zustände gar leicht verwischen. Der Ausdruck scheinbarer Zellenlıăufchen mit dem Keimbläschen in der Mitte existirt und wird gewöhnnlich bedingt durch Querschnitte von selır dünnen Schläuchen, wic der auf Taf. III. Fig. I oder Taf. II. Fig. 4. -

Es kommen indessen im Eierstocke auch kleine Zellenhäufchen vor, welche sich als Pflüg er, Eierstöcke. 
solche isoliren lassen. Diese erscheinen von verschiedlenster Grösse. Die an Volum bedeutenderen aus likinen und grossen Zellen bestehend, sondern sich später in die beliannten oben beschriebenen secundăren Schläuche. Daraus folg̨, dass rundliche Anlagen, aus denen Drüsensäcke sich lıerausbilden, im Eicrstoche nachgewiesen werden können. Ich vermuthe der Analogie nach, dass sie an dor Oberflache entstehen. Denn solange sie in einem Schnitt sich in silu befinden, weiss man nicht, ol es sich um einen Schlauch oder ein Zellenhäufchen handelt. Wurde dieses aher isolirt, so fehlt natürlich wieder der situs. Ich habe diese Bildungen bei älteren jungen Katzen von 3-4. Wochen gesehen, während bei den jüngeren die Schläuche als sehr dünne Gänge in radiảrer Richtung das Organ durchsetzen. Ich halte es deshalb für wahrscheinlich, dass wenn in der späteren Zeit der Oogenese, wo die Rinde des Eierstocks mit dicht aneinanderliegenden Eisäcken vollgepfropft ist, noch neue Nachschübe der Schlauchbildung von der Oberflache ausgehen, diese keinen Platz finden, un nach dem Inneren vorzudringen und deshalb an der Oberfläche zu verschieden gestalteten Săcken heranwachsen. Ich habe in meiner vorläufigen Mittheilung solche Zellenhäufchen »Schlauchknospen« genannt. Doch weiss ich nicht, ob alle Schläuche bei der ersten Bildung eine solche kuglige Wucherung unter dem Peritoneum bilden und dann einen dünnen Fortsatz in das Gewebe des Stroma's einsenken. Beim Kalbe habe ich allerdings oft Bilder gehabt, welche hierfür sprachen. Dass neben diesen "Schlauchknospen“ noch Zelleuhaufchen von vermuthlich anderer Berleutung im Eierstocke vorkommen, habe ich bereits oben besprochen.

Gehen wir in unserer Betrachtung der neueren Errungenschaften, über welche Einstimmigkeit herrscht, weiter, so haben wir des so lıafugen Vorkommens von zwei und drei Eiern in einer mit Epithel ausgekleideten Cyste zu erwähnen. Alle behandeln diese oft gesehene Erscheinung als Curiosität. Sie hört es zu sein auf, wenn man weiter heobachtet, dass zuweilen auch mehr als drei, nämlich vier, ja viele Eier von allen Entwicklungsstufen in einem Schlauche vorkommen, und dass die Follikel durch Abschnürung von diesen entstehen.

Scurös war oflenbar nahe daran, die ganze Oogenese zu finden, da er zugibt, dicht unter der albuginea des Eierstocks der ausgewachsenen Katze freie bläschenförmige Kerne mit einem deutlichen Kernkörperchen gesehen zu haben, sowie auch solche, welche um sich noch eine zarte länglich geformte Membran zu haben schienen. Bei jungen Thieren vermochte er keinen näheren Aufschluss zu erhalten. Obwohl man deutlich erkennt, dass ihn jetzt bei diesen sehr zarten Gebilden seine Methoden im Stiche lassen, ist es doch sehr deutlich, wie ausserordentlich nahe seine Untersuchungen an die meinigen heranreichen. Ich hoffe deshalb, dass bald noch der letzte Punkt zwischen uns beseitigt sein wird, in welchem wir nicht ubereinstimmen. 


\section{Erklärung der 'Tafeln.}

Taf. I.

(Alle Präparate sind vom Kalbe.)

Fig. 1. Isolirter Follikel des Kalbes. Vergrösserung: genau 400.

Fig. 2. Follikel des Kalbes. Vergr.: genau 560.

Fig. 3. Follikel des Kalhes. Vergr.: genau 400.

Fig. 4. Follikelkette des Kalbes, vollkommen isolirt. Vergr.: genau 400.

Fig. 5. In Abschnürung begriffene primordiale Follikelanlage. Vergr.: genau 400.

Fig. 6. In Abschnürung begriflene primordiale Follikelanlage, zum Theil isolirt Vergr.: genau 400.

Fig. 7. In Abschnürung begriffene primordiale Follikelanlage. Vergr.: genau 400.

Fig. 8. Eischläuche vom Kalbe (Schnitt). Vergr. : genau 400.

Fig. 9. Ganz isolirte primordiale Follikelanlage. Vergr.: genau 560.

Fig. 10. Zwei nicht ganz abgeschnürte Follikel. Vergr.: genau 400.

Fig. 11. Primordiale aus schönen Epithelien bestehende Follikelanlage mit aufsitzenden in Abschnürung begriffenen Follikeln. Vergr.: genau 400.

Fig. 12. Dasselbe. Vergr.: genau 400.

Fig. 13. Junger Follikel, dessen Ei noch mit einer Eikette $(b b)$ zusammenhängt. Vergr.: genau 400.

\section{Taf. II.}

(Alle Prïparate sind vom Kalbe.)

Fig. 1. Isolirte Eikette vom Kalbe. Vergrösserung: genau 400.

Fig. 2. Eikette in einem Schlauche, der Cylinderepithel entwickelt hat. Vergr.: genau 400.

Fig. 3. Eischlauch mit Eiketten und Keimfach als Inhalt. Vergr.: genau 400.

Fig. 4. Vollkommen isolirter junger Eischlauch mit deutlichem Canal, Keimfach und Querschnitt. Vergr.: ungefähr 400.

Fig. . Isolirter GraAf'scher Follikel.

Fig. 6. Grosse Sclilauche vom Kalbe. Vergr.: genau 4.00.

Fig. 7. Isolirter ganz junger Drüsenschlauch. Vergr.: genau 400

Fig. 8 u. 9. Muthmasslich dasselbe. Vergr.: genau 400.

Fig. 10. Das über die Ovarienoberflache hinziehende Peritonecim. 


\section{Taf. III.}

(Alle Präparate sind von der Katze.)

Fig. 1. Ein ganz isolirter Eischlauch mit in Bildung begriffenen Follikieln, der noch mit dem

Peritoneum unnittelbar zusammenhängt. Vergr.: genan ö60. Oxalsảurepråparat.

Fig. 2-14. Ureier der Katze von verschiedener Grösse (frische Präparate). Vergr. : genau š60.

Fig. 15-28. Ureier der Katze. Oxalsäurepraparate. Vergr.: genau 500.

Fig. $29(a$ u. b). Kranke Ureier aus dem init liydropischen Cysten erfillten Eierstock einer alten Katze. Einzelnen Zellen fehlt der Kern. Alle enthalten grosse dunkle Körner, wie sie in normalen Eiern oder jungen Follike!n njcht vorkonmen: Frisches Präparat.

\section{Taf. IV.}

(Alle Priparate sind von der Katze.)

Fig. 1. Eisack mit evidentem Canalsystem und ansitzenden in Abschnïrung begriffenen Follikeln $(\gamma \gamma)$. Oxalsảurepräparat. Vergrösserung: genau 360 .

Fig. 2. Vollkommen isolirter Eisack mit Keinfach $(\boldsymbol{A})$, in Alsschnürung begriffenen Follikeln $(\gamma \gamma)$ und sich sondernden Eilietten. Deutliches Canalsystem. Oxalsäure-Carminpriparat in Glycerin. Vergr.: genau 560 .

Fig. 3. Follikelkette von einer alten Katze. Frisch isolirt. Mit verlünnter Essigsaure behandelt. Vergr.: ungefihr :3:30.

Fig. 4. Zwei Eier, welche von kleinen Zellen umwachsen werden. Vergr.: genau ̋̈60.

Fig. 5. Ganz isolirter Eisack. Oxalsäurepräparat. Vergar.: genau ö60.

Fig. 6, 7, 8, 9. Junge Follikel mit glanzenden Ringen. Vergr.: genau ̈̈60. (Frisch.)

Fig. 10. Ein isolirtes Keimbläschen mit Keimfleck. Vergr.: genau 560. (Frisch.)

Fig. 11. Ein conischer Follikel. Vergr.: genau 360.

Fig. 12. Ein in fettiger Degeneration begrillener Follikel. Vergr.: genau מ̋60.

\section{Taf. V.}

Fig. I. Schlauch einer jungen Katze mit Keulenzellen. Vergr.: genau 5̋ 0 .

Fig. 2. Querschnitt eines Eikettensacks der Katze. Vergr.: genau 3030 .

Fig. 3. In Bildung begriffene Follikel der Katze. Vergr.: genau 550.

Fig. 4. u. 5. Junge Eizellen der Katze. Vergr.: genau 550.

Fig. 6. Zwillingszellen in der zou pellucida der Katze. Vergr.: 5ö0.

Fig. 7 u. 8. Fast reife Eier mit Spundzellen in der zona. Vergr.: $3 \ddot{0} 0$.

Fig. 9 u. 10. Schlauche aus den Ovarium einer alten Hündin. Vergr.: ungefahr 400.

Fig. 11. Ein Schlauch, in dem ein Follikel sich entwickelt, von einer alten Hündin. • Vergr.: ungefähr 4.00 .

Fig. 12. Eiketten (in humor aquens) vom jungen Ilunde. $d$ mit Essigsảure behandelt. Verger.: genaıı $̈ \ddot{0} 0$. 

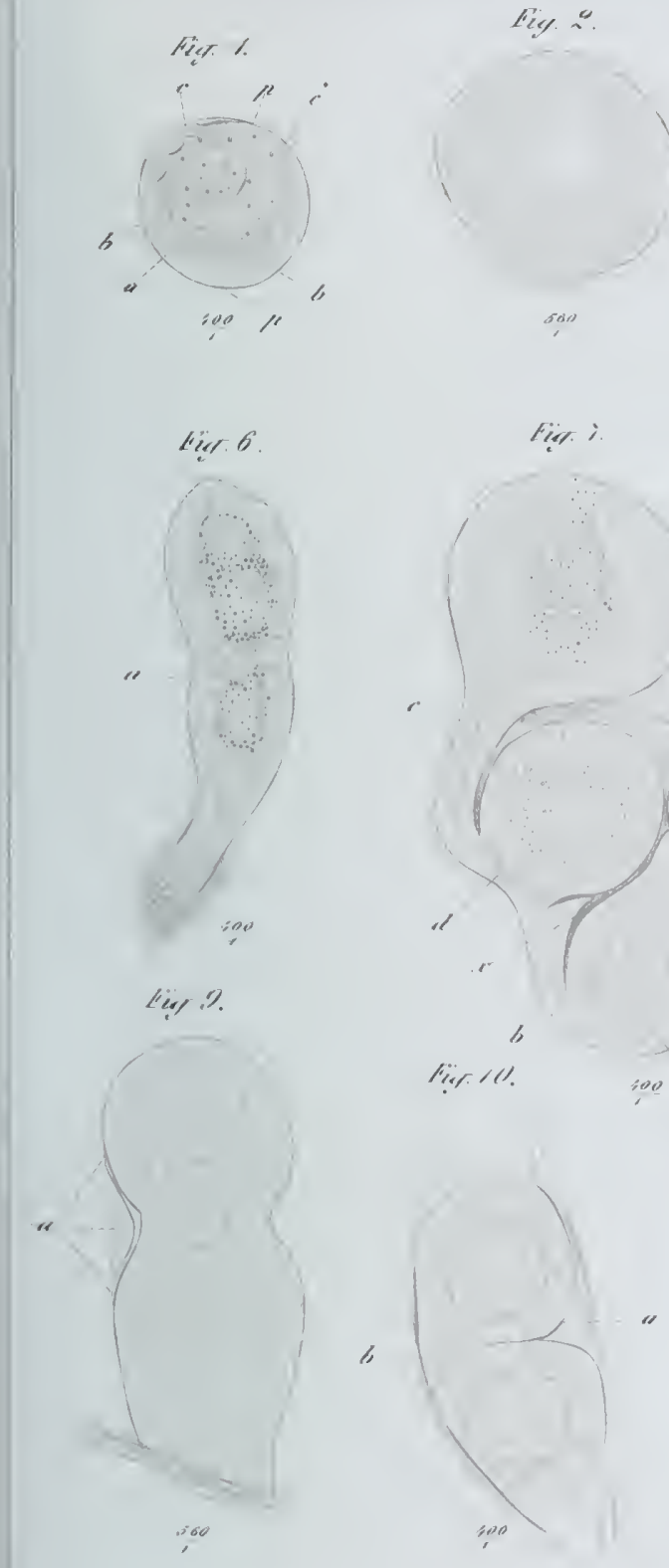

Hii. II

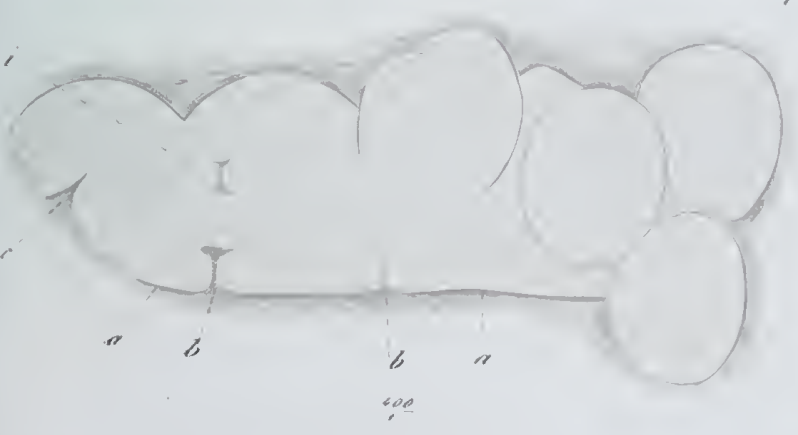

Figs
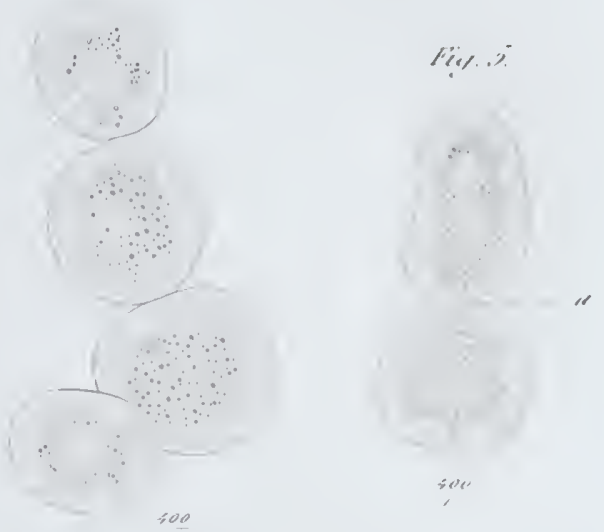

Hiof. $f$. 



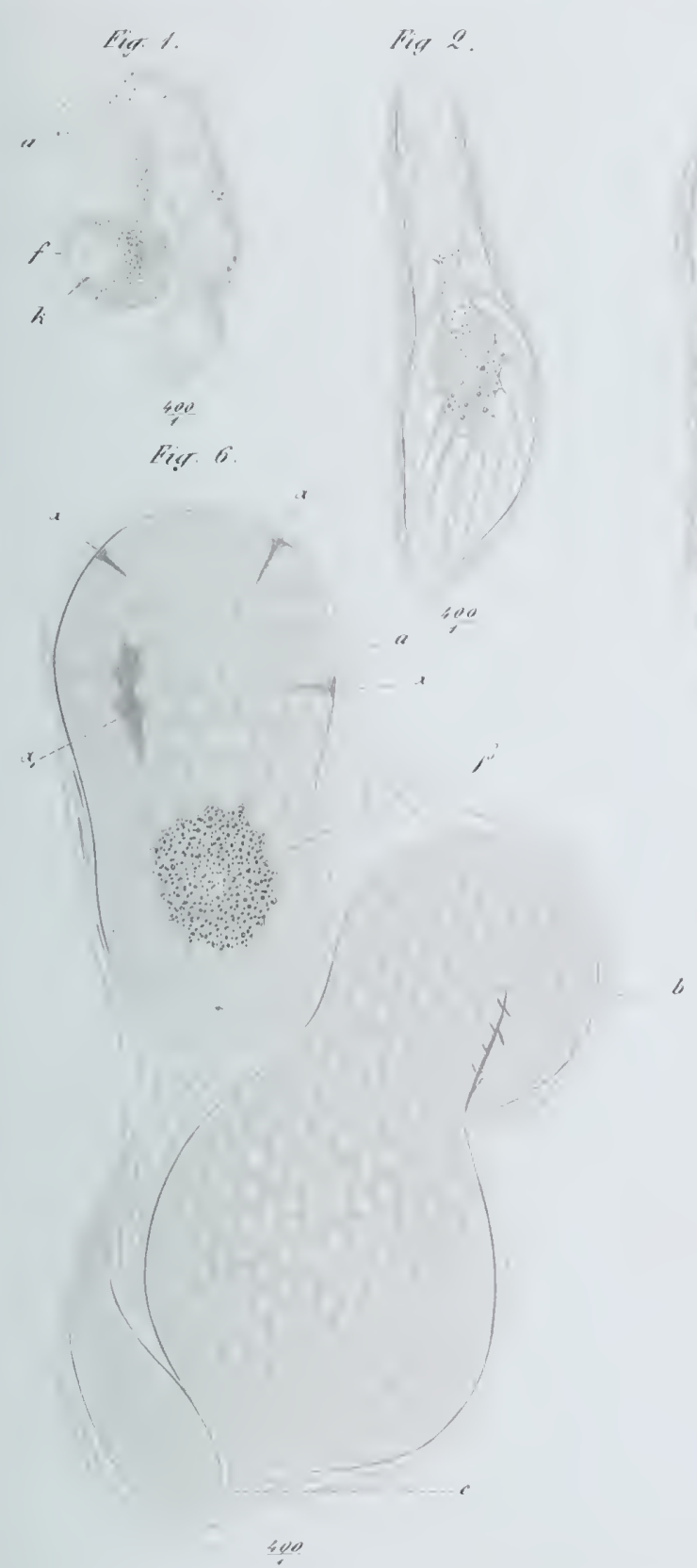

Fin .

Fis of

Live
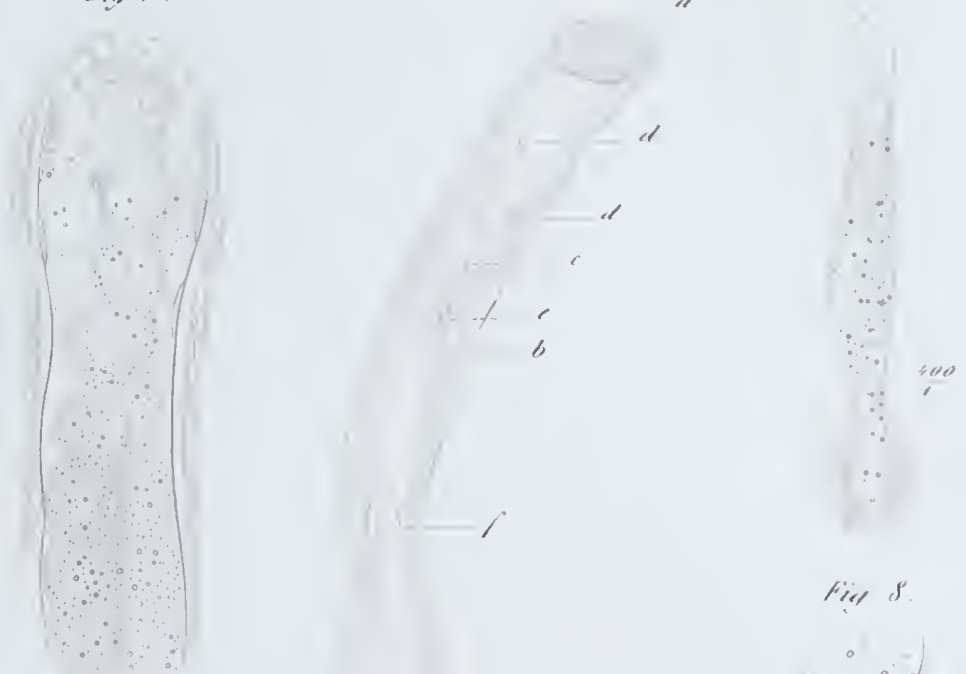

6

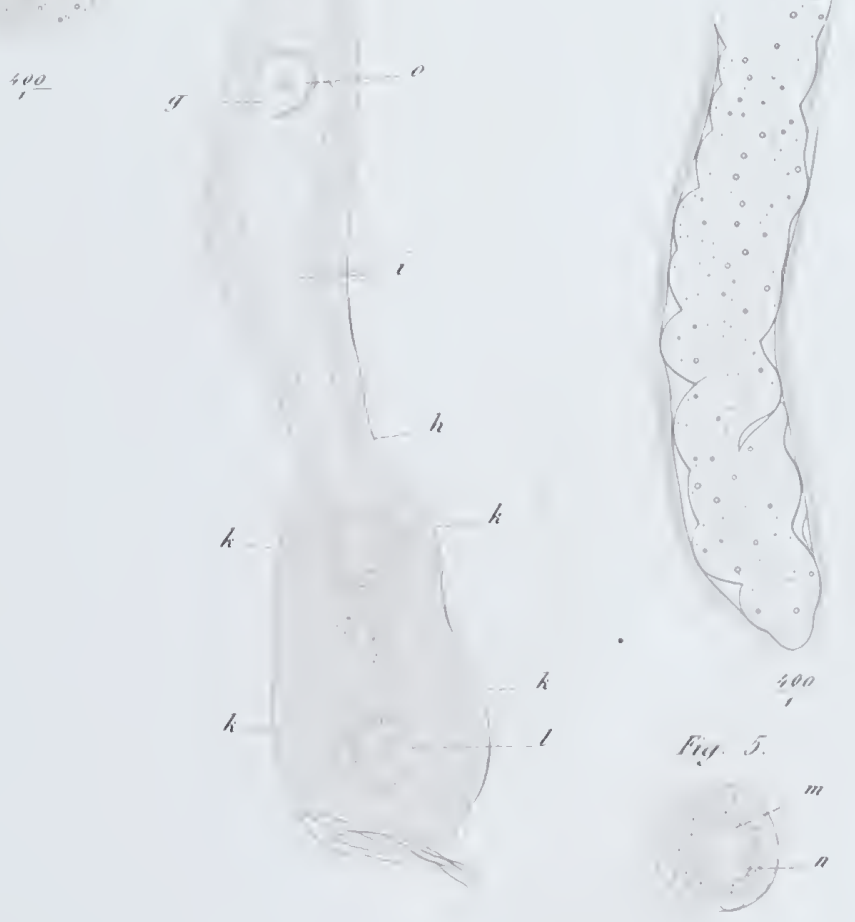

Pier IO

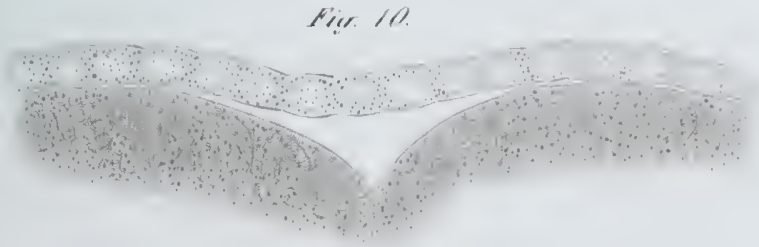

Fire :"

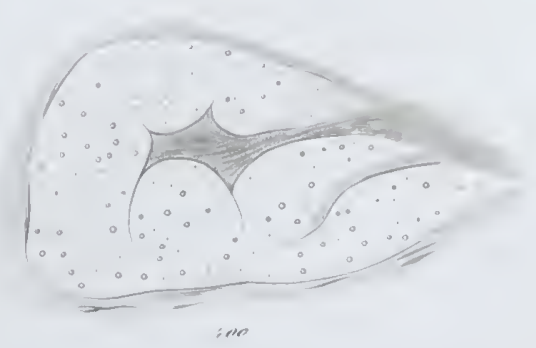



Pis.

Sir, (1)

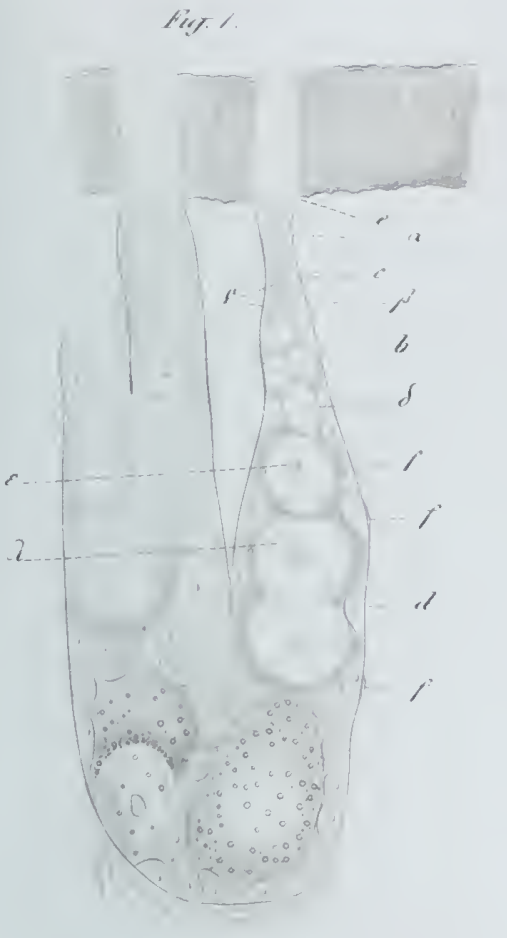

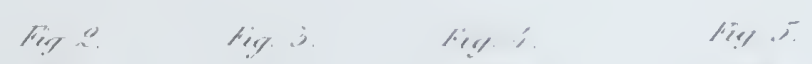
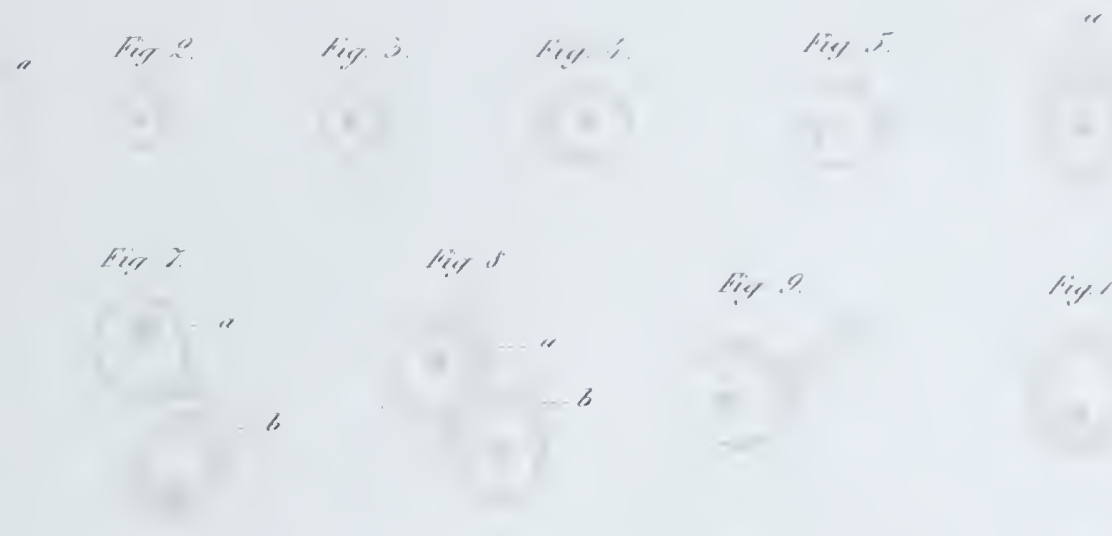

ling is

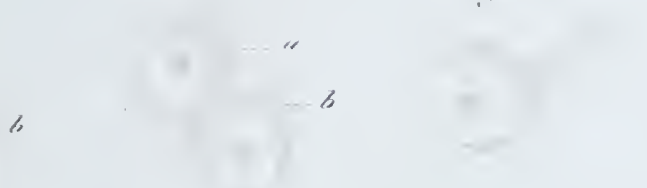

live /l)

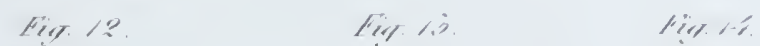

Fis, II.

.5se

Fin 10

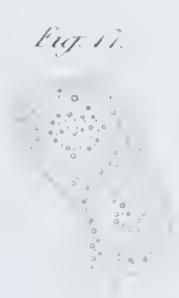

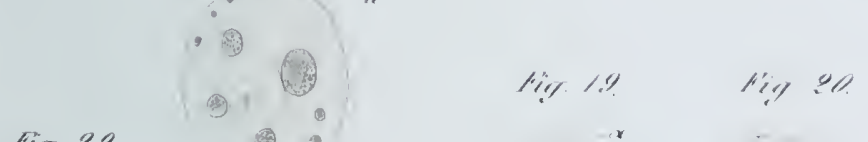

(3)

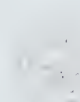

liin ?

lin. ?P

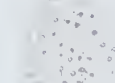

(iii) if
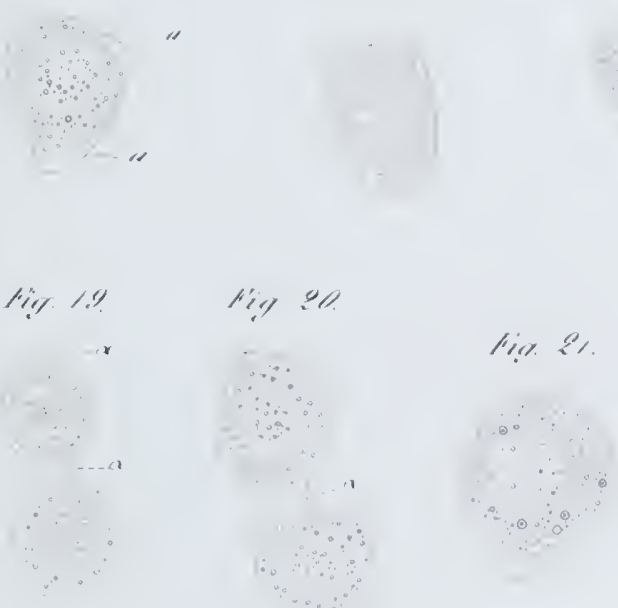

lii, :"

$-4$

(18) 0

- 3 3

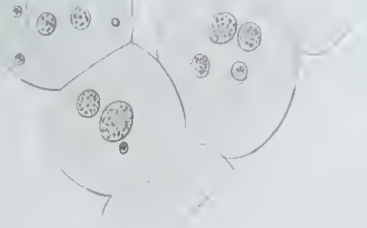

Hin ?

lin? ?"

rier ?.5

Nin 80
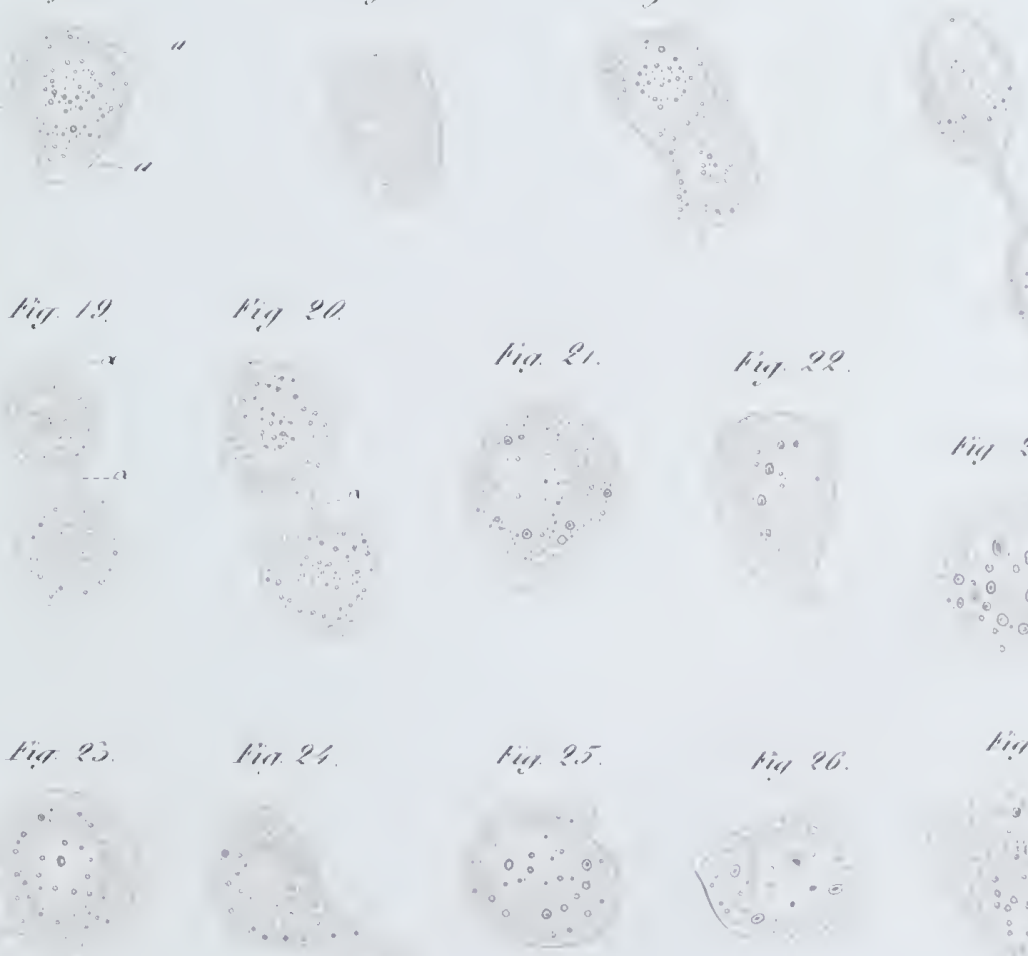

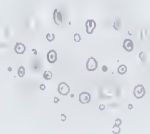

fin? ? 


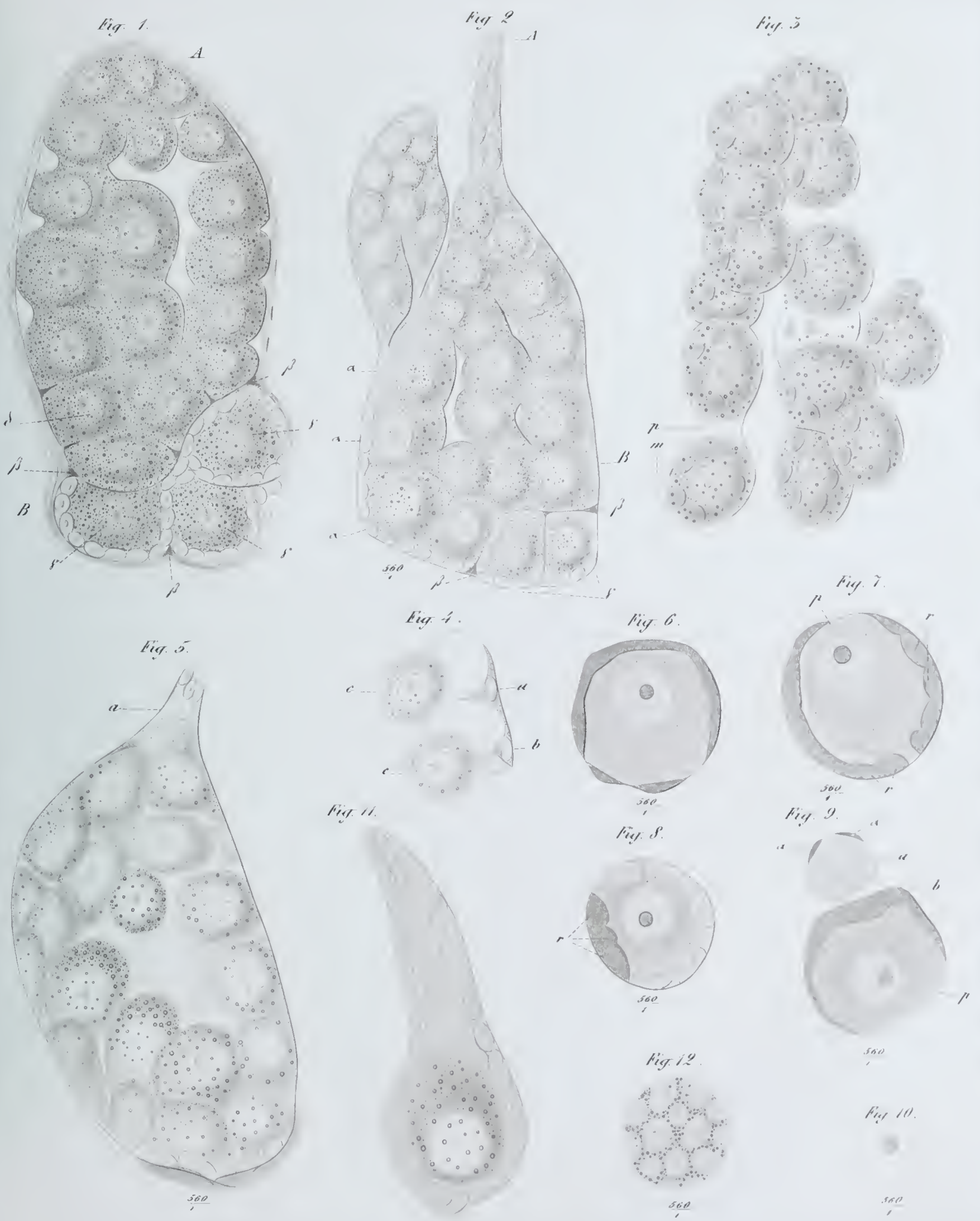

Fig, 111 . 



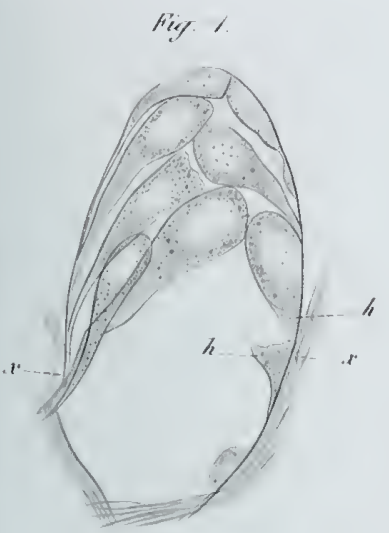

500

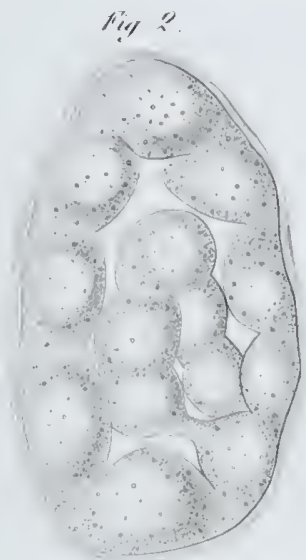

yis
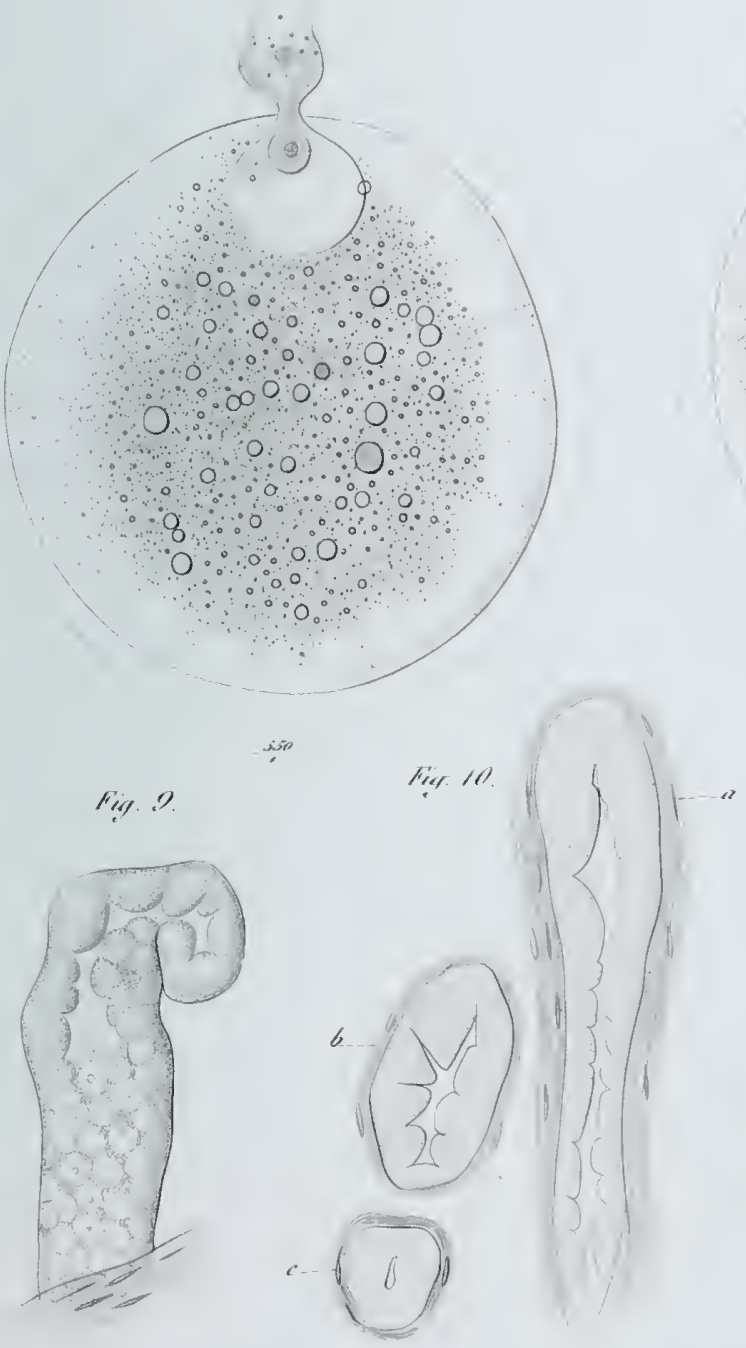

Fir ;

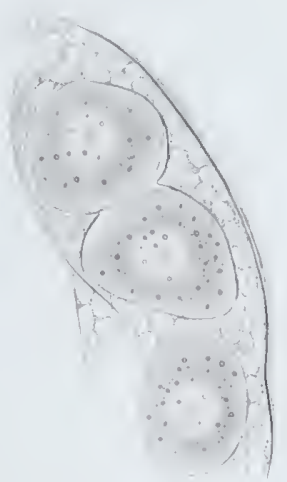

Fir y yis
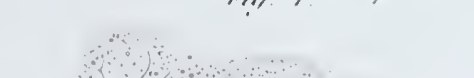
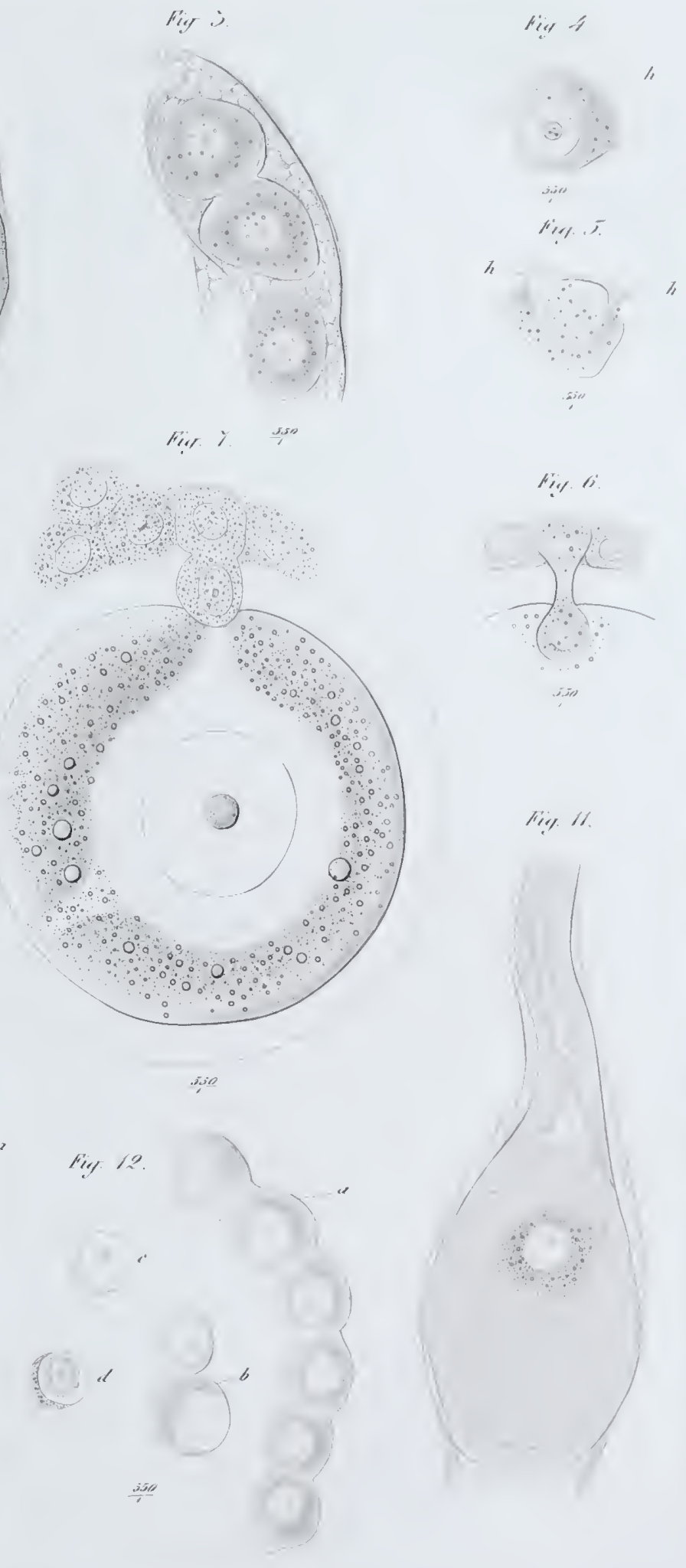
